JOINT TRANSPORTATION RESEARCH PROGRAM

FHWA/IN/JTRP-2010/27

Final Report

USE OF DYNAMIC CONE PENETRATION AND CLEGG HAMMER TESTS FOR QUALITY CONTROL OF ROADWAY COMPACTIOIN AND CONSTRUCTION

Hobi Kim

Monica Prezzi

Rodrigo Salgado

April 2010 


\section{TECHNICAL Summary}

INDOT Research

Technology Transfer and Project Implementation Information

TRB Subject Code:

Publication No. FHWA/IN/JTRP-2010/27, SPR-3009

April 2010

Final Report

\section{Use of Dynamic Cone Penetration and Clegg Hammer Tests for Quality Control of Roadway Compaction and Construction}

\section{Introduction}

Soil compaction quality control is currently accomplished by determining the in-place compacted dry unit weight and comparing it with the maximum dry unit weight ( $\gamma d$ max $)$ obtained from a standard laboratory compaction test. INDOT requires that the inplace dry unit weight for compacted soil be over 95\% of the laboratory maximum dry unit weight. In order to determine the inplace dry unit weight, INDOT engineers generally use the nuclear gauge, which is hazardous and also cumbersome due to strict safety requirements. Thus, several tests, such as the Dynamic Cone Penetration Test (DCPT) and the Clegg Hammer Test (CHT), have been considered as alternatives. In spite of significant research performed to interpret the results of the DCPT and
CHT, no reliable correlations are available in the literature to employ these tests for soil compaction quality control. Therefore, the main goal of the present study is to evaluate the use of the DCPT and the CHT for compaction quality control and to develop interpretation methods for the DCPT and CHT.

In this research, a number of DCPTs and CHTs was performed on road sites in Indiana, in a test pit, and in a special test chamber at Purdue University. A statistical approach was applied to account for in situ compaction variability to develop compaction quality criteria using the test results.

\section{Findings}

Based on the test results provided by INDOT, we developed correlations between maximum dry unit weight ( $\gamma d \max$ ), optimum moisture content (OMC, wcopt), plastic limit $(P L)$, and liquid limit $(L L)$ for Indiana soils. The specification of many agencies in the U.S. for density control (e.g., 95\% relative compaction) has been in effect for more than 30 years. The data available in the literature indicates that the actual mean values of relative compaction achieved on the sites were roughly two to three percent greater than the specification requirements, but about $20 \%$ of the test results did not meet the specification requirements. Several studies indicate that relative compaction on site is normally distributed. Specifications accounting for the variability would be desirable.
Based on the experimental program undertaken to assess the Dynamic Cone penetration Test (DCPT) and the Clegg Hammer Test (CHT), DCP criteria for compaction quality control were suggested by dividing the soils considered into three groups based on the AASHTO soil classification. In addition, the statistical variability of the test results was considered in the development of the DCP criteria for compaction quality control. Based on the analysis of the data collected, the following equations are proposed in this report.

(a) A-3 soils:

The minimum required blow count (NDCP)req|0 12" for $0-12 "$ penetration varies from 7 to 10 ; it is a function of the coefficient of 
uniformity $\mathrm{Cu}$. The following equation was proposed for A-3 soils:

(NDCP)req $\mid 0 \sim 12 "=4.0 \ln (\mathrm{Cu})+2.6$

The (NDCP)req|0 12" is the minimum required blow count for 0 -to-12 inch penetration that implies an RC of $95 \%$ with high probability.

(b) "Granular" soil (A-1 and A-2 soils, except soils containing gravel):

The minimum required blow count (NDCP)req|0 12" for this type of soil is influenced by the fine particles that are present in the soil. Since the plasticity index and the amount of fine particles contained in the "granular" soil correlate with the OMC, the minimum required blow count for "granular" soils is suggested as a function of the OMC as follows:

(NDCP)req $\mid 0 \sim 12 "=59 \exp (-0.12 w c o p t)$

where wcopt $=$ optimum moisture content. The (NDCP)req|0 12" is the minimum required blow count for 0 -to-12 inch penetration that implies an RC of $95 \%$ with high probability. (c) Silty, clayey soils:

The minimum required blow count correlates with the plasticity index and the percentage of soil by weight passing the \#40 sieve. Thus, we propose the minimum required blow count (NDCP)req for silty clay soils as a function of the plasticity index and the percentage of soil by weight passing the \#40 sieve (F40) according to:

(NDCP)req $\mid 0 \sim 6 "=17 \exp [-0.07 P I(F 40 / 100)]$

where $(\mathrm{NDCP})$ req $\mid 0 \sim 6 "=$ minimum required blow count for 0 -to-6 inch penetration that implies an RC of $95 \%$ with high probability, $P I=$ plasticity index, and $F 40=\%$ passing the \# 40 sieve; and

(NDCP)req|6 12" = 27exp[-0.08PI(F40/100)]

where (NDCP)req|6 12" = minimum required blow count for 6-to-12 inch penetration that implies an RC of $95 \%$ with high probability.

The relationship of Clegg Impact Value (CIV) with relative compaction exhibited considerable variability.

\section{Implementation}

The DCP criteria proposed in this study can be tentatively used in soil compaction quality control for soils like those studied in this research. Based on the test results, we suggest the use of DCPT as a tool for soil compaction quality control. This research found that the DCPT was effective in ensuring the required relative compaction for soil compacted at the specified water content.

Implementation projects can help refine the findings of this research and facilitate the use of the DCPT in routine projects by INDOT engineers. In the long run, the DCPT can progressively replace the nuclear density gauges, which are hazardous and also cumbersome to use.

Since DCPT compaction control criteria are still in the development stages, it is

recommended that further research be performed to investigate the short and longterm feasibility of using DCPT as a quality control tool in the context of field implementation projects.

\section{Contacts}

\section{For more information:}

\section{Prof. Monica Prezzi}

Principal Investigator

School of Civil Engineering

Purdue University

West Lafayette IN 47907

E-mail: $\underline{\text { mprezzi@purdue.edu }}$

\author{
Indiana Department of Transportation \\ Office of Research and Development \\ 1205 Montgomery Street \\ P.O. Box 2279 \\ West Lafayette, IN 47906 \\ Phone: (765) 463-1521 \\ Fax: (765) 497-1665
}




\section{Purdue University}

Joint Transportation Research Program

School of Civil Engineering

West Lafayette, IN 47907-1284

Phone: (765) 494-9310

Fax: (765) 496-7996

E-mail: jtrp@ecn.purdue.edu

http://www.purdue.edu/jtrp 
Final Report

FHWA/IN/JTRP-2010/27

\title{
USE OF DYNAMIC CONE PENETRATION AND CLEGG HAMMER TESTS FOR QUALITY CONTROL OF ROADWAY COMPACTION AND CONSTRUCTION
}

\author{
by \\ Hobi Kim \\ Monica Prezzi \\ Rodrigo Salgado \\ Geotechnical Engineering \\ School of Civil Engineering \\ Joint Transportation Research Program \\ Project No. C-36-36-VV \\ File No. 06-14-47 \\ SPR-3009

\begin{abstract}
Prepared in Cooperation with the
Indiana Department of Transportation

and the U.S. Department of Transportation

Federal Highway Administration
\end{abstract}

The contents of this report reflect the views of the authors, who are responsible for the facts and the accuracy of the data presented herein. The contents do not necessarily reflect the official views or policies of the Indiana Department of Transportation or the Federal Highway Administration at the time of publication. The report does not constitute a standard, specification, or regulation.

\author{
Purdue University \\ West Lafayette, IN 47907 \\ April 2010
}




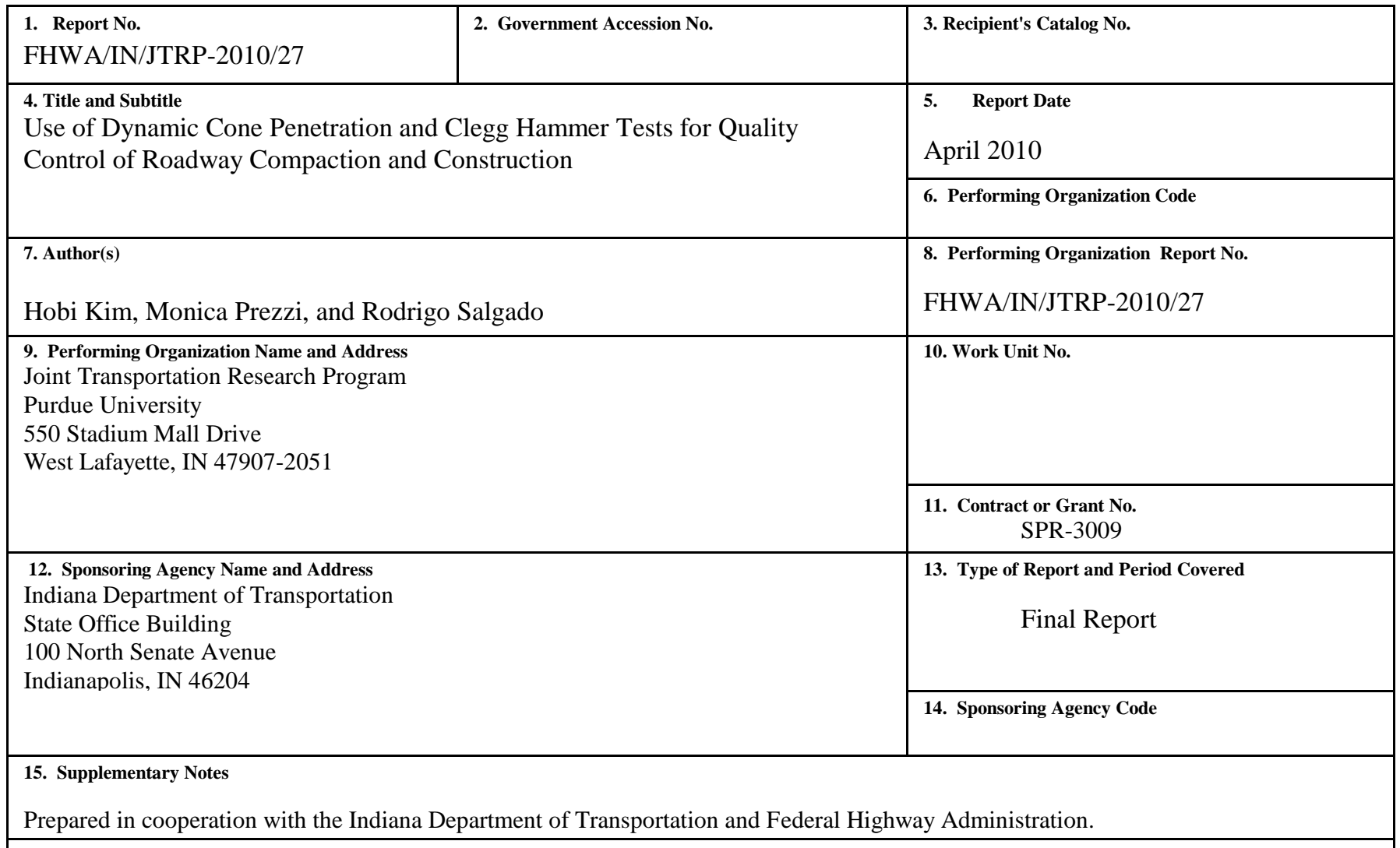

\section{Abstract}

Soil compaction quality control presently relies on the determination of the in-place compacted dry unit weight, which is then compared with the maximum dry unit weight obtained from a laboratory compaction test. INDOT requires that the in-place dry unit weight for compacted soil be over $95 \%$ of the laboratory maximum dry unit weight. In order to determine the in-place dry unit weight, INDOT engineers generally use nuclear gauges, which are hazardous and also costly because of the required safety precautions. Thus, several alternative tests such as the Dynamic Cone Penetration Test (DCPT) and the Clegg Hammer Test (CHT) were introduced as testing tools for soil compaction quality control. However, no reliable correlations are available in the literature to employ these tests for soil compaction quality control. The main objectives of this research were to evaluate the use of the DCPT and the CHT results to develop criteria for soil compaction quality control. A number of DCPTs and CHTs was performed on Indiana road sites, in a test pit, and in the soil test chamber at Purdue University. Since soil compaction varies from place to place, a statistical approach was applied to account for the compaction variability in the development of the criteria for soil compaction quality control.

Based on the DCP tests performed on several INDOT road sites, as well as in the test pit at Purdue University, and the requirement that the in-place dry unit weight of the fill material be over $95 \%$ of the laboratory maximum dry unit weight, minimum required DCP blow counts (NDCP)req were proposed for soils belonging to three groups of the AASHTO (American Association of State Highway and Transportation Officials) soil classification system.

For the DCPT, the minimum required blow count for 0-to-12 inch penetration, (NDCP) $\mid 0 \sim 12$ " associated with an RC of $95 \%$ for A-3 soil varied from 7 to 10; it is a function of the coefficient of uniformity. For A-1 soil and A-2 soils except those containing gravel, the (NDCP) $\mid 0 \sim 12$ " was a function of the optimum moisture content. For silty clays, the minimum required blow counts, (NDCP) $\mid 0 \sim 6$ " and (NDCP)|6 12" were a function of the plasticity index and the soil percentage passing the \#40 sieve. Since the relationship of Clegg Impact Value (CIV) with relative compaction exhibited considerable variability, no criterion for CHT was proposed.

Dynamic analyses hold promise in forming the basis for interpretation of the DCPT and CHT results since predictions of the penetration process (DCPT) and accelerations (CHT) for sand under controlled conditions were very reasonable.

\section{Key Words}

Dynamic Cone Penetration Test (DCPT); Clegg Hammer Test (CHT); Quality Control (QC); soil compaction; dynamic analysis

\section{Distribution Statement}

No restrictions. This document is available to the public through the National Technical Information Service, Springfield, VA 22161

\begin{tabular}{|c|c|c|c|}
\hline $\begin{array}{c}\text { 19. Security Classif. (of this report) } \\
\text { Unclassified }\end{array}$ & 20. Security Classif. (of this page) & 21. No. of Pages \\
& Unclassified & 249
\end{tabular}


$\begin{array}{lll} & \text { Page }\end{array}$

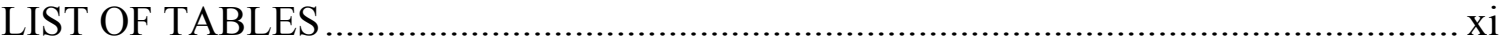

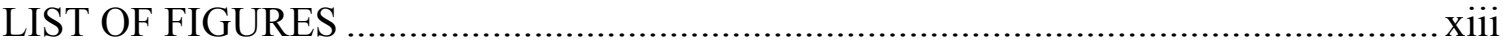

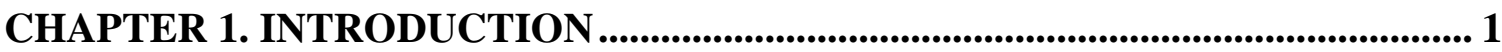

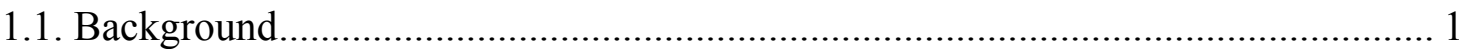

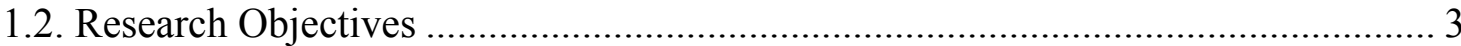

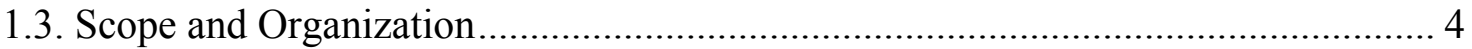

CHAPTER 2. OVERVIEW ON SUBGRADE DESIGN AND CONSTRUCTION ... 7

2.1. Introduction ........................................................................................... 7

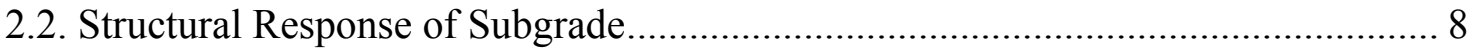

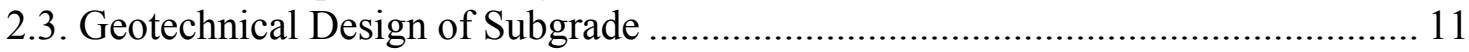

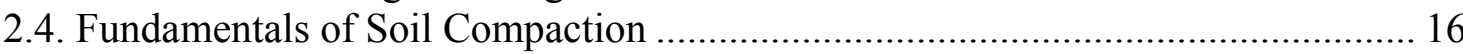

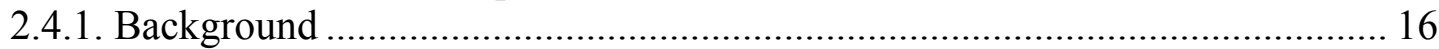

2.4.2. Structures and Engineering Properties of Compacted Soils ............................ 17

2.4.3. Compaction Characteristics of Soils …………………................................. 20

2.4.4. Variables Affecting Soil Compaction .......................................................... 24

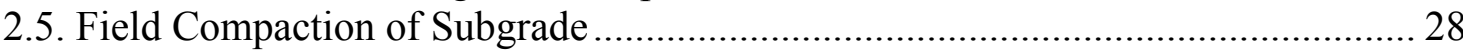

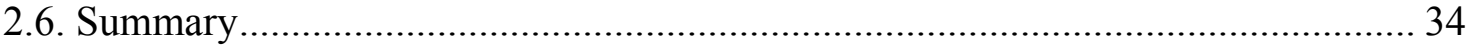

CHAPTER 3. QUALITY CONTROL OF SUBGRADE COMPACTION ................ 36

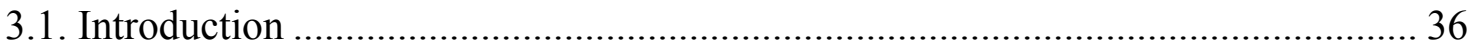

3.2. Density-Based Compaction Control Tests …………............................................... 39

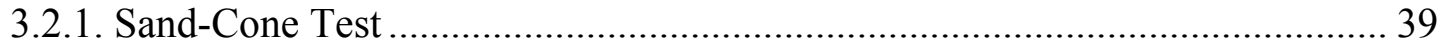

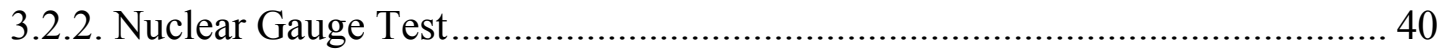

3.3. Performance-Based Compaction Control Tests .................................................... 44

3.3.1. California Bearing Ratio (CBR) Test.......................................................... 44

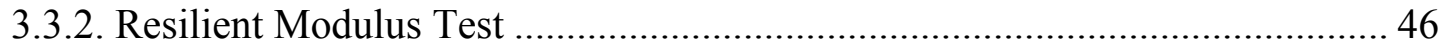

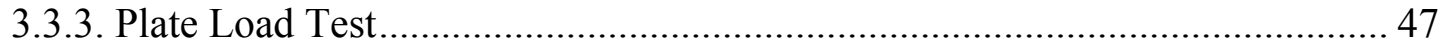

3.3.4. Light Falling-Weight Deflectomter Test...................................................... 49

3.3.5. Soil Stiffness Gauge (SSG, Geogauge) Test.................................................... 52

3.3.6. Dynamic Cone Penetration Test.................................................................... 54

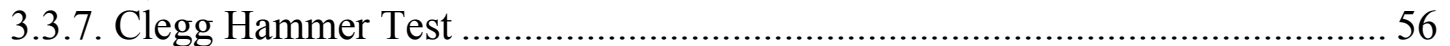

3.3.8. Continuous Compaction Control Test............................................................... 60 
3.4. Specifications for Quality Control of Subgrade Compaction................................. 63

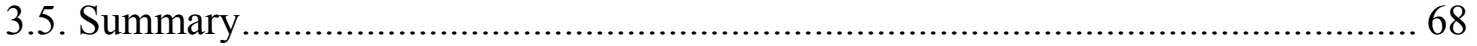

CHAPTER 4. COMPACTION VARIABILITY OF SOIL............................................. 70

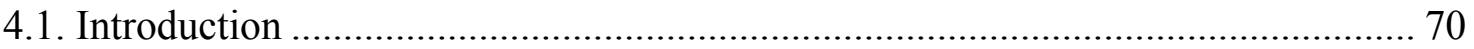

4.2. Basic Statistical Concepts.............................................................................. 72

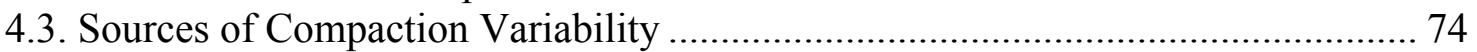

4.4. Accounting for Compaction Variability in Determining the Specification Limits 81

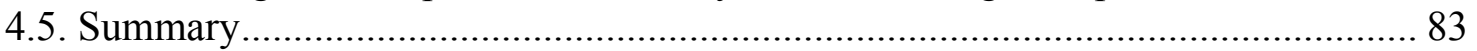

CHAPTER 5. ASSESSMENT OF DYNAMIC ANALYSIS ....................................... 86

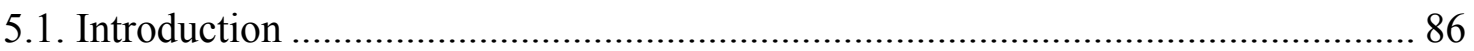

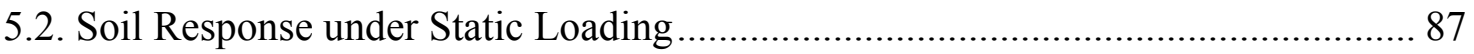

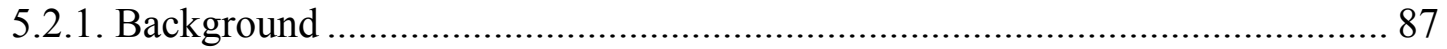

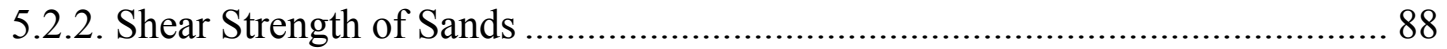

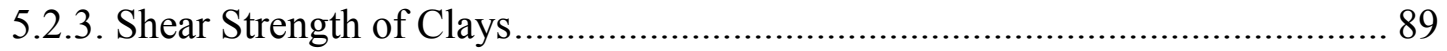

5.2.4. Limit Bearing Capacity of Shallow Footings................................................. 90

5.2.5. Limit Base Capacity of Deep Footings ............................................................ 93

5.3. Soil Response under Dynamic Loading ............................................................ 97

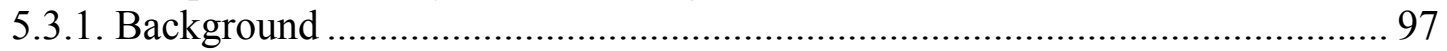

5.3.2. Vertical Oscillation of Footings ....................................................................... 99

5.4. Suggested Model for the Interpretation of in situ Tests ......................................... 106

5.4.1. Selection of the Dynamic Model for the Clegg Hammer Test....................... 106

5.4.2. Selection of the Dynamic Model for the Dynamic Cone Penetration Test.... 112

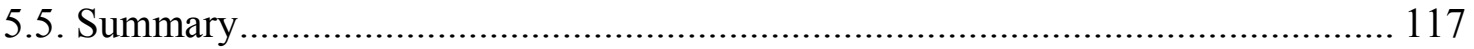

CHAPTER 6. FIELD TESTS ON INDIANA SOILS ................................................... 121

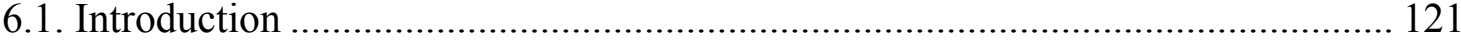

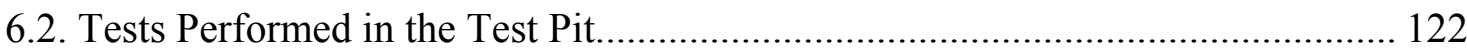

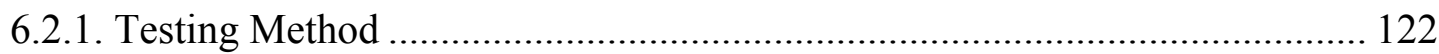

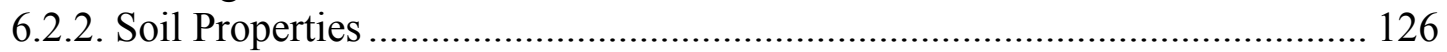

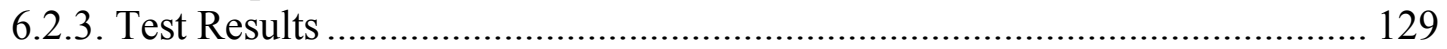

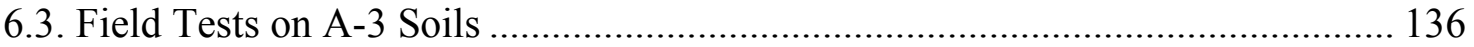

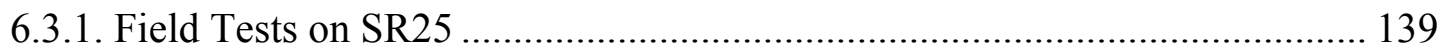

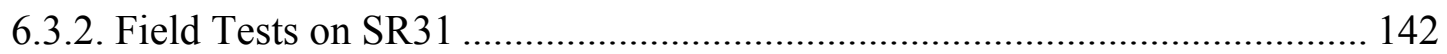

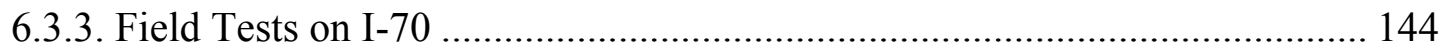

6.3.4. Summary of Test Results on A-3 Soils ..................................................... 148

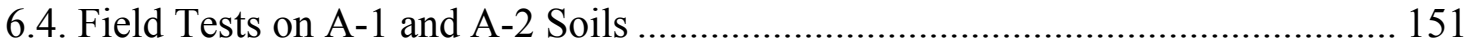

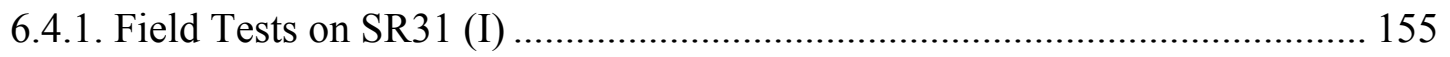

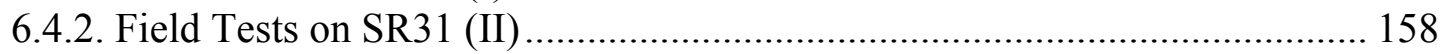

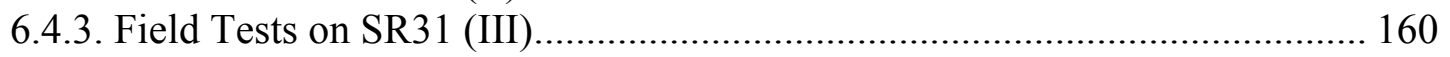

6.4.4. Field Tests on SR31 (Plymouth) .............................................................. 163 
6.4.5. Field Tests on Access Road to Honda Plant ................................................... 166

6.4.6. Summary of Test Results on A-1 and A-2 Soils ........................................... 170

6.5. Field Tests on Silty Clay (A-4 to A-7 soil) ...................................................... 172

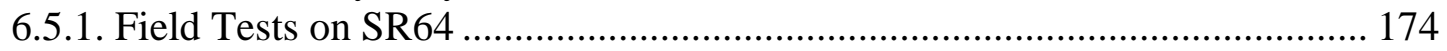

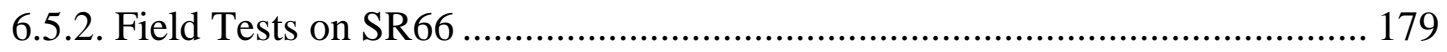

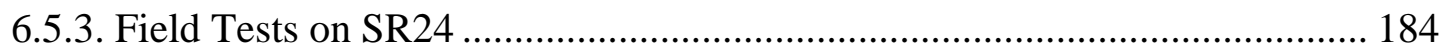

6.5.4. Summary of Test Results on Silty Clay …………........................................ 189

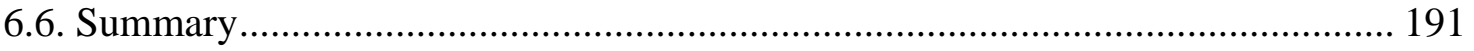

\section{CHAPTER 7. DYNAMIC CONE PENETRATION TESTS AND CLEGG} HAMMER TESTS PERFORMED IN A TEST CHAMBER..................................... 195

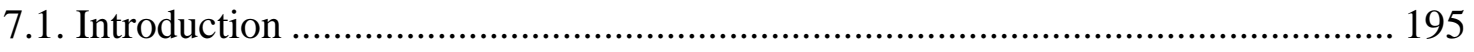

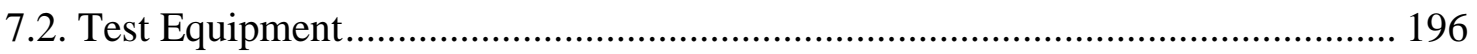

7.2.1. Test Chamber and Pluviation Procedure........................................................ 196

7.2.2. Engineering Properties of Test Sand............................................................ 199

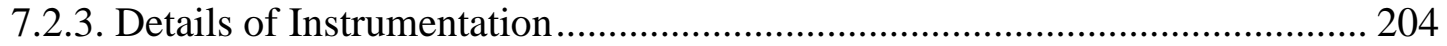

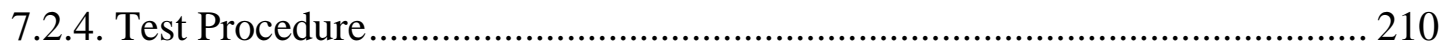

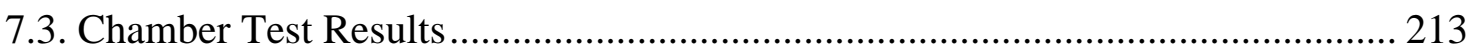

7.3.1. Static Test Results ...................................................................................... 213

7.3.2. Dynamic Test Results .............................................................................. 217

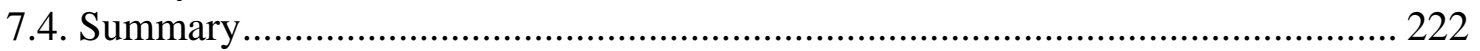

\section{CHAPTER 8. INTERPRETATION OF THE RESULTS USING DYNAMIC}

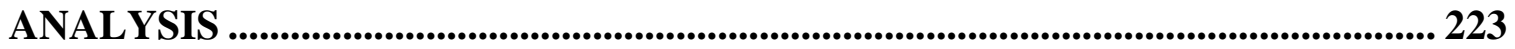

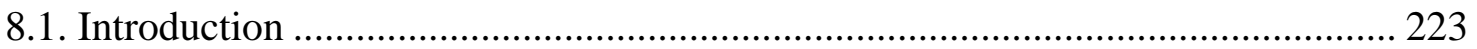

8.2. Input Parameters for the Dynamic Analyses .......................................................... 224

8.3. Validation of the Results of the Tests Performed in the Purdue Test Chamber... 229

8.3.1. Prediction of Static Test Results in Sand ................................................... 229

8.3.2. Prediction of Dynamic Test Results in Sand............................................... 231

8.4. Validation of the Preliminary Test Results in Clay ................................................ 234

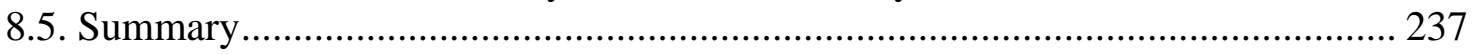

CHAPTER 9. SUMMARY AND CONCLUSIONS.................................................... 238

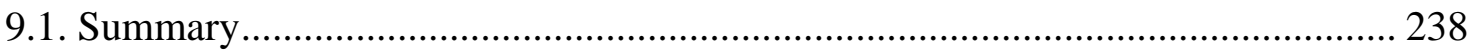

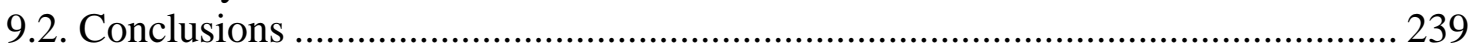

9.3. Suggestions for Future Research ........................................................................ 244

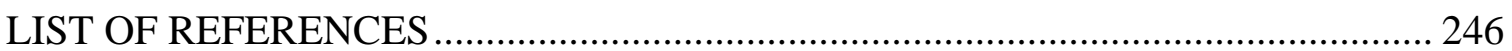




\section{LIST OF TABLES}

Table $\quad$ Page

Table 2.1 AASHTO soil classification (after ASTM D3282-93) .................................. 12

Table 2.2 Minimum laboratory testing requirements for pavement designs (after ARA

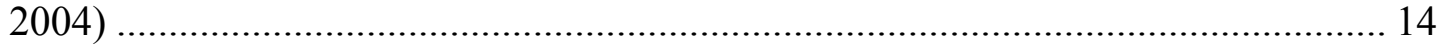

Table 2.3 Geotechnical input parameters required for pavement design (after ARA 2004). 15

Table 2.4 Typical ranges of maximum dry unit weights and optimum moisture contents

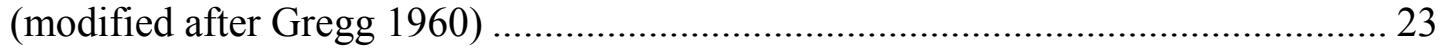

Table 2.5 The relationship between $\gamma_{d \max }, w c_{o p t}$, plastic limit and liquid limit ................ 25

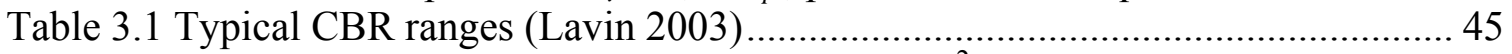

Table 3.2 Modulus of subgrade reaction of sands $\left(\mathrm{MN} / \mathrm{m}^{2} / \mathrm{m}\right)$................................... 48

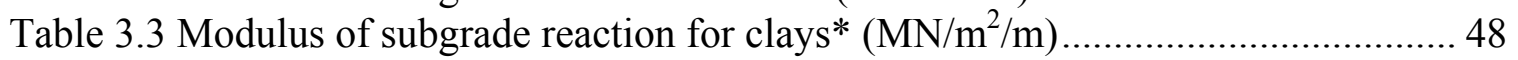

Table 3.4 ISSMGE criteria for compaction QC based on the Zorn-LWD modulus........ 51

Table 3.5 DCP criteria $\left(\mathrm{N}_{\mathrm{DCP}}\right)$ for a penetration of 0 to $150 \mathrm{~mm}(0$ to $6 \mathrm{inch}) \ldots \ldots \ldots \ldots \ldots . . . . .56$

Table 3.6 Various Clegg Hammer Test product configurations (Lafayette Instrument Co.,

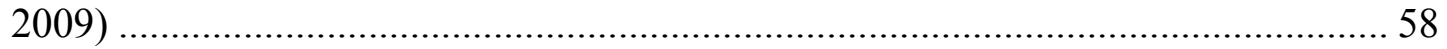

Table 3.7 Summary of the correlations between CBR and CIV * ................................. 59

Table $3.8 \mathrm{CIVs}$ corresponding to $90 \% \mathrm{RC}$ at optimum moisture content (modified after

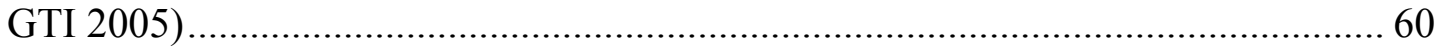

Table 3.9 Summary of compaction control specifications adopted by various

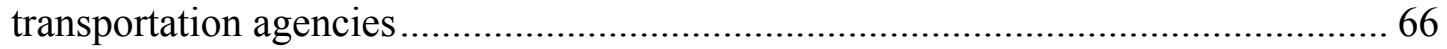

Table 4.1 Variability of laboratory test (data from Liu and Thompson 1966) ............... 78

Table 4.2 Variability of relative compaction data from the literature .............................. 80

Table 6.1 Different compaction targets .................................................................. 124

Table 6.2 The particle-size distribution analysis and classification of the soil sample .. 127

Table 6.3 Summary of compaction test and Atterberg limit tests............................... 128

Table 6.4 Summary of the sand cone, DCPT, and CHT results ................................. 130

Table 6.5 Summary of grain-size distribution analyses and compaction tests .............. 139

Table 6.6 Summary of the DCP results with the coefficient of uniformity $\left(C_{u}\right)$ and

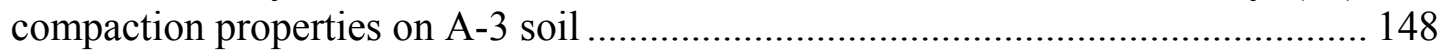

Table 6.7 Summary of grain-size distribution analyses and compaction tests .............. 155

Table 6.8 Summary of the DCP results together with compaction properties of "granular"

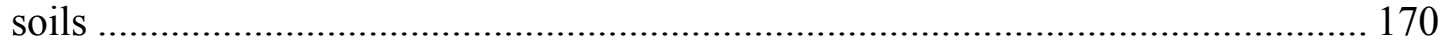

Table 6.9 Summary of the plasticity and compaction properties of the soil samples.... 173

Table 6.10 Summary of the DCP results with the plasticity and percent passing the \#200

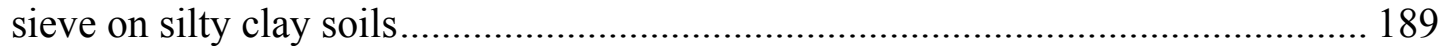

Table 6.11 Relationship between $\mathrm{N}_{\mathrm{DCP}}, C_{u}, w c_{o p t}, P I$, and percent the \#40 passing sieve 
Table 6.12 Relationship between $\left(\mathrm{N}_{\mathrm{DCP}}\right)_{\text {req }}$ 0 12" and coefficient of uniformity $\left(C_{u}\right) \ldots . .192$ Table 6.13 Relationship between $\left(\mathrm{N}_{\mathrm{DCP}}\right)_{\text {req }} \mid 0 \sim 12$ " and optimum moisture content $\left(w c_{\text {opt }}\right) 192$ Table 6.14 Relationship between $\mathrm{N}_{\mathrm{DCP}}, C_{u}, w C_{o p t}, P I$, and percent the \#40 passing sieve

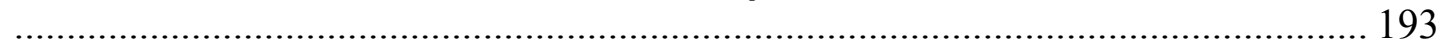

Table 7.1 Engineering properties of F-55 sand (data from Lee 2008)......................... 200

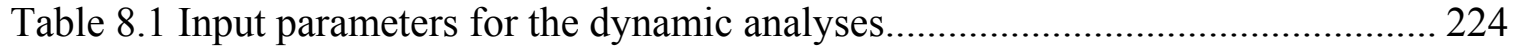

Table 8.2 Maximum dry unit weight and specific gravity used for the dynamic analysis 225

Table 8.3 Summary of measured and predicted static penetration resistance of the DCP 231

Table 8.4 Summary of measured and predicted $\mathrm{N}_{\text {DCP }}$ of clay in the test pit................. 236

Table 9.1 Relationship between $\left(\mathrm{N}_{\mathrm{DCP}}\right)_{\text {req }} \mid 0 \sim 12$ " and coefficient of uniformity $\left(C_{u}\right) \ldots \ldots .240$

Table 9.2 Relationship between $\left(\mathrm{N}_{\mathrm{DCP}}\right)_{\text {req }} \mid 0 \sim 12$ " and optimum moisture content $\left(w c_{\text {opt }}\right) .241$

Table 9.3 Relationship between $\mathrm{N}_{\mathrm{DCP}}, C_{u}, w C_{o p t}, P I$, and percent the \#40 passing sieve 243 


\section{LIST OF FIGURES}

Figure

Page

Figure 2.1 Schematic of vertical stress distribution due to wheel load acting on pavements.

Figure 2.2 Pavement behavior under moving wheel load (a) stresses acting on element along with the transient stress distribution, and (b) strain distribution with depth within the pavement layers and the subgrade (modified after Brown 1996).

Figure 2.3 Strains developed in the subgrade versus time under repeated loads (modified

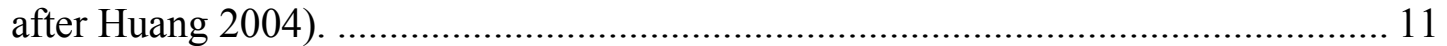

Figure 2.4 Examples of compaction curves (modified after Lambe 1962). ................... 17

Figure 2.5 Typical compaction curve for cohesionless sands and sandy gravels (modified

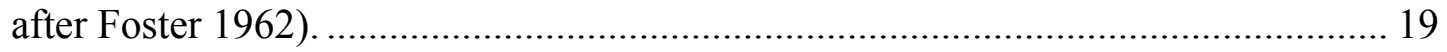

Figure 2.6 INDOT family of curves (modified after INDOT Manual 2007). ................. 21

Figure 2.7 Relationships between maximum dry density, optimum moisture content, and Atterberg limits (data from Woods 1940 and INDOT Manual 2007)...................... 24

Figure 2.8 Relationship between maximum dry density and Atterberg limits: (a) maximum dry density vs. plastic limit, and (b) maximum dry density vs. liquid limit.

Figure 2.9 Effect of plasticity on compacted density for various compaction energies (Rollings and Rollings 1996)...... 27

Figure 2.10 Stress distributions within soil under compactors (modified after Rollings and Rollings 1996).

Figure 2.11 Typical growth curves: (a) A-1-b soil (well-graded sand), and (b) A-7-6 soil (heavy clay) (data from Lewis 1959).................................................................... 30

Figure 2.12 The effect of travel speed of the compactor in: (a) Well-graded sand; (b) Heavy clay (data from Selig and Yoo 1977)........................................................ 32

Figure 3.1 Nuclear gauge measurements: (a) backscatter mode for density measurement, (b) direct transmission mode for density measurement, and (c) moisture detection

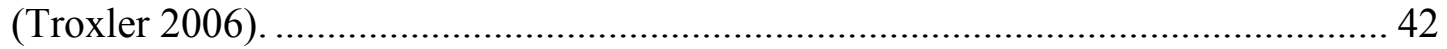

Figure 3.2 Schematic of LWD showing various component of the equipment (modified

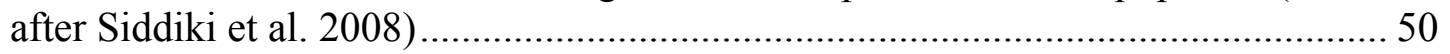

Figure 3.3 Schematic of the Geogauge (modified after Alshibli et al 2005).................. 53

Figure 3.4 Schematic of the Dynamic Cone Penetrometer (modified after ASTM D 6951-

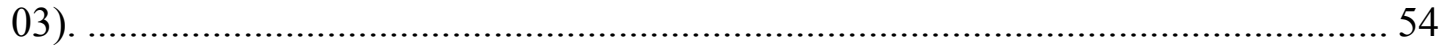

Figure 3.5 Photograph of Clegg Hammer Test (hammer weight, 10kg)..................... 58 Figure 3.6 Geodynamik compactor equipped with monitoring system components

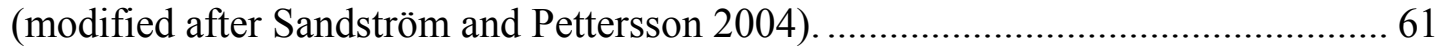

Figure 3.7 Smooth drum compaction monitoring systems for soil (White 2008)......... 62 Figure 4.1 Variability in the compaction level achieved along an embankment............ 71 
Figure 4.2 A normally distributed frequency curve ....................................................... 73

Figure 4.3 Conceptual frequency diagram of in situ test results.................................... 82

Figure 5.1 Expansion of a cavity from zero initial radius (modified after Salgado and

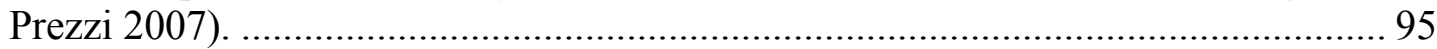

Figure 5.2 Sources of damping on soil. .................................................................... 98

Figure 5.3 Mechanism of soil reaction mobilization: (a) vertical oscillation of a rigid shallow footing on soil and (b) the vertical oscillation of the soil due to a dropping object. 100

Figure 5.4 Lysmer's reaction model: (a) schematic of the model; and (b) spring and dashpot and plots of $\mathrm{R}_{\mathrm{s}}(\mathrm{t})-\mathrm{w}$ and $\mathrm{R}_{\mathrm{d}}(\mathrm{t})$ - w relationship.................................... 103

Figure 5.5 Pile-hammer-soil system of Smith model (modified after Smith 1960)..... 105

Figure 5.6 Selected base reaction model (modified after Loukidis et al. 2008), ............ 108

Figure 5.7 DCPT (a) DCP test sequence; (b) discretization of DCP into lumped masses

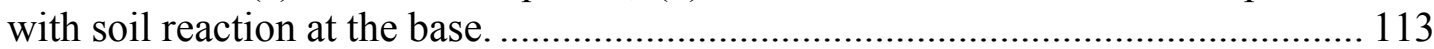

Figure 6.1 The photograph of the test pit...................................................................... 123

Figure 6.2 Test pit: (a) Cross-sectional view of DCPT and CHT test locations, and (b) schematic view of the test pit with the test locations ............................................ 125

Figure 6.3 Particle-size distributions of the soil tested. ............................................. 126

Figure 6.4 Compaction curve for the soil ............................................................. 127

Figure 6.5 Unconfined compression test results on the soil for different relative

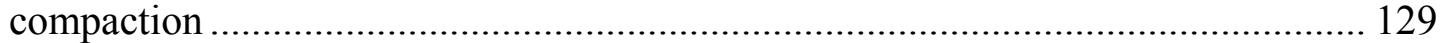

Figure 6.6 Histograms of DCPT pit results: (a) 0-to-6 inch penetration and (b) 6-to-12

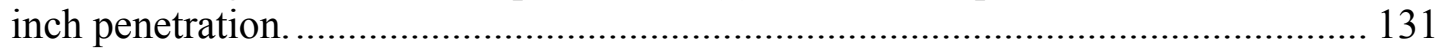

Figure 6.7 Histograms of DCPT pit results at 95\% RC plotted together with the minimum required blow count: (a) 0-to-6 inch penetration and (b) 6-to-12 inch penetration. 133

Figure 6.8 Histograms of DCPT pit results plotted together with the minimum required blow count: (a) 0-to-6 inch penetration and (b) 6-to-12 inch penetration................. 134

Figure 6.9 The Clegg Hammer Test results in the test pit at five different relative

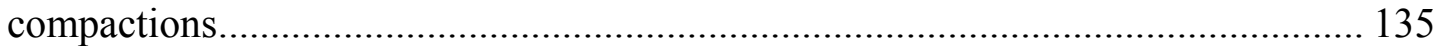

Figure 6.10 Particle-size distributions of A-3 soils. .................................................. 137

Figure 6.11 Compaction curves of the soil samples from: (a) SR25 site, (b) SR31 site, and

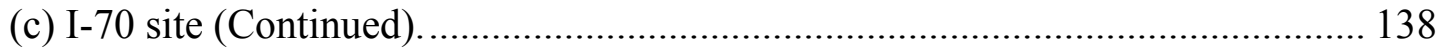

Figure 6.12 Histogram of DCPT results (SR25): 0-to-12 inch penetration.................... 140

Figure 6.13 Histogram of DCPT results at $95.6 \%$ RC plotted together with the minimum required blow count (SR25): 0-to-12 inch penetration. ........................................... 141

Figure 6.14 Histogram of DCPT results plotted together with the minimum required blow count (SR25): 0-to-12 inch penetration.............................................................. 141

Figure 6.15 Histogram of DCPT results (SR31): 0-to-12 inch penetration.................... 143

Figure 6.16 Histogram of DCPT results at $96.7 \%$ RC plotted together with the minimum required blow count (SR31): 0-to-12 inch penetration. .......................................... 143

Figure 6.17 Histogram of DCPT results plotted together with the minimum required blow count (SR31): 0-to-12 inch penetration............................................................... 144

Figure 6.18 Histogram of DCPT results (I-70): 0-to-12 inch penetration. ..................... 145

Figure 6.19 Histogram of DCPT results at $95.0 \%$ RC plotted together with the minimum required blow count (I-70): 0 -to-12 inch penetration. ............................................. 146 
Figure 6.20 Histogram of DCPT results plotted together with the minimum required blow

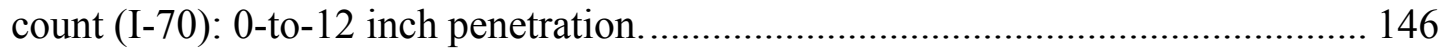

Figure 6.21 CIV versus relative compaction (I-70) ................................................ 147

Figure 6.22 The coefficient of uniformity versus the $\left.\left(\mathrm{N}_{\mathrm{DCP}}\right)_{\text {req }}\right|_{0 \sim 12}$ " for A-3 soils. ....... 150

Figure 6.23 Particle-size distributions of "granular" soils.......................................... 151

Figure 6.24 Compaction curves for the soil samples from: (a) SR31 (I) and (b) SR31 (II)

(c) SR31 (III) and (d) SR31 (Plymouth) (e) Honda access road site (Continued)... 154

Figure 6.25 Histogram of DCPT results [SR31 (I)]: 0-to-12 inch penetration............... 156

Figure 6.26 Histogram of DCPT results at $95.1 \%$ RC plotted together with the minimum required blow count [SR31 (I)]: 0-to-12 inch penetration. .................................. 157

Figure 6.27 Histogram of DCPT results plotted together with the minimum required blow

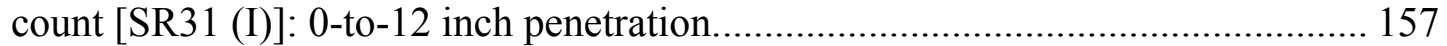

Figure 6.28 Histogram of DCPT results [SR31 (II)]: 0-to-12 inch penetration.............. 159

Figure 6.29 Histogram of DCPT results at $94.7 \%$ RC plotted together with the minimum required blow count [SR31 (II)]: 0-to-12 inch penetration................................... 159

Figure 6.30 Histogram of DCPT results plotted together with the minimum required blow

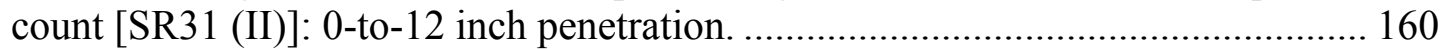

Figure 6.31 Histogram of DCPT results [SR 31 (III)]: 0-to-12 inch penetration........... 162

Figure 6.32 Histogram of DCPT results at $94.8 \%$ RC plotted together with the minimum required blow count [SR31 (III)]: 0-to-12 inch penetration.................................. 162

Figure 6.33 Histogram of DCPT results plotted together with the minimum required blow

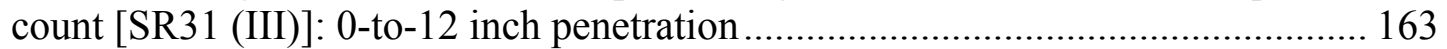

Figure 6.34 Histogram of DCPT results [SR 31 (Plymouth)]: 0-to-12 inch penetration. 164

Figure 6.35 Histogram of DCPT results at $95.0 \%$ RC plotted together with the minimum required blow count [SR 31 (Plymouth)]: 0-to-12 inch penetration....................... 165

Figure 6.36 Histogram of DCPT results plotted together with the minimum required blow count [SR 31 (Plymouth)]: 0-to-12 inch penetration. ............................................ 165

Figure 6.37 Histogram of DCPT results (access road to Honda plant): 0-to-12 inch

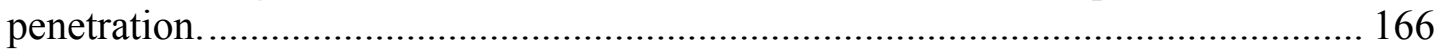

Figure 6.38 Histogram of DCPT results at $95.3 \%$ RC plotted together with the minimum required blow count (access road to Honda plant): 0-to-12 inch penetration .......... 167

Figure 6.39 Histogram of DCPT results plotted together with the minimum required blow count (access road to Honda plant): 0-to-12 inch penetration. .................................. 167

Figure 6.40 CIV versus relative compaction (access road to Honda plant)................... 168

Figure 6.41 The CHT results vs. water contents (access road to Honda plant).............. 169

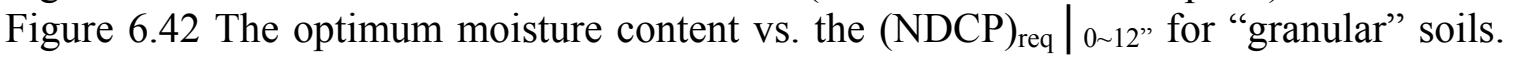
171

Figure 6.43 Particle-size distributions of silty clay soils.......................................... 172

Figure 6.44 Compaction curves of the soil samples from the SR66, SR64, and SR24 sites. 173

Figure 6.45 Histograms of DCPT results (SR64): (a) 0-to-6 inch penetration and (b) 6-to-

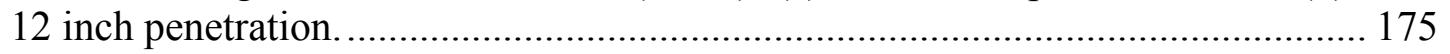

Figure 6.46 Histograms of DCPT results at $96.0 \% \mathrm{RC}$ plotted together with the minimum required blow count (SR64): (a) 0-to-6 inch penetration and (b) 6-to-12 inch penetration. 177 
Figure 6.47 Histograms of the DCPT results plotted together with the minimum required blow count (SR64): (a) 0-to-6 inch penetration and (b) 6-to-12 inch penetration... 178 Figure 6.48 Histograms of DCPT results (SR66): (a) 0-to-6 inch penetration and (b) 6-to12 inch penetration. 180

Figure 6.49 Histograms of DCPT results at 95.6\% RC plotted together with the minimum required blow count (SR66): (a) 0-to-6 inch penetration, and (b) 6-to-12 inch penetration. 182

Figure 6.50 Histograms of DCPT results plotted together with the minimum required blow count (SR66): (a) 0-to-6 inch penetration and (b) 6-to-12 inch penetration... 183

Figure 6.51 Histograms of DCPT results (SR24): (a) 0-to-6 inch penetration and (b) 6-to12 inch penetration. 185

Figure 6.52 Histograms of DCPT results at $95.6 \% \mathrm{RC}$ plotted together with the minimum required blow count (SR24): (a) 0-to-6 inch penetration, and (b) 6-to-12 inch penetration. 187

Figure 6.53 Histograms of DCPT results plotted together with the minimum required blow count (SR24): (a) 0-to-6 inch penetration and (b) 6-to-12 inch penetration... 188

Figure 6.54 The $(\mathrm{PI})(\%$ passing the $\# 40$ sieve $)$ versus the $\left(\mathrm{N}_{\mathrm{DCP}}\right)_{\text {req }} \mid 0 \sim 6$ " and $\left(\mathrm{N}_{\mathrm{DCP}}\right)_{\text {req }} \mid 6 \sim 12$ "

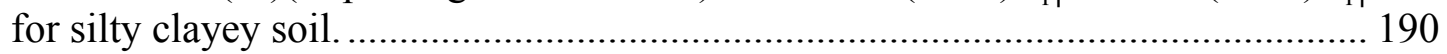

Figure 7.1 Photograph of the soil chamber (modified after Lee 2008). ....................... 197

Figure 7.2 Schematic view of the sand pluviator (modified after Lee 2008)................ 199

Figure 7.3 Grain size distribution of F-55 sand and Ottawa sand (modified after Lee

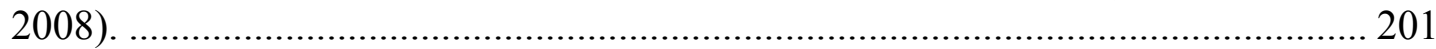

Figure 7.4 A SEM micrograph of F-55 sand grains. ................................................ 202

Figure 7.5 Photographs of (a) DCP bar, and (b) set of plates used in the tests. ............ 205

Figure 7.6 Photographs of (a) the Pile Driving Analyzer, and (b) the accelerometers

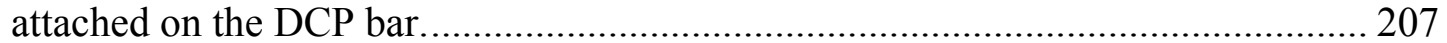

Figure 7.7 Photographs of (a) the oscilloscope and (b) the CHT. ............................... 209 Figure 7.8 Static load test set-up for (a) the DCP tests, and (b) the plate load tests....... 212 Figure 7.9 Static load-settlement curves obtained for dense and medium dense sand using

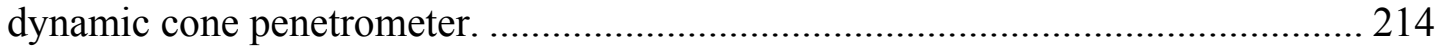

Figure 7.10 Load-settlement curves for the plates bearing on sand. .......................... 215

Figure 7.11 Photographs of the surface of the samples after testing on (a) dense sand and (b) medium dense sand............................................................................... 216

Figure 7.12 Time history curves at several depths of (a) penetration, and (b) velocity. 218 Figure 7.13 Measured vs. calculated penetration per blow $(\mathrm{mm} / \mathrm{blow})$ at the DCP head. 219

Figure 7.14 Acceleration versus time history for Clegg Hammer Tests on dense sand. 220 Figure $7.15 \mathrm{CIV}$ versus relative compaction for the sand sample............................. 221

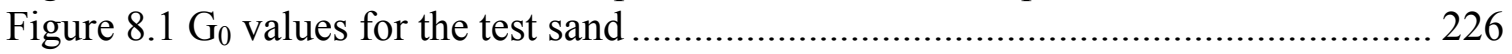

Figure 8.2 Comparison of predicted and measured capacities for plate load tests performed on dense and medium dense sand samples...................................... 230

Figure 8.3 Comparison of predicted and measured acceleration in the chamber.......... 232 Figure 8.4 Predicted and measured CIV versus relative compaction. ......................... 233

Figure 8.5 Comparison of predicted and measured penetration per blow ( $\mathrm{mm} / \mathrm{blow})$ at

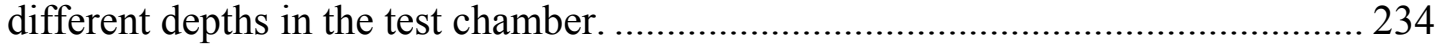


Figure 8.6 Predicted and measured CIV versus relative compaction for the pit tests.... 235 


\section{CHAPTER 1. INTRODUCTION}

\subsection{Background}

A pavement structure is mainly composed of the surface course, the base course, and the subbase layers on a prepared subgrade. Subgrade, as the foundation of the pavement structure, may often govern the pavement performance and, hence, the overall stability of the pavement. Any pavement structure, either concrete or asphalt, is prone to excessive stresses when constructed on a poor subgrade. Therefore, a quality subgrade enhances pavement performance by supporting the traffic loads without undue deflection and without creating stresses that damage a pavement structure.

In situ or nearby soil is typically used in the construction of a subgrade. This soil is compacted at a water content near its optimum moisture content (OMC). Effective assessment of subgrade compaction is essential to ensuring the stability of the subgrade against traffic loads.

Subgrade compaction quality control is typically done by determining the in-place compacted dry unit weight and water content of the subgrade and comparing the obtained values with laboratory compaction test results. Typically, regardless of soil type, the required dry unit weight for compacted soil should be over $95 \%$ of the laboratory maximum dry unit weight determined by the standard Proctor test (Hilf 1991). 
In order to determine the in-place dry unit weight and the water content of compacted subgrade soils, field project engineers generally use nuclear moisture-density gauges and sometimes sand cone tests. Many agencies specify these practices for quality control. However, use of either the nuclear gauge or the sand-cone test is hazardous, slow, labor-intensive, or, in certain cases, not practical at sites where there is a large variability in fill materials along any tested section (Fiedler et al. 1998, Livneh and Goldberg 2001, Nazzal 2003). Also, even though the dry unit weight and the water content of subgrade soils are indicators of the compaction quality of the subgrade, these measurements do not always reflect all of the geotechnical properties that govern the subgrade behavior under traffic loads.

In response to this need for safe, simple, and quick but effective methods to assess the quality of subgrade compaction on site, the Dynamic Cone Penetration Test (DCPT) and the Clegg Hammer Test (CHT) were introduced.

The Dynamic Cone Penetrometer (DCP) is a dynamic in situ penetration test. The DCP is composed of an upper shaft that is rigidly connected to an $8 \mathrm{~kg}$ (17.6-lb) drop hammer, a lower shaft that contains an anvil, at the top and a cone at the bottom, and the cone, which has an apex angle of 60 degrees and is replaceable. In order to perform the test, the hammer is dropped on the anvil and the cone rapidly penetrates the underlying layers. The DCP measures the dynamic penetration resistance of soil in situ. The DCP is portable and relatively inexpensive.

The Clegg Hammer Test (CHT) was developed by Dr. Baden Clegg in the 1970s for compaction quality control of roadways and embankments (Clegg 1976, Garrick and Scholer 1985). It consists of three components: (1) a flat-ended cylindrical hammer, (2) a 
piezoelectric accelerometer attached on the top of the hammer, and (3) a guide tube. The CHT measures the deceleration of the falling hammer when the hammer strikes the soil surface. The accelerometer mounted on the hammer records the deceleration which is expressed in terms of the Clegg Impact Value (CIV), defined as the ratio of the deceleration to the tenth of gravitational acceleration $\left(98 \mathrm{~m} / \mathrm{s}^{2}\right)$.

In spite of significant research performed to interpret the test results of the DCPT and the $\mathrm{CHT}$, no reliable correlations are available in the literature between the results of these tests and the compaction properties of the subgrade, mainly because most of the studies have attempted to develop only empirical correlations of limited applicability.

Since the DCPT is a dynamic test, the results of the test reflect, to some extent, the "dynamic" properties of the soil. In order to develop reliable correlations, the underlying physics of this test needs to be considered. The DCPT can be modeled in a way similar to how pile driving is simulated and the CHT in a way similar to how a footing under impact loading is simulated.

\section{2. $\underline{\text { Research Objectives }}$}

The main objective of this research was to develop methods to interpret the results of the DCPT and the CHT. In order to achieve this goal, a series of DCPTs and CHTs was performed on Indiana road sites, in a test pit, and in a test chamber at Purdue University, West Lafayette, Indiana. Also, analytical and numerical solutions capable of simulating the DCPT and the CHT processes were explored in this study. The main goals of this research are as follows: 
1. Assessment of results of DCPT and CHT performed on several road sites in the state of Indiana;

2. Assessment of results of DCPT and CHT performed in sand samples prepared in a test chamber and in clayey soil samples prepared in a test pit;

3. Selection of analytical models that simulate the DCPT and CHT;

4. Verification of the prediction capability of the analytical models using the test results for both the DCPT and the CHT;

5. Development of correlations between the DCPT and the CHT results and soil compaction properties.

\subsection{Scope and Organization}

This report presents background information on soil compaction and field compaction quality control methods. It also includes the analytical models used to simulate the DCPT and the CHT and the details of the experimental program. The results of the tests performed on Indiana soils as well as those of tests performed on a soil pit and in a test chamber are also discussed. Correlations between the DCPT and the CHT results and soil compaction properties are proposed. The report is organized into nine chapters, which are outlined below:

CHAPTER 1 provides an introduction. 
CHAPTER 2 introduces background information on subgrade design and construction.

CHAPTER 3 reviews field compaction tests for quality control of subgrade compaction and also provides information on specifications used by transportation agencies for soil compaction quality control.

CHAPTER 4 explains the sources of compaction variability and proposes a procedure for the development of quality control criteria of soil compaction using in situ test results.

CHAPTER 5 includes a literature review of dynamic analysis and the selection of models for interpreting DCPT and CHT results.

CHAPTER 6 presents preliminary test results performed on a soil pit as well as field test results of the DCPT and the CHT performed on several types of soils at Indiana road sites. The test results also include the compaction properties of the soils tested.

CHAPTER 7 describes the DCPT and CHT performed on the chamber and the details of the chamber test setup. The results of these tests performed under controlled conditions were used to validate the analytical results. 
CHAPTER 8 compares the predictions from the dynamic analysis with the DCPT and the CHT results obtained in a test pit and in a special test chamber at Purdue University.

CHAPTER 9 summarizes the findings of this research and provides recommendations for future research. 


\section{CHAPTER 2. OVERVIEW ON SUBGRADE DESIGN AND CONSTRUCTION}

\subsection{Introduction}

Based on their mechanical behavior, road pavements are categorized into three major groups: flexible, rigid, and composite. Although these pavement types transfer the traffic loads to its subgrade through different mechanisms (see Figure 2.1), the subgrade, which is the pavement foundation, should support these loads without undergoing excessive deformation. Moving traffic wheel loads are typically dynamic and repeated in nature causing elastic and plastic deformations in the pavement. Generally, the failure of pavement structures is largely because of plastic deformations.

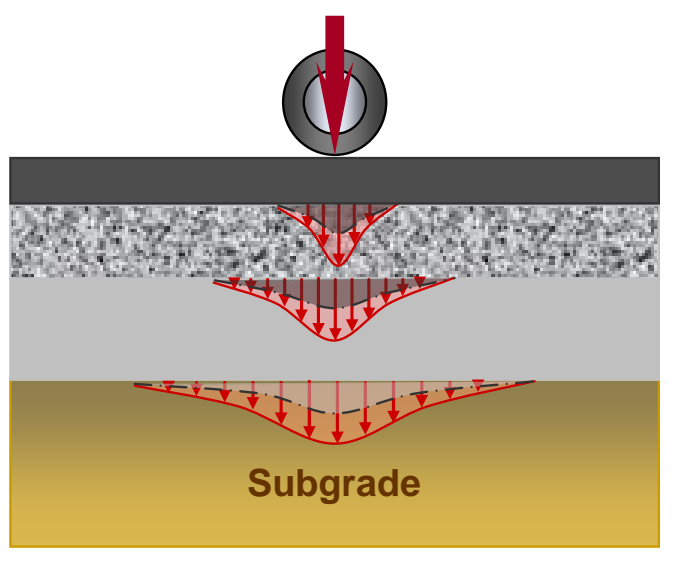

(a) Flexible pavement

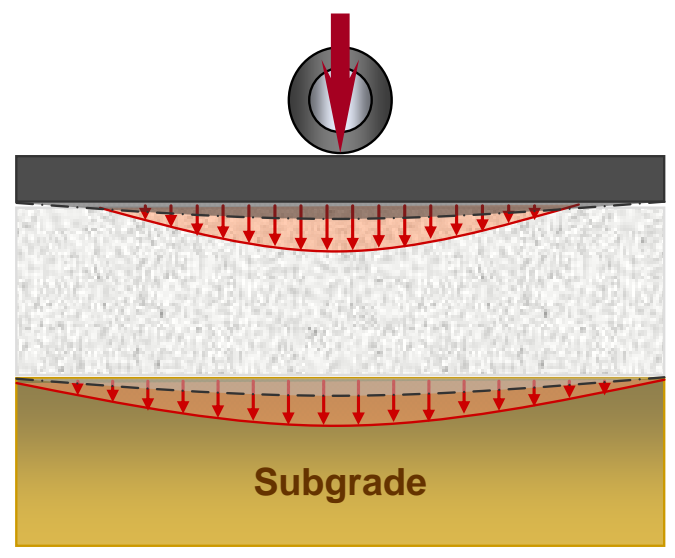

(b) Rigid pavement

Figure 2.1 Schematic of vertical stress distribution due to wheel load acting on pavements. 
Several factors affect the subgrade soil behavior [i.e., soil characteristics, method of compaction, degree of saturation (water content), dry unit weight of subgrade, and stress level and history]. In this chapter, we briefly discuss the subgrade response to traffic loading as well as its design. Lastly, the soil compaction theory used in the determination of the quality of pavement subgrade is discussed.

\subsection{Structural Response of Subgrade}

When a single moving wheel load acts on a pavement, the load creates a transient stress pulse [see Figure 2.2 (a)]. Due to these imposed stresses, the pavement layers, including the subgrade, deform. The deformation of each pavement layer and the subgrade can be obtained by integrating a strain diagram as the one shown in Figure 2.2 (b). A significant amount of the surface deflection takes place due to the deformation of the subgrade [refer to Figure $2.2(\mathrm{~b})]$.

Huang (2004) indicated that the deformation of a properly compacted subgrade is almost recoverable under small traffic loads. Since the plastic deformation of the subgrade decreases with increasing number of load cycles, the deformation developed in the subgrade becomes essentially recoverable after a large number of repeated load cycles are applied to the pavement. 

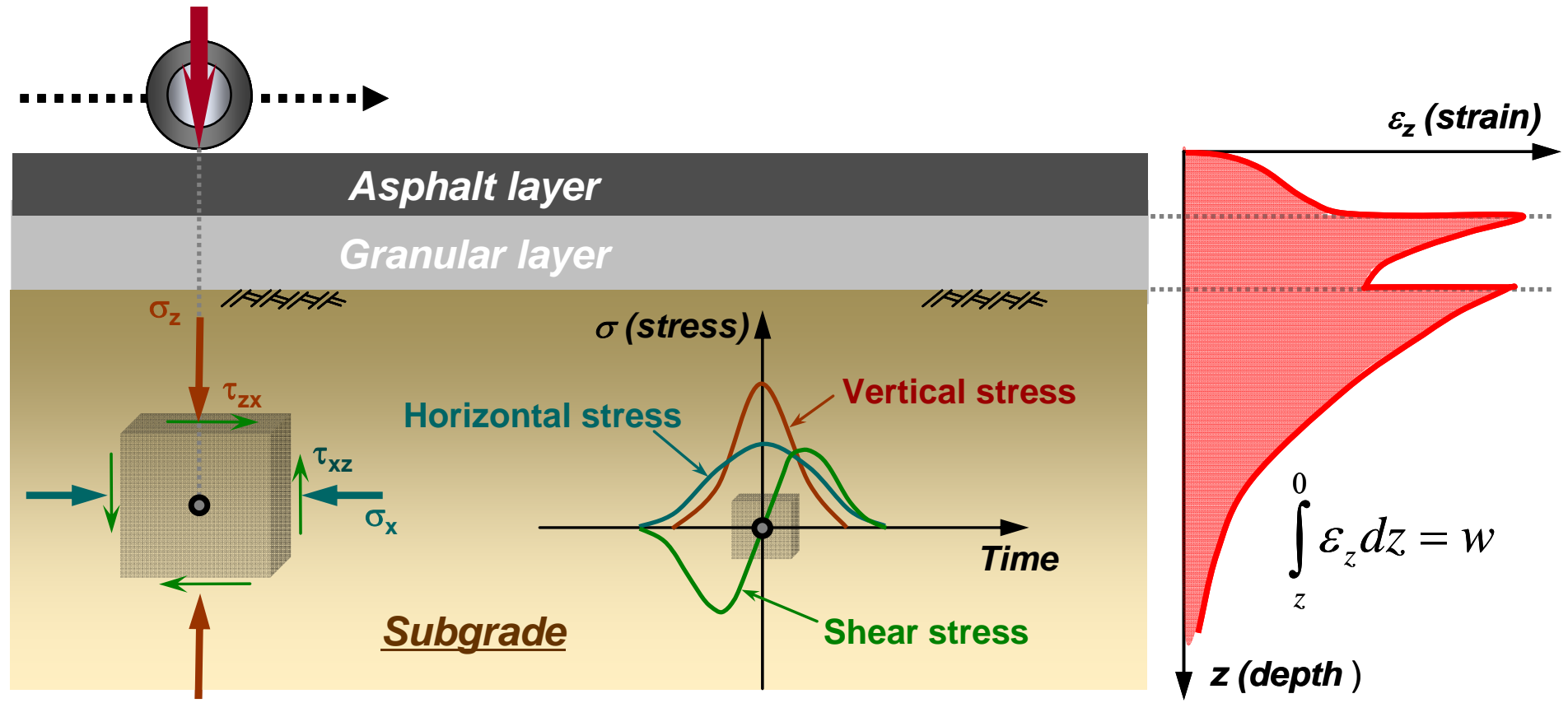

(a)

(b)

Figure 2.2 Pavement behavior under moving wheel load (a) stresses acting on element along with the transient stress distribution, and (b) strain distribution with depth within the pavement layers and the subgrade (modified after Brown 1996). 
In order to carry out a mechanistic pavement analysis and design, it is vital to work with subgrade properties that reflect its dynamics. In this regard, the parameter "resilient modulus" was introduced in California during the 1950s (Brown 1996). The resilient modulus $\left(M_{R}\right)$, defined as the elastic modulus based on the recoverable strain under repeated loading, is given by:

$$
\mathrm{M}_{\mathrm{R}}=\frac{\sigma_{\mathrm{d}}}{\varepsilon_{\mathrm{r}}}
$$

where $\sigma_{d}$ is the deviator stress, and $\varepsilon_{r}$ is the recoverable (elastic) strain under repeated loading.

Resilient modulus is one of the dynamic subgrade properties that can be used for mechanical analysis of multilayered pavement structures. However, as shown in Figure 2.3, the subgrade behavior in the inelastic range also influences the subgrade behavior. In order to understand the structural response of the subgrade, we should account for the inelastic behavior as well as the elastic behavior of the subgrade since elastic soil response takes place only at very small deformation levels (Salgado 2008). 


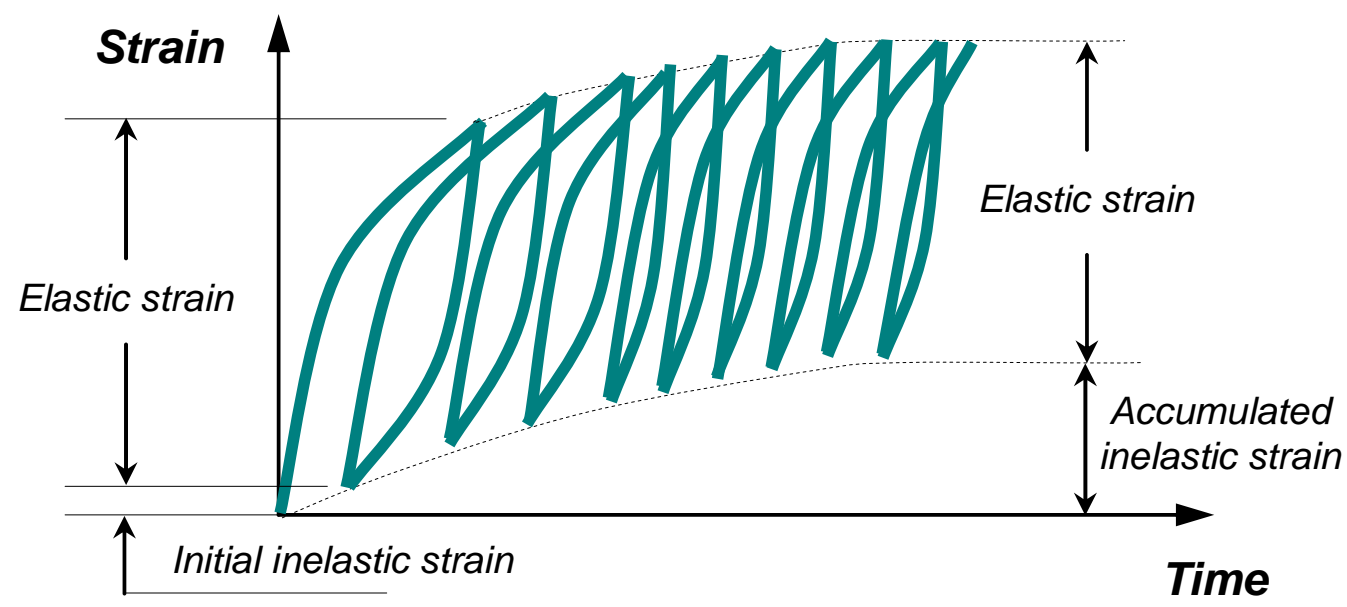

Figure 2.3 Strains developed in the subgrade versus time under repeated loads (modified after Huang 2004).

\subsection{Geotechnical Design of Subgrade}

Subgrade design has grown in importance over time. By the early 1920s, engineers relied on the experience gained from the successes and failures of the pavements designed up to that time (Schwartz and Carvalho 2007). As experience-based pavement design evolved, there was a need to categorize the subgrade soil types by their quality as a pavement material. Hogentogler and Terzaghi (1929) in U.S. Bureau of Public Roads (PR), later became the Federal Highway Administration, suggested a soil classification system that could be used in an empirical method of subgrade design without mechanical testing of subgrade soils. According to this classification system, uniform subgrades were designated from A-1 to A-8, while nonuniform subgrades, from B-1 to B-3. The Public 
Roads Classification System was later modified into the American Association of State Highway and Transportation Officials (AASHTO) soil classification system (ASTM D3282) that is commonly used for subgrade design and construction (see Table 2.1). Subgrade soils are currently classified per the AASHTO soil classification system.

Table 2.1 AASHTO soil classification (after ASTM D3282-93)

\begin{tabular}{|c|c|c|c|c|c|c|c|c|c|c|c|}
\hline $\begin{array}{c}\text { General } \\
\text { Description }\end{array}$ & \multicolumn{7}{|c|}{ Granular materials } & \multicolumn{4}{|c|}{ Silt-Clay materials } \\
\hline \multirow{2}{*}{$\begin{array}{c}\text { Group } \\
\text { Classification }\end{array}$} & \multicolumn{2}{|c|}{ A-1 } & \multirow[t]{2}{*}{ A-3 } & \multicolumn{4}{|c|}{ A-2 } & \multirow{2}{*}{ A-4 } & \multirow{2}{*}{ A-5 } & \multirow{2}{*}{ A-6 } & \multirow{2}{*}{ A-7 } \\
\hline & A-1-a & A-1-b & & A-2-4 & A-2-5 & A-2-6 & A-2-7 & & & & \\
\hline \multicolumn{12}{|l|}{$\%$ passing } \\
\hline No. 10 & $\begin{array}{c}50 \\
\max \end{array}$ & & & & & & & & & & \\
\hline No. 40 & $\begin{array}{c}30 \\
\max \\
\end{array}$ & $\begin{array}{c}50 \\
\max \end{array}$ & $\begin{array}{c}51 \\
\min \\
\end{array}$ & & & & & & & & \\
\hline No. 200 & $\begin{array}{c}15 \\
\max \\
\end{array}$ & $\begin{array}{c}25 \\
\max \end{array}$ & $\begin{array}{c}10 \\
\max \end{array}$ & $\begin{array}{c}35 \\
\max \\
\end{array}$ & $\begin{array}{c}35 \\
\max \\
\end{array}$ & $\begin{array}{c}35 \\
\max \end{array}$ & $\begin{array}{c}35 \\
\max \\
\end{array}$ & $\begin{array}{c}36 \\
\mathrm{~min} \\
\end{array}$ & $\begin{array}{c}36 \\
\min \\
\end{array}$ & $\begin{array}{c}36 \\
\min \\
\end{array}$ & $\begin{array}{c}36 \\
\mathrm{~min} \\
\end{array}$ \\
\hline Liquid limit & & & & $\begin{array}{l}40 \\
\max \end{array}$ & $\begin{array}{c}41 \\
\min \end{array}$ & $\begin{array}{c}40 \\
\max \end{array}$ & $\begin{array}{c}41 \\
\min \end{array}$ & $\begin{array}{c}40 \\
\max \end{array}$ & $\begin{array}{c}41 \\
\min \end{array}$ & $\begin{array}{c}40 \\
\max \end{array}$ & $\begin{array}{c}41 \\
\min \end{array}$ \\
\hline $\begin{array}{l}\text { Plasticity } \\
\text { Index }\end{array}$ & $\begin{array}{c}6 \\
\max \end{array}$ & & N.P. & $\begin{array}{c}10 \\
\max \end{array}$ & $\begin{array}{c}10 \\
\max \end{array}$ & $\begin{array}{c}11 \\
\min \end{array}$ & $\begin{array}{c}11 \\
\min \end{array}$ & $\begin{array}{c}10 \\
\max \end{array}$ & $\begin{array}{c}10 \\
\max \end{array}$ & $\begin{array}{c}11 \\
\min \end{array}$ & $\begin{array}{c}11 \\
\min \end{array}$ \\
\hline $\begin{array}{c}\text { Usual types of } \\
\text { significant } \\
\text { constituent } \\
\text { materials }\end{array}$ & \multicolumn{2}{|c|}{$\begin{array}{c}\text { Stone } \\
\text { Fragments, } \\
\text { Gravel and } \\
\text { Sand }\end{array}$} & $\begin{array}{l}\text { Fine } \\
\text { Sand }\end{array}$ & \multicolumn{4}{|c|}{$\begin{array}{l}\text { Silty or Clayey } \\
\text { Gravel and Sand }\end{array}$} & \multicolumn{2}{|c|}{$\begin{array}{l}\text { Silty } \\
\text { Soils }\end{array}$} & \multicolumn{2}{|c|}{$\begin{array}{l}\text { Clayey } \\
\text { Soils }\end{array}$} \\
\hline $\begin{array}{l}\text { General rating } \\
\text { as subgrade }\end{array}$ & \multicolumn{7}{|c|}{ Excellent to Good } & \multicolumn{4}{|c|}{ Fair to Poor } \\
\hline
\end{tabular}

Plasticity index of A-7-5 subgroup is equal to or less than LL minus 30. Plasticity index of A-7-6 subgroup is greater than LL minus 30.

At the end of the 1950s, the American Association of State Highway Officials (AASHO) Road Test was conducted to study the performance of pavement structures under actual traffic loading conditions (Croney 1977). The results obtained from the ASSHO Road Test were used to establish a pavement design guide that primarily relies 
on the index properties of the subgrade (i.e., California Bearing Ratio, CBR). This design guide is popular among most of the transportation agencies in the U.S. However, some state agencies have devised their own index tests that have been used in the design of pavements. For example, Illinois uses the Illinois Bearing Ratio (IBR); Florida, the Florida Limerock Bearing Ratio (LBR); Washington, California, and Minnesota use the Resistance Value (R-value); and Texas uses the Texas triaxial classification value (Christopher et al. 2006). Different state agencies take different approaches as well to subgrade design with different field construction and monitoring [quality control (QC) and quality assurance (QA)] methods and specifications for subgrade compaction.

The pavement design guide was developed on an empirical basis so it cannot account for various design conditions, such as the dynamic nature of traffic loading, climate conditions, and diverse material properties. Thus, FHWA introduced the Mechanistic-Empirical (M-E) Pavement Design Guide (ARA 2004), which incorporated the theories of mechanics into the design of pavements, to better predict the pavement response for given loading conditions. At present, there are several design methods available to consider the mechanical stability of pavements.

Several mechanical input parameters are required for the method in the M-E Design Guide. Also, several laboratory and field tests are recommended to characterize the subgrade soil. Table 2.2 shows the minimum laboratory testing requirements. After performing the laboratory tests, the geotechnical input parameters for the methods in the M-E Design Guide are obtained. Depending on the hierarchical level, different properties may be required. Table 2.3 shows the geotechnical input parameters required for pavement design. 
Table 2.2 Minimum laboratory testing requirements for pavement designs (after ARA 2004)

\begin{tabular}{|c|c|c|c|}
\hline Type of laboratory test & Deep Cuts & $\begin{array}{c}\text { High } \\
\text { Embankments }\end{array}$ & At-Grade \\
\hline Proctor test (compaction) & $V$ & & $V$ \\
\hline Atterberg limits & $V$ & $V$ & $V$ \\
\hline Gradation & $V$ & & $V$ \\
\hline Shrink-Swell tests & $V$ & $V$ & \\
\hline Permeability tests & & $V$ & \\
\hline Consolidation tests & $V$ & $V$ & $V$ \\
\hline Shearing and bearing strength & $V$ & & \\
\hline Resilient modulus & & $V$ & \\
\hline
\end{tabular}


Table 2.3 Geotechnical input parameters required for pavement design (after ARA 2004).

\begin{tabular}{|c|c|}
\hline Property & Description \\
\hline \multicolumn{2}{|l|}{ General } \\
\hline$\gamma_{\tau}$ & In situ total unit weight \\
\hline$K_{0}$ & Coefficient of lateral earth pressure \\
\hline \multicolumn{2}{|c|}{ Stiffness/Strength of subgrade and Unbound Layers } \\
\hline$k_{\text {dynamic }}$ & Backcalculated modulus of subgrade reaction \\
\hline$k_{1}, k_{2}, k_{3}$ & Nonlinear resilient modulus parameters \\
\hline$M_{R}$ & Resilient modulus \\
\hline CBR & California Bearing Ratio \\
\hline$R$ & R-value \\
\hline$a_{i}$ & Layer coefficient \\
\hline DCPI & Dynamic Cone Penetration Index \\
\hline PI & Plasticity Index \\
\hline \multirow[t]{2}{*}{ P200 } & Percent passing No. 200 sieve \\
\hline & AASHTO soil class and USCS soil classification \\
\hline$v$ & Poisson's ratio \\
\hline$\phi$ & Interface friction angle \\
\hline
\end{tabular}

As mentioned in Table 2.3, the stiffness and strength properties of the subgrade soil are required inputs in pavement design following the M-E Design Guide as many of the geotechnical properties influence pavement performance. 


\subsection{Fundamentals of Soil Compaction}

\subsubsection{Background}

Following the design process, the subgrade is built on site. At the time of construction, field construction personnel ensure that the subgrade is constructed as designed. Proper compaction of the subgrade determines its quality.

Compaction is the process by which the soil particles are artificially rearranged and packed together into a denser state through the application of mechanical energy. Compaction increases the concentration of soil solids, and therefore decreases its void ratio. Since soil compaction forces the soil into a denser state, it is capable of resisting more stresses with less deformation. Another benefit of soil compaction is that it decreases the sensitivity of the soil to environmental changes, such as those caused (1) by variability in water content and (2) freezing and thawing. As a result, soil compaction also increases the uniformity of the subgrade.

Prior to the advent of compaction, earth fills were allowed to settle over a period of a few years under their own self-weight before placement of the pavement on the fill. Until the late 1920s, soil compaction was performed largely on a trial-and-error basis. After Stanton (1928) first used soil compaction tests to determine the optimum moisture content and maximum dry density, Proctor (1933) extended his study and presented the effect of soil compaction on shear strength and permeability. He also contributed to establishing the standard laboratory compaction test, popularly known as "Proctor test." 


\subsubsection{Structures and Engineering Properties of Compacted Soils}

After Proctor's study, several significant research studies were done to explain the compaction characteristics of soils (Lambe 1958a; Lambe 1958b; Seed and Chan 1959; Lambe 1962; and Foster 1962). Figure 2.4 illustrates the compaction characteristics of soil.

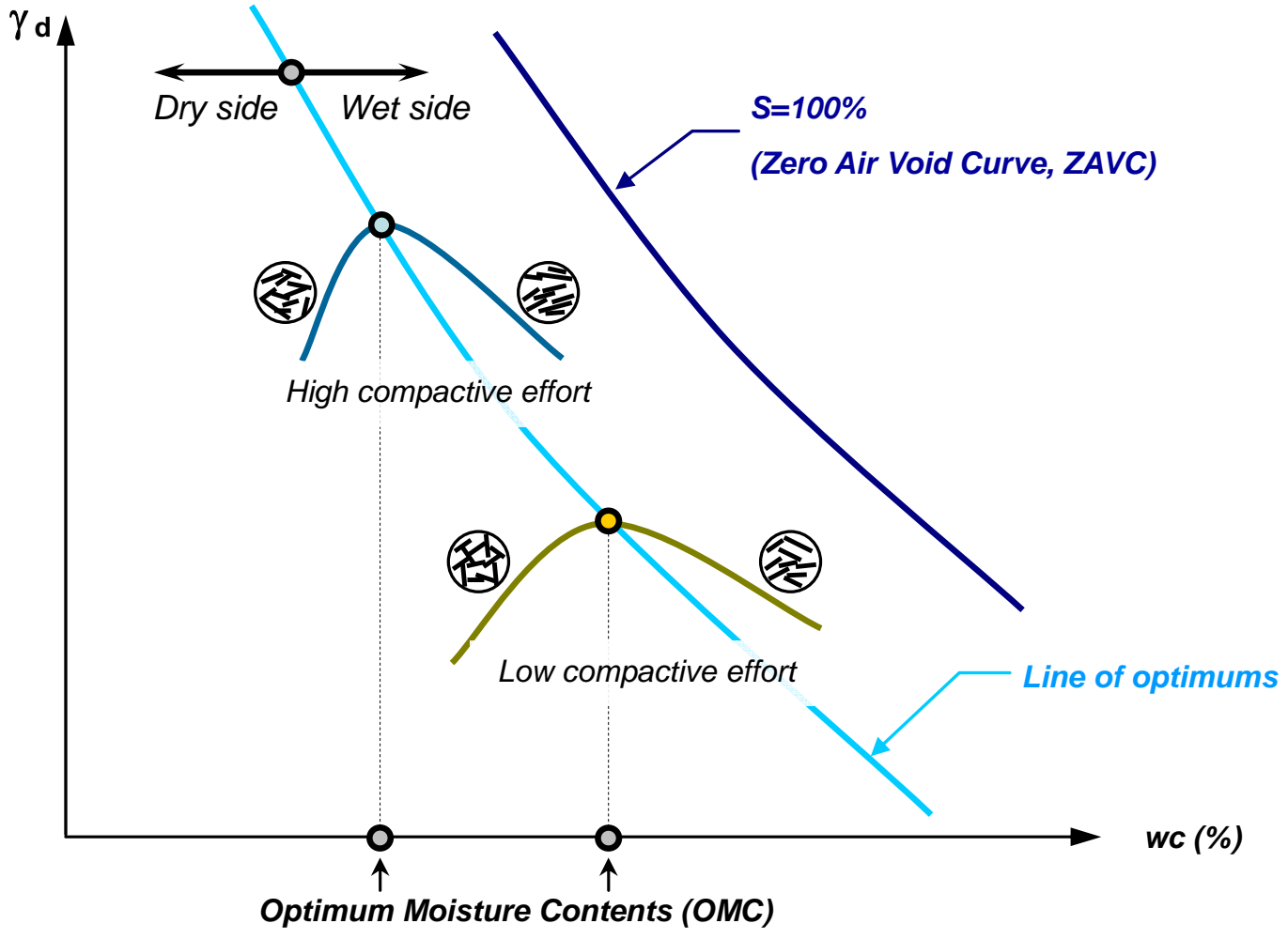

Figure 2.4 Examples of compaction curves (modified after Lambe 1962).

As can be seen in Figure 2.4, soils in a dried state cannot be compacted well. Adding water helps the soil particles to slide against each other, thereby enabling dense packing of particles within a given volume. This phenomenon occurs until the molding 
water content reaches the optimum moisture content (OMC). However, if more water is added to the soil mass after the OMC is reached, the water starts occupying space that would otherwise have been occupied by soil solids and the compacted dry unit weight of the soil therefore decreases. The compaction curve, which quantifies the relationship between the dry unit weights and the molding water contents, depends on (1) the soil type, (2) the amount of compaction effort, and (3) the compaction equipment type.

Knowledge of the change of soil fabric with water content is helpful in understanding the compaction characteristics of soil (see Figure 2.4). At a given compaction effort, by increasing the molding water content, the soil fabric becomes more oriented and the pore-water tension between adjacent soil particles decreases. Soil compacted on the dry side of optimum has a flocculated fabric; soil compacted on the wet side of optimum has dispersed fabric. When the compaction effort increases, the soil particles tend to have a relatively more parallel arrangement. Soils containing fine particles with more elongated or platy shapes typically display this behavior. Silty-clay materials (A-4, A-5, A-6, and A-7 soils), including some "granular" materials (some A-2 soils) fall in this category. Soils compacted on the dry side of optimum (flocculated) have higher stiffness than soils compacted on the wet side of optimum (dispersed). In addition to soil fabric and structure, suction can also have an impact on the stiffness of the compacted soil, making the soil stronger, particularly for soils compacted at water contents on the dry side of optimum.

However, for sandy soils, classified as A-3 soils, including some A-1 and A-2 soils, the soil fabric is completely different. These types of soils allow very fast drainage. During compaction of these soils, there is little change of particle arrangement. Rather, if 
water is added to the soil from a completely dry state, water films start to form around the soil particles, resulting in an apparent cohesion in the soil. Therefore, these soils form a loose honeycomb structure within a certain range of water contents. This effect is called "bulking." (refer to Figure 2.5).

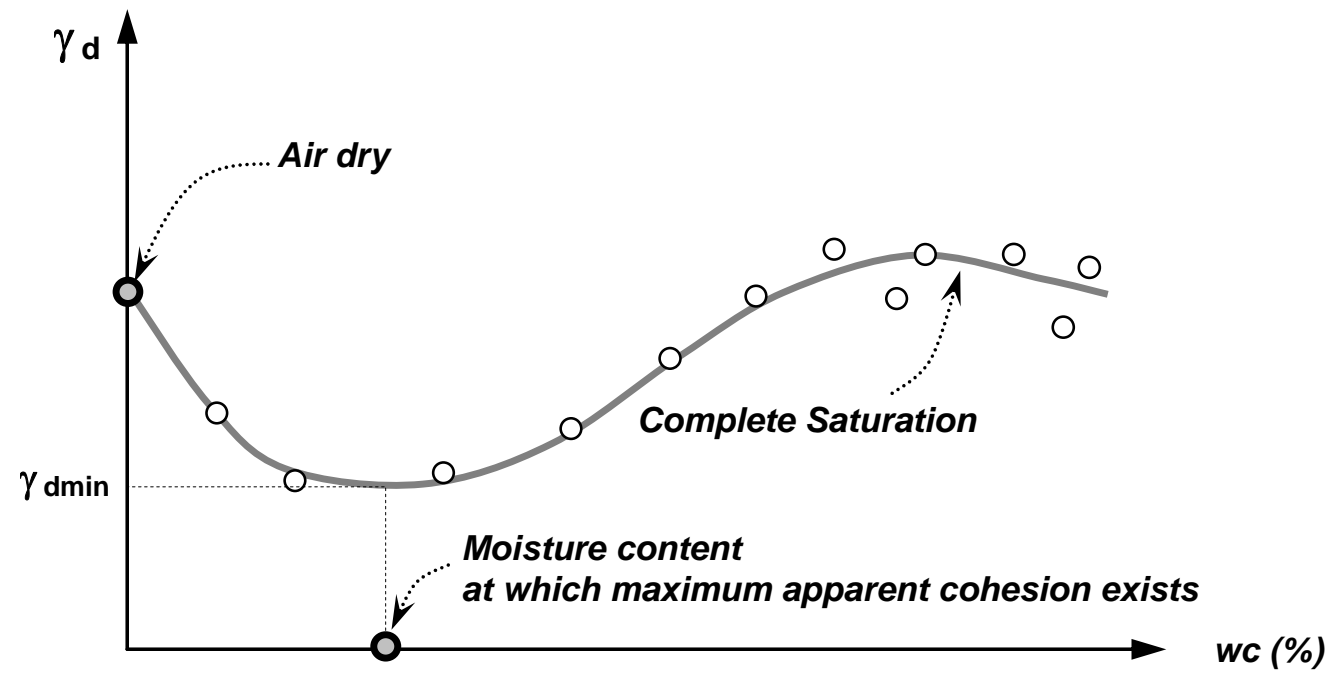

Figure 2.5 Typical compaction curve for cohesionless sands and sandy gravels (modified after Foster 1962).

When the apparent cohesion reaches its maximum value, the void spaces in the soil are also at their maximum. Bulking disappears when the soil becomes completely saturated because of no apparent cohesion. 


\subsubsection{Compaction Characteristics of Soils}

Some researchers attempted to obtain general compaction curves and to establish correlations between index properties and compaction parameters $\left(\gamma_{\mathrm{dmax}}\right.$ and $\left.w c_{o p t}\right)$. Woods and Litehiser (1938) performed an extensive laboratory testing program and performed 1,383 Proctor tests on soils excavated in the state of Ohio. They observed that numerous compaction test results for various soil types yielded a set of compaction curves with similar shape and geometry. These compaction curves, plotted in one graph, are called a "family of curves". Similarly, the Indiana Department of Transportation (INDOT) developed a family of curves based on numerous standard Proctor tests performed on Indiana soils (INDOT Manual 2007, Figure 2.6). As shown in Figure 2.6, most soils with the same maximum dry density have identical curves. In addition, the compaction curves that have higher maximum dry unit weights have steeper slopes with lower optimum moisture contents.

Once the family of curves is established, with just one point of the curve, the maximum dry density and the optimum moisture content of the soil to be compacted in situ can be estimated (AASHTO T272-04). This procedure, known as the one-point Proctor test, has been used by several states agencies, including INDOT (INDOT Manual 2007). 


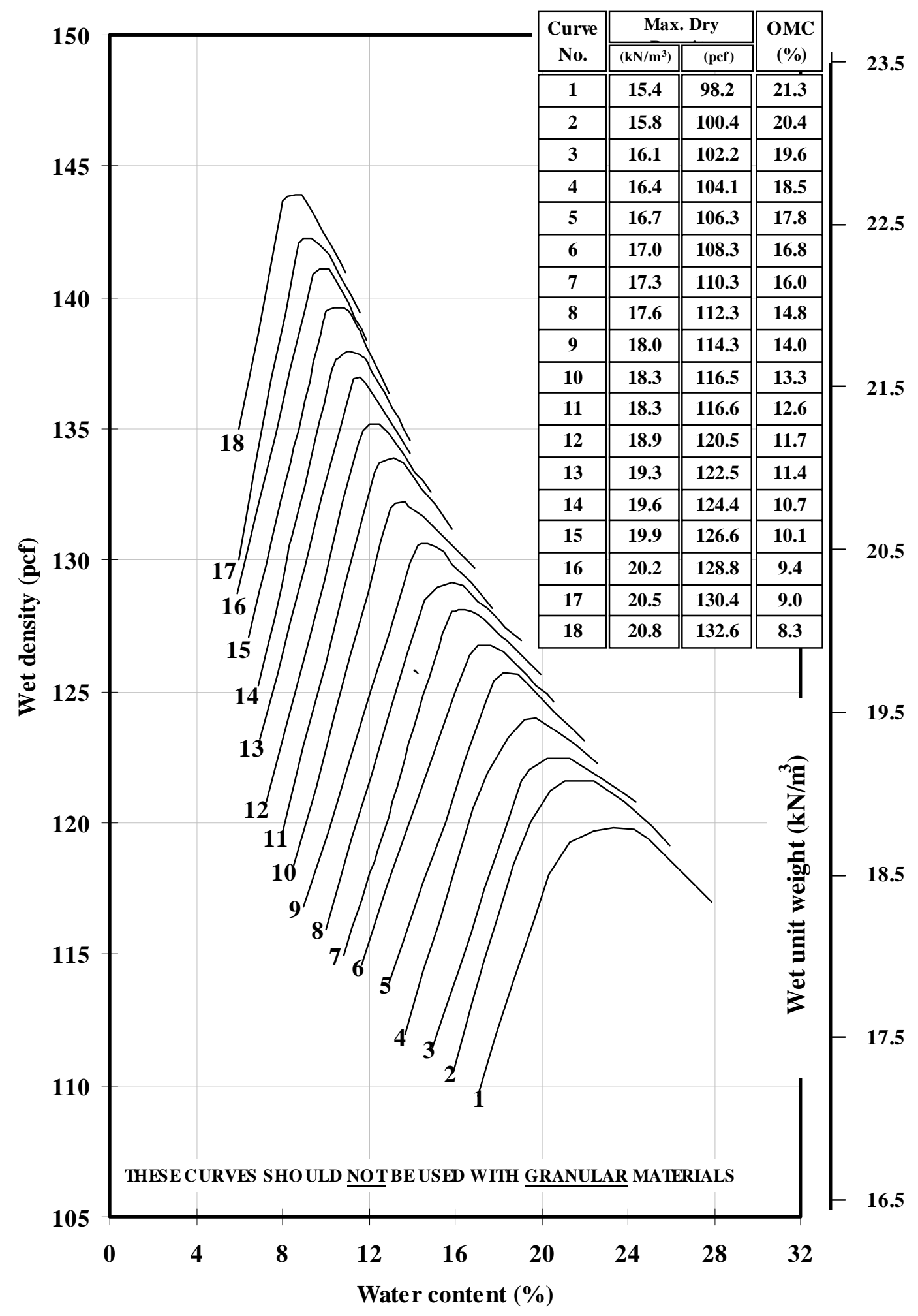

Figure 2.6 INDOT family of curves (modified after INDOT Manual 2007). 
With regard to the one-point Proctor test, Wermers (1963) showed the effectiveness of the procedure based on 861 compaction tests. Wermers (1963) compared results from the one-point Proctor test and the standard laboratory Proctor test and concluded that the difference in the arithmetic mean between the results of the two test methods was only -0.19 percent, indicating that the OMC obtained from Figure 2.6 was $0.19 \%$ higher on average than that obtained by the standard Proctor test. Wermers (1963) also showed that the 92 percent of the $\gamma_{\mathrm{dmax}}$ values obtained from the one-point Proctor tests was within $4.0 \mathrm{pcf}\left(0.63 \mathrm{kN} / \mathrm{m}^{3}\right)$ of the $\gamma_{\mathrm{dmax}}$ values obtained from the laboratory Proctor tests.

Similarly, Gregg (1960) provided typical ranges of maximum dry densities and optimum moisture contents of soils utilizing the AASHTO classification (see Table 2.4). According to Gregg (1960), soils with higher maximum dry densities have a higher content of well-graded sandy soils, while soils with lower maximum dry densities have a higher content of silty-clayey soils. 
Table 2.4 Typical ranges of maximum dry unit weights and optimum moisture contents (modified after Gregg 1960)

\begin{tabular}{|c|c|c|c|c|c|}
\hline \multirow{2}{*}{$\begin{array}{c}\text { AASHTO } \\
\text { Classification }\end{array}$} & \multirow{2}{*}{$\begin{array}{c}\text { Soil } \\
\text { Description }\end{array}$} & \multirow{2}{*}{$\begin{array}{c}\text { Anticipated } \\
\text { performance of } \\
\text { compacted soil }\end{array}$} & \multicolumn{2}{|c|}{$\begin{array}{l}\text { Typical ranges of } \\
\gamma_{\mathrm{dmax}}\end{array}$} & \multirow{2}{*}{$\begin{array}{c}\mathrm{OMC} \\
(\%)\end{array}$} \\
\hline & & & pcf & $\mathrm{kN} / \mathrm{m}^{3}$ & \\
\hline $\begin{array}{l}\text { A-1-a } \\
\text { A-1-b }\end{array}$ & $\begin{array}{l}\text { Well-graded } \\
\text { gravel/sand } \\
\text { mixtures }\end{array}$ & $\begin{array}{l}\text { Good to } \\
\text { excellent }\end{array}$ & $115-142$ & $18.1-22.3$ & $7-15$ \\
\hline $\begin{array}{l}\text { A-2-4 } \\
\text { A-2-5 } \\
\text { A-2-6 } \\
\text { A-2-7 }\end{array}$ & $\begin{array}{c}\text { Silty or } \\
\text { clayey gravel } \\
\text { and sand }\end{array}$ & $\begin{array}{l}\text { Fair to } \\
\text { excellent }\end{array}$ & $110-135$ & $17.3-21.2$ & $9-18$ \\
\hline A-3 & Fine sand & Fair to good & $100-115$ & $15.7-18.1$ & $9-15$ \\
\hline$A-4$ & $\begin{array}{l}\text { Sandy silts } \\
\text { and silts }\end{array}$ & Poor to good & $95-130$ & $14.9-20.4$ & $10-20$ \\
\hline A-5 & $\begin{array}{l}\text { Elastic silts } \\
\text { and clays }\end{array}$ & Unsatisfactory & $85-100$ & $13.3-15.7$ & $20-35$ \\
\hline A-6 & Silt-clay & Poor to good & $95-120$ & $14.9-18.8$ & $10-30$ \\
\hline A-7-5 & $\begin{array}{c}\text { Elastic silty } \\
\text { clay }\end{array}$ & Unsatisfactory & $85-100$ & $13.3-15.7$ & $20-35$ \\
\hline A-7-6 & Clay & Poor to fair & $90-115$ & $14.1-18.1$ & $15-30$ \\
\hline
\end{tabular}




\subsubsection{Variables Affecting Soil Compaction}

Woods $(1938,1940)$ carried out an extensive study to investigate the correlations between the characteristics of soil and compaction parameters. Based on 1,318 test results, Woods (1940) proposed a relationship between maximum dry density, optimum moisture content, and Atterberg limits (see Figure 2.7). Woods (1940) also observed that a unique relationship exists between the maximum dry density and the optimum moisture content of a soil.

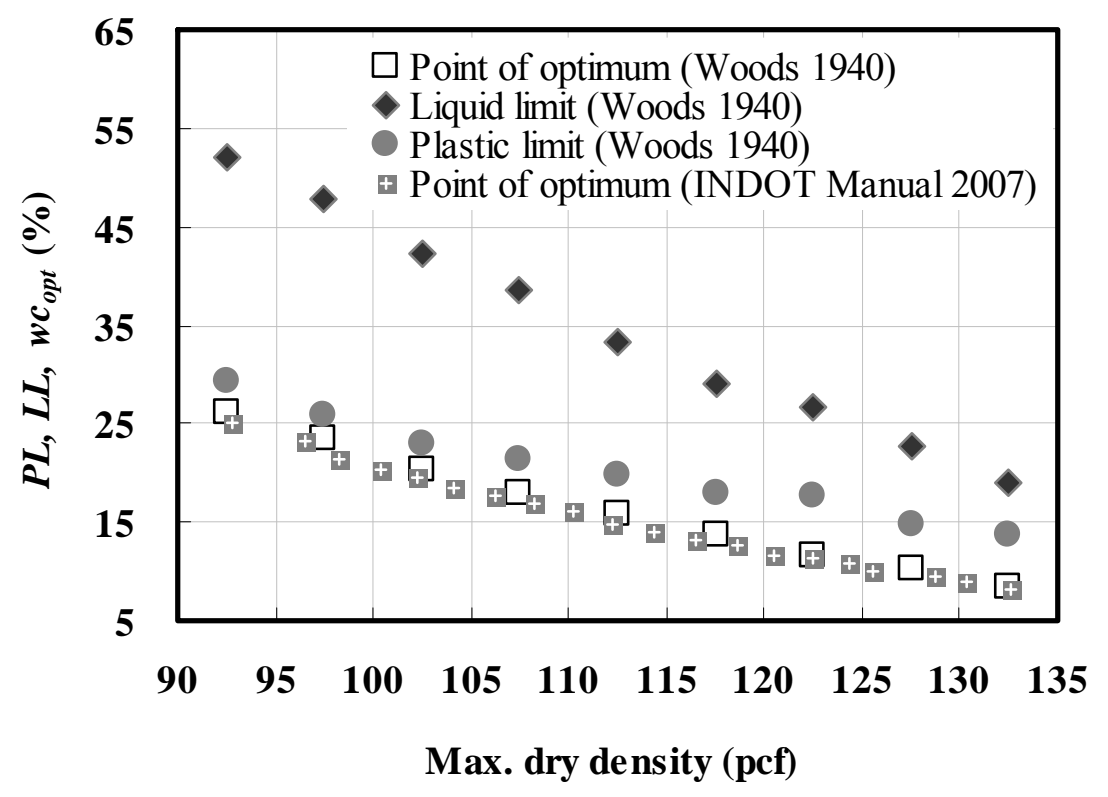

Figure 2.7 Relationships between maximum dry density, optimum moisture content, and Atterberg limits (data from Woods 1940 and INDOT Manual 2007).

Figure 2.7 also shows that, for a given compaction effort, the optimum moisture content is generally only a few percentage points less than the plastic limit. Note that the 
values presented by Woods (1940) are the arithmetic mean values of test results. However, several researchers independently have found that a relationship exists between dry unit weight, optimum moisture content, and the plasticity index (Basheer 2001; Gurtug and Sridrahan 2003; Omar et. al. 2003; Sridharan and Nagaraj 2004; Sivrikaya 2007; Sivrikaya et al. 2008), and this relationship is well captured by the work of Woods (1940).

Based on 102 test results obtained from Indiana soil samples, we also found that $\gamma_{\mathrm{dmax}}$ and the OMC correlate well with the liquid limit, and especially, with the plastic limit. see Figure 2.8). Using test results obtained in Indiana soil samples, we propose the equations to compute the compaction properties using the plasticity index (see Table 2.5). Since three equations with four parameters are presented in Table 2.5, one of the parameters are provided, the other parameters can be obtained using the equations shown in Table 2.5.

Table 2.5 The relationship between $\gamma_{d \max }, w c_{o p t}$, plastic limit and liquid limit

\begin{tabular}{|c|c|c|}
\hline $\begin{array}{c}\text { Parameters considered in } \\
\text { developing the relationship }\end{array}$ & Relationship & $\mathrm{R}^{2}$ \\
\hline$w C_{\text {opt }}(\%), \gamma_{\text {dmax }}(\mathrm{pcf})$ & $w C_{\text {opt }}=327.42 \exp \left(-0.0276 \gamma_{\text {dmax }}\right)$ & $*$ \\
\hline$P L(\%), \gamma_{\text {dmax }}(\mathrm{pcf})$ & $P L=-48.024 \ln \left(\gamma_{\text {dmax }}\right)+245.82$ & 0.66 \\
\hline$L L(\%), \gamma_{\text {dmax }}(\mathrm{pcf})$ & $L L=-85.018 \ln \left(\gamma_{\text {dmax }}\right)+434.75$ & 0.54 \\
\hline
\end{tabular}

* The equation is the locus of the points of optimum in Figure 2.7. 


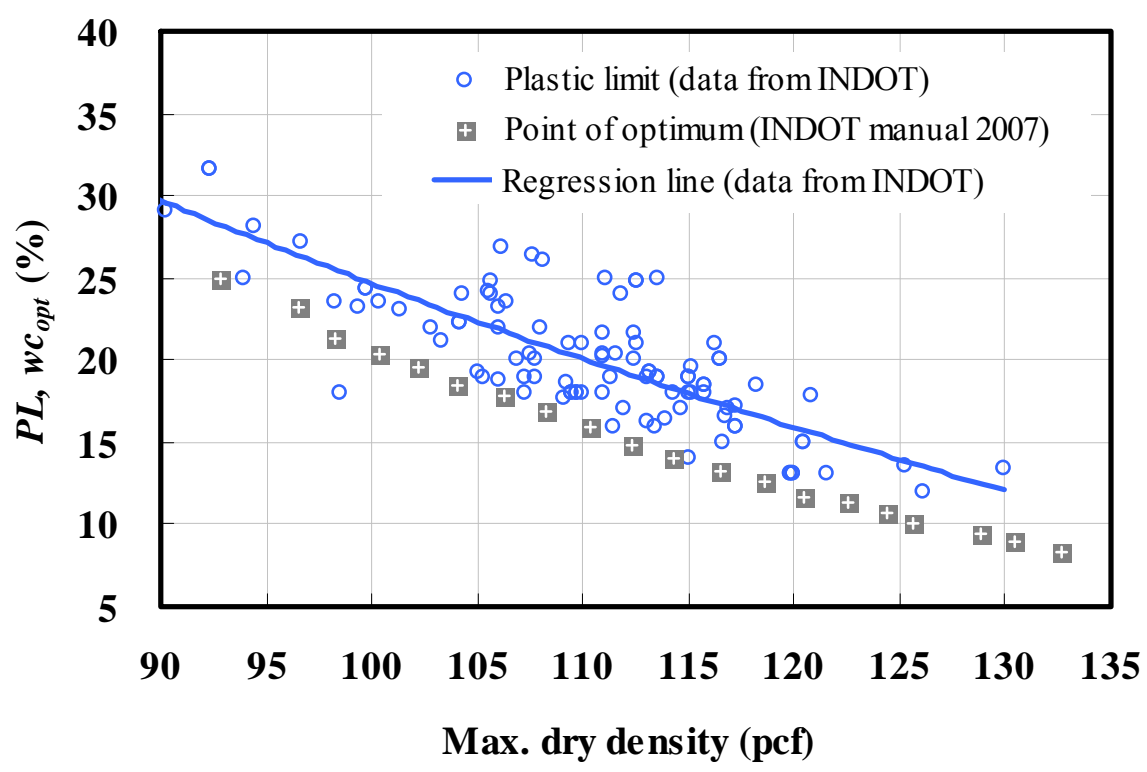

(a)

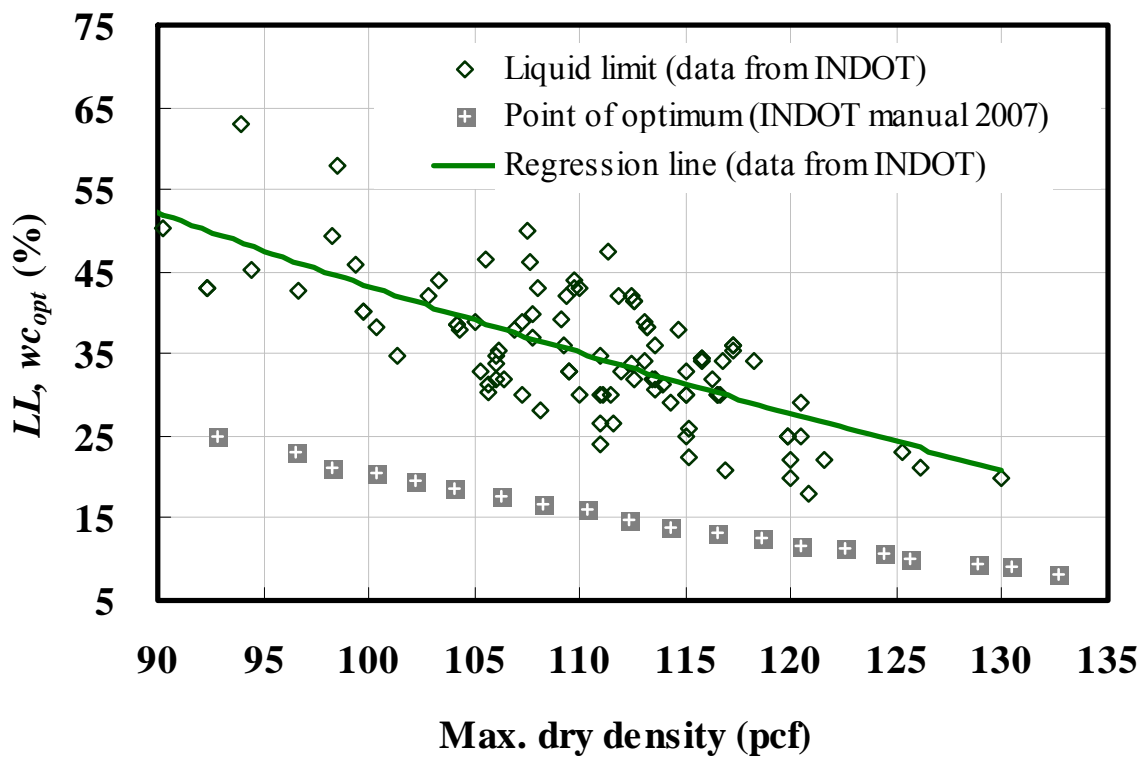

(b)

Figure 2.8 Relationship between maximum dry density and Atterberg limits: (a) maximum dry density vs. plastic limit, and (b) maximum dry density vs. liquid limit. 
With respect to the effect of plasticity on the soil compaction achievement, Rollings and Rollings (1996) investigated the effect of plasticity on the unit weight of soil. After normalizing 20 case studies with respect to the compaction energy, they found that the more plastic soils had a larger difference between their standard compaction effort and the modified compaction effort (see Figure 2.9). This research showed that for a given compaction effort soils that exhibited lower plasticity could more easily achieve the desired density.

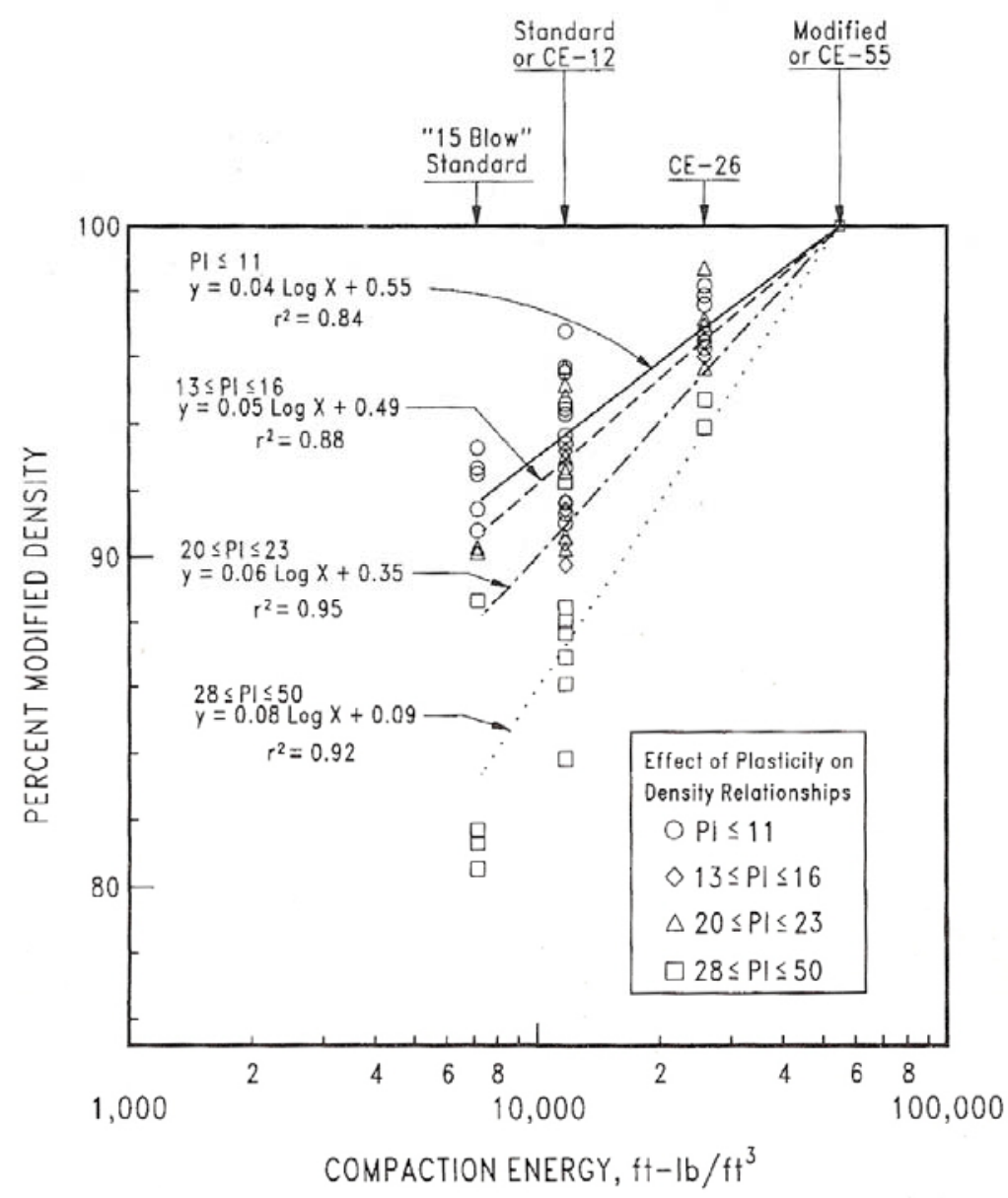

Figure 2.9 Effect of plasticity on compacted density for various compaction energies (Rollings and Rollings 1996). 


\subsection{Field Compaction of Subgrade}

On a construction site, there are many variables that control the quality of soil compaction. Among these variables, as discussed in the previous section, the molding water content of soils influences greatly the dry density of the subgrade. As a result, the molding water content also influences the strength of the subgrade (Price 1978). In addition, the molding water content strongly affects the ultimate moisture condition that will exist in the subgrade. If the molding water content is close to optimum, then changes in water content and volume of the compacted soil are minimized. A relatively constant moisture condition helps reduce the degradation of stiffness and strength of the subgrade, resulting in better uniformity of the subgrade.

In addition to the molding water content, the lift thickness and the condition of the soil affect field compaction. The lift thickness controls the quality of soil compaction because it affects the compaction energy experienced by soil located at the bottom of the lift for a given compaction equipment. Typical lift thicknesses of soil in a loose state range from eight to 18 inches, depending on the soil type and type of compactor used.

The foundation under the fill soil is also very critical. If the fill soil is not on firm ground, some portion of the compaction effort might be dissipated during compaction of the fill. Rollings and Rollings (1996) showed one example to explain the effect of underlying soil stiffness by conducting a layered elastic analysis using the computer program BISAR which is widely used for pavement analysis. In the example, the modulus of elasticity of a firm foundation is assumed to be equal to 25,000 psi (172.4 $\mathrm{MN} / \mathrm{m}^{2}$ ), corresponding to sandy soil, and the modulus of elasticity of a soft foundation is 
assumed to be 5,000 psi $\left(34.5 \mathrm{MN} / \mathrm{m}^{2}\right)$, corresponding to soft clay. Based on the analysis, the stress distributions under two different rollers for two different foundations were obtained as shown in Figure 2.10 (Rollings and Rollings 1996). From the figure, the stresses available for compacting a six-inch-thick lift of surface material are significantly reduced for the soft clay foundation due to the dissipation of energy in deforming the soft soil mass. Therefore, compaction of fills is a lot less effective over a weak foundation.

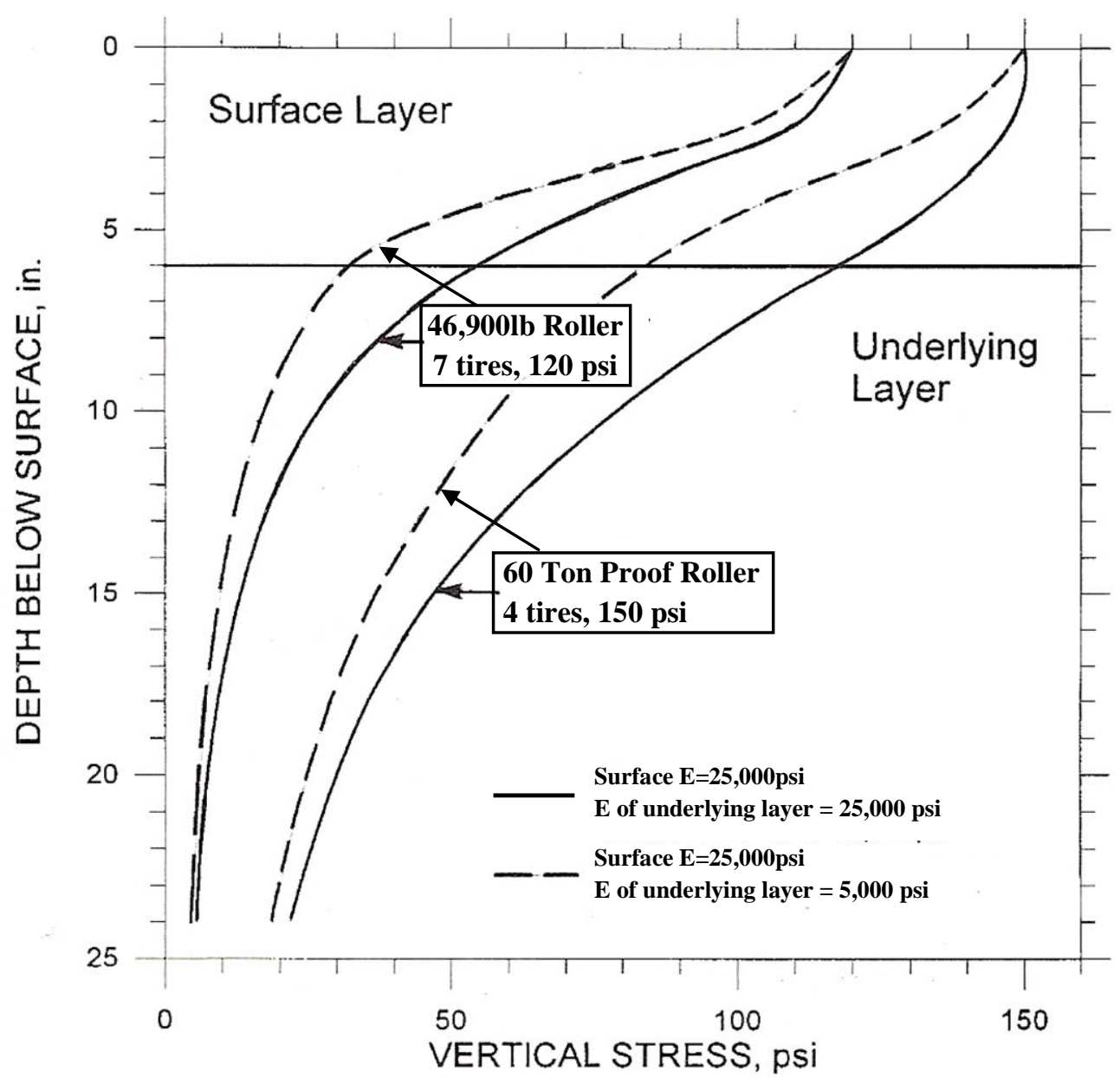

Figure 2.10 Stress distributions within soil under compactors (modified after Rollings and Rollings 1996). 
Field compaction variables are also related to the characteristics of the compactors: (1) mass, (2) travel speed, (3) number of passes, and (4) operating frequency. These compactor characteristics influence the compaction energy, the stress level, and the depth of influence.

Figure 2.11 shows typical relationships between the number of compactor passes and the dry unit weight (these are called "typical growth curves") that reflect the effect of the mass of the compactors as well as the soil type.

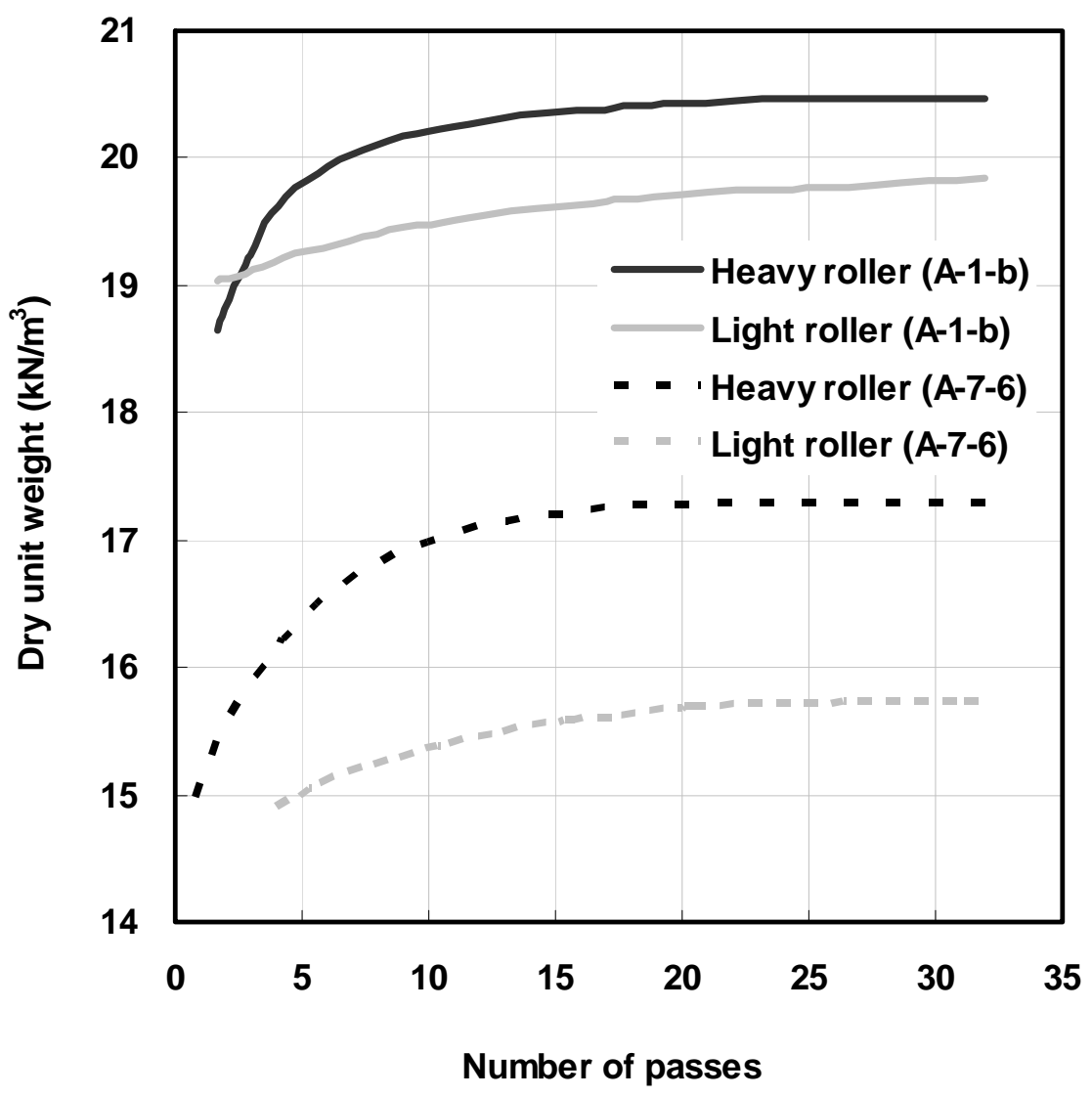

Figure 2.11 Typical growth curves: (a) A-1-b soil (well-graded sand), and (b) A-7-6 soil (heavy clay) (data from Lewis 1959). 
The typical growth curves in Figure 2.11 were obtained for two types of soils [well-graded sand (A-1-b) and heavy clay (A-7-6)] compacted with a heavy roller with a wheel load of 22,400 lb (10.2 ton) and tire pressure of $140 \mathrm{psi}(965 \mathrm{kPa})$ and a light roller with a wheel load of 2,985lb (1.4 ton) and tire pressure of 36 psi (248 $\mathrm{kPa})$. The heavy roller compacted a 12-inch loose lift, while the light roller compacted a nine-inch loose lift. The soils in all cases were compacted at moisture contents close to the optimum.

As shown in Figure 2.11, the larger the mass of the compactor and the number of passes of the compactor, the greater its effectiveness. Also, the rate of increase of the dry unit weight is higher initially and becomes negligible as the number of compactor passes increases. Asymptotic curves were observed regardless of the soil type and the energy of the compactor, although the soils compacted with heavier equipment reached an asymptote at a lower number of passes than the lighter equipment.

Figure 2.12 exhibits the effect of travel speed of the compactor with a wheel load of $17,0001 \mathrm{~b}$. It is interesting to note that the unit weight of soil increases for a given number of passes of the compactor when the compaction equipment travels more slowly. 


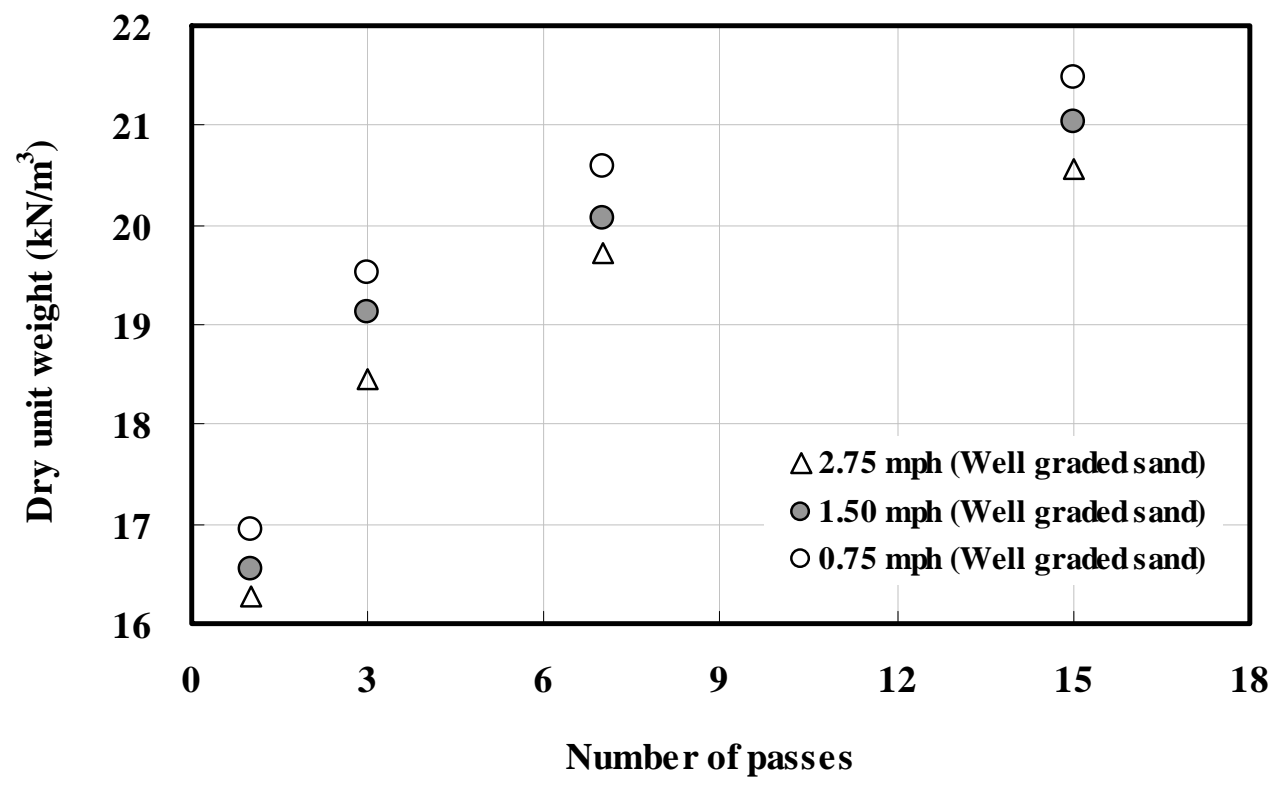

(a)

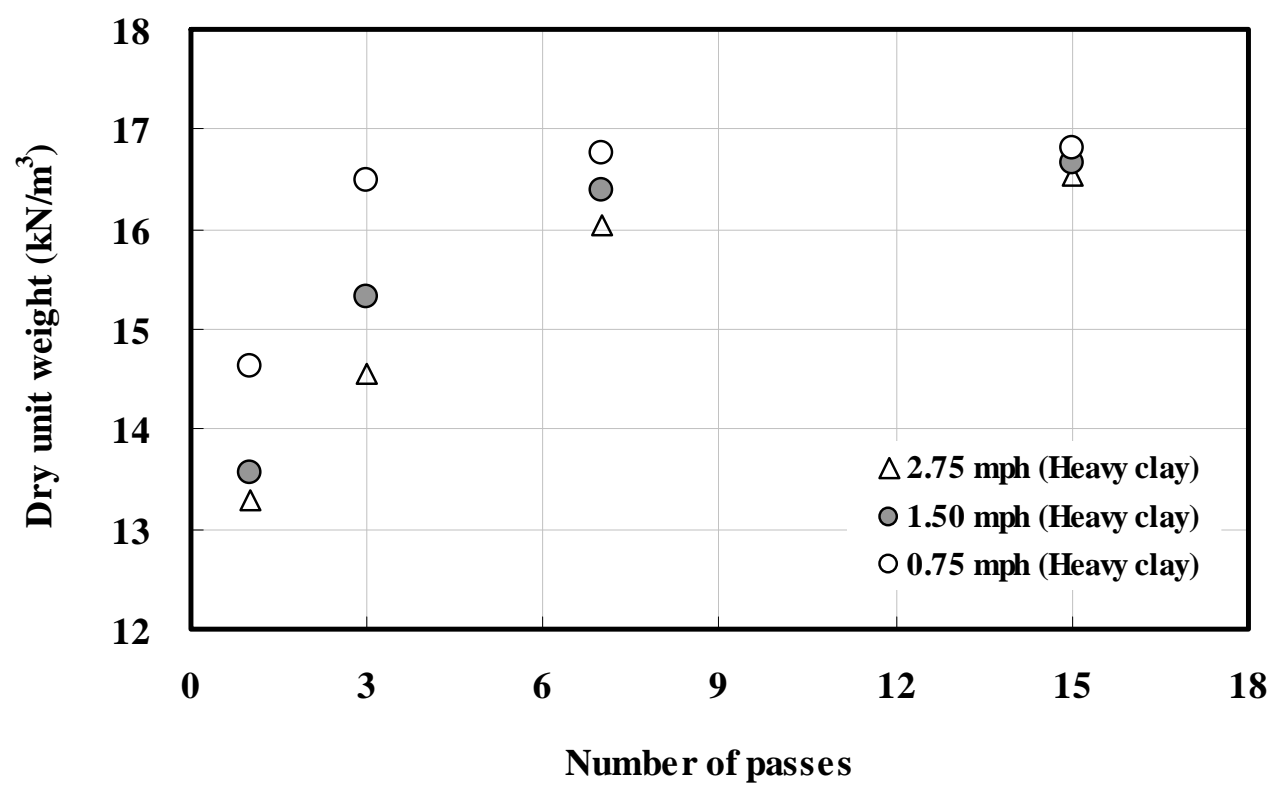

(b)

Figure 2.12 The effect of travel speed of the compactor in: (a) Well-graded sand; (b) Heavy clay (data from Selig and Yoo 1977). 
Vibration increases the effectiveness of the compactor drastically in the case of sandy soils, but less or minimally in the case of silty-clayey materials. The dynamic force of the compactor helps the soil particles to rearrange and pack tighter into a given space. Selig and Yoo (1977) concluded that, for several soil types, a peak develops in the density vs. frequency curve for frequencies between $20 \mathrm{~Hz}$ and $55 \mathrm{~Hz}$ (generally, at about 40Hz). This "optimum" frequency depends on the compactor-soil system and therefore, changes with the compacted state of the soil during compaction. 


\subsection{Summary}

Moving traffic wheel loads are dynamic and repetitive in nature, causing elastic and plastic deformations in the pavement. Generally, the failure of the pavement structure is largely because of plastic deformations. Several factors affect subgrade soil behavior [i.e., the soil intrinsic variables, method of compaction, degree of saturation (water content), the dry unit weight of subgrade, and the stress level and history].

FHWA developed the Mechanistic-Empirical (M-E) Pavement Design Guide (ARA 2004), which incorporated the theories of mechanics into the design of pavements to better predict the pavement response for given loading conditions. At present, there are several design methods available to consider the mechanical stability of pavements.

Compaction leads to a drop in void ratio. The compaction curve quantifies this phenomenon, which is a function of (1) soil type, (2) amount of the compaction effort, and (3) the types of compaction equipment. Soil compacted on the dry side of optimum has a flocculated fabric; soil compacted on the wet side of optimum has dispersed fabric. If the compaction effort increases, the soil particles tend to develop a relatively more parallel arrangement. This particle arrangement explains why soils compacted on the dry side of optimum show higher stiffness than those soils compacted on the wet side of optimum. Sandy soils, there is little change of particle arrangement during the compaction process. Rather, "bulking" occurs between the air-dried and completely saturated states. 
Woods and Litehiser (1938) observed that numerous compaction test results for various soil types yielded a set of compaction curves with a similar shape and geometry, called the "the family of curves." In the family of curves, soils that have higher maximum dry densities have a higher content of well-graded "granular" soils, while soils that have lower maximum dry densities have a higher content of silty-clayey soils. Also, it was found that $\gamma_{\mathrm{dmax}}$ and the OMC correlate well with the liquid limit, and even better with the plastic limit.

On a construction site, there are many variables that control the quality of soil compaction. In addition to the characteristics of soils, the soil compaction variables are generally related to characteristics of the compactor: (1) mass, (2) travel speed, (3) number of passes and (4) operating frequency. Vibration of the compactor increases the effectiveness of the compactor drastically in the case of sandy or gravelly soils but not significantly in the case of silty-clayey materials. 


\section{CHAPTER 3. QUALITY CONTROL OF SUBGRADE COMPACTION}

\subsection{Introduction}

Quality control (QC) of subgrade compaction is carried out in the following sequence. First, project engineers determine the compaction quality control criterion in terms of the in situ compacted unit weight and water content based on laboratory compaction tests performed on subgrade samples. Second, a test pad is constructed in situ and a few representative test spots are randomly selected and tested in order to establish the lift thickness and the number of passes of the compactor required to meet the compaction $\mathrm{QC}$ criterion proposed in the first step. The earthwork construction then proceeds, and field inspectors perform compaction QC tests during the course of the construction to ensure that the desired criterion is met.

QC of soil compaction in situ typically involves determining the in situ compacted dry unit weight $\left(\gamma_{d f i e l d}\right)$ and the water content $(w c)$ of a compacted lift of the

fill material and comparing the measured $\gamma_{\text {dfield }}$ and $w c$ with the laboratory compaction test results. In other words, the compacted subgrade is assessed in terms of its dry unit weight, expressed as a percentage of the laboratory maximum dry unit weight achieved in the compaction test, and water content. For instance, the Indiana Department of Transportation (INDOT) requires that the in situ dry unit weight of the fill material be over $95 \%$ of the laboratory maximum dry unit weight $\left(\gamma_{d m a x}\right)$ and that the in situ water 
content be within $-2 \%$ and $+1 \%$ of the laboratory optimum moisture content (OMC) for all soil types (INDOT 2006). The in situ dry unit weight and the in situ water content are typically measured in the field using: (1) a sand-cone apparatus together with drying of soil in a stove or microwave oven, or (2) a nuclear gauge. At present, most agencies employ nuclear gauges for field compaction QC because sand-cone tests are cumbersome and time consuming to perform.

Although in-place dry unit weight has been the focus of QC, the strength and the stiffness of the subgrade determine its performance in service. Measurement of compacted dry unit weight is an indirect means to assess the mechanical response of subgrade. Researchers have attempted to devise tests to assess the mechanical properties of the compacted subgrade related to its in situ strength or stiffness. The California Bearing Ratio (CBR) test and the Plate Load Test (PLT) were used in the past for this purpose. The drawbacks of these tests are detailed in later sections.

Recently, some agencies have adopted relatively new dynamic in situ tests that can be used to assess the strength or the stiffness of compacted subgrade subjected to dynamic loading. Among the widely accepted are: 1) the Clegg Hammer Test (CHT), which consists of rapid undamped impact elements, 2) the Soil Stiffness Gauge (SSG), which is composed of small devices that measure the dynamic response of compacted soil to low energy impulses applied over a range of frequencies, 3) the Light FallingWeight Deflectometer (LFWD) [such as the German Dynamic Plate (GDP), the Prima 100 LFWD, and the Transport Research Laboratory Foundation Tester (TFT)], which consists of a mass falling on a bearing plate (Fleming et al. 2007). These tests typically require a data acquisition system to capture the dynamic response of compacted soil. 
The Dynamic Cone Penetration Test (DCPT) is used to measure dynamic in situ penetration resistance of compacted soil as a function of depth. The test results are expressed in terms of dynamic blow counts or in terms of depth of penetration per blow; these can be correlated with both the stiffness and strength parameters of the subgrade.

All of these tests, however, have the shortcoming of providing an assessment of the mechanical response of a very small portion of the fill volume around the testing location. In order to overcome this limitation, research has been conducted to evaluate the quality of compaction along the entire volume of the compacted soil using compaction rollers using a Continuous Compaction Control (CCC) technique. Although the CCC holds a lot of potential, there are issues that should be addressed before it is widely used in practice. In this chapter, we review commonly used density-based compaction control tests, along with existing in situ tests to evaluate the stiffness or strength of compacted subgrade. The procedures, advantages and disadvantages of each test are also discussed. Finally, the chapter summarizes the in situ compaction quality control specifications adopted by various state agencies. 


\subsection{Density-Based Compaction Control Tests}

\subsubsection{Sand-Cone Test}

The sand cone test was one of the most widely used tests performed on site to determine the in situ unit weight of compacted soil until the nuclear gauge test gained popularity. The test procedure involves the following steps: (1) dig a hole, (2) determine the weight and water content of the soil removed from the hole, and (3) estimate the volume of the excavated hole (ASTM D1556). The sand cone test typically uses Standard Ottawa Sand (ASTM C778) to determine the volume of the hole created. Prior to determining the unit weight of soil in-place, the unit weight of the Ottawa sand placed within a hole should be calibrated.

There are several drawbacks associated with the use of the sand cone test in measuring unit weight of compacted soil. It is a time-consuming because even skilled technicians need more than 30 minutes on site to perform a single test (Krebs and Walker 1971), time during which all construction activity nearby the test spot stops. When the soil excavated from the hole contains oversized particles such as gravels and cobbles, the measurements are likely to be erroneous. In addition, the excavated hole must independently hold its shape during testing, which is a difficult proposition especially for A-1 and A-3 type soils. When vibration sources, such as construction traffic, are present near the test location, they might densify the Standard Ottawa sand within the test hole and, as a result, the unit weight of the compacted soil may be underestimated. Due to these shortcomings, the sand cone test is now rarely used as a QC test. 


\subsubsection{Nuclear Gauge Test}

As the highway construction industry searched for methods to build foundations quickly, engineers explored faster QC tests to evaluate the quality of subgrade compaction. The nuclear gauge came about in the early 1970s and gained in popularity when an industrywide calibration standard for this test was developed (Troxler 2000). The greatest advantage of the nuclear gauge test over conventional destructive tests is that it is faster to perform. The dry unit weight and the water content of soil can be obtained quickly once the specific gravity of the in situ soil is known.

The nuclear gauge works on the principle of emitting gamma radiation and detecting the reflected rays in order to determine the wet unit weight of the soil. Higher density soils contain a greater number of electrons with which the photons of the gamma radiation interact. Thus, the higher the wet unit weight of soil, the lower the number of photons are returned to the receiver. Therefore, there is an inverse relationship between the density of the soil and the returned photon count rate (Mooney et al. 2008). The dry unit weight of compacted soil (defined as the mass of soil per unit volume) is then calculated using the detected rate of gamma radiation with the previously established calibration data considering the radioactive decay and the chemical composition of measured materials (ASTM D 6938).

In addition to density measurement, the nuclear gauge is equipped to measure the water content of soil. When the nuclear gauge source emits high-speed neutrons into the soil, hydrogen atoms present in a soil-water medium retard these high-speed neutrons. The number of slow-speed neutrons detected by the gauge indicates the amount of hydrogen atoms present in the medium and, thus, its water content. 
Nuclear gauges are typically operated in two modes to measure the unit weight of the soil (see Figure 3.1). With respect to the accuracy of the test results, Winter and Clarke (2002) concluded that the direct transmission mode yields a more accurate density profile than the backscatter mode. The INDOT Manual (2007) also recommends the use of the direct transmission mode for quality control of soil compaction on-site. For water content measurement, the neutron source and detector are located near the bottom of the gauge [refer to Figure 3.1 (c)].

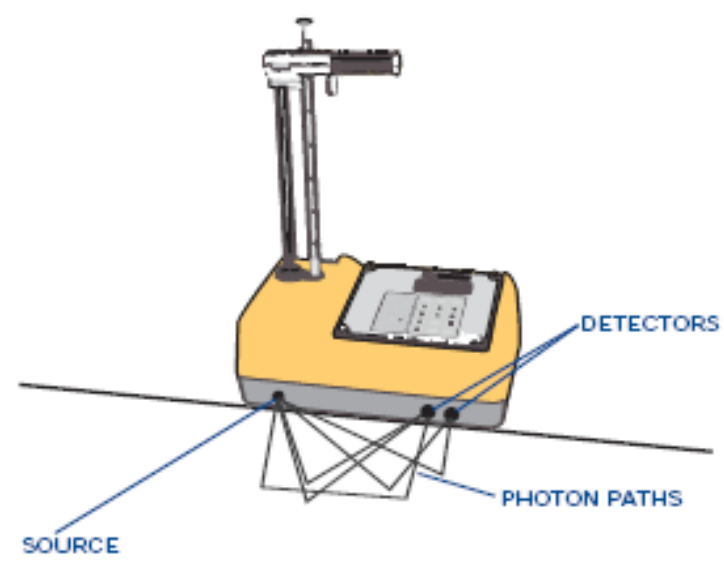

(a)

Figure 3.1 Nuclear gauge measurements: (a) backscatter mode for density measurement (Cont'd). 


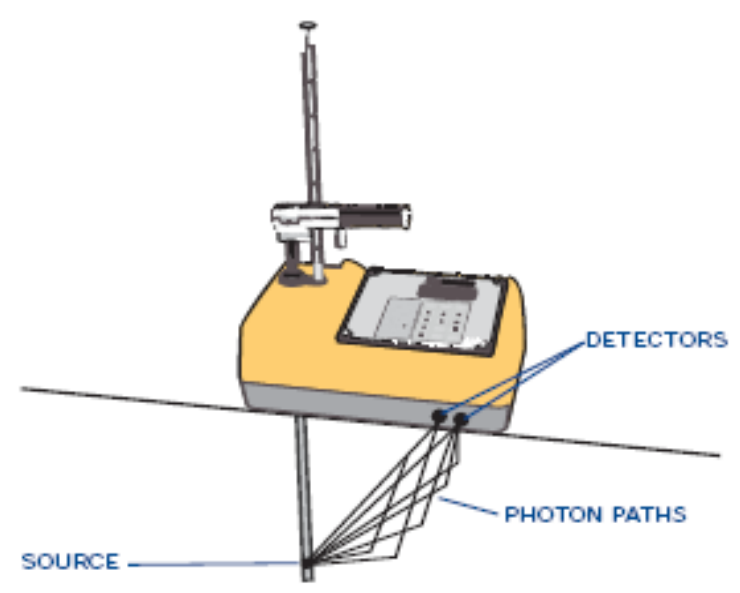

(b)

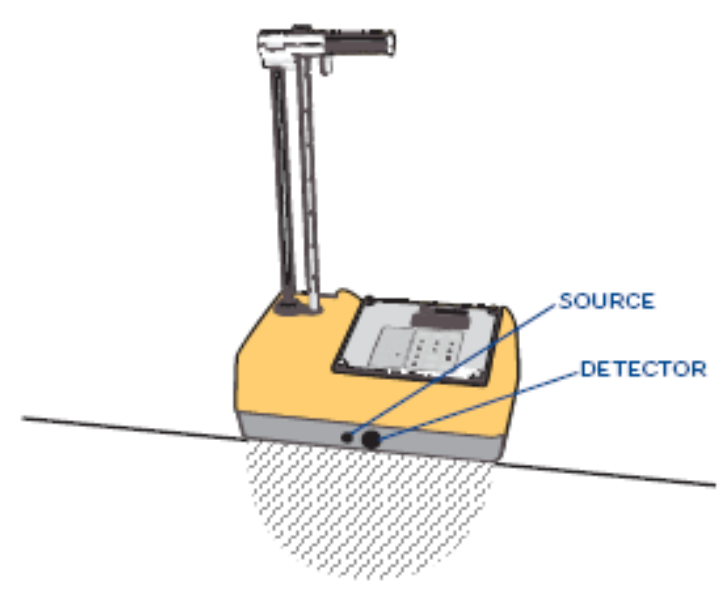

(c)

Figure 3.1 Nuclear gauge measurements: (a) backscatter mode for density measurement, (b) direct transmission mode for density measurement, and (c) moisture detection (Troxler 2006).

With respect to the accuracy of the test, the errors associated with calibration are less in the case of the nuclear gauge test than for the sand cone test. In addition, when heterogeneous soil conditions exist, nuclear gauge testing is likely to provide more 
accurate measurements. This difference in accuracy is due to the larger representative size of the volume covered by the source of the nuclear gauge, compared to the volume of the excavated hole for the sand cone test.

However, in order to evaluate the accuracy of both tests, Noorany et al. (2000) conducted laboratory tests using a large-size soil compaction apparatus (a tank $117 \mathrm{~cm}$ diameter and $122 \mathrm{~cm}$ deep). The tank was filled with compacted clayey sand (SC) of known weight and water content. Several nuclear gauge and sand cone tests were performed side-by-side on the soil. They observed that the sand cone test results were closer to the actual values than the nuclear gauge test results. A significant source of error was due to the lower accuracy of the water content readings using the nuclear device.

Currently, although the nuclear gauge device is widely used for QC of subgrade compaction, it possesses the following serious drawbacks that sometimes prevent its use. The foremost drawback is that the nuclear gauge uses a radioactive material that can be potentially dangerous to the health of the field personnel. Thus, the gauge operators must be specially trained and be familiar with the applicable safety procedures and government regulations. In addition, measurements may be affected by the chemical composition of the soil tested (ASTM D 6938). For example, as the nuclear gauge indirectly measures the water content by measuring the hydrogen present in the material, the measurement is bound to involve more errors in the case of materials that already contain hydrogen atoms in their chemical composition. Calibration of the nuclear gauge is essential for accurate measurement of in situ compacted density. Consequently, several agencies in the U.S. have begun abandoning the use of nuclear gauges for QC testing. 


\subsection{Performance-Based Compaction Control Tests}

\subsubsection{California Bearing Ratio (CBR) Test}

The California Bearing Ratio (CBR) test is a static penetration test used to assess the strength of pavement materials used for subgrade, subbase, or base course applications. In order to evaluate the strength of the material, a piston bar of cross-sectional area equal to three square inches $\left(19.35 \mathrm{~cm}^{2}\right)$ is plunged into the soil at a rate of $0.05 \mathrm{inch} / \mathrm{minute}$ $(1.27 \mathrm{~mm} / \mathrm{minute})$. The unit loads required for up to $12.7 \mathrm{~mm}$ of penetration are recorded. The ratio of the recorded unit load for a given penetration to that of a standard value for the same penetration is taken as the CBR value. The standard values correspond to the unit loads for well-graded crushed stone (AASHTO T193-99; ASTM D 1883-07; ASTM D 4429-04). The CBR values for soil are typically reported at $2.54 \mathrm{~mm}$ (0.1in.) of penetration, and the reference stress corresponds to $6.9 \mathrm{MPa}(1,000 \mathrm{psi})$ for this penetration value. If penetration resistance is at its peak value during the test, the pressure determined at $5.08 \mathrm{~mm}(0.2 \mathrm{in}$.) of penetration, which has a reference stress of 1,500 psi (10.3 MPa), is taken as the CBR. Table 3.1 shows the typical ranges of CBR values for various soil types.

The CBR was primarily proposed to evaluate the strength of cohesive materials having maximum particle sizes of less than 19mm (0.75in.) (AASHTO T193-99; ASTM D 1883-07; ASTM D 4429-04). Pavement design based on CBR values has been very popular among various federal agencies. 
Table 3.1 Typical CBR ranges (Lavin 2003)

\begin{tabular}{|c|c|c|}
\hline Soil description & AASHTO classification & CBR values \\
\hline $\begin{array}{c}\text { High percentage of } \\
\text { granular material }\end{array}$ & A-1; A-2;some A-3 & $>15$ \\
\hline $\begin{array}{c}\text { Some granular } \\
\text { material mixed with } \\
\text { some silt and/or clay }\end{array}$ & A-2; A-3; some A-4; A-6; A-7 & $10 \sim 14$ \\
\hline $\begin{array}{c}\text { Sandy clays, sandy } \\
\text { silts, light silt-clays, } \\
\text { some plasticity }\end{array}$ & A-4 to A-7, low group indices & $6 \sim 9$ \\
\hline $\begin{array}{c}\text { Plastic clays, fine silts, } \\
\text { very silt-clays, clay } \\
\text { with mica }\end{array}$ & A-4 to A-7, high group indices & $<6$ \\
\hline
\end{tabular}

The most important concern with respect to using CBR values in pavement design is that the CBR test does not simulate the shear stresses that are generated due to repeated traffic loading. In addition, it is possible to obtain the same CBR values for two specimens that have very different stress-strain behavior (Turnbull 1950; Brown 1996). Nevertheless, several transportation agencies in the U.S. still use the CBR test, even though it has been abandoned by the California Department of Transportation (Caltrans), the originator of the CBR. Due to the drawbacks associated with using the CBR test results for pavement design, other tests, such as the Dynamic Cone Penetrometer (DCP), the Lightweight Falling Weight Deflectometer (FWD), and the Clegg Hammer Test (CHT), are being increasingly used in practice; these are described later in this section. 


\subsubsection{Resilient Modulus Test}

The resilient modulus $\left(\mathrm{M}_{\mathrm{R}}\right)$ is defined as:

$$
\mathrm{M}_{\mathrm{R}}=\frac{\sigma_{\mathrm{d}}}{\varepsilon_{\mathrm{r}}}
$$

where $\sigma_{d}$ is the deviator stress and $\varepsilon_{r}$ is the recoverable (elastic) strain under repeated loading. In order to obtain the resilient modulus, a resilient modulus test should be performed using either an unconfined compression or triaxial testing equipment to obtain the soil stress-strain relationship under repeated loading conditions. After preparing the sample for $M_{R}$ testing, the actuator mounted on the apparatus applies small repeated loads. There are five stages of repeated axial cyclic stresses $(13.8 \mathrm{kPa}, 27.6 \mathrm{kPa}, 41.4 \mathrm{kPa}$, $55.2 \mathrm{kPa}$, and $68.9 \mathrm{kPa}$ ) for three levels of confining stresses $(13.8 \mathrm{kPa}, 27.6 \mathrm{kPa}$, and 41.4kPa), as per the AASHTO T 307 specification. Load and deformation sensors continuously record the values during testing, and the stress-strain relationship of the sample is established.

Although the resilient modulus testing simulates the response of the subgrade soil to traffic loading conditions, it is impractical to use the $M_{R}$ test as a quality control method because of the complex and time-consuming efforts involved in sample preparation and performance of the test. Also, a sample prepared in a laboratory may not simulate precisely the subgrade state and under which condition it exists at a construction site. 


\subsubsection{Plate Load Test}

The plate load test is used for determining the modulus of subgrade reaction and the limit unit load $\left(q_{b L}\right)$ of the subgrade. There are two standards for plate load tests based on the loading conditions: nonrepetitive static plate load tests (ASTM D 1195) and repetitive static plate load tests (ASTM D 1196).

According to the ASTM specifications, circular bearing plates are typically used; these are arranged in a pyramid fashion to ensure rigidity during the course of the test. The loading sequence should be such that the maximum load increment does not exceed 10 percent of the expected limit unit load of the soil. During testing, the load is typically applied using a hydraulic jack, with reaction provided by heavy construction equipment. For each load increment, the settlement of the plate is obtained by averaging the dial gauge readings placed on diametrically opposite sides of the plate. At the end of the test, the load-deflection curve of the soil is obtained. The modulus of subgrade reaction is then determined. It is expressed as:

$$
k=\frac{Q}{w}
$$

where $Q$ is the unit load on the plate, and $w$ is the settlement associated with the unit load. The value of $k$ depends on the elastic properties of the subgrade and on the dimensions of the area of the plate (Terzaghi 1955). The stress-displacement curve is nonlinear due to the elasto-plastic behavior of soil. Therefore, the modulus of subgrade reaction is a function of the pressure applied on the bearing plate. Also, the value of the modulus of 
subgrade reaction depends on the size of the plate used for the test because the size determines the mobilized mean confining stress that the soil below the plate experiences. The larger the diameter of the plate, the greater is the depth to which the soil is stressed. Terzaghi (1955) suggested typical values of the modulus of subgrade reaction for both sands and clays determined using $30.4 \mathrm{~cm}$ by $30.4 \mathrm{~cm}$ square plates (refer to Tables 2.1 and 2.2). In sands, the modulus of subgrade reaction increases with depth.

Table 3.2 Modulus of subgrade reaction of sands $\left(\mathrm{MN} / \mathrm{m}^{2} / \mathrm{m}\right)$

\begin{tabular}{|c|c|c|c|}
\hline Soil Characteristics & Loose & Medium & Dense \\
\hline Dry or Moist Sand & $6-18$ & $18-90$ & $90-300$ \\
\hline Submerged Sand & 7.5 & 24 & 90 \\
\hline
\end{tabular}

* These values are based on tests performed on $30.4 \mathrm{~cm} \times 30.4 \mathrm{~cm}$ square plates or beams $30.4 \mathrm{~cm}$ wide. Values have been modified from Terzaghi (1955).

Table 3.3 Modulus of subgrade reaction for clays* $\left(\mathrm{MN} / \mathrm{m}^{2} / \mathrm{m}\right)$

\begin{tabular}{|c|c|c|c|}
\hline Consistency of clay & Stiff & Very stiff & Hard \\
\hline${\text { Values of } \mathrm{q}_{\mathrm{u}}^{\dagger}(\mathrm{kPa})}^{\text {Ranges for } \mathrm{k}}$ & $96-192$ & $192-383$ & $>383$ \\
\hline $15-30$ & $30-60$ & $>60$ \\
\hline
\end{tabular}

* These values are based on tests performed on $30.4 \mathrm{~cm} \times 30.4 \mathrm{~cm}$ square plates or beams $30.4 \mathrm{~cm}$ wide. Values have been modified from Terzaghi (1955).

${ }^{\dagger} \mathrm{q}_{\mathrm{u}}$ : unconfined compressive strength

A plate load test requires a reaction (e.g., a heavy truck) system to provide reaction to the load increments applied on the plate. In addition, the test procedure is very cumbersome and time consuming, requiring skilled personnel to conduct the test. Hence, the plate load test is seldom used as a compaction quality control test. 


\subsubsection{Light Falling-Weight Deflectomter Test}

The Light Weight Deflector (LWD) is a portable falling-weight deflectometer used to measure the in situ elastic modulus $\left(E_{L W D}\right)$ of the compacted material. LWD is also known as the Lightweight Falling Weight Deflector (LFWD) or as Portable-FallingWeight Deflectometer (PFWD).

The LWD is basically composed of a falling mass and a displacement-measuring sensor attached at the center of a bearing plate (see Figure 3.2). The test is performed by releasing the falling weight from a standard height onto the bearing plate using the top fix and release mechanism. An impulse load is imparted on the compacted soil through the plate. The resulting central deflection of the bearing plate is obtained either by integrating the velocity measurements taken from a velocity transducer or by double integrating the acceleration data taken from an accelerometer. A display shows the central deflection and the $E_{L W D}$, which is obtained from the elastic solution (Livneh and Goldberg 2001; Alshibli et al. 2005; Lin et al 2006; Fleming et al 2007):

$$
E_{L W D}=\frac{q r\left(1-v^{2}\right)}{w} f_{R}
$$

where $E_{L W D}$ is the Young's modulus of the subgrade $(\mathrm{MPa}) ; f_{R}$ is the plate rigidity factor ( $\pi / 2$ for a rigid plate), $q$ is the maximum contact pressure $(\mathrm{kPa}), r$ is the radius of the bearing plate $(\mathrm{m}), v$ is the Poisson's ratio of the soil, $w$ is the peak deflection $(\mathrm{mm})$, which is obtained either by using a velocity sensor or an accelerometer. 
In spite of the uncertainties associated with its application, some transportation agencies have attempted to use the LWD as a compaction quality control method, mainly due to its simplicity in operation (Lin et al. 2006; Nazzal et al. 2007).

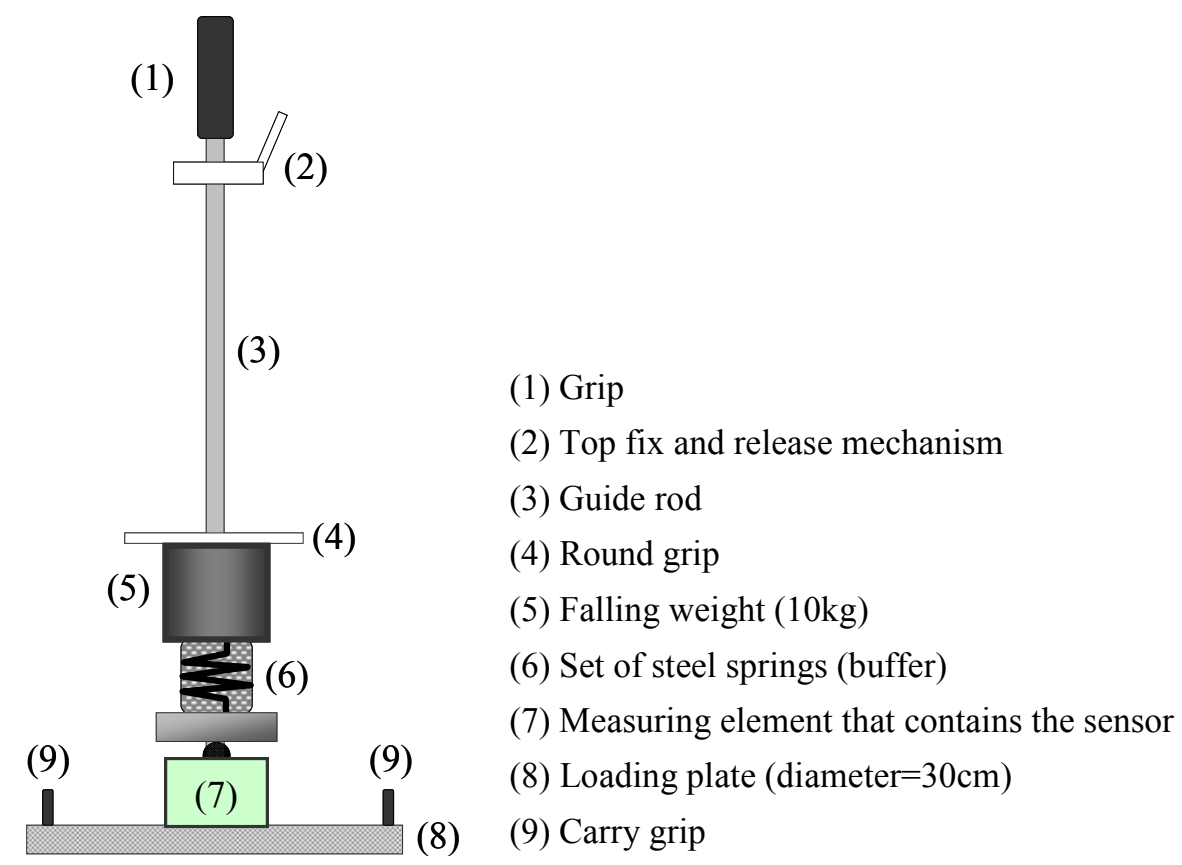

Figure 3.2 Schematic of LWD showing various component of the equipment (modified after Siddiki et al. 2008)

There are several different LWD models, depending on the manufacturer of the device. The models differ in terms of the drop hammer weight, the height of fall, the size of the bearing plate, the number of buffers available to dampen the impulse, the rate of loading, the measuring sensor and the data acquisition. Regardless of the LWD model used and the possible deformations in the measurements between the different models, the data is used to estimate the elastic modulus of the soil. 
Many studies in the literature have attempted to relate the elastic modulus $E_{L W D}$ to the results of various other commonly used tests, such as the CBR test, the PLT, the Geogauge, and the DCPT (Livneh and Goldberg 2001; Alshibli et al. 2005; Lin et al. 2006; Nazzal et al. 2007; Fleming et al. 2007; Kim et al. 2007).

Recently, the International Society for Soil Mechanics and Geotechnical Engineering (ISSMGE 2005) established a specification for earthwork compaction QC using LWD testing. In addition, the Minnesota Department of Transportation (MnDOT) developed a pilot specification for the LWD. Table 3.4 shows the ISSMGE criteria for compaction QC based on the Zorn-LWD modulus. The $E_{L W D}$ values correspond to the in situ compacted dry unit weight values equal to or greater than $95 \%$ of the maximum dry unit weight obtained with the Standard Proctor in the laboratory. A similar criterion was also developed by the MnDOT Pilot Specification (Mooney et al. 2008).

Table 3.4 ISSMGE criteria for compaction QC based on the Zorn-LWD modulus

\begin{tabular}{|c|c|}
\hline Level & E $_{\text {LWD from Zorn LWD (MPa) }}$ \\
\hline $1 \mathrm{~m}$ below subgrade & 18 (cohesive) to 24 (cohesionless) \\
\hline Top of subgrade & 30 (cohesive) to 38 (cohesionless) \\
\hline Top of subbase layer & 58 (rounded) to 68 (angular) \\
\hline Top of base layer & 70 (rounded) to 82 (angular) \\
\hline
\end{tabular}

Since the falling mass of the LWD induces both nonlinear elastic and plastic deformation to the subgrade, the elastic modulus calculated with Eq. 3.3 may be in error. To account for this shortcoming in LWD testing, some researchers have modeled the subgrade soil as a combination of a linear spring and a damping material (Loizos et al. 
2003). Due to the drawbacks discussed here, LWD testing has not yet gained popularity among U.S. federal agencies as a compaction quality control method.

\subsubsection{Soil Stiffness Gauge (SSG, Geogauge) Test}

The soil stiffness gauge (SSG), also called the Geogauge, is a modified device that was initially developed to locate buried land mines. With the consent of the U.S. Department of Defense, the Federal Highway Administration (FHWA) in collaboration with Humboldt Manufacturing Co., Bolt, Beranek \& Newman (BBN), and CNA Consulting Engineers, developed the Geogauge (Fiedler et al. 1998, see Figure 3.3).

The Geogauge measures the mechanical impedance of soil at the surface and captures the force imparted to the soil along with the resulting surface deflection. The Geogauge vibrates 25 times and induces displacements smaller than $1.27 \times 10^{-6} \mathrm{~m}$ to the ground at frequencies between 100 and $196 \mathrm{~Hz}$ (Geogauge manual 2007). In order to analyze the test results, the developers of the Geogauge test employed the static elastic solution that Poulos and Davis (1974) presented for computing the stiffness $(k)$ of a circular ring on a semi-infinite mass (Fiedler et al. 1998).

$$
k=\frac{r E}{\left(1-v^{2}\right) \omega\left(\frac{r_{i}}{r_{O}}\right)}
$$


where $E$ is the modulus of subgrade $(\mathrm{MPa}) ; r_{i} / r_{o}$ is the ratio of the radii of the Geogauge ring $(44.5 \mathrm{~mm} / 57.15 \mathrm{~mm}=0.78)$; $v$ is the Poisson's ratio.

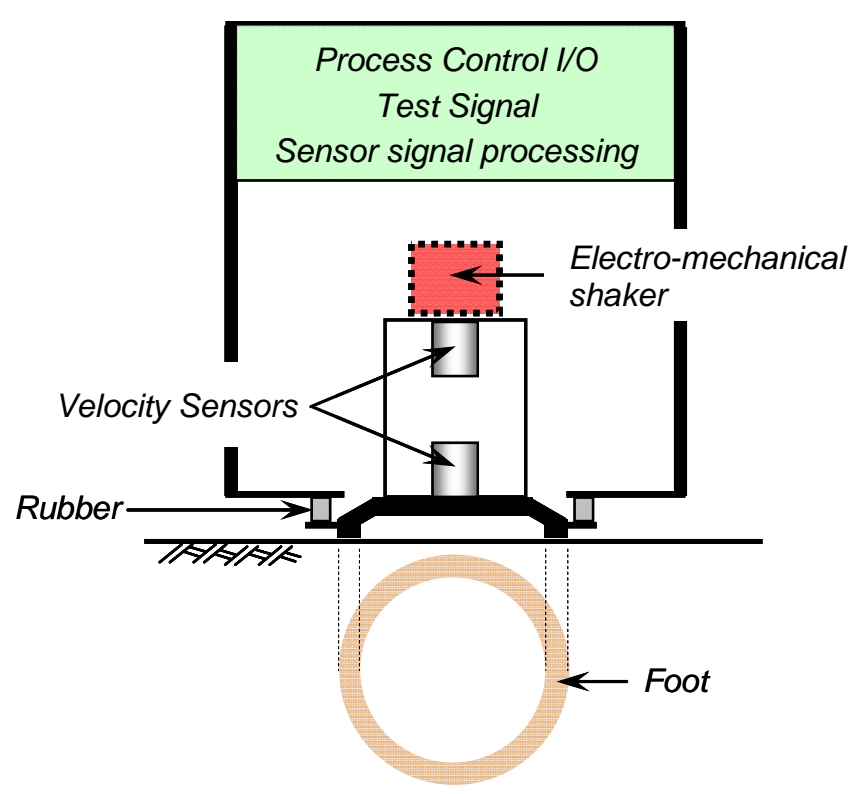

Figure 3.3 Schematic of the Geogauge (modified after Alshibli et al 2005).

Since the static elastic solution, which is used for the interpretation of the test results, does not account for the dynamic sequence of the test, the modulus computed with Eq. 3.4 is not able to capture the dynamic sequence of the test. For example, the Geogauge has several rubber isolators, which functions as a single degree of freedom having specific spring and damping constants. Also, as shown in Figure 3.3, the foot bears directly on the soil and supports the weight of the Geogauge dynamically against the mechanical impedance of soil. Thus, in order to evaluate the soil compaction using the test, it is necessary to account for the dynamic sequence of the test into the analysis. 


\subsubsection{Dynamic Cone Penetration Test}

The Dynamic Cone Penetrometer (DCP) is a portable device that was first introduced by Scala (1956) to assess the strength of subgrade. The DCP is a simple and easy-to-use device that is widely used to measure the penetration resistance of in situ materials at shallow depths.

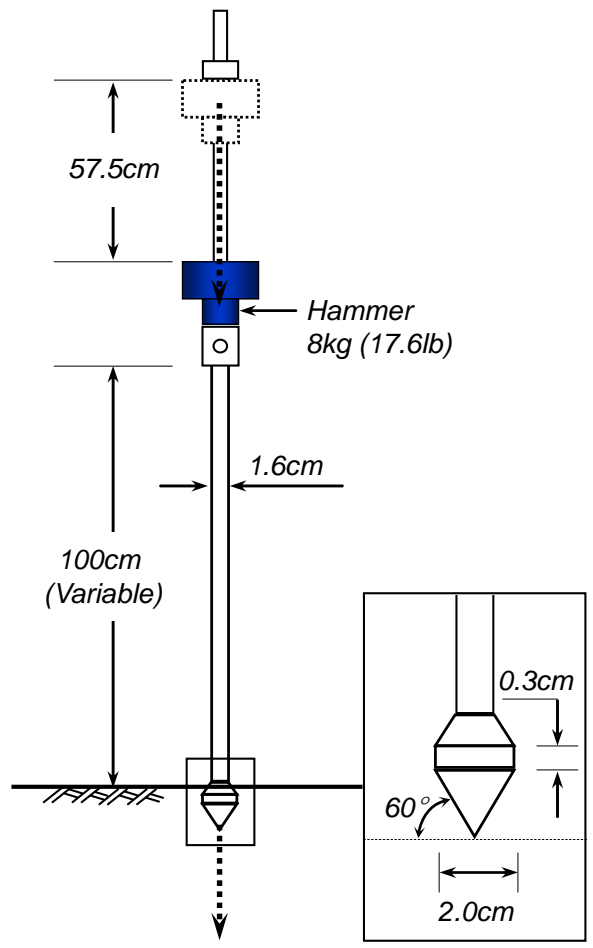

Figure 3.4 Schematic of the Dynamic Cone Penetrometer (modified after ASTM D 6951$03)$.

The DCP consists of (1) an upper shaft that is rigidly connected to an $8 \mathrm{~kg}(17.6 \mathrm{lb})$ drop hammer, (2) a lower shaft with an anvil at the top and a cone at the bottom, and (3) a replaceable cone tip with an apex angle of 60 degrees and a diameter of $20 \mathrm{~mm}$ (see Figure 3.4). In order to perform a DCP test, the hammer is dropped from a standard fall 
height. The energy transferred to the cone by the impact of the hammer on top of the anvil enables penetration of the cone into the ground. A Dynamic Cone Penetration Index (DCPI), expressed as the penetration per blow $(\mathrm{mm} / \mathrm{blow})$, is recorded as a function of depth. Since the DCPI value corresponds to the penetration of the cone for only a very small depth increment, little success has been achieved in correlating the DCPI with other material properties (Salgado and Yoon 2003). Thus, the DCP blow count $\left(\mathrm{N}_{\mathrm{DCP}}\right)$, defined as the number of blows required for a specified cone penetration [e.g., 0 to $150 \mathrm{~mm}$ ( 0 to 6 inch) or 0 to $300 \mathrm{~mm}$ ( 0 to $12 \mathrm{inch})$ ] is often used instead.

In the last decade, several agencies, such as state DOTs and the U.S. Army Corp of Engineers, have expressed interest in using the DCP for compaction QC (Amini 2003). Table 3.5 shows the $\mathrm{N}_{\mathrm{DCP}}$ criteria corresponding to a depth of penetration equal to 0 to $150 \mathrm{~mm}$ (0 to 6 inch) according to several DOT agencies (note that the $\mathrm{N}_{\mathrm{DCP}}$ values shown in the table were converted from DCPI values). The criteria proposed by the Illinois and North Carolina DOTs are independent of the type of material, whereas the Iowa and Minnesota DOTs proposed values for "frictional" and "cohesive" materials. The values suggested by the Illinois and North Carolina DOTs correspond to a CBR = 8.0, which indicates a stable subgrade. The Iowa DOT DCP criteria are based on the requirement that the compacted dry unit weight in situ should exceed $95 \%$ of the laboratory compaction maximum dry unit weight. 
Table 3.5 DCP criteria ( $\left.\mathrm{N}_{\mathrm{DCP}}\right)$ for a penetration of 0 to $150 \mathrm{~mm}$ (0 to $\left.6 \mathrm{inch}\right)$

\begin{tabular}{|c|c|c|c|c|c|}
\hline & Agency & $\begin{array}{l}\text { Illinois DOT } \\
\text { (ILDOT) }\end{array}$ & Iowa DOT & $\begin{array}{c}\text { Minnesota } \\
\text { DOT } \\
\text { (MnDOT) } \\
\end{array}$ & $\begin{array}{c}\text { North } \\
\text { Carolina } \\
\text { DOT }\end{array}$ \\
\hline \multicolumn{2}{|c|}{ "Frictional" soil } & \multirow{3}{*}{$6.1^{\mathrm{a}}$} & $3.4 \sim 4.4^{\mathrm{b}}$ & $12.5^{\mathrm{c}}$ & \multirow{3}{*}{$4.0^{\mathrm{d}}$} \\
\hline \multirow{2}{*}{$\begin{array}{l}\text { "Cohesive" } \\
\text { soil }\end{array}$} & Silt & & \multirow{2}{*}{$3.8 \sim 4.4^{\mathrm{b}}$} & \multirow{2}{*}{$6.0^{\mathrm{c}}$} & \\
\hline & Clay & & & & \\
\hline
\end{tabular}

${ }^{a}$ DCP blow counts associated with a CBR of 8 (ILDOT 2005)

b Iowa DOT classified the soil either "suitable soil" or "unsuitable soil" in each group of soil. The values show the ranges of it (Larsen et al. 2007)

c The criteria of frictional soil apply for "granular" base layer; MnDOT recorded NDCP values only for blow counts that are higher than two (Burnham 1997)

${ }^{\mathrm{d}}$ DCP blow counts associated with a CBR of 8 (Gabr et al. 2000)

Most researchers have suggested criteria for the DCPT based only on the recorded DCPI, without considering the impact of the increase in confining stresses with depth. However, according to Jayawickrama et al. (2000), DCP blow counts at greater depths are higher than those at shallow depths due to greater confinement. Also, other factors, such as gradation and particle angularity, are typically not taken into account. Compared to the other available compaction QC methods, This device has the potential of becoming a useful testing method as an in situ compaction QC test method due to its simplicity and quickness of operation.

\subsubsection{Clegg Hammer Test}

The Clegg Hammer Test (CHT) is an impact test device that was developed by Clegg (1976) to evaluate the mechanical properties of compacted soil. Originally, Asai (1960) developed an apparatus that had a dropping weight. The acceleration of the falling weight was measured and correlated with the modulus of subgrade $k$ determined by static plate 
load tests. More sophisticated equipment, which were capable of measuring the acceleration of the falling weight using two geophones, were also developed (Szendrei and Freeme 1970).

Clegg (1976) realized that there was the need to develop simpler equipment for compaction QC in situ. Clegg (1976) developed, in Australia, a test device for QC that originally made use of a modified Proctor compaction hammer (hammer weight: $4.5 \mathrm{~kg}$ weight, and drop height: $0.45 \mathrm{~m}$ ) with an accelerometer attached at the top and encased in a guide tube. Clegg (1976) also simplified the dynamic measuring technique by capturing only the peak deceleration of the falling hammer, which was correlated to the stiffness or the shear strength of the material at the location where the hammer was dropped. The output of the CHT is displayed in terms of the Clegg Impact Value (CIV). One unit of CIV is equal to $98.1 \mathrm{~m} / \mathrm{s}^{2}$, ten times the acceleration due to gravity. It is typically determined after four hammer drops at a given test location.

Currently, five different CHT models are available on the market; the original model developed by Clegg (1976) uses a modified compaction hammer. These models have varying hammer weights and drop heights. The lighter ones are typically used for evaluating relatively soft materials such as recreational turf and the playing ground for baseball, while the heavier models are used for evaluating stiff materials, such as compacted soil and base course material (Clegg 1983; Canaway et al. 1990; Rogers and Waddington 1990; Erchul 1999). Figure 3.5 shows the 10kg CHT that was used in this research. 
Table 3.6 Various Clegg Hammer Test product configurations (Lafayette Instrument Co., 2009)

\begin{tabular}{|c|c|c|c|c|}
\hline Product & Model No. & $\begin{array}{c}\text { Drop weight } \\
(\mathrm{kg})\end{array}$ & $\begin{array}{c}\text { Drop height } \\
(\mathrm{m})\end{array}$ & $\begin{array}{c}\text { Diameter of } \\
\text { the hammer } \\
(\mathrm{m})\end{array}$ \\
\hline $20 \mathrm{~kg} \mathrm{CHT}$ & $95056 \mathrm{~A}$ & 20 & 0.30 & 0.13 \\
\hline $10 \mathrm{~kg} \mathrm{CHT}$ & $95055 \mathrm{~A}$ & 10 & 0.30 & 0.13 \\
\hline $4.5 \mathrm{~kg} \mathrm{CHT}$ & $95050 \mathrm{~A}$ & 4.5 & 0.45 & 0.05 \\
\hline $2.25 \mathrm{~kg} \mathrm{CHT}$ & $95049 \mathrm{~A}$ & 2.25 & 0.45 & 0.05 \\
\hline $0.5 \mathrm{~kg} \mathrm{CHT}$ & $95048 \mathrm{~A}$ & 0.5 & 0.45 & 0.05 \\
\hline
\end{tabular}

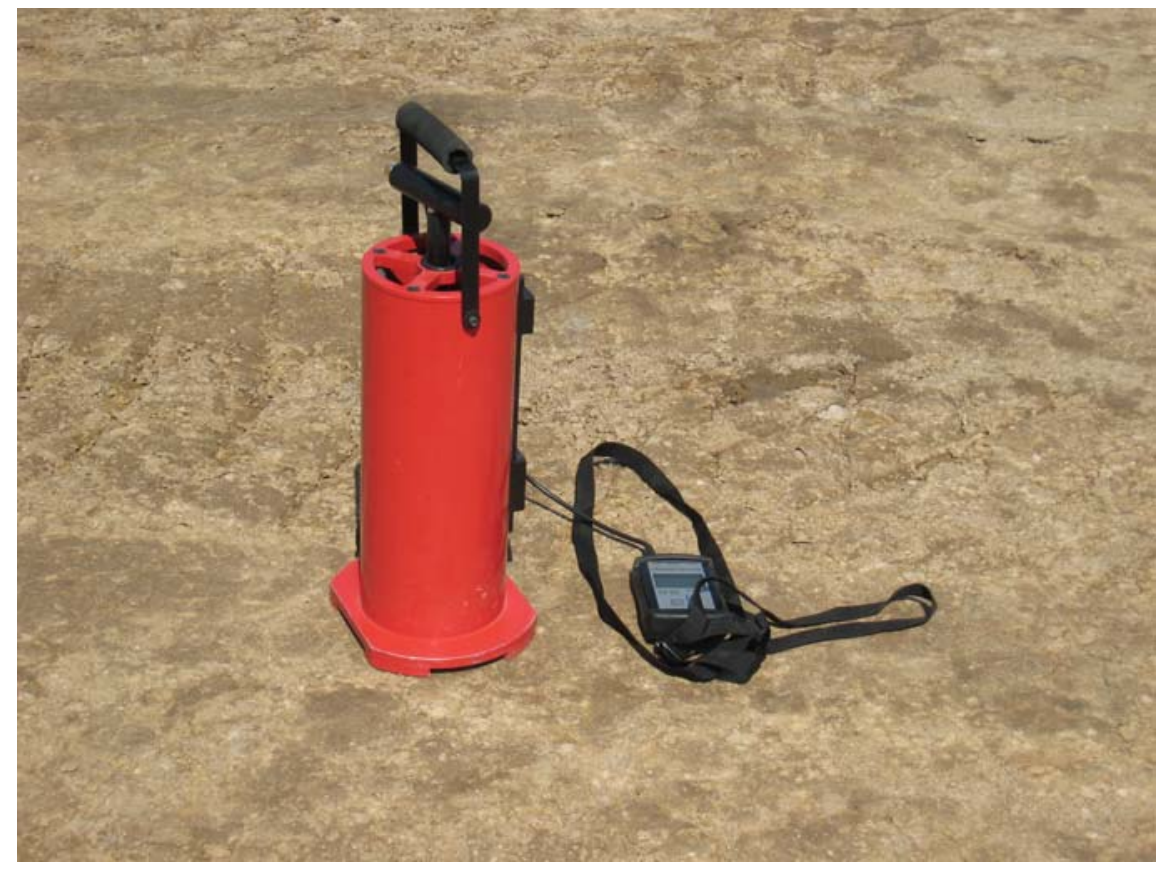

Figure 3.5 Photograph of Clegg Hammer Test (hammer weight, 10kg).

Several research studies were carried out to correlate the CIV and the mechanical properties of pavement materials. Since Clegg $(1978,1980)$ proposed that the CHT can 
be used as an alternative to the CBR, several research studies have proposed relationships between the CIV and the CBR (Yoder et al. 1982; Garrick and Scholer 1985; Mathur and Coghlans 1987; Al-Amoudi et al. 2002). Table 3.7 is a summary of the correlations developed between the CBR and the CIV. Janoo et al. (1999) investigated the use of the CHT for evaluating the compressive strength of treated subgrade. Similarly, Guthrie and Reese (2008) utilized the CHT for specifying a setting time for cement-treated base material.

Table 3.7 Summary of the correlations between CBR and CIV*

\begin{tabular}{|c|c|c|}
\hline Research & $\begin{array}{c}\text { Test condition } \\
\text { /Material tested }\end{array}$ & Correlation equation \\
\hline Clegg (1980, 1983) & In situ /Base course & $C B R=0.072(C I V)^{2}$ \\
\hline Mathur and Coghlans (1987) & & $C B R=0.1085(C I V)^{1.863}$ \\
\hline Al-Amoudi et al. (2002) & Lab \& In situ & $C B R=0.1691(C I V)^{1.695}$ \\
\hline
\end{tabular}

* These correlations were developed using $4.5 \mathrm{~kg}$ CHT

Recently, the Gas Technology Institute (GTI 2005 and 2006) investigated the use of the CHT as a quality control test to determine soil compaction parameters such as compacted dry unit weight and moisture content. Table 3.8 shows the range of the CIV for various soil types. 
Table 3.8 CIVs corresponding to $90 \% \mathrm{RC}$ at optimum moisture content (modified after GTI 2005)

\begin{tabular}{|c|c|c|c|}
\hline CIV & Sand $\left(\mathrm{A}-2^{*}\right)$ & Silty-clay $\left(\mathrm{A}-6^{*}\right)$ & Stone-base $\left(\mathrm{A}-1^{*}\right)$ \\
\hline $10 \mathrm{~kg}$ CHT & $6-8$ & $8-12$ & $12-14$ \\
\hline
\end{tabular}

However, all the correlations proposed in the literature are empirical in nature. These relationships should be used with caution as the CIV has been correlated with properties that reflect the static response of the material, such as the CBR. As the CHT is dynamic in nature, research needs to be done in order to relate the CIV with mechanical properties that reflect the dynamic response of the material.

\subsubsection{Continuous Compaction Control Test}

The existing compaction quality control tests are completed by checking the compacted in situ dry unit weight ( $\left.\gamma_{\text {dfield }}\right)$ for a specified lift thickness, number of compactor passes, and range of moisture content $(w c)$. However, all the methods discussed in the previous two sections of this chapter are performed at specific test locations at the construction site and, hence, are based on spot checking.

In order to overcome the limitation of spot-checking tests, continuous compaction control (CCC) was developed almost 30 years ago in Europe (Forssblad 1980; Thurner and Sandström 1980). The basic principle of CCC is to make use of compaction rollers that have a machine-integrated accelerometer that is used to record compaction rollerground interaction against the compaction energy. Using global positioning system (GPS) along with the geographic information system (GIS), compaction roller-based 
measurement of the soil response provides real-time data over the entire compacted area (Rinehart and Mooney 2009). The recorded data reflect the dynamic ground stiffness or strength, which indicates the compaction level achieved in the field.

In the last two decades, several manufacturers have developed compaction rollers that can be used for CCC. Most of the companies install accelerometers in the drum of the roller and use machine energy to compute the mechanical properties of the compacted material (Camargo et al. 2007). Figure 3.6 shows one example of the compacter manufactured by Geodynamik Co. The compactor in the figure is equipped with compaction monitoring system components.

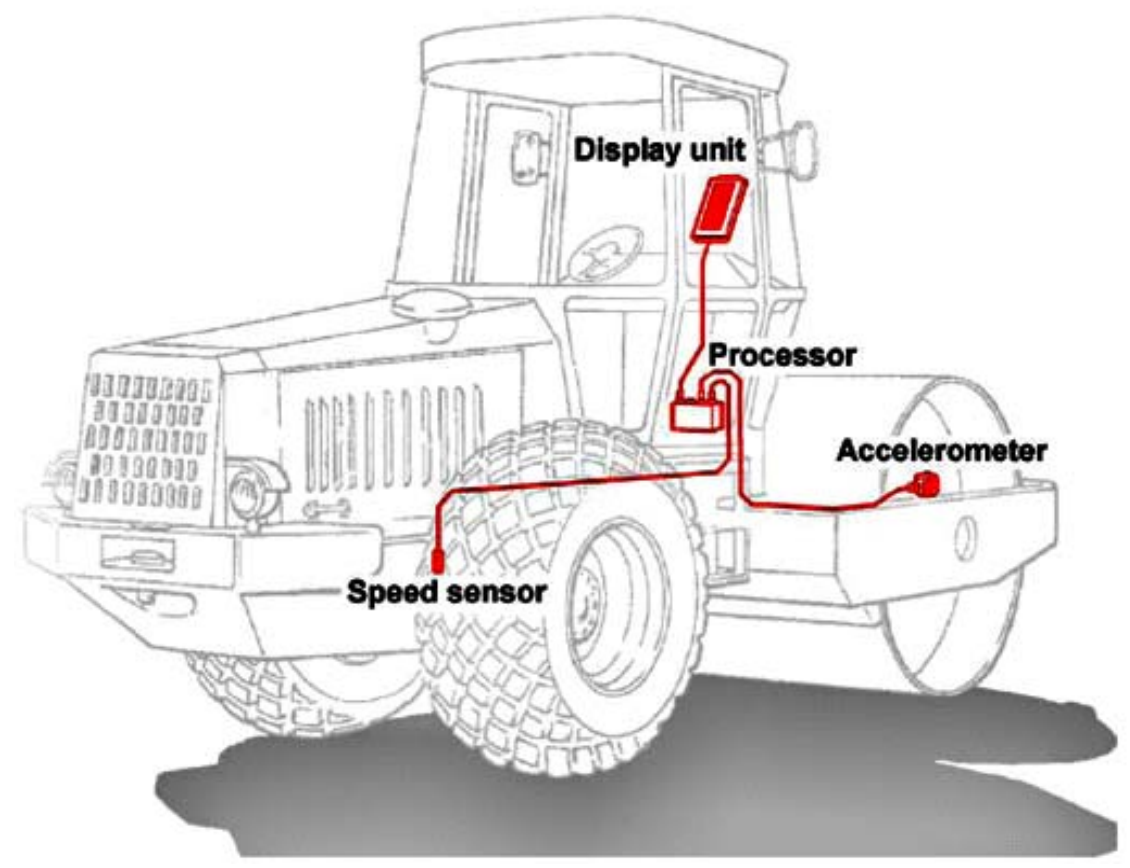

Figure 3.6 Geodynamik compactor equipped with monitoring system components (modified after Sandström and Pettersson 2004). 
The main advantage of $\mathrm{CCC}$ is that the instrumented compactor enables field personnel to perform real-time compaction QC. The QC checks are displayed on a computer screen in the cab of the compactor (see Figure 3.7). With recent advances in Global Positioning System (GPS) and Geographic Information System (GIS), many researchers have been actively involved in developing CCC (White et al. 2004; Rahman et al. 2008; White and Thompson 2008; Rinehart and Mooney 2009).
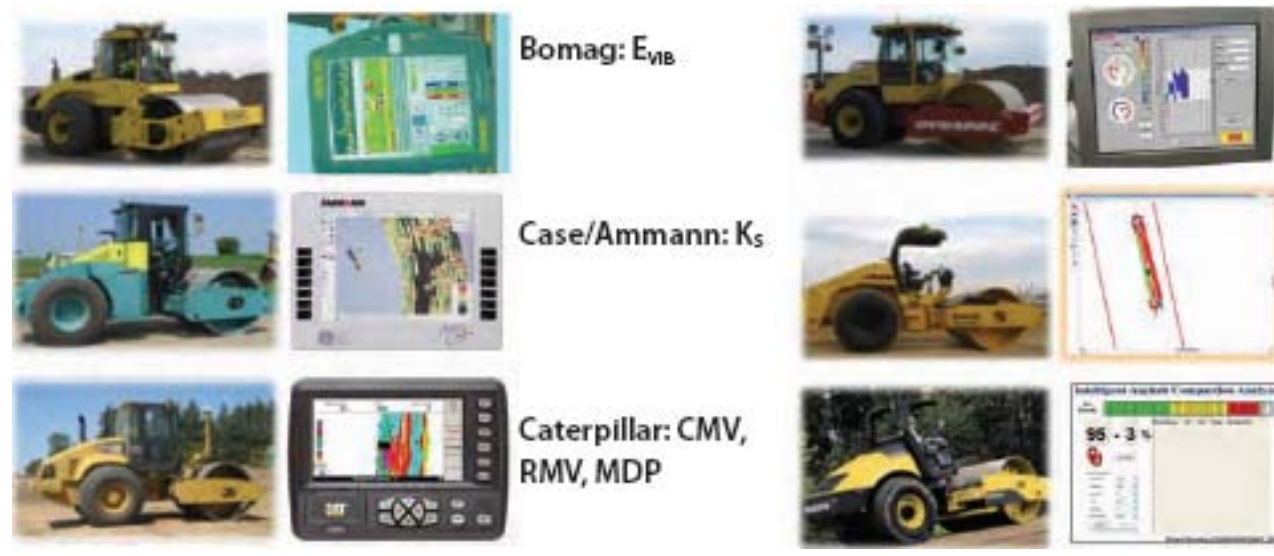

Dynapac: CMV, Bouncing Vslue
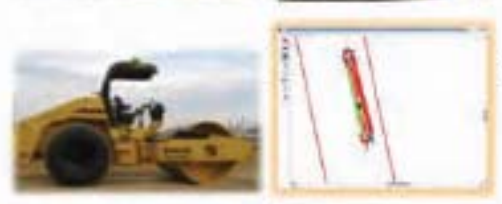

Sakai: CCV
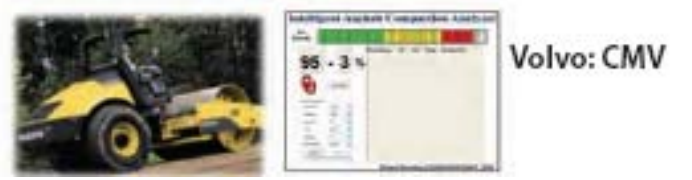

Figure 3.7 Smooth drum compaction monitoring systems for soil (White 2008).

However, in practice, there are currently several problems that need to be addressed before $\mathrm{CCC}$ can be adopted as a quality control technique. First, there are no standard parameters for CCC. Instead, there are more than six different CCC parameters depending on the equipment manufacturer, as each has individually developed CCC to fit their own model of the compactor (see Figure 3.7). Second, even though U.S. transportation agencies are beginning to investigate the applications for $\mathrm{CCC}$ in conjunction with field demonstration projects, only a few projects have been completed 
and no widely accepted specifications are available in the U.S. (White et al., 2007). Third, since CCC generates data for quality control of compaction over the entire project area at every stage of the compaction process, the data files are too large to be easily managed with state-of-the-art electronic technology. Thus, the development of related technology is necessary for adopting CCC in practice. Finally, most practitioners are still unfamiliar with CCC technology.

\subsection{Specifications for Quality Control of Subgrade Compaction}

A specification is defined as an explicit set of detailed statements prescribing materials, dimensions, and quality of work for something to be built, installed, or manufactured (American Heritage Dictionary 2001). Therefore, specifications for subgrade compaction should detail all necessary requirements. In addition, specifications should be both practical and reasonable so that construction is as economical as possible (both in terms of cost and time). For example, if unrealistic levels of compaction are required, contractors might not be able to satisfy such a specification requirement.

In the specification for compaction of soils in the field, there are typically three items involved: (1) method specification; (2) end-product specification; and (3) performance specification (TRB 2009)

In a method specification, the work procedure is detailed. It includes the compactor type, mass, and travel speed, as well as the number of compactor passes. In addition, the type of soil, molding water content, and lift thickness is described. In this type of specification, the work procedure must be inspected to guarantee the quality of 
compaction. Experience has shown, however, that this specification tends to obligate the agency to accept the completed work regardless of quality (TRB 2009).

With an end-product specification, agencies specify the required values for the dry unit weight and water content of the compacted soil. Agencies typically specify the required relative compaction to be achieved in situ. In this specification, density-based compaction control tests should be performed to ensure the quality of compaction. Endproduct specifications allow contractors to choose techniques and work procedures to improve the quality or economy, or both, of the compacted soil (TRB 2009).

A performance specification defines the performance characteristics of the final product and links them to construction, materials, and other items under contractor control (FHWA 2009). The performance of the compacted soil can be checked by in situ tests. Performance is described in this specification by means of changes in physical condition of compacted subgrade and its response to the load (TRB 2009). Since our final goal is to have compacted soil that meets the performance requirements, this specification is most appropriate to evaluate performance of the end product over time.

From these three categories of specifications for earthwork, which one is widely adopted by agencies and how does it work? Wahls (1967) reviewed highway specifications and showed that most U.S. DOT agencies relied on the end-product type of specification, with density requirement checks. However, the specifications of several states also included method requirements, such as the maximum lift thickness. Almost half of the states employed $95 \%$ relative compaction $(\mathrm{RC})$ as a requirement, while some states specified either $100 \%$ or $90 \%$. Wahls (1967) indicated that these variations in 
density requirements resulted from engineering judgment and experience with local construction practices rather than from theoretical considerations.

At present, most agencies adopt end-product specifications along with method specifications, as shown in Table 3.9. The specifications of various agencies in the U.S. indicate that most states follow the $95 \% \mathrm{RC}$ specification for density requirement. Also, water content is specified at about -2 to $+2 \%$ of the optimum moisture content on average before compaction. Some agencies have a slightly higher or lower RC requirement. In general, 95\% RC with an acceptable range for the soil moisture content (about -2 to $+2 \%$ of the optimum moisture content) is widely accepted as a criterion for soil compaction. 
Table 3.9 Summary of compaction control specifications adopted by various transportation agencies

\begin{tabular}{|c|c|c|c|c|}
\hline \multirow{2}{*}{ Agency } & \multirow{2}{*}{ Condition } & \multicolumn{2}{|c|}{ Compaction Requirement } & \multirow{2}{*}{ NOTE } \\
\hline & & Minimum Relative Compaction & Range of water content & \\
\hline \multirow{2}{*}{$\begin{array}{l}\text { AASHTO } \\
(2003)\end{array}$} & $\begin{array}{l}\text { for subgrade with A-1, A-2-4, A- } \\
2-5 \text {, and A-3 soil }\end{array}$ & $100 \%$ & \multirow[t]{2}{*}{ within $-2 \%$ to $+2 \%$ from $\mathrm{OMC}$} & \\
\hline & mostly for other cases & $95 \%$ & & \\
\hline \multirow{2}{*}{$\begin{array}{l}\text { Illinois } \\
(2007)\end{array}$} & $\begin{array}{c}\text { Embankment less than } 3-\mathrm{ft} \text { in } \\
\text { height }\end{array}$ & $\begin{array}{c}\text { Upper } 1.5 \mathrm{ft}, 95 \% \\
\text { First lift greater than } 1.5 \mathrm{ft} \text { to } 90 \% \text { with } \\
\text { remainder } 95 \%\end{array}$ & \multirow{2}{*}{$\begin{array}{l}\text { Top } 2 \mathrm{ft} \text {. not more than } 120 \% \text { of } \\
\text { OMC } \\
\text { Adjacent to structure, not more } \\
\text { than } 110 \% \text { of OMC }\end{array}$} & \\
\hline & $\begin{array}{c}\text { Embankment more than } 3 \text {-ft in } \\
\text { height }\end{array}$ & $\begin{array}{c}\text { Lower } 1 / 3,90 \% \\
\text { First lift above lower } 1 / 3 \text { to } 93 \% \text { with } \\
\text { remainder to } 95 \%\end{array}$ & & \\
\hline \multirow{3}{*}{$\begin{array}{l}\text { Texas } \\
(2004)\end{array}$} & $\mathrm{PI} \leq 15$ & $\mathrm{RC} \leq 98 \%$ & & \\
\hline & $15<\mathrm{PI} \leq 35$ & $98 \% \leq \mathrm{RC} \leq 102 \%$ & $\begin{array}{c}\text { within a range that can acquire } \\
\text { more than } 98 \% \mathrm{RC} \text { in a lab } \\
\text { compaction test }\end{array}$ & \\
\hline & $35<$ PI & $95 \% \leq \mathrm{RC} \leq 100 \%$ & $\begin{array}{c}\text { within a range that can acquire } \\
\text { more than } 95 \% \mathrm{RC} \text { in a lab } \\
\text { compaction test }\end{array}$ & \\
\hline \multirow{2}{*}{$\begin{array}{l}\text { New York } \\
(2008)\end{array}$} & Subgrade area & $95 \%$ & \multirow{2}{*}{$\begin{array}{l}\text { Not specified (Contractor's } \\
\text { responsibility) }\end{array}$} & \multirow{2}{*}{$\begin{array}{l}\text { Field compaction } \\
\text { is not allowed } \\
\text { between Nov. } 1 \\
\text { and April } 1 \\
\end{array}$} \\
\hline & Embankment & $90 \%$ & & \\
\hline $\begin{array}{l}\text { Mississippi } \\
\quad(2004)\end{array}$ & & $\begin{array}{l}95 \% \sim 98 \% \text { (the average of two tests will } \\
\text { be the test value) }\end{array}$ & $\begin{array}{l}\text { Contractor's responsibility to } \\
\text { maintain the proper moisture } \\
\text { content during the compaction }\end{array}$ & \\
\hline \multirow{2}{*}{$\begin{array}{c}\text { Indiana } \\
(2006)\end{array}$} & Top 1ft subgrade & $99 \%$ & \multirow{2}{*}{ within $-2 \%$ to $+1 \%$ from $\mathrm{OMC}$} & \multirow{2}{*}{$\begin{array}{l}\text { Proofrolling } \\
\text { when specified }\end{array}$} \\
\hline & All cases except above & $95 \%$ & & \\
\hline $\begin{array}{l}\text { Iowa }^{\dagger} \\
(2006)\end{array}$ & All embankments & $95 \%$ & $\begin{array}{l}\text { Variable such that adequate } \\
\text { compaction is achieved }\end{array}$ & \\
\hline
\end{tabular}




\begin{tabular}{|c|c|c|c|c|}
\hline \multirow{2}{*}{ Agency } & \multirow{2}{*}{ Condition } & \multicolumn{2}{|c|}{ Compaction Requirement } & \multirow[t]{2}{*}{ NOTE } \\
\hline & & Minimum Relative Compaction & Range of water content & \\
\hline \multirow{2}{*}{$\begin{array}{l}\text { Missouri } \\
(1999)\end{array}$} & $\begin{array}{l}\text { Within top } 18 \text {-in. of subgrade or } \\
\text { within } 100 \mathrm{ft} \text { of structures }\end{array}$ & $95 \%$ & \multirow{2}{*}{$\begin{array}{c}\text { Such that adequate compaction is } \\
\text { achieved }\end{array}$} & \\
\hline & Unless otherwise noted & $90 \%$ & & \\
\hline \multirow{2}{*}{ Minnesota $^{\dagger}$} & $\begin{array}{c}\text { Upper 3-ft. of embankment or } \\
\text { adjacent to structures }\end{array}$ & $100 \%$ & $65 \% \sim 102 \% \mathrm{OMC}$ & \\
\hline & All cases except above & $95 \%$ & $65 \% \sim 115 \% \mathrm{OMC}$ & \\
\hline \multirow{2}{*}{$\begin{array}{l}\text { South } \\
\text { Dakota }^{\dagger} \\
(2006)\end{array}$} & At the top of the berm slope & $97 \%$ & \multirow{2}{*}{$\begin{array}{c}\text { If } \mathrm{OMC}<15 \% \text {, then } \pm 4 \% \text { from } \\
\text { OMC } \\
\text { If OMC }>15 \% \text {, then }-4 \% \text { to }+6 \% \\
\text { from OMC }\end{array}$} & \\
\hline & All cases except above & $95 \%$ & & \\
\hline \multirow{2}{*}{$\begin{array}{l}\text { Wisconsin } \\
\quad(2009)\end{array}$} & $\begin{array}{c}\text { Embankment less than 6-ft high } \\
\text { or within } 200-\mathrm{ft} \text { of a bridge } \\
\text { abutment }\end{array}$ & $95 \%$ & \multirow{2}{*}{$\begin{array}{l}\text { Such that the material does not rut } \\
\text { excessively and material can be } \\
\text { compacted properly }\end{array}$} & \multirow{2}{*}{$\begin{array}{c}\text { Quality } \\
\text { Management } \\
\text { Plan (QMP) }\end{array}$} \\
\hline & Embankment greater than 6-ft & $\begin{array}{c}\text { More than 6-ft below finished grade to } \\
90 \% \text {, otherwise } 95 \%\end{array}$ & & \\
\hline \multirow{4}{*}{$\begin{array}{l}\text { Virginia } \\
(2007)\end{array}$} & For most cases & $95 \%$ & \multirow{4}{*}{ within $\pm 20 \%$ of $\mathrm{OMC}$} & \\
\hline & $\begin{array}{c}\text { Top 6-in } \\
\text { (if \% retained on \#4 sieve }< \\
50 \% \text { ) } \\
\end{array}$ & $100 \%$ & & \\
\hline & $\begin{array}{c}\text { (if } 50 \%<\% \text { retained on } \# 4 \text { sieve } \\
\leq 60 \% \text { ) }\end{array}$ & $95 \%$ & & \\
\hline & 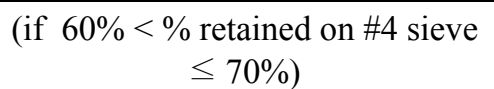 & $90 \%$ & & \\
\hline
\end{tabular}

${ }^{+}$Data taken from White et al (2007) 


\subsection{Summary}

Quality Control (QC) of soil compaction typically involves determining the in-place compacted dry unit weight $\left(\gamma_{d f i e l d}\right)$ and the water content $(w c)$ of a compacted lift of fill material and comparing the measured $\gamma_{d f i e l d}$ and $w c$ with the laboratory compaction test results. In order to measure the in situ dry unit weight and water content, most agencies employ the nuclear gauge for field compaction QC because sand cone tests are cumbersome and time consuming to perform. However, since the measurement of the compacted dry unit weight of soil is an indirect means to assess the mechanical response of subgrade, road engineers have attempted to devise testers that be used to assess the mechanical properties of the compacted subgrade related to its in situ strength or stiffness. The California Bearing Ratio test and the Plate bearing test were used for this purpose, but these tests have been abandoned for QC testing due to their shortcomings. Currently, there are some testers that have been developed for measuring the stiffness or strength of subgrade: (1) the Clegg Hammer Test (CHT), (2) the Soil Stiffness Gauge (SSG) test, and (3) the Light Falling-Weight Deflectometer (LFWD) test. These testers have the potential to capture the dynamic response of compacted soil, although the present analytical solutions for the tests do not account for the dynamic loading. For greater depth, the Dynamic Cone Penetration test is used to measure the dynamic in situ penetration resistance as a function of depth. The test result is in the form of dynamic blow counts or penetration rates that are correlated with both the stiffness and the strength parameters of subgrade. However, most researchers have suggested the criteria 
for the DCPT using the DCPI alone without considering the confining effect. Also, the other factors such as gradation and particle angularity exist that have not been accounted for. As a result, the device will be a useful and versatile field quality control device once a reasonable criterion is established.

All of the above, however, are spot tests and can only cover a very small portion of the fill volume. The Continuous Compaction Control (CCC) technique is under development to evaluate the quality of the compaction over the entire volume of compacted soil, but it needs to be improved for practical use.

Typical specifications for field compaction indicate the type of laboratory compaction tests to be used as a reference and specify the percentage of the reference laboratory compaction test results that will be required in the field. Specifications for the molding water content should also fall within a certain range of the OMC. In general, the specification for density control (i.e. $95 \%$ relative compaction) has effectively functioned for more than 30 years and therefore should ensure the performance of compacted soil. 


\section{CHAPTER 4. COMPACTION VARIABILITY OF SOIL}

\subsection{Introduction}

Every construction material has variations in its composition and properties. Geomaterials are more variable than other man-made materials that are used in the construction industry, such as concrete and steel. When soils are compacted in-place, the variability associated with compaction can be quite significant, even with "homogeneous" soils (Yoder and Witczak 1975). Then, what is the source of this variability in soil compaction? And why is compaction variability of soil important?

In the case of soil compaction, variability can be mainly classified as (1) spatial variability, and (2) variability associated with the technique of measurement. First, even areas compacted at few meters apart may exhibit variability. Second, every measurement is bound to have some level of randomness. This randomness is caused by the testing method itself and/or the person performing the test. Figure 4.1 illustrates how relative compaction varies in space. 


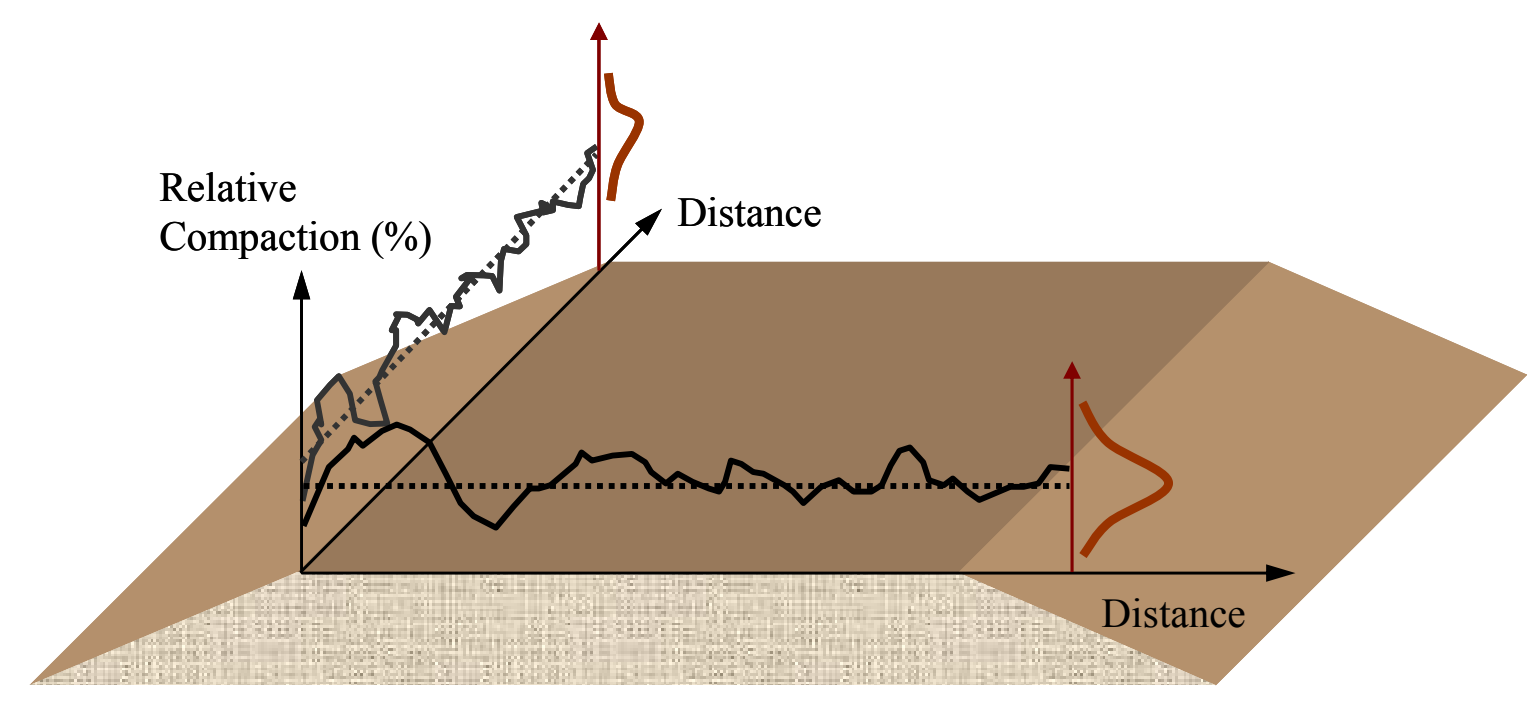

Figure 4.1 Variability in the compaction level achieved along an embankment.

Why is compaction variability important? For proper performance of a pavement structure constructed over the subgrade, uniform compaction of the subgrade soil should be achieved in the field (refer to CHAPTER 2). Nonuniformities of the subgrades may induce local and permanent deformations, such as bumps, corrugations, and depressions on the pavement surface. In addition, since compaction quality control test results are subject to variance due to compaction variability, specification limits used for compaction quality control are appropriate when they relate to a measure of the variability in compacted soil (Hughes 1996), though the specifications of many transportation agencies indicate a specific value for the quality control of soil compaction.

In this chapter, we will discuss the sources of soil variability, focusing on compaction variability, and will review the literature pertinent to the typical variability associated with compacted soil. The chapter then will present how to account for compaction variability in determining the specification limits for soil compaction. 


\subsection{Basic Statistical Concepts}

In order to quantify variability in soil, some basic statistical concepts need to be understood. Figure 4.2 shows a normally distributed frequency curve that is obtained by plotting the frequency histogram of $n$ sampling units from a sample in the conceptual population. The conceptual population is a complete set of all the values that is impossible to measure (Devore 2004). A sample is a set of values that is a subset (a portion) of the population. Sampling units are the values in a sample determined by collecting information from a sample. A statistical distribution can be described in terms of mean and variance, standard deviation, or coefficient of variation.

In the statistical distribution shown in Figure 4.2, the mean identifies the weighted average of the values in the sampling units. The mean can be expressed as:

$$
\mu=\frac{\sum_{i=1}^{n} x_{i}}{n}
$$

where $\mu$ is the mean of the sampling units, $n$ is the number of sampling units, and $x_{i}$ is the value of the sample at $i$. 


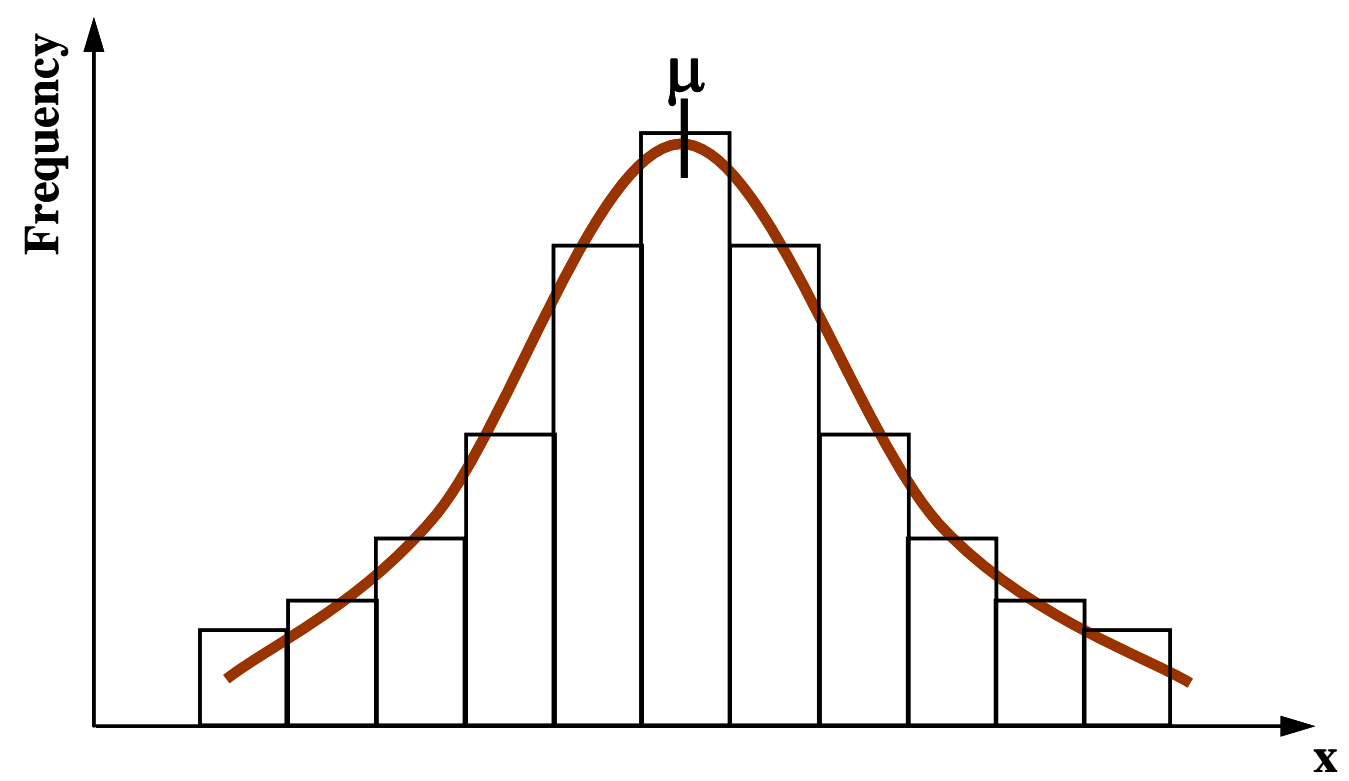

Figure 4.2 A normally distributed frequency curve.

From Figure 4.2, we can also compute the variance, which is a measure of the squared dispersion of sampling units. In general, the variance of a population is denoted as $\sigma^{2}$, while the variance of the sampling units is denoted as $s^{2}$. The variance of the sampling units is expressed as:

$$
s^{2}=\sum_{i=1}^{n} \frac{\left(x_{i}-\mu\right)^{2}}{n-1}
$$

Since the units of variance are not the same as that of the physical quantity measured, it is useful to quantify the variability of the statistical distribution in terms of the standard deviation. Mathematically, the standard deviation (s) is expressed as: 


$$
\mathrm{s}=\sqrt{\sum_{i=1}^{\mathrm{n}} \frac{\left(\mathrm{x}_{\mathrm{i}}-\mu\right)^{2}}{\mathrm{n}-1}}
$$

A parameter used as a relative measure of variability is the coefficient of variation (COV). The COV is expressed as:

$$
\operatorname{COV}(\%)=\left(\frac{\mathrm{s}}{\mu}\right) \times 100
$$

Since COV is dimensionless, it is useful for comparing the variability among different measurements.

\subsection{Sources of Compaction Variability}

In order to quantify the variation of in-place soil compaction, it is necessary to identify the sources of variability that are observed in compacted soil. There are three principal sources contributing to variability in soil compaction:

\section{(1) Spatial Variability of Compacted Soil}

Natural soil may vary to some extent with space. In a natural soil deposit, spatial variability results primarily from the natural geologic processes that lead to soil formation and that continually modify the in situ soil characteristics (Phoon and Kulhawy 1996). Although the variability of compacted soil is typically less than the variability of nature, 
it still exists. Again, even within a section spanning only few meters, the composition of soil, for instance, its particle size and shape can vary significantly, indirectly affecting the density for a given method of compaction. Also, the variability of water content, which controls the compacted dry unit weight of the soil, is another source of spatial variability that can contribute to variability in soil density (Price 1978).

In addition, spatial variability results from compaction process. For example, the travel speed, number of passes of a compactor, and the lift thickness can vary on a site. This variability is inherent and is a function of the characteristics of the soil.

(2) Variability due to Sampling and Testing

Improper sample size selection may result in conceptual population bias and, as a consequence, cause either underestimation or overestimation of the relative compaction measured at the site. For example, when project engineers perform testing, they select only a small representative area of the site; and from these sampling test results, they evaluate the in-place compaction achieved at the site. Using this procedure, there is uncertainty in the test results introduced by sampling. Although the variability in soil compaction due to sampling and testing could conceptually be separated, they are grouped together as their effects can not be independently quantified (Hughes 1996). Sampling variability means two samples taken from the same spot and tested using the same procedure do not show identical test results. However, it is also possible that the test should produce the same result (because the soil property has the same value for both samples) but does not because of testing variability. As far as testing variability is 
concerned, the proficiency of the test operators, the test apparatus, and the test procedures influence the variability to a great extent.

(3) Variability in the Results of Laboratory and Field Compaction Tests

This source of variability is unique to soil compaction. As presented in the previous chapter, we know that relative compaction is defined as the ratio of the in-place dry unit weight of soil to the maximum dry unit weight of soil obtained from the laboratory compaction test. However, the question arises as to how closely laboratory compaction tests can simulate actual field compaction. In the laboratory, the size of the standard mold is only 4.5 in. $(11.43 \mathrm{~cm})$ in diameter and 4.6 in. $(11.68 \mathrm{~cm})$ in height (ASTM D 698). Also, the energy imparted by the compaction hammer in the laboratory is different from the energy that is produced by the field compaction equipment. Moreover, at a given site, the number of laboratory compaction tests performed is limited. This means that when calculating relative compaction values, we use a maximum dry unit weight value obtained from a limited number of maximum dry unit weights taken from a small number of laboratory compaction tests. For example, slightly different soils are grouped together and regarded as the same soil when computing the relative compaction values.

To summarize, compaction variability results from the different soil composition and variability in the compaction process. When attempting to estimate this variability using tests, the estimates get distorted and magnified by variability due to sampling and testing. 
Liu and Thompson (1966) studied the variability in laboratory soil tests using their laboratory test results along with the data available in Shook and Fang (1961), Ballard and Weeks (1963), and Liu and Thornburn (1964). The laboratory soil tests considered by Liu and Thompson (1966) included Atterberg limit tests (liquid limit and plastic limit), laboratory compaction tests, and specific gravity tests. Table 4.1 is a summary of the laboratory tests performed. The table shows the variation observed in the test results based on three studies (Case A, Case B, and Case C). In order to investigate the effect of sources of variability to the test results, the laboratory tests were performed with the following three conditions:

1) Two technicians performed ten tests per person on three different types of soils [A-6 (8), A-6 (9), and A-7-6 (15)] in a single laboratory using the same apparatus (Case A, refer to Table 4.1)

2) Five technicians performed a single test per person on nine different types of soils within a single laboratory using the same apparatus (Case B, refer to Table 4.1)

3) 99 laboratories performed a single set of tests per laboratory on three different type of soils (Case C, refer to Table 4.1).

Table 4.1 illustrates that the standard deviation of Case $\mathrm{C}$ is significantly larger than the others. Also, the variability of the plasticity index between testers performing tests in a given laboratory did not exceed a standard deviation of 2.54 (see Case B in Table 4.1). Table 4.1 indicates that the standard deviation associated with the maximum dry density was less than three $\operatorname{pcf}\left(0.47 \mathrm{kN} / \mathrm{m}^{3}\right)$. The optimum moisture content showed variation similar to those of the Atterberg limits. The variability in the specific gravity test results appeared to be less. 
Table 4.1 Variability of laboratory test (data from Liu and Thompson 1966)

\begin{tabular}{|c|c|c|c|c|c|c|c|c|}
\hline \multirow{2}{*}{$\begin{array}{l}\text { Test } \\
\text { property }\end{array}$} & \multirow{2}{*}{$\begin{array}{c}\text { No. } \\
\text { of } \\
\text { soils }\end{array}$} & \multirow{2}{*}{$\begin{array}{l}\text { No. of } \\
\text { operators } \\
\text { per Lab }\end{array}$} & \multirow{2}{*}{$\begin{array}{l}\text { No. of } \\
\text { Tests per } \\
\text { operators }\end{array}$} & \multirow{2}{*}{$\begin{array}{l}\text { No. } \\
\text { of } \\
\text { labs }\end{array}$} & \multicolumn{2}{|c|}{$\mathrm{s}$} & \multicolumn{2}{|c|}{$\operatorname{COV}(\%)$} \\
\hline & & & & & Average & Range & Average & Range \\
\hline \multicolumn{9}{|l|}{ Case A } \\
\hline LL (\%) & 3 & 2 & 10 & 1 & 0.70 & $0.56-0.85$ & 2.0 & $1.5-2.5$ \\
\hline PL (\%) & 3 & 2 & 10 & 1 & 0.72 & $0.64-0.88$ & 3.6 & $3.0-4.0$ \\
\hline PI (\%) & 3 & 2 & 10 & 1 & 0.84 & $0.64-0.99$ & 6.0 & $3.7-8.7$ \\
\hline \multicolumn{9}{|l|}{ Case B } \\
\hline LL (\%) & 9 & 5 & 1 & 1 & 1.10 & $0.44-2.14$ & 4.0 & $1.7-7.7$ \\
\hline PL (\%) & 9 & 5 & 1 & 1 & 1.03 & $0.37-2.20$ & 6.5 & $2.3-13.2$ \\
\hline PI (\%) & 9 & 5 & 1 & 1 & 1.53 & $0.94-2.54$ & 14.6 & $6.7-33.8$ \\
\hline \multicolumn{9}{|l|}{ Case C } \\
\hline LL (\%) & 3 & 1 & 1 & 99 & 3.20 & $1.7-5.4$ & 7.8 & $6.2-9.9$ \\
\hline PL (\%) & 3 & 1 & 1 & 99 & 2.80 & $2.1-3.5$ & 12.3 & $9.1-15.5$ \\
\hline PI (\%) & 3 & 1 & 1 & 99 & 3.90 & $2.4-5.7$ & 43.5 & $17.8-78.0$ \\
\hline $\begin{array}{c}\gamma_{\mathrm{dmax}} \\
\text { (pcf)* }\end{array}$ & 3 & 1 & 1 & 99 & 2.31 & $1.93-2.54$ & 2.2 & $1.8-2.5$ \\
\hline ** & 3 & 1 & 1 & 99 & 2.62 & $2.10-2.90$ & 2.3 & $1.9-2.5$ \\
\hline $\begin{array}{l}\mathrm{Wc}_{\mathrm{opt}} \\
(\%)^{*}\end{array}$ & 3 & 1 & 1 & 99 & 1.70 & $1.10-2.67$ & 9.3 & $7.0-12.9$ \\
\hline$* *$ & 3 & 1 & 1 & 99 & 1.24 & $0.83-1.96$ & 8.6 & $6.3-12.9$ \\
\hline Gs & 3 & 1 & 1 & 65 & 0.07 & $0.06-0.12$ & 2.9 & $2.0-4.4$ \\
\hline
\end{tabular}

Note: *standard Proctor test $* *$ modified Proctor test 
With respect to the variability in relative compaction, Table 4.2 summarizes the data compiled from the literature on the variability in the level of compaction of various soil types tested. The variability in the statistical distribution of relative compaction values depends on the moisture control, the uniformity in the compaction effort, the variation observed in a given soil type, and the capacity of soil to be affected by the compaction effort (Sherman et al. 1967). It is interesting to note that the mean values of relative compaction $(\mathrm{RC})$ presented in Table 4.2 were on average two to three percent greater than the required relative compaction. Also, even with two to three percent higher mean values than the required $\mathrm{RC}$, about $10 \%$ up to $38 \%$ of the sample units did not achieve the required $\mathrm{RC}$ as shown in Table 4.2.

The relative compaction data available in the literature is normally distributed. Note that considerable scatter of RC values can exist, particularly in sandy soils (the data for sandy soils are more scattered than those of silty-clay soils). The COVs of RC values depends primarily on the type of soil. However, no strong correlation between the COVs and the required $\mathrm{RC}$ was observed in Table 4.2. For example, COV ranged between 0.034 and 0.059 in case of $95 \% \mathrm{RC}$ requirement and between 0.026 and 0.059 in case of $90 \%$ RC requirement, except one case with 0.073 .

Since considerable scatter of relative compaction values exists in subgrade compaction, there is the need of performing field tests frequently to assess the quality of subgrade compaction. This is another reason why quality control tests should be quick and easy to perform. 
Table 4.2 Variability of relative compaction data from the literature

\begin{tabular}{|c|c|c|c|c|c|c|c|c|}
\hline \multirow[b]{2}{*}{ Source } & \multirow{2}{*}{$\begin{array}{l}\text { Required } \\
\text { RC } \\
(\%)\end{array}$} & \multirow{2}{*}{ Soils used for the compaction } & \multirow{2}{*}{$\begin{array}{l}\text { No. of } \\
\text { samples }\end{array}$} & \multicolumn{4}{|c|}{ Relative compaction $(\%)$} & \multirow{2}{*}{$\begin{array}{l}\text { Percentage } \\
\text { less than } \\
\text { required RC } \\
(\%) \\
\end{array}$} \\
\hline & & & & Range & $\begin{array}{c}\text { Mean } \\
(\mu)\end{array}$ & $\mathrm{SD}(\mathrm{s})$ & $\mathrm{COV}^{*}$ & \\
\hline \multirow{3}{*}{$\begin{array}{l}\text { Williams } \\
\text { and } \\
\text { Yoder } \\
(1967)\end{array}$} & \multirow{3}{*}{95} & $\begin{array}{c}\gamma_{\mathrm{dmax}}=110.4 \mathrm{pcf} \sim 123.3 \mathrm{pcf} \\
\mathrm{wc}_{\mathrm{opt}}=12 \% \sim 18 \%,(25 \leq \mathrm{LL} \leq 44 \\
9 \leq \mathrm{PI} \leq 19)\end{array}$ & 101 & $84-116$ & 100.6 & 5.3 & 0.053 & $23 *$ \\
\hline & & $\begin{array}{c}\gamma_{\mathrm{dmax}}=116.6 \mathrm{pcf} \sim 133.6 \mathrm{pcf} \\
\mathrm{wc}_{\mathrm{opt}}=7 \% \sim 11 \%,(14 \leq \mathrm{LL} \leq 34,0 \leq \mathrm{PI} \leq 14)\end{array}$ & 99 & $80-110$ & 96.8 & 5.7 & 0.059 & $16^{*}$ \\
\hline & & $\begin{array}{c}\gamma_{\mathrm{dmax}}=106.8 \mathrm{pcf} \sim 125.8 \mathrm{pcf} \\
\mathrm{wc}_{\mathrm{opt}}=9.5 \% \sim 16 \%,(19 \leq \mathrm{LL} \leq 39 \\
4 \leq \mathrm{PI} \leq 15)\end{array}$ & 101 & $84-108$ & 98.2 & 4.5 & 0.046 & $38 *$ \\
\hline \multirow{3}{*}{$\begin{array}{l}\text { Sherman } \\
\text { et al. } \\
(1967)\end{array}$} & \multirow{3}{*}{90} & A-4* & 200 & $87-98$ & 92.86 & 2.44 & 0.026 & 8.5 \\
\hline & & A-6* & 200 & $85-97$ & 90.54 & 3.09 & 0.034 & 43.0 \\
\hline & & A-2-6* & 176 & $80-103$ & 93.64 & 5.52 & 0.059 & 23.9 \\
\hline \multirow{4}{*}{$\begin{array}{l}\text { Weber } \\
\text { and } \\
\text { Smith } \\
(1967)\end{array}$} & \multirow{2}{*}{90} & \multirow{2}{*}{ Not provided } & $240 *$ & $77-107$ & 95.6 & 4.4 & 0.046 & 12 \\
\hline & & & $800^{*}$ & $80-114$ & 94.8 & 4.3 & 0.045 & 7.5 \\
\hline & \multirow{2}{*}{95} & \multirow{2}{*}{ Not provided } & $750^{*}$ & $84-112$ & 97.0 & 3.6 & 0.037 & 14 \\
\hline & & & $410^{*}$ & 89-111 & 98.6 & 3.4 & 0.034 & 11 \\
\hline \multirow{3}{*}{$\begin{array}{l}\text { Noorany } \\
(1990)\end{array}$} & \multirow{3}{*}{90} & Silty sand & 24 & $81-97$ & 91 & 3.9 & 0.043 & 17 \\
\hline & & $\begin{array}{l}\text { Nonuniform clayey, gravelly sand to } \\
\text { sandy gravel }\end{array}$ & 16 & $77-99$ & 88 & 6.4 & 0.073 & 62 \\
\hline & & Uniform silty clay & 22 & 89-103 & 94 & 3.4 & 0.036 & 14 \\
\hline
\end{tabular}

* Data acquired from the literature 


\subsection{Accounting for Compaction Variability in Determining the Specification Limits}

In the previous section, we saw that several factors can lead to variability in soil compaction. This variability should be accounted for while establishing the specification criterion for soil compaction. For example, if the specification requirement is to obtain an in-place compacted dry unit weight corresponding to $95 \% \mathrm{RC}$, this value should have high probability of occurrence. Table 4.2 suggests that a mean $\mathrm{RC}$ value of roughly three percent higher than the required $\mathrm{RC}$ needs to be achieved in order to obtain the required $\mathrm{RC}$ in most of the compacted area.

In order to utilize in situ tests for a compaction $\mathrm{QC}$, the criteria using the tests need to account for compaction variability. In this regard, the following statistical approach can be adopted. First, a minimum value of the test measurement that encompasses at least a certain percentage (e.g., 80\%) of occurrences in the frequency diagrams of test results associated with the required RC is first selected (see Figure 4.3). In the second step, the minimum value of the test measurement is tested for test results less than the minimum required value. The test here is that the most of test measurements, e.g.,90\% of test measurements, corresponding to less than the required $\mathrm{RC}$ must be less than the selected minimum value.

In the case of the DCPT, the blow count satisfying both requirements will be referred to as the minimum required blow count. It provides reasonable assurance that, if the measured blow count matches or exceeds it, the desired relative compaction will have been achieved. 


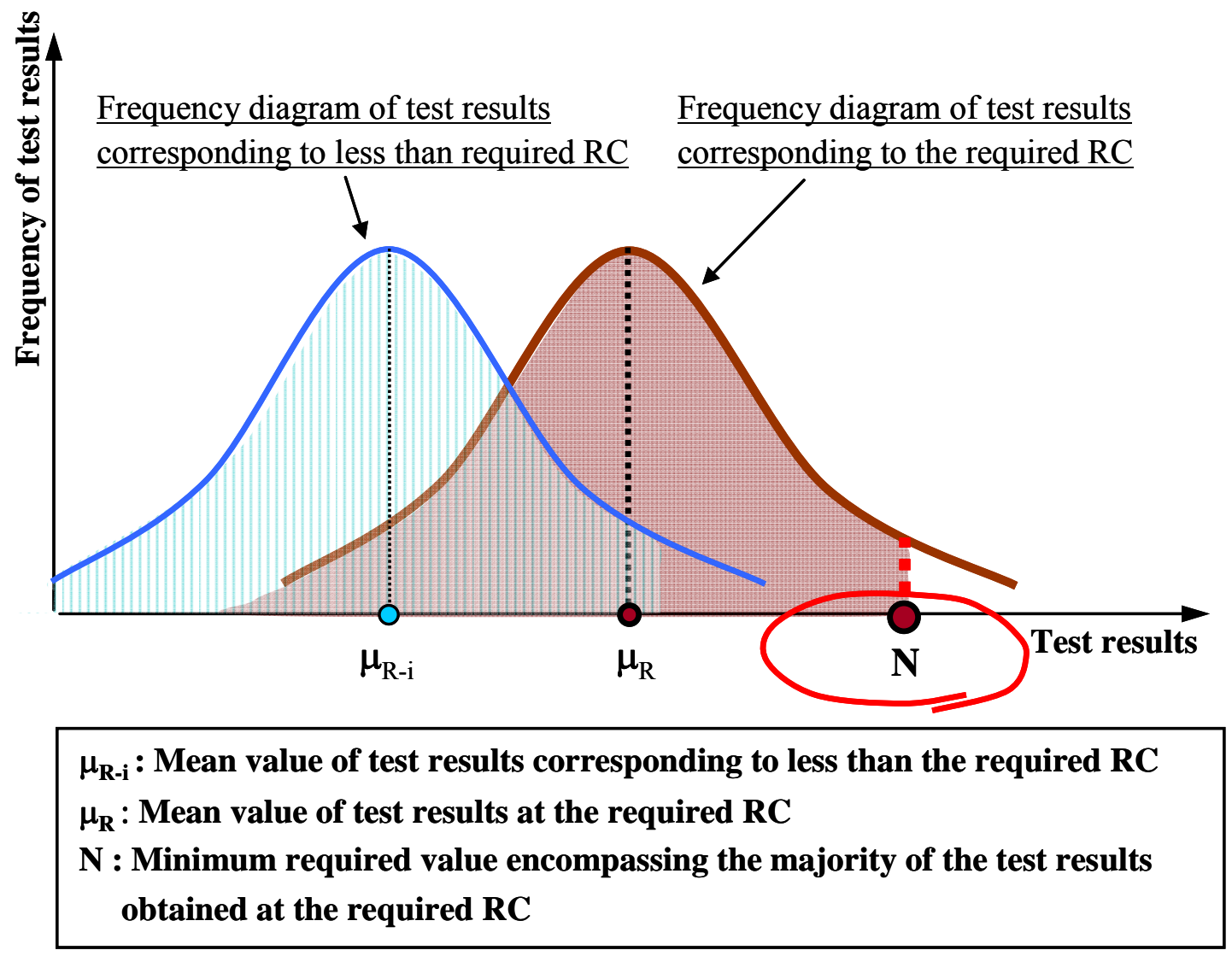

Figure 4.3 Conceptual frequency diagram of in situ test results. 


\subsection{Summary}

When soils are compacted in-place, the variability associated with compaction can be quite significant (Yoder and Witczak 1975). For proper performance of a pavement structure constructed over a subgrade, uniform compaction of the subgrade soil should be targeted in the field

In order to quantify variability in soil, some basic statistical concepts need to be understood, such as mean, variance, standard deviation, and covariance (COV). Mean identifies the weighted average of the values in the sampling units and can be expressed as:

$$
\mu=\frac{\sum_{i=1}^{n} x_{i}}{n}
$$

where $\mu$ is the mean of the sampling units, $n$ is the number of sampling units, and $x_{i}$ is the value of the sample at $i$. Variance $\left(\mathrm{s}^{2}\right)$ is a measure of the squared dispersion of sampling units and is expressed as:

$$
s^{2}=\sum_{i=1}^{n} \frac{\left(x_{i}-\mu\right)^{2}}{n-1}
$$

The standard deviation is $(\mathrm{s})$ is the square root of the variance. 
A parameter used as a relative measure of variability is the coefficient of variation (COV). Since COV is dimensionless, it is useful for comparing the variability among different measurements. The $\mathrm{COV}$ is expressed as:

$$
\operatorname{COV}(\%)=\left(\frac{s}{\mu}\right) \times 100
$$

Compaction variability results from the different soil composition and variability in the compaction process. When attempting to estimate this variability using tests, the estimates get distorted and magnified by variability due to sampling and testing.

Liu and Thompson (1966) showed that the variability of laboratory test results in different laboratories was significantly larger than the variability for a single tester and for two testers in a single laboratory. They also indicated that a careful tester was able to reproduce the Atterberg limits according to the standard procedure with a standard deviation of less than 1.0 and a coefficient of variation (COV) of less than 10 percent.

With respect to the variability of relative compaction on site, the mean values of $\mathrm{RC}$ presented in several references were roughly two to three percent greater than the specification requirements. Also, even the cases with two to three percent higher mean values than the required $\mathrm{RC}$, about $10 \%$ up to $38 \%$ of the sample units did not achieve the required $\mathrm{RC}$.

The relative compaction data available in the literature is normally distributed. Note that considerable scatter of RC values can exist, particularly in sandy soils (the data for sandy soils are more scattered than those of silty-clay soils). Thus, the COVs of the 
$\mathrm{RC}$ values primarily depend on the type of soil. However, no strong correlation between the COVs and the required $\mathrm{RC}$ was observed in the literature available.

When utilizing in situ tests for a compaction QC, the criteria using the tests need to account for compaction variability. In this regard, a statistical approach can be adopted. First, a minimum value of the test measurement that encompasses at least a certain percentage of occurrences in the frequency diagrams of test results associated with the required $\mathrm{RC}$ is first selected. In the second step, the minimum required value of the test measurement is tested for test results less than the minimum required value. The test here is that the most of test measurements corresponding to less than the required $\mathrm{RC}$ must be less than the selected value. In the case of the DCPT, the blow count satisfying both requirements will be referred to as the minimum required blow count. It provides reasonable assurance that, if the measured blow count matches or exceeds it, the desired relative compaction will have been achieved. 


\section{CHAPTER 5. ASSESSMENT OF DYNAMIC ANALYSIS}

\subsection{Introduction}

When a dynamic in situ test such as dynamic cone penetrometer and Clegg Hammer are performed on a site, the measurements made during the test reflect dynamic interaction of the apparatus with the soil. If a load is applied very slowly on soil through in situ device, no rate effects occur and the total resistance is equal to the static resistance. Rate effects appear when the load is quickly applied to the soil. Dynamic resistance then mobilizes. Thus, the total resistance $R$ mobilized at the interface of the device with the soil consists of a static component $R_{s}$ and a dynamic component $R_{d}$ (Salgado 2008):

$$
\mathrm{R}=\mathrm{R}_{\mathrm{s}}+\mathrm{R}_{\mathrm{d}}
$$

The chapter starts by examining the static resistance. It then discusses dynamic resistance. Methods for interpreting the results of two in situ dynamic tests, the Dynamic Cone Penetration Test (DCPT) and the Clegg Hammer Test (CHT), are then presented, including the dynamic models selected to analyze. 


\subsection{Soil Response under Static Loading}

\subsubsection{Background}

The static soil response of in situ tests is represented by its bearing capacity. When we determine the bearing capacity for the footing design, e.g., piling engineering, the most widely used criterion is the ultimate bearing capacity at which the footing settlement is about $10 \%$ of the pile diameter, denoted as $\mathrm{q}_{\mathrm{b}, 10 \%}$ (Salgado 2008). However, the bearing capacity considered here, for the dynamic analysis, is the limit-state bearing capacity, denoted as $\mathrm{q}_{\mathrm{bL}}$. The limit-state bearing capacity is the bearing capacity that is fully mobilized resistance of the soil against the external forces when the soil below and nearby the footing experiences overall failure. Since its limit bearing capacity is strongly correlated with the shear strength of the soil, it is important to obtain the accurate shear strength of the soil to precisely estimate the limit bearing capacity. With respect to the shear strength of soil, the shear strength of sands is different from that of clays due to the differences in their nature.

In addition, depending on the type of in situ tests, the bearing capacity is differently addressed. In case of the Clegg Hammer test, since the load is transferred to the soil surface, the bearing capacity of the Clegg Hammer is estimated using the bearing capacity equations for shallow foundations. In case of the dynamic cone penetrometer, the bearing capacity equations for deep foundations can be used for estimating the bearing capacity of the dynamic cone penetrometer. 


\subsubsection{Shear Strength of Sands}

Several factors determine the shear strength of sands: soil state variables (relative density and confinement) the nature and characteristics of the soil particles, and environmental factors (Salgado 2008). Once the intrinsic soil variables are determined according to the nature of the sand, the shear strength of sands is the function of soil state variables. In order to account for the soil state variables, Bolton (1986) proposed an empirical equation that can account for the dilatancy of sands:

$$
\phi_{\mathrm{p}}=\phi_{\mathrm{c}}+\mathrm{A}_{\psi} \mathrm{I}_{\mathrm{R}}
$$

where $\phi_{p}=$ peak friction angle, $\phi_{c}=$ critical-state friction angle, $A_{\psi}=3$ for triaxial conditions and to 5 for plane-strain conditions, and $I_{R}$ is the relative dilatancy index. $I_{R}$ is defined in terms of the relative density and the mean effective stress level and is expressed as:

$$
I_{R}=I_{D}\left[Q-\ln \left(\frac{100 \sigma_{m p}^{\prime}}{p_{A}}\right)\right]-R_{Q}
$$

where $I_{D}=D_{R} / 100\left(D_{R}=\right.$ relative density, $\left.\%\right), Q$ and $R_{Q}=$ fitting parameters that depend on the intrinsic characteristics of the sand, $p_{A}=$ reference stress $(=100 \mathrm{kPa}=0.1 \mathrm{MPa} \approx$ 1 tsf $\approx 2000 \mathrm{psf}$ ), and $\sigma_{m p}^{\prime}=$ mean effective stress at peak shear strength. 
Bolton (1986) found $Q=10$ and $R_{Q}=1$ to correlate reasonably well with the results of a large number of laboratory tests performed on many different clean silica sands. Bolton's empirical correlation adequately represents the shear strength of sands accounting for dilatancy, which depends on the sand relative density and confinement.

Chakraborty and Salgado (2008) correlated the critical state $\phi$, the peak friction angle, relative density, and confining stress for stresses ranging from very low (singledigit) values to $197 \mathrm{kPa}$. They found that $Q$ varies from 6.9 to 9.6 and $R_{Q}$ varies from 0.03 to 0.73 depending on the confinement level.

\subsubsection{Shear Strength of Clays}

In clays, the rate of loading is typically much faster than the rate of dissipation of pore water pressure induced by loading, especially compared with sands. Randolph and Murphy (1985) proposed a correlation between the ratio of the undrained shear strength $\left(s_{u}\right)$ to the effective stress $\left(\sigma_{v}^{\prime}\right)$ and the critical-state friction angle $\phi_{\mathrm{c}}$ of the clay based on the research by Wroth (1984):

$$
\frac{\mathrm{s}_{\mathrm{u}}}{\sigma_{\mathrm{v}}^{\prime}}=\frac{\phi_{\mathrm{c}}}{100}
$$

where $s_{u}=$ undrained shear strength of the clay and $\phi_{c}=$ critical-state friction angle.

Alternatively, the undrained shear strength of clay can be estimated from the cone resistance $q_{c}($ Salgado 2008): 


$$
\mathrm{s}_{\mathrm{u}}=\frac{\mathrm{q}_{\mathrm{c}}-\sigma_{\mathrm{v}}}{\mathrm{N}_{\mathrm{k}}}
$$

where $q_{c}=$ cone resistance, $\sigma_{v}=$ total vertical stress, and $N_{k}=$ the cone factor. Eq 5.5 is essentially the bearing capacity equation with the surcharge, $q_{0}$, equal to the total stress at a desired depth. Salgado (2008) suggested that $N_{k}$ should be of the order of ten based on the $N_{k}$ values reported in the literature.

\subsubsection{Limit Bearing Capacity of Shallow Footings}

In order to estimate the bearing capacity of shallow foundations, we commonly use the bearing capacity equation, which independently accounts for the effect of soil cohesion, surcharge, and soil unit weight (Loukidis and Salgado 2009). In sands, for a shallow foundation embedded in a sand deposit acted upon by a vertical load, the bearing capacity equation can be expressed in terms of the surcharge and the unit weight of soil (Lyamin et al. 2007). In case of shallow foundations on the surface of sands, no surcharge exist and hence, the bearing capacity equation can be reduced to

$$
\mathrm{q}_{\mathrm{bL}}=\frac{\mathrm{Q}_{\mathrm{bL}}}{\mathrm{A}_{\text {footing }}}=0.5\left(\mathrm{~s}_{\gamma}\right) \gamma \mathrm{BN}_{\gamma}
$$

where $q_{b L}=$ limit bearing capacity, $Q_{b L}=$ limit load, $A_{\text {footing }}=$ area of the footing, $s_{\gamma}=$ shape factor, $N_{\gamma}=$ bearing capacity factor accounting for the contribution of the self- 
weight of soil on the footing bearing capacity, $\gamma=$ unit weight representative of the soil below the base of the footing, $B=$ footing width.

In order to find $q_{b L}$ of a footing, we need to find the bearing capacity factor, $N_{\gamma}$ and the shape factor, $s_{\gamma}$. Since these factors are functions of the mobilized friction angle under the footing, we first must know the confinement below the footing, which controls the mobilized friction angle. Below the footing, there is an infinite number of possible slip planes located at different depths. Each of these planes is subjected to a different confinement level and, hence, different friction angles could be calculated for each of them. The mobilized friction angle is lower near the footing, where the mean effective stress is larger, and higher, at a point away from the footing, where the mean effective stress is smaller. Also, as the applied load on the footing increases, the mobilized friction angles are developed due to the increase in confinement below the footing until the footing reaches a limit state.

Based on numerical analysis, Loukidis and Salgado (2006) proposed an equation to calculate a "representative" mean effective stress along the slip surface under circular footings for estimating the mobilized friction angle in bearing capacity calculations as follows:

$$
\sigma_{\mathrm{mp}}^{\prime}=13.6 \mathrm{p}_{\mathrm{A}}\left(\frac{\gamma \mathrm{B}}{\mathrm{p}_{\mathrm{A}}}\right)^{0.7}
$$


where $\sigma_{m p}^{\prime}=$ mean effective stress at peak shear strength and $p_{A}=$ reference stress $(=$ $100 \mathrm{kPa}=0.1 \mathrm{MPa} \approx 1 \mathrm{tsf} \approx 2000 \mathrm{psf})$

Once we compute the representative mean effective stress mobilized below the footing on the verge of bearing capacity failure, Eq. 5.2 and Eq. 5.3, suggested by Bolton (1986), can be used to calculate the mobilized friction angle below the footing.

We can then compute the bearing capacity factor $N_{\gamma}$. Recently, Martin (2005) arrived at exact solutions for $\phi$ up to $60^{\circ}$. The following equation fits very closely the $N_{\gamma}$ values suggested by Martin (Salgado 2008):

$$
\mathrm{N}_{\gamma}=\left(\mathrm{N}_{\mathrm{q}}-1\right) \tan (1.32 \phi)
$$

where $\mathrm{N}_{\mathrm{q}}=\frac{1+\sin \phi}{1-\sin \phi} \mathrm{e}^{\pi \tan \phi}$, and $\phi=$ mobilized friction angle. With respect to the shape factor for $N_{\gamma}$, Lyamin et al. (2007) proposed the following equation for a square footing: .

$$
s_{\gamma}=1+0.0336 \phi
$$

Lyamin et al. (2007) suggested that, in the case of circular footings, the shape factor of Eq. 5.9 should be multiplied by $1+0.002 \phi$.

To summarize, we can compute the bearing capacity of shallow footings as follows: 
1. Compute $\sigma_{m p}^{\prime}$ using Eq. 5.7

2. Compute the mobilized friction angle $\phi$ below the footing using Eq. 5.2 and Eq. 5.3 .

3. Compute $N_{\gamma}$ and $s_{\gamma}$ using Eq. 5.8 and Eq. 5.9, respectively.

4. Compute the limit bearing capacity $\left(\mathrm{q}_{\mathrm{bL}}\right)$ using Eq. 5.6.

The limit bearing capacity of shallow foundations on the surface of clays can be calculated as follows:

$$
\mathrm{q}_{\mathrm{bL}}=\mathrm{N}_{\mathrm{c}} \mathrm{s}_{\mathrm{u}}
$$

where $q_{b L}=$ limit bearing capacity, $N_{c}=$ bearing capacity factor accounting for the cohesion intercept. Salgado (2008) indicated that $N_{c}$ is approximately equal to 5.14 based on the slipline method.

\subsubsection{Limit Base Capacity of Deep Footings}

When a penetrating object is introduced vertically into the ground, it creates and expands a cylindrical cavity into the soil (see Figure 5.1). Thus, a relationship exists between the soil penetration resistance and the pressure required to expand a cylindrical cavity in the soil from zero initial radius. 
In sands, Salgado and Prezzi (2007) found that the base resistance increases nonlinearly, at decreasing rates, with increasing vertical effective stress. This is quantified by the following equation (Salgado and Prezzi 2007):

$$
\frac{\mathrm{q}_{\mathrm{bL}}}{\mathrm{p}_{\mathrm{A}}}=1.64 \exp \left[0.1041 \phi_{\mathrm{c}}+\left(0.0264-0.0002 \phi_{\mathrm{c}}\right) \mathrm{D}_{\mathrm{R}}\right]\left(\frac{\sigma_{\mathrm{h}}^{\prime}}{\mathrm{p}_{\mathrm{A}}}\right)^{0.841-0.0047 \mathrm{D}_{\mathrm{R}}} \text { Eq. } 5.11
$$

where $q_{b L}=$ limit base resistance, $\phi_{c}$ is the critical-state friction angle, $D_{R}=$ relative density $(\%), p_{A}=$ reference stress $(=100 \mathrm{kPa}=0.1 \mathrm{MPa} \approx 1$ tsf $\approx 2000 \mathrm{psf})$, and $\sigma_{h}{ }_{h}$ is the horizontal effective stress at the desired depth before penetration. 


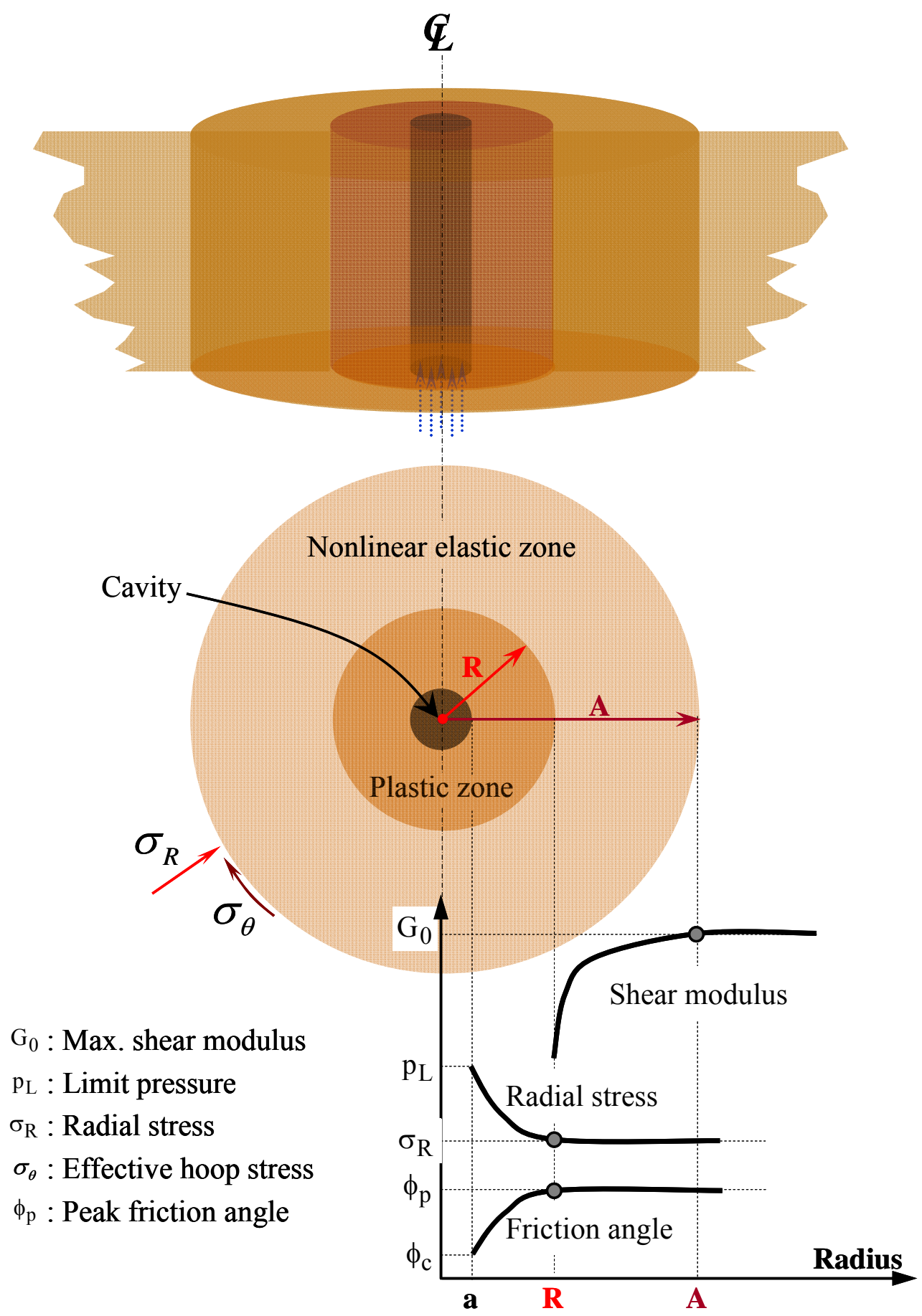

Figure 5.1 Expansion of a cavity from zero initial radius (modified after Salgado and Prezzi 2007). 
Salgado (2008) also indicated that the analysis and experimental data show that the limit base resistance $q_{b L}$ of a driven pile is approximately equal to the cone penetration resistance $q_{c}$ in sands.

With respect to deep foundations in clays, the limit base resistance is controlled by the undrained shear strength, which is similar to the limit base resistance of shallow foundations in clays. Thus, the bearing capacity equation can be expressed as (Salgado 2008):

$$
\mathrm{q}_{\mathrm{bL}}=5.14\left(\mathrm{~s}_{\mathrm{su}} \mathrm{d}_{\mathrm{su}}\right) \mathrm{s}_{\mathrm{u}}+\mathrm{q}_{0}
$$

where $s_{s u}=$ shape factor, $d_{s u}=$ depth factor, and $q_{0}=$ a surcharge. If the maximum values of traditional shape and depth factors $s_{s u}=1.2$ and $d_{s u}=1.5$, proposed by Meyerhof (1951), are used in Eq. 5.12, we get:

$$
\mathrm{q}_{\mathrm{bL}}=9.25 \mathrm{~s}_{\mathrm{u}}
$$

It is common practice in piling engineering to round down 9.25 in Eq. 5.13 down 9.0 (Salgado 2008). Salgado et al. (2004) showed that $q_{b L} / s_{u}$ ranges from 11.0 (lower bound) to 14.0. Salgado (2008) indicated that based on research to date, the range of $q_{b L} / s_{u}$ lies approximately between 9 and 14. 


\subsection{Soil Response under Dynamic Loading}

\subsubsection{Background}

Since dynamic pile driving began drawing the attention of engineers, several classical formulae based on energy concepts have interested engineers. One example is the Dutch formula that is expressed as (Sanglerat 1972):

$$
\mathrm{R}_{\mathrm{u}}=\frac{\left(\mathrm{M}_{\mathrm{h}}\right)^{2} \mathrm{H}}{\operatorname{PR}\left[\mathrm{A}\left(\mathrm{M}_{\mathrm{h}}+\mathrm{M}_{\mathrm{p}}\right)\right]}
$$

where $R_{u}=$ pile unit resistance in decanewton per $\mathrm{cm}^{2}\left(\mathrm{daN} / \mathrm{cm}^{2}\right)$ or bar, $P R=$ penetration per blow in $\mathrm{cm}, M_{h}=$ mass of the hammer in $\mathrm{kg}, H=$ height of fall of the hammer in $\mathrm{cm}$, $M_{P}=$ mass of the pile in $\mathrm{kg}$, and $A=$ cross-sectional area of the pile in $\mathrm{cm}^{2}$.

Since this energy concept assumes that the driving energy is completely absorbed by the pile, it does not account for the dynamic response of soil, and therefore, the concept cannot capture the dynamic response of soil.

Certainly, a better approach is to model the soil by a set of springs and dashpots. A spring constant may be used to represent static resistance, while the effects of loading rate on resistance are modeled through a damping constant. In this framework, damping reflects a gradual decrease of vibration with time.

For the most part, in soil dynamics, damping is classified into two types: radiation and material damping (see Figure 5.2). Radiation damping is associated with the 
attenuation of the waves due to the propagation of vibration over a larger space from a small spot. Hence, sometimes it is also called "geometrical damping." Material damping refers to the absorption of energy due to hysteretic behavior of material during oscillation. For example, viscous damping is one of the material damping that involves a decrease in the amplitude of the wave because of viscosity. Another example is the conversion of the energy of a traveling wave into heat (Kramer 1996). The damping described here results in the loss of the energy during wave propagation.

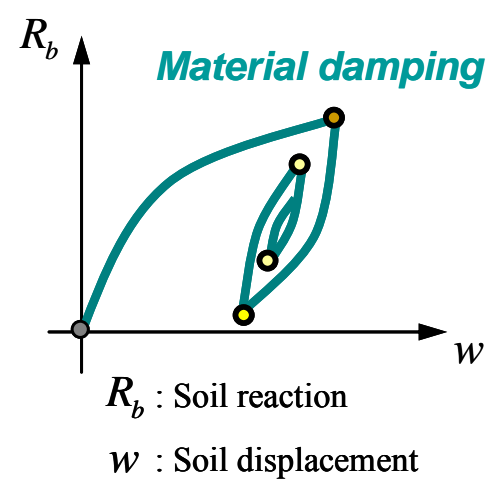

\section{Radiation damping}

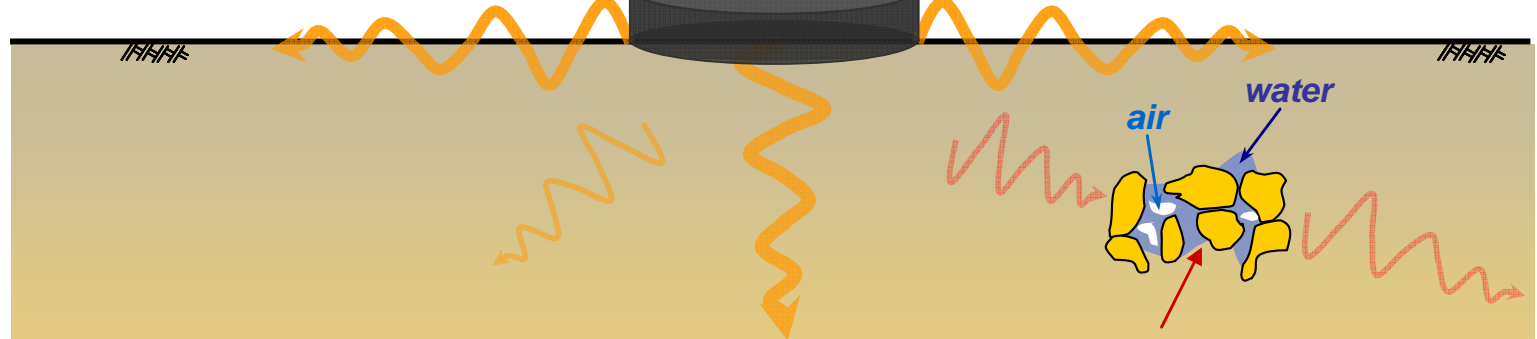

Viscous damping

Figure 5.2 Sources of damping on soil.

If the strains are large, material damping can be substantial and, if they are small, it may be negligible. Radiation damping represents a purely geometric effect, which 
exists at small and large strain amplitudes. For typical footings, radiation damping is often larger than material damping (Trifunac et al. 2001).

\subsubsection{Vertical Oscillation of Footings}

We saw in the previous section that the total resistance acting at the soil surface due to the dynamic load is composed of a static component and a dynamic component. Thus, the dynamic in situ test results from dynamic cone penetration test or Clegg Hammer Test reflect the dynamic response of soil. From the viewpoint of soil, the mechanism of soil reaction mobilization caused by the vertical oscillation of a rigid footing on soil and the vertical oscillation of the soil due to dropping objects is fundamentally identical (see Figure 5.3). Accordingly, the development of the solution for the dynamic behavior of foundations on soil therefore can be adopted in interpreting the results of dynamic in situ tests. 


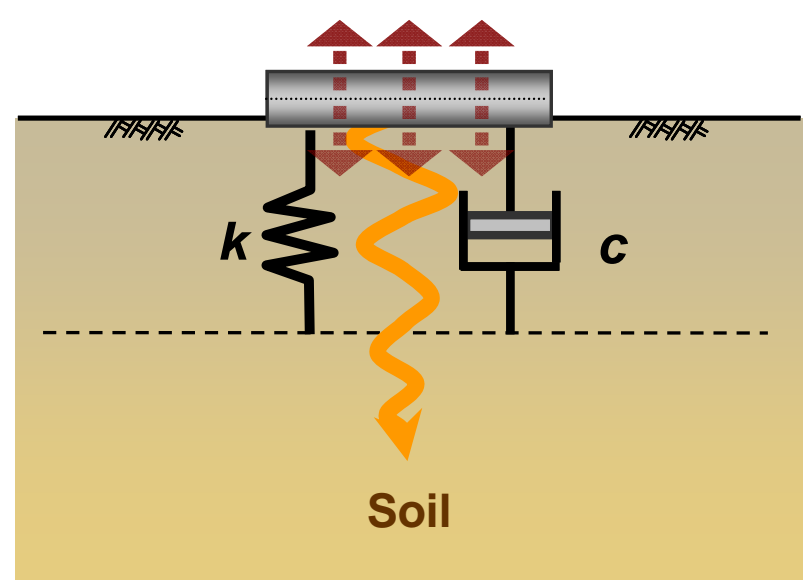

(a)

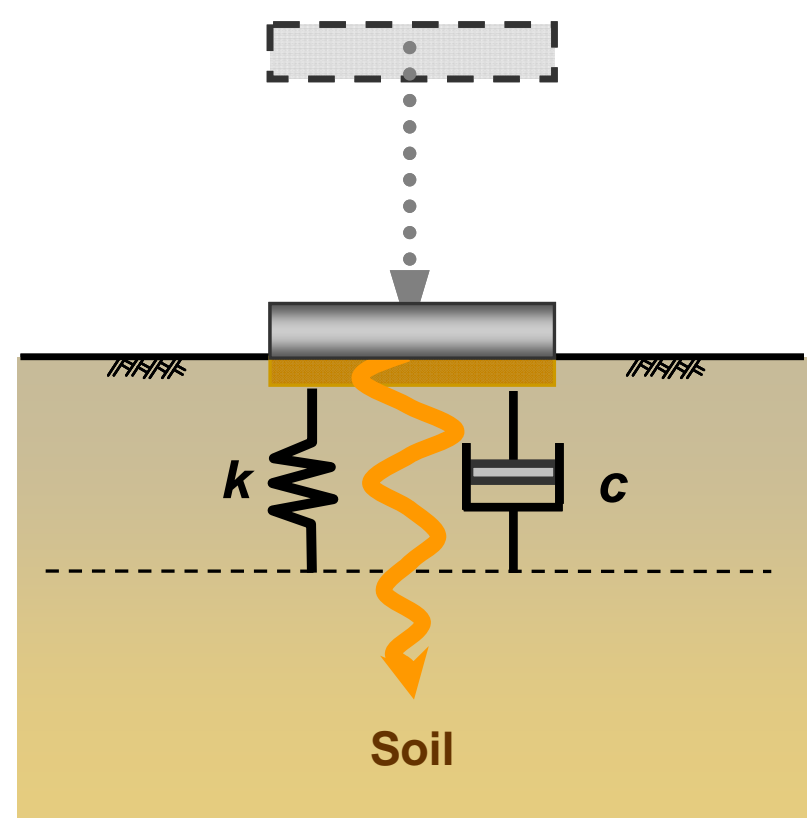

(b)

Figure 5.3 Mechanism of soil reaction mobilization: (a) vertical oscillation of a rigid shallow footing on soil and (b) the vertical oscillation of the soil due to a dropping object. 
With respect to the linear spring-damping model for the dynamic analysis, the original analytical solutions were based on assumptions of uniformly distributed vertical stress distributions beneath the footing found by Reissner (Anam and Roesset 2004). Reissner (1936) mathematically derived an analytical solution for the vertical oscillations of footings resting on a semi-infinite half-space. Reissner (1936) assumed the soil beneath foundation soil to be perfectly elastic, isotropic, and homogeneous. Although Reissner's theory was not immediately applied in the field of soil dynamics, it became the basis of analytical studies of oscillators resting on half-space (Richart et al. 1970).

Based on Reissner's solution, Lysmer (1965) developed a solution of the ground response under a circular rigid footing using the combination of a linear spring and a damping constant [see Figure 5.4 (a)]. Lysmer (1965) adopted the spring constant ( $\left.\mathrm{k}_{\mathrm{b}, \mathrm{Lys}}\right)$ that is equal to the static elastic solution, that is expressed as:

$$
\mathrm{k}_{\mathrm{b}, \text { Lys }}=\frac{4 \mathrm{Gr}}{1-\mathrm{v}}
$$

where $r$ is the radius of circular rigid footing, $G$ is the shear modulus of soil, and $v$ is the Poisson's ratio of the soil. As shown in Figure 5.4 (b), the spring constant proposed by Lysmer (1965) is linked to the static resistance of soil.

In Lysmer's analogue, the dynamic resistance of soil is taken into account by the damping coefficient that is expressed as: 


$$
C_{\text {Lys }}=\frac{3.4 r^{2} \sqrt{\left(\gamma_{m} g\right) G}}{1-v}
$$

where $\gamma_{m}$ is the wet unit weight of soil, and $g$ is the acceleration due to the earth's gravity. As shown in Figure 5.4 (b), the damping constant proposed by Lysmer (1965) is linked to the velocity of soil, which accounts for the time-dependent behavior of soil. 
$r$ : Radius of the footing

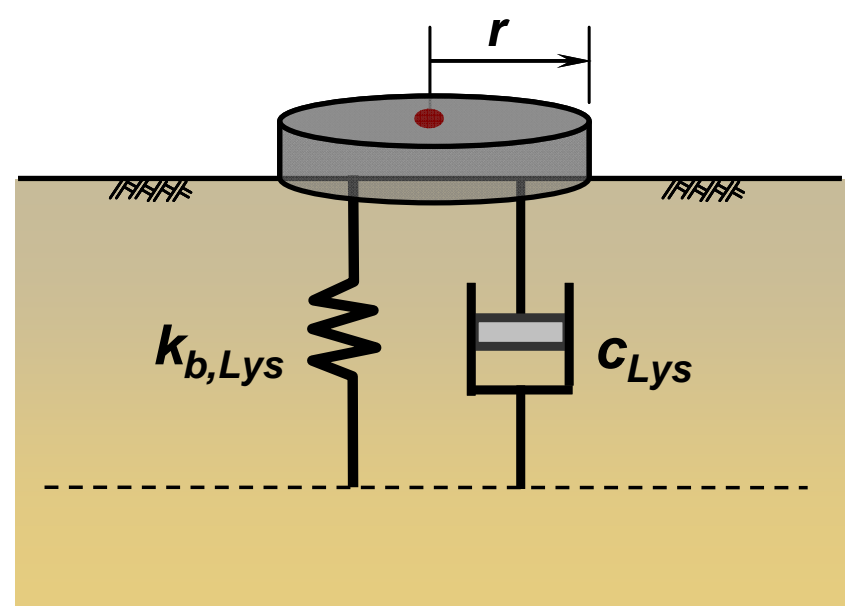

(a)
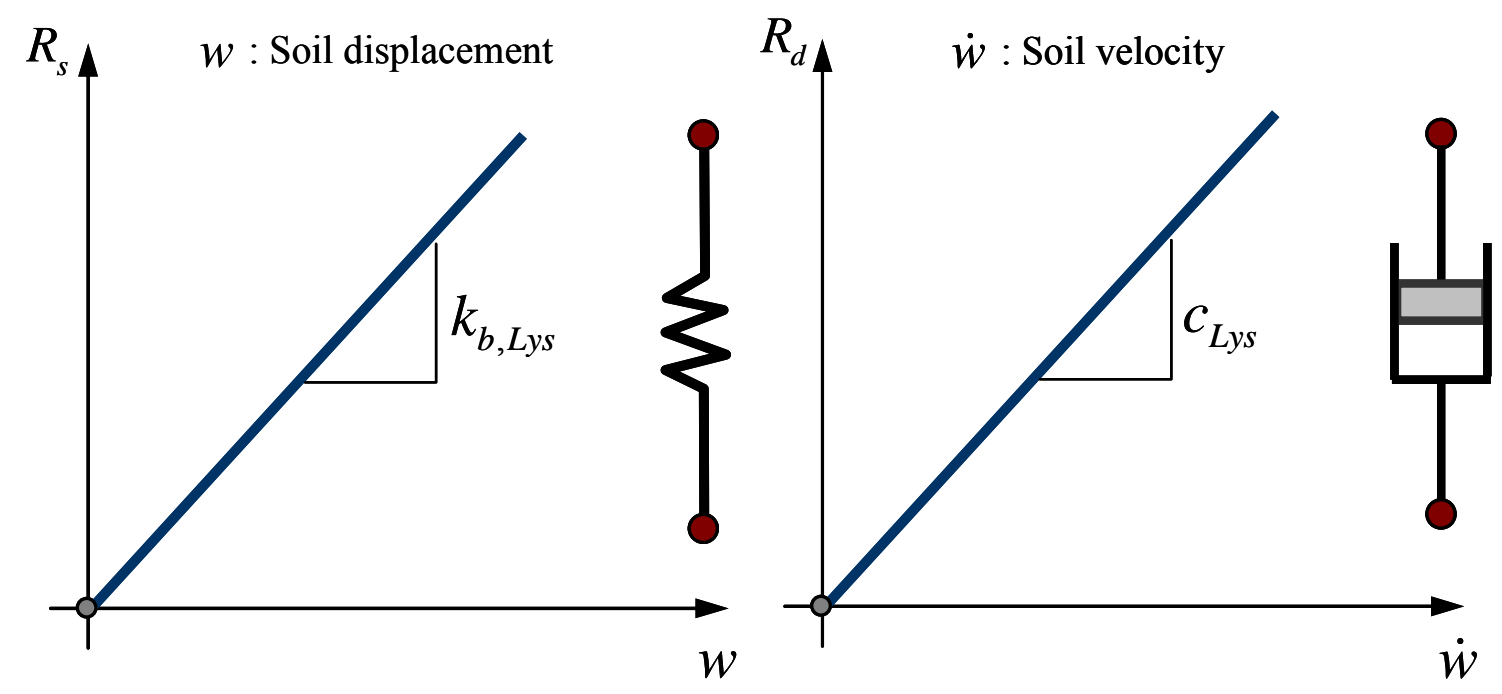

(b)

Figure 5.4 Lysmer's reaction model: (a) schematic of the model; and (b) spring and dashpot and plots of $R_{s}(t)-w$ and $R_{d}(t)$ - w relationship. 
The main contribution of Lysmer's study was that he established a bridge between the elastic half-space theory and the mass-spring-dashpot system and provided values for the spring and damping constants (Richart et al. 1970). According to the extensive review of dynamic soil-structure interaction by Kausel (2010), a lot of researches have been performed based on Lysmer's analogue in the context of footing vibrations.

Davies and Karim (1995) performed dynamic analysis based on Lysmer's analogue to interpret the results of Clegg hammer test. Davies and Karim (1995) conducted the analysis using an elastodynamic solution. From the analysis, they were able to obtain the ground response to impact by a mass using the free-vibration condition described by the equation of motion. Since the analytical results demonstrated very high impact stresses, Davies and Karim (1995) concluded that the analysis was not directly applicable to the interpretation of the CHT. However, this lack of compatibility of the analysis with the CHT is also due to the fact that the analysis did not account for soil nonlinearity.

Again, the linear-elastic spring constant illustrated in Figure 5.4 (a) is not able to accurately simulate response of a footing on soil, as the static component should be bounded by a limit bearing capacity, as discussed in previous sections.

Smith (1960) introduced a dynamic model to perform pile driving analysis. Smith (1960) employed the linear-elastic, perfectly-plastic soil model to analyze the dynamic response of soil. In the Smith (1960) model, the soil reaction is described through a linear-elastic perfectly-plastic spring constant with the dashpot coefficient. Also, the pile is divided into finite elements connected to springs (see Figure 5.5). 


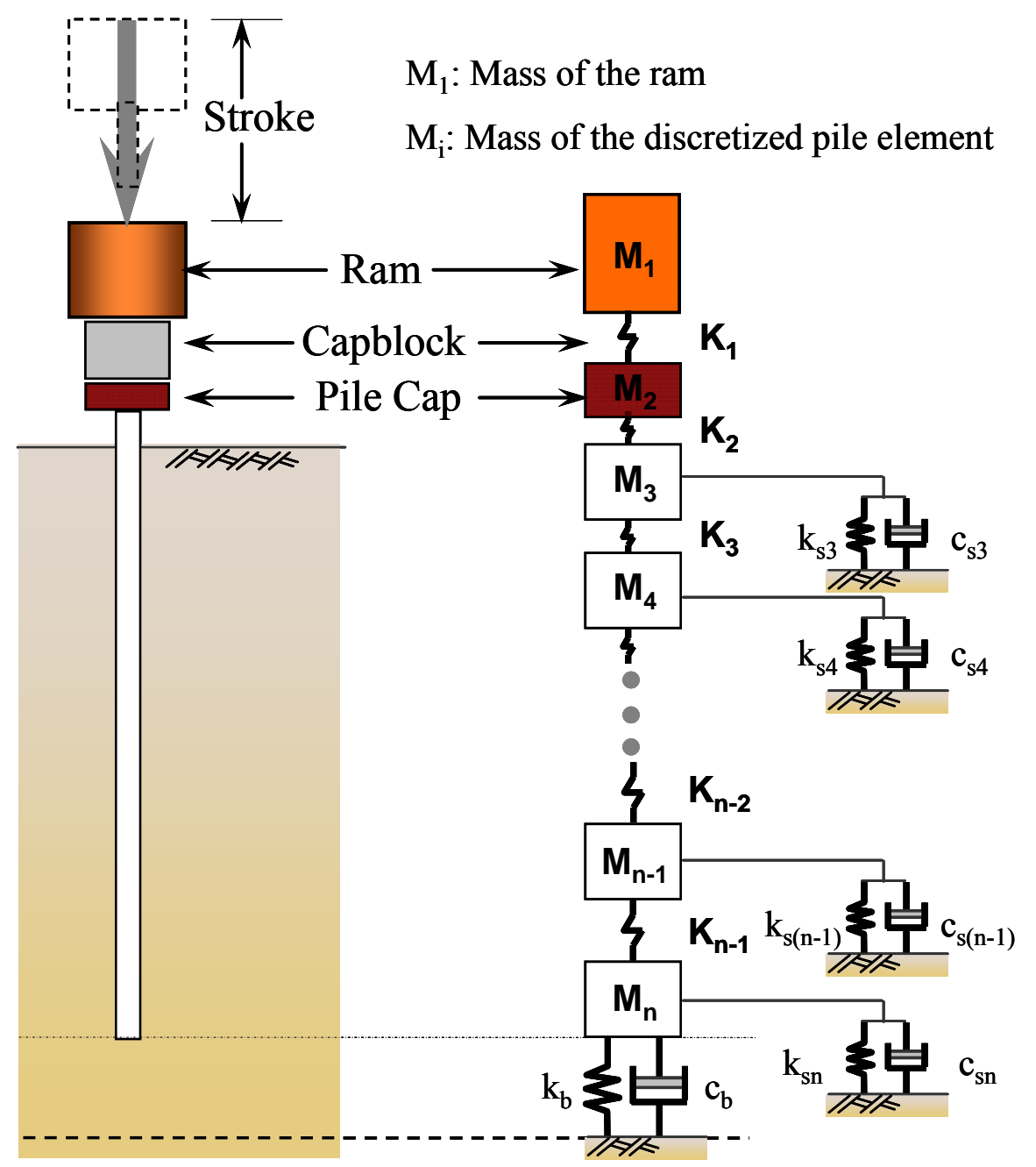

$\mathrm{K}_{1}$ : Spring constant of the capblock

$\mathrm{K}_{\mathrm{i}}$ : Spring constant of the pile

$\mathrm{k}_{\mathrm{si}}$ : Spring constant of the soil at shaft $\mathrm{c}_{\mathrm{si}}$ : dashpot constant of soil at shaft

$\mathrm{k}_{\mathrm{b}}$ : Spring constant of the soil at base $\mathrm{c}_{\mathrm{si}}$ : dashpot constant of soil at base

Figure 5.5 Pile-hammer-soil system of Smith model (modified after Smith 1960).

With regard to the vertical oscillation of footings in deep soil (such as a pile base), the dynamic response during pile driving events is often approached through the model used for the oscillation of shallow footings on a semi-infinite half-space. 
After the Smith (1960) model, some advanced models for pile driving analysis also employed Lysmer's framework to interpret the dynamic response of the pile base. For example, in order to account for the elasto-plastic state of soil, Deeks and Randolph (1995) incorporated a plastic slider along with sets of rheological model configurations based on finite element results. However, Deeks and Randolph (1995) reported that the results of analyses using Lysmer's analogue were in good agreement with the dynamic model presented by Deeks and Randolph (1995) when the Poisson's ratio was less than $1 / 3$.

\subsection{Suggested Model for the Interpretation of in situ Tests}

\subsubsection{Selection of the Dynamic Model for the Clegg Hammer Test}

Dynamic loading leads to nonlinear hysteretic response of the soil that reflects modulus degradation and gradual increase of energy loss (Vucetic and Dobry 1991, Loizos and Boukovalas 2005). Physically, when the impact mass is dropped onto the ground surface, the impacted portion of soil first stores the energy with elastic deformation and then absorbs the energy through hysteretic dissipation. When the soil resistance is mobilized due to the impact, soil resistance cannot increase infinitely with an increase in displacement. Rather, the resistance should be bound to a limit bearing capacity. Yet in Lysmer's analogue, the soil resistance against dynamic loading continuously increases as the loading increases, regardless of the limit state. 
During the Clegg Hammer Test, the data logger in the CHT captures the maximum deceleration in terms of the Clegg Impact Value CIV $\left(=98 \mathrm{~m} / \mathrm{s}^{2}\right)$. In order to correlate the CIV with soil properties, it is necessary to obtain the magnitude and characteristics of the dynamic loads involved in the CHT. Also, the nonlinear response of the soil under the Clegg hammer at the moment of impact needs to be modeled properly. In addition, damping must be accurately represented.

Recently, Loukidis et al. (2008) proposed a base reaction model for interpreting the dynamic response of soil. The proposed model accounts for soil nonlinearity and hysteresis, viscous damping, and radiation damping. The proposed model consists of a nonlinear spring connected in parallel to a radiation dashpot (see Figure 5.6). 


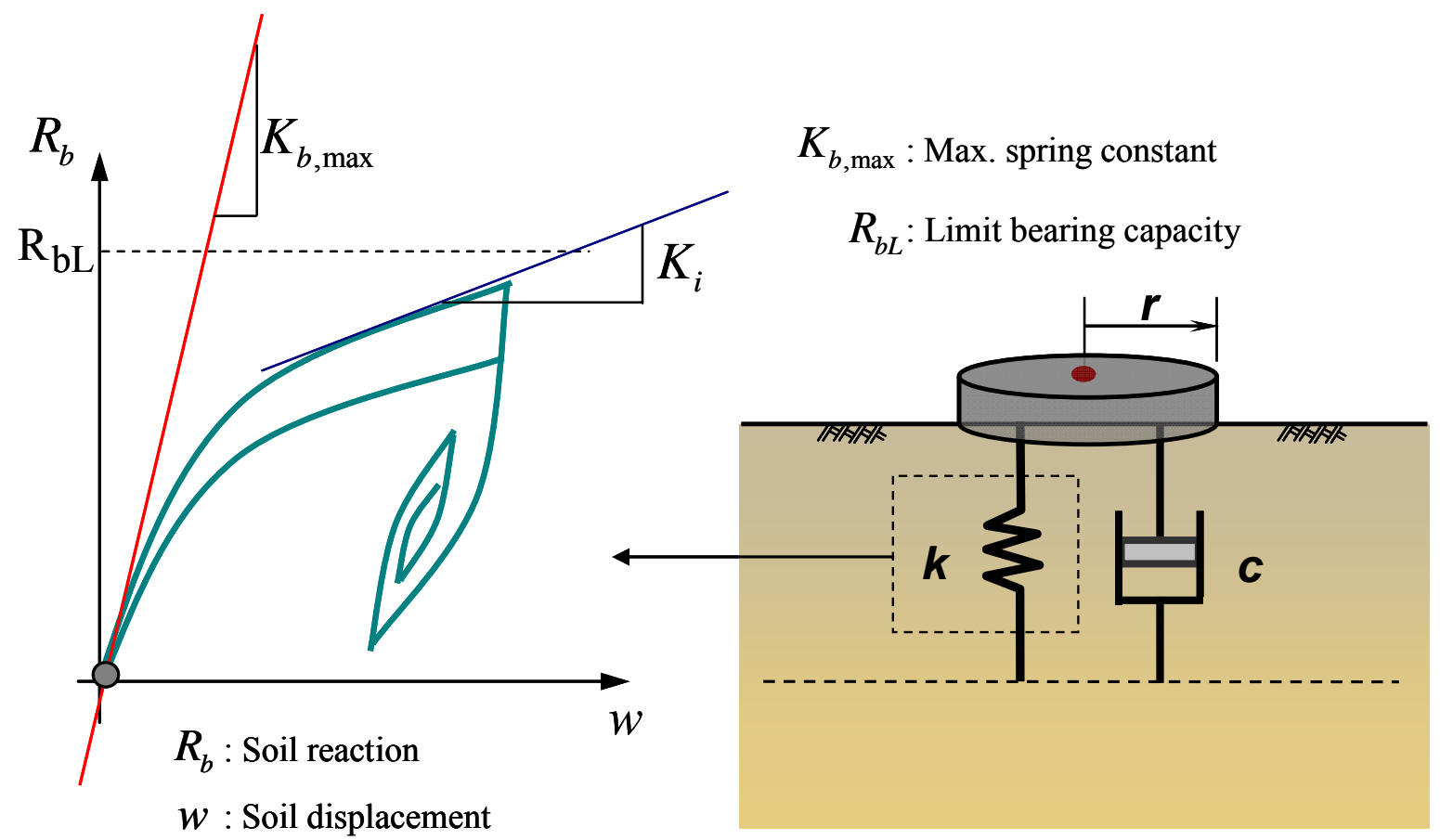

Figure 5.6 Selected base reaction model (modified after Loukidis et al. 2008).

The source of material damping is the nonlinear behavior of soil and its hysteresis, which is reflected in the nonlinear spring function, a mathematically advanced form of the extended Masing-type function introduced by Kramer (1996). According to the dynamic model presented by Loukidis et al. (2008), the spring constant of this function is a hyperbolic-type load displacement relationship that can be expressed as:

$$
\mathrm{K}=\frac{\mathrm{dR}_{\mathrm{b}}}{\mathrm{dw}}=\frac{\mathrm{K}_{\mathrm{b}, \max }}{\left(1+\mathrm{b}_{\mathrm{f}} \frac{\left|\mathrm{R}_{\mathrm{b}}-\mathrm{LOI} \times \mathrm{R}_{\mathrm{b}, \text { rev }}\right|}{(\mathrm{LOI}+1)\left|\operatorname{sgn} \cdot \mathrm{R}_{\mathrm{bf}}-\mathrm{R}_{\mathrm{b}}\right|}\right)^{2}}
$$


where $K_{b, \text { max }}$ is the maximum elastic spring constant, $R_{b}$ is the limit base capacity, $R_{b, r e v}$ is the spring reaction at the last displacement reversal, and LOI is the loading index parameter ( $L O I=0$ for a virgin loading, 1 for other cases). The signum function is denoted by sgn, which extracts the sign of a real number. $b_{f}$ is a model parameter that controls the rate of degradation of the base spring constants. For modeling the radiation dashpot, the Lysmer's dashpot is adopted.

The dynamic model selected, originally presented by Loukidis et al. (2008), accounts for the unloading-reloading response of soil due to dynamic loads. As shown in Figure 5.6, the base reaction due to dynamic loading reaches $R_{b f}$ asymptotically, with an increase in the dynamic displacement. Also, if a setback takes place during the analysis, $R_{b, r e v}$ is loaded at the point where the setback occurs. The path of the unloading-reloading curves takes the same shape as that of the backbone curve. The selected model captures hysteretic damping by using variables such as $L O I, R_{b, r e v}$ and the signum function (Loukidis et al. 2008).

The selected model also accounts for viscous damping. According to Loukidis et al. (2008), the dynamic limit bearing capacity $R_{b f}$ is set as a function of the base velocity and is expressed as:

$$
\mathrm{R}_{\mathrm{bf}}=\mathrm{Q}_{\mathrm{bL}}\left[1+\mathrm{m}\left(\dot{\mathrm{w}}_{\mathrm{b}}\right)^{\mathrm{n}}\right]
$$


where $Q_{b L}$ is the static limit load, and $m$ and $n$ are parameters controlling rate effects on soil strength. Eq. 5.18 implies that the limit bearing capacity during dynamic behavior is equal to the static limit load when the velocity of the footing is zero.

Using the rheological model combined the spring constant suggested by Loukidis et al. (2008) and the dashpot constant suggested by Lysmer (1965), the equation of motion can be applied to obtain the dynamic response of the Clegg hammer test.

The ground response to the impact of a mass M can be obtained using the solution of the free-vibration problem:

$$
\mathrm{M} \ddot{\mathrm{w}}+\mathrm{C} \dot{\mathrm{w}}+\mathrm{Kw}=0
$$

where $K$ is the spring constant in Eq. 5.17, $C$ is the damping constant in Eq. 5.16, and $\ddot{w}$, $\dot{w}$, and $w$ are acceleration, velocity, and displacement, respectively. This is the classic one-degree-of-freedom system governed by a linear differential equation.

The single degree of freedom (SDOF) transient response is fundamental to most types of vibratory behavior. Even within SDOF with free vibration condition, however, the solution of the equation of motion varies depending on how the spring constant and damping characteristics are predetermined. In the analysis, soil nonlinearity and hysteresis, radiation damping, and viscous damping are accounted for using Eq 5.16 to 5.18 .

The equation of motion, even for a single-degree-of-freedom system, cannot be solved explicitly if the ground acceleration varies with time or if the system involves 
nonlinear behavior (Chopra 2007). Thus, in order to solve the problem, a numerical timestepping method, namely, the finite difference method is adopted in the analysis.

First, the time step $(\Delta \mathrm{t})$ should be determined. Then, the equation of motion can be rewritten as:

$$
\mathrm{M} \ddot{\mathrm{w}}_{\mathrm{i}}+\mathrm{C}_{\mathrm{i}}+\mathrm{K}_{\mathrm{i}} \mathrm{w}_{\mathrm{i}}=0
$$

Also, the spring constant can also be rewritten as:

$$
\left(\mathrm{dR}_{\mathrm{b}}\right)_{\mathrm{i}}=\frac{\mathrm{K}_{\mathrm{b}, \max }}{\left(1+\mathrm{b}_{\mathrm{f}} \frac{\left|\left(\mathrm{R}_{\mathrm{b}}\right)_{\mathrm{i}-1}-\mathrm{LOI} \times\left(\mathrm{R}_{\mathrm{b}, \mathrm{rev}}\right)_{\mathrm{i}-1}\right|}{(\mathrm{LOI}+1)\left|\operatorname{sgn} \cdot \mathrm{R}_{\mathrm{bf}}-\left(\mathrm{R}_{\mathrm{b}}\right)_{\mathrm{i}-1}\right|}\right)^{2}}(\mathrm{dw})_{\mathrm{i}}
$$

Eq. 5.21

The equation of motion in eq. 5.20 is subjected to the boundary conditions $\dot{w}=$ initial impact velocity and $w=0$ when the time is equal to zero. Using the boundary condition, the equation of motion can be solved step-by-step using the following procedure:

1. Compute $\left(d R_{b}\right)_{i}$ using equation 5.20

2. Compute $\left(R_{b}\right)_{i}=\left(R_{b}\right)_{i-1}+\left(d R_{b}\right)_{i}$

3. Compute the acceleration $\ddot{\mathrm{w}}_{\mathrm{i}}=-\frac{\left[\mathrm{C} \dot{\mathrm{w}}_{\mathrm{i}}+\left(\mathrm{R}_{\mathrm{b}}\right)_{\mathrm{i}}\right]}{\mathrm{M}}$ 
4. Compute the velocity and displacement using the following equations:

$$
\begin{aligned}
\dot{\mathrm{w}}_{\mathrm{i}+1} & =\dot{\mathrm{w}}_{\mathrm{i}}+\ddot{\mathrm{w}}_{\mathrm{i}} \Delta \mathrm{t} \\
\mathrm{w}_{\mathrm{i}+1} & =\mathrm{w}_{\mathrm{i}}+\dot{\mathrm{w}}_{\mathrm{i}} \Delta \mathrm{t}
\end{aligned}
$$

In the analysis, the numerical procedure may become unstable if we input very small or large time increments.

\subsubsection{Selection of the Dynamic Model for the Dynamic Cone Penetration Test}

In the DCPT, the tester records the blow counts required for penetrating a certain depth (e.g., 0-to-6 inches or 0-to-12 inches). For proper dynamic analysis of the DCPT, it is essential to understand the sequence of the test. As shown in Figure 5.7 (a), when the hammer drops and hits the anvil, the cone tip of the DCP penetrates the soil. Since the diameter of the cone tip $(2.0 \mathrm{~cm})$ is larger than that of the DCP bar $(1.7 \mathrm{~cm})$, the side resistance of soil can be neglected. Even in sandy soils, it was observed that the hole made by the DCPT sustained itself in the field because of apparent cohesion.

In summary, we can model the DCPT with a series of steel elements along with soil reaction at the base only (see Figure 5.7). For the base model, the same framework used for the CHT was adopted. 


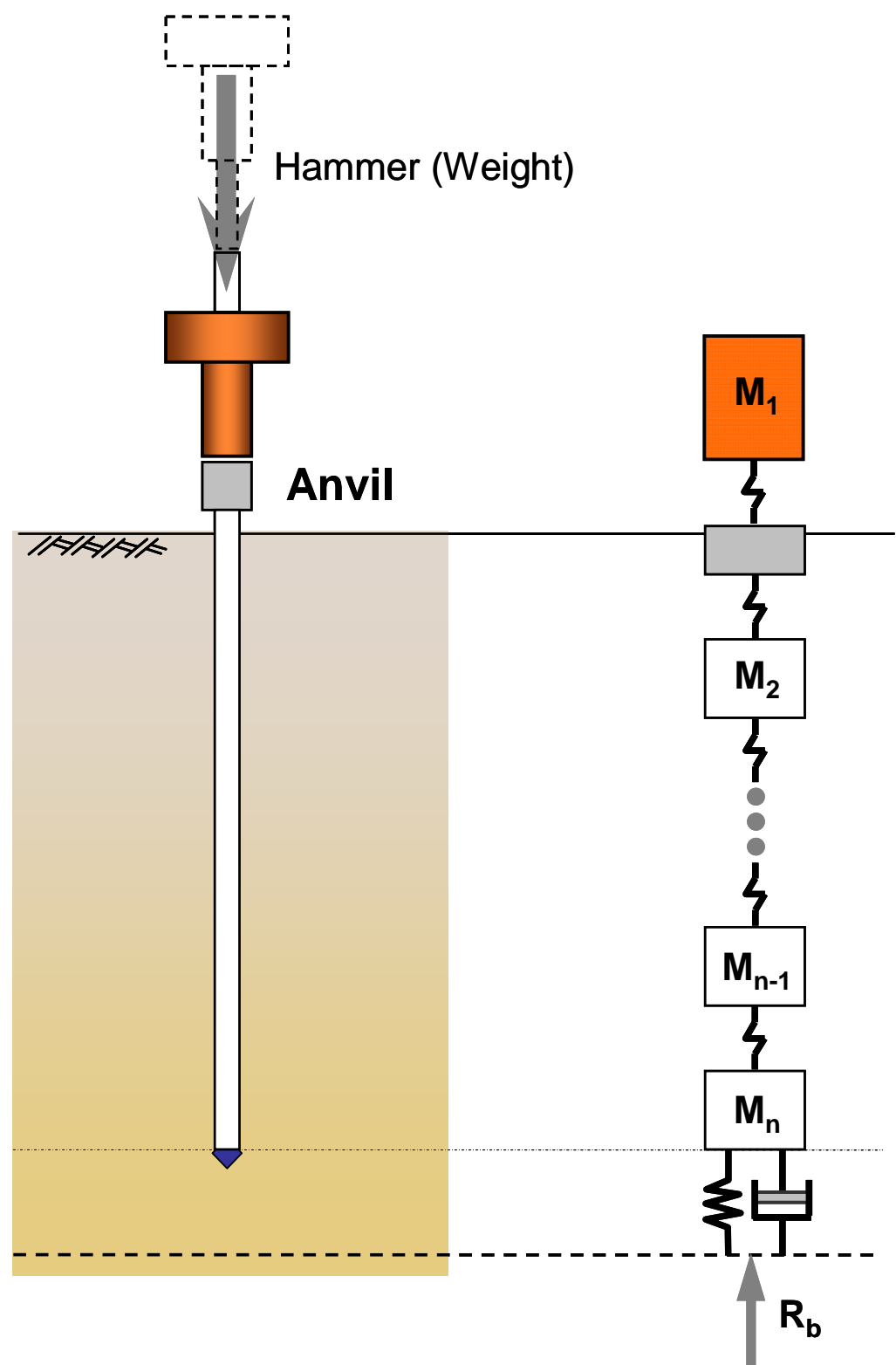

(a)

(b)

Figure 5.7 DCPT (a) DCP test sequence; (b) discretization of DCP into lumped masses with soil reaction at the base.

However, differences exist between the CHT and the DCPT. First, the CHT does not have the overburden pressure that the DCPT has. At shallow depths, a significant 
portion of the damping of soil takes place due to Rayleigh waves that the DCPT does not have as it penetrates deeper. In order to account for the depth effect on pile base during dynamic motion, Loukidis et al. (2008) proposed the equation based on the finite difference analysis using FLAC. Based on the FLAC simulations, Loukidis et al. (2008) suggested the static stiffness depth factor $D_{f}$ can be expressed as:

$$
\mathrm{D}_{\mathrm{f}}=(1.27-0.12 \ln v)-(0.27-0.12 \ln v) \exp \left[-0.83\left(\frac{\mathrm{D}}{\mathrm{B}}\right)^{0.826}\right]
$$

where $v$ is the Poisson's ratio, $B$ is the diameter of the DCPT, and $D$ is the depth where the tip is located. In case of dynamic depth factor, Loukidis et al. (2008) also found the following correlation:

$$
\mathrm{D}_{\mathrm{f}, \mathrm{dyn}}=\left(\mathrm{D}_{\mathrm{f}}\right)^{1.7}
$$

where $D_{f, d y n}$ is the dynamic depth factor. Then, the initial spring constant can be modified as:

$$
\mathrm{K}_{\mathrm{b}, \max }=\left(\mathrm{D}_{\mathrm{f}}\right)^{1.7} \mathrm{~K}_{\text {Lys }}
$$

With respect to the dashpot constant, the embedment factor is equal to 1.3 when $\mathrm{D} / \mathrm{B}$ is large. Physically, this means that the vertical source of vibration creates the 
oscillation of the soil not only downward, but also upward and laterally (Balthaus and Kielbassa 1986). Considering this effect, Loukidis et al. (2008) conducted the FLAC analysis and modified the damping constant that can be expressed as:

$$
\mathrm{C}_{\mathrm{b}}=\mathrm{C}_{\mathrm{emb}} \mathrm{C}_{\text {Lys }}=1.3 \mathrm{C}_{\text {Lys }}
$$

As part of interpreting the dynamic response of the DCPT for soils, the ground response to the impact of a mass $\mathrm{M}$ can be obtained using the following equation of motion:

$$
[\mathrm{M}]\left\{\ddot{\mathrm{w}}_{\mathrm{i}}\right\}+\left[\mathrm{C}_{\mathrm{b}}\right]\left\{\dot{\mathrm{w}}_{\mathrm{i}}\right\}+[\mathrm{K}]\left\{\mathrm{w}_{\mathrm{i}}\right\}+\mathrm{R}=0
$$

where $[K]$ is the matrix of the spring constant, $\left[C_{b}\right]$ is the matrix of the damping constant, and $\{\ddot{w}\},\{\dot{w}\}$, and $\{w\}$ are the matrixes of acceleration, velocity, and displacement, respectively. This system of equations of motion can be solved numerically using the finite difference technique. Using the time-stepping methods developed by Newmark (1959), the displacement, velocity, and acceleration of each segment of DCP at time $t+\Delta t$ can be computed using the following equations:

$$
\{\mathrm{w}\}_{(\mathrm{t}+\Delta \mathrm{t})}=\frac{1}{\left[\mathrm{~K}_{\text {eff }}\right]}\left(\begin{array}{l}
-\mathrm{R}_{\mathrm{t}}+[\mathrm{M}]\left\{\frac{1}{\beta \Delta \mathrm{t}^{2}}\{\mathrm{w}\}_{(\mathrm{t})}+\frac{1}{\beta \Delta \mathrm{t}}\{\dot{\mathrm{w}}\}_{(\mathrm{t})}+\left(\frac{1}{2 \beta}-1\right)\{\ddot{\mathrm{w}}\}_{(\mathrm{t})}\right\} \\
+[\mathrm{C}]\left\{\frac{\gamma}{\beta \Delta \mathrm{t}}\{\mathrm{w}\}_{(\mathrm{t})}+\left(\frac{\gamma}{\beta}-1\right)\{\dot{\mathrm{w}}\}_{(\mathrm{t})}+\Delta \mathrm{t}\left(\frac{\gamma}{2 \beta}-1\right)\{\ddot{\mathrm{w}}\}_{(\mathrm{t})}\right\}
\end{array}\right) \text { Eq. } 5.27
$$




$$
\begin{aligned}
& \{\dot{w}\}_{(\mathrm{t}+\Delta \mathrm{t})}=\frac{\gamma}{\beta \Delta \mathrm{t}}\left(\{w\}_{(t+\Delta \mathrm{t})}-\{w\}_{(t)}\right)-\left(\frac{\gamma}{\beta}-1\right)\{\dot{w}\}_{(t)}-\Delta \mathrm{t}\left(\frac{\gamma}{2 \beta}-1\right)\{\ddot{w}\}_{(t)} \quad \text { Eq. } 5.28 \\
& \{\ddot{w}\}_{(\mathrm{t}+\Delta \mathrm{t})}=\frac{1}{\beta \Delta \mathrm{t}^{2}}\left[\{w\}_{(t+\Delta \mathrm{t})}-\{w\}_{(t)}-\Delta \mathrm{t}\{\dot{w}\}_{(t)}\right]-\left(\frac{1}{2 \beta}-1\right)\{\ddot{w}\}_{(\mathrm{t})}
\end{aligned}
$$

where $\left[\mathrm{K}_{\mathrm{eff}}\right]$ is the modified stiffness matrix, given by

$$
\left[\mathrm{K}_{\mathrm{eff}}\right]=\frac{1}{\beta \Delta \mathrm{t}^{2}}[\mathrm{M}]+\frac{\gamma}{\beta \Delta \mathrm{t}}[\mathrm{C}]+[\mathrm{K}]
$$

When performing the analysis using the finite difference techniques, the selection of $\gamma$ and $\beta$ is crucial to the convergence of the solution. According to the Newmark (1959), typical selection for $\gamma$ is $1 / 2$ and $1 / 6 \leq \beta \leq 1 / 4$ is satisfactory from all points of view, including the accuracy of the analytical solution. 


\subsection{Summary}

An accurate method that evaluates the dynamic behavior of soil under dynamic loads is to model the soil by using a set of springs and dashpots. A spring constant is associated with the static resistance of soil and the damping of soil corresponds to the rate effect of soil against dynamic loads. In this framework, the damping reflects a gradual decrease of vibration with time.

When a load is applied gradually, as occurs in typical construction sequences, rate effects gradually increase as the time to apply the load decreases. Thus, the total resistance $R(t)$ acting at the surface of the soil consists of the static component $R_{S}(t)$ and the dynamic component $R_{d}(t)$ (Salgado 2008):

$$
R(t)=R_{s}(t)+R_{d}(t)
$$

With regard to the vertical oscillations of footings resting on soil, Lysmer (1965) postulated the ground with the combination of a spring and a damping constant. Lysmer's analogue represents the spring constant that is expressed as:

$$
\mathrm{k}_{\mathrm{b}, \mathrm{Lys}}=\frac{4 \mathrm{Gr}}{1-\mathrm{v}}
$$


where $r$ is the radius of the circular rigid footing, $G$ is the shear modulus of the soil, and $v$ is the Poisson's ratio of the soil (see Figure 5.3). Also, the damping coefficient is given as:

$$
\mathrm{C}_{\text {Lys }}=\frac{3.4 \mathrm{r}^{2} \sqrt{\left(\gamma_{\mathrm{m}} \mathrm{g}\right) \mathrm{G}}}{1-v}
$$

where $\gamma_{m}$ is the wet unit weight of the soil and $g$ is the acceleration due to the earth's gravity.

The nonlinear stress-strain behavior of soils makes the analysis complex. The impacted portion of the soil first stores the energy with elastic deformation and then absorbs the energy due to hysteretic dissipation. Even though the analysis can be improved by introducing soil nonlinearity, only a few attempts have been made (AbouJaoude 2006).

In order to correlate the CIV with the ground conditions, it is necessary to obtain the magnitude and characteristics of the dynamic loads involved in the CHT. Recently, Loukidis et al. (2008) proposed a base reaction model accounting for soil nonlinearity and hysteresis, viscous damping, and radiation damping. The proposed model consists of a nonlinear spring connected in parallel to a radiation dashpot (see Figure 5.7). Radiation dashpot is identical to Lysmer's dashpot and is given by:

$$
\mathrm{C}_{\text {Lys }}=\frac{3.4 \mathrm{r}^{2} \sqrt{\left(\gamma_{\mathrm{m}} \mathrm{g}\right) \mathrm{G}_{\max }}}{1-v}
$$


The source of material damping is the nonlinear behavior of soil and its hysteresis, which is reflected in the nonlinear spring function, a mathematically advanced form of the extended Masing type function introduced by Kremer (1996). The spring constant of this function illustrates a hyperbolic-type load displacement relationship and can be expressed as:

$$
\mathrm{K}=\frac{\mathrm{dR}_{\mathrm{b}}}{\mathrm{dw}}=\frac{\mathrm{K}_{\mathrm{b}, \max }}{\left(1+\mathrm{b}_{\mathrm{f}} \frac{\left|\mathrm{R}_{\mathrm{b}}-\mathrm{LOI} \times \mathrm{R}_{\mathrm{b}, \mathrm{rev}}\right|}{(\mathrm{LOI}+1)\left|\operatorname{sgn} \cdot \mathrm{R}_{\mathrm{bf}}-\mathrm{R}_{\mathrm{b}}\right|}\right)^{2}}
$$

where $K_{b, \max }$ is the maximum elastic spring constant, $R_{b}$ is the limit base capacity, $R_{b, \text { rev }}$ is the spring reaction at the last displacement reversal, and $L O I$ is the loading index parameter ( $L O I=0$ for a virgin loading, 1 for other cases). The signum function is denoted by sgn, which extracts the sign of a real number. $b_{f}$ is a model parameter that controls the rate of degradation of the base spring constants.

In order to interpret the dynamic response of the CHT for soils, the ground response to impact by mass $\mathrm{M}$ can be obtained using the solution of the free-vibration problem:

$$
\mathrm{M} \ddot{\mathrm{w}}+\mathrm{C} \dot{\mathrm{w}}+\mathrm{Kw}=0
$$


where $K$ is the spring constant in eq. 5.18, $C$ is the damping constant in eq. 5.17; and $\ddot{w}, \dot{w}$, and $w$ are acceleration, velocity, and displacement respectively. This is a classic one-degree-of-freedom system governed by a linear differential equation.

For the dynamic analysis of the DCPT, it is essential to understand the sequence of the test. Differences exist between the CHT and the DCPT. First, the CHT does not have the overburden pressure that the DCPT has. At shallow depths, a significant portion of the damping of soil takes place due to Rayleigh waves that the DCPT does not have as it penetrates deeper. Loukidis et al. (2008) proposed the equation that accounts for the effect of embedment using the finite difference code FLAC.

As part of interpreting the dynamic response of the DCPT for soils, the ground response to impact by mass $\mathrm{M}$ can be obtained using the equation of motion. 


\section{CHAPTER 6. FIELD TESTS ON INDIANA SOILS}

\subsection{Introduction}

Since the Dynamic Cone Penetration Test (DCPT) and the Clegg Hammer Test (CHT) were introduced, several researchers have attempted to use these tests for soil compaction quality control (Burnham 1997, White et al 1999, Gabr et al. 2000, Jayawickrama et al. 2000, Salgado and Yoon 2003, Abu-Farsakh et al. 2005, GTI 2005, Ampadu and Arthur 2006). However, these studies did not develop specific correlations for the various types of soil.

A comprehensive experimental program was undertaken to assess the use of the DCPT and the CHT for compaction control. The experimental program consisted of tests performed in a pit and in the field. The DCPTs and CHTs were performed on-site at several INDOT highway construction projects in Indiana. In order to establish the soil compaction quality control criteria using the DCPT and CHT, a number of tests were performed along with other density-based tests such as the nuclear gauge and sand cone tests. By doing so, the DCPT and CHT could be correlated with the dry unit weight associated with the INDOT specification limit, which is $\mathrm{RC} \geq 95 \%$.

Since the dynamic behavior of both the DCPT and CHT are somewhat different, depending on the soil type, the test results were summarized according to the type of soil, categorized by the AASHTO classification. During testing, the soils containing a 
significant amount of gravel-sized particles were excluded because the particle size effects increase significantly considering the dimensions of both the DCPT and CHT.

This chapter presents the results of the tests performed in the test pit located on the southern side of the Bowen Laboratory for Large-Scale Civil Engineering Research at Purdue University in West Lafayette, Indiana, as well as the tests performed at several INDOT construction sites.

A major thrust of this chapter is providing values of the minimum required blow count for various soil types and $95 \%$ relative compaction. As defined in section 4.4 , the blow count satisfying both requirements will be referred to as the minimum required blow count. It provides reasonable assurance that, if the measured blow count matches or exceeds it, the desired relative compaction will have been achieved.

\subsection{Tests Performed in the Test Pit}

\subsubsection{Testing Method}

The purpose of the tests performed on the southern side of the Bowen Laboratory was to investigate the DCPT and CHT results in well controlled conditions because on-site construction conditions, water content in particular, fluctuate considerably due to weather. The test pit, shown in Figure 6.1, has an internal diameter of $130 \mathrm{~cm}$ and a height of $130 \mathrm{~cm}$. 


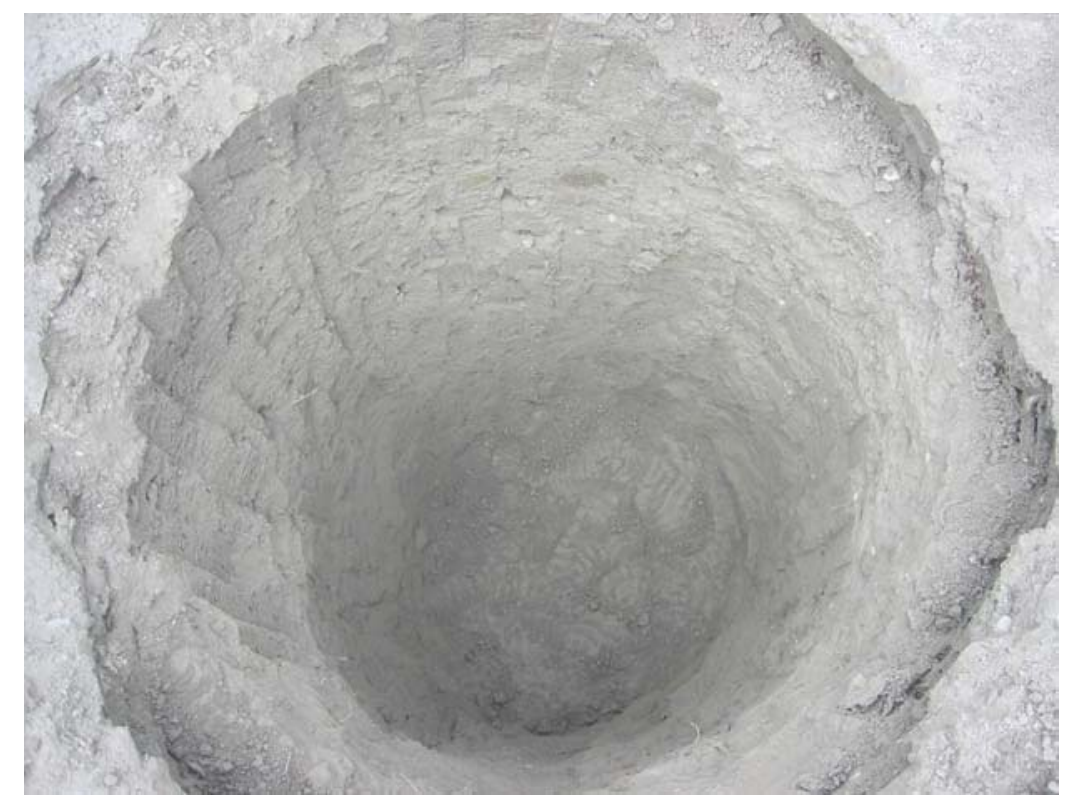

Figure 6.1 The photograph of the test pit

Preparation of the sample and the testing procedure involved the following steps.

1. A volume of soil sufficient to fill the pit when compacted was set aside. Its water content was adjusted so that it was as close as possible to the Optimum Moisture Content (OMC).

2. The soil was placed inside the pit at a level of one-fourth the pit height using a shovel.

3. The soil was then compacted using a $16 \mathrm{~kg}$ dropping mass. In order to control the relative compaction of the compacted soil in the pit, the soil was compacted at five different compaction energy levels by changing the number of drops of the $16 \mathrm{~kg}$ mass (see Table 6.1). Also, two samples were taken for measurement of their water content.

4. Additional soil was placed on top of the soil already compacted and then compacted using the same mass with the number of drops specified in Table 6.1. 
Table 6.1 Different compaction targets

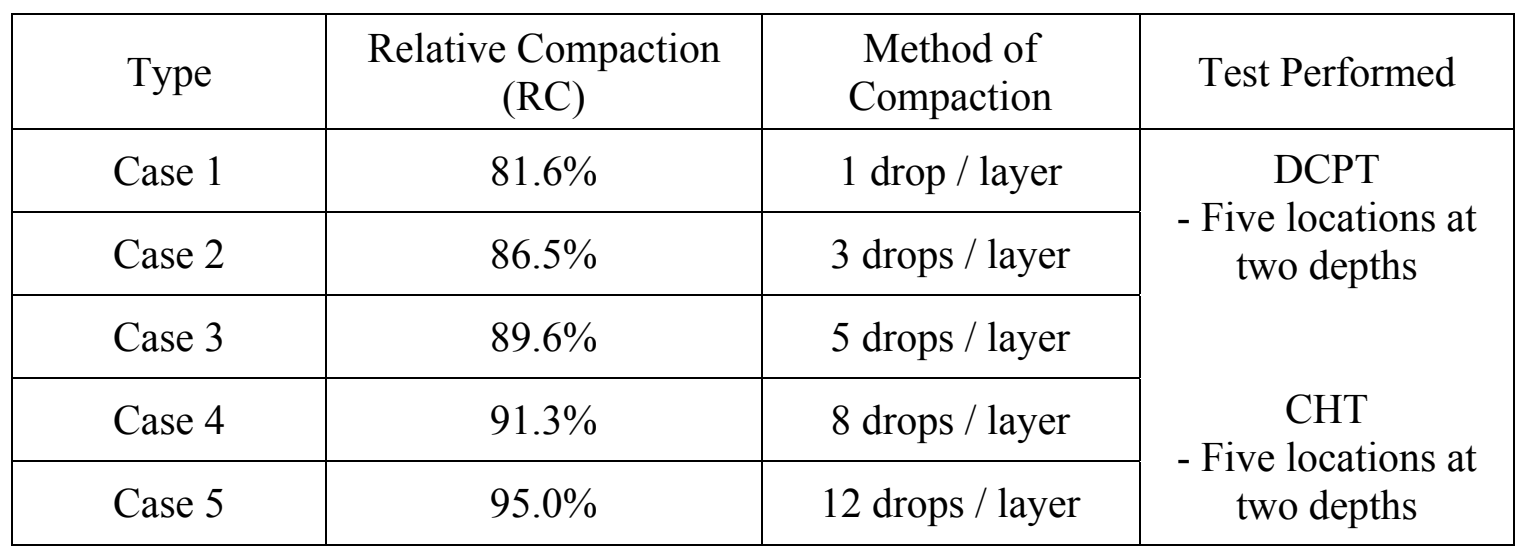

5. The first set of tests was carried out at the locations shown in Figure 6.2 (a) and (b).

6. The procedure described for steps 2 to 4 was repeated as two more layers were placed and compacted on top of the surface where the first set of tests was performed. A second set of tests was then conducted as shown in Figure 6.2. A sand cone test was conducted at the center of the sample to investigate the dry unit weight of the compacted soil. Also, two samples were taken for water content measurements.

The CHT apparatus used for this research was a 10kg hammer type, Model 95005A, produced by a Lafayette company. The DCP apparatus used in the testing was manufactured in accordance with ASTM D6951-03. 


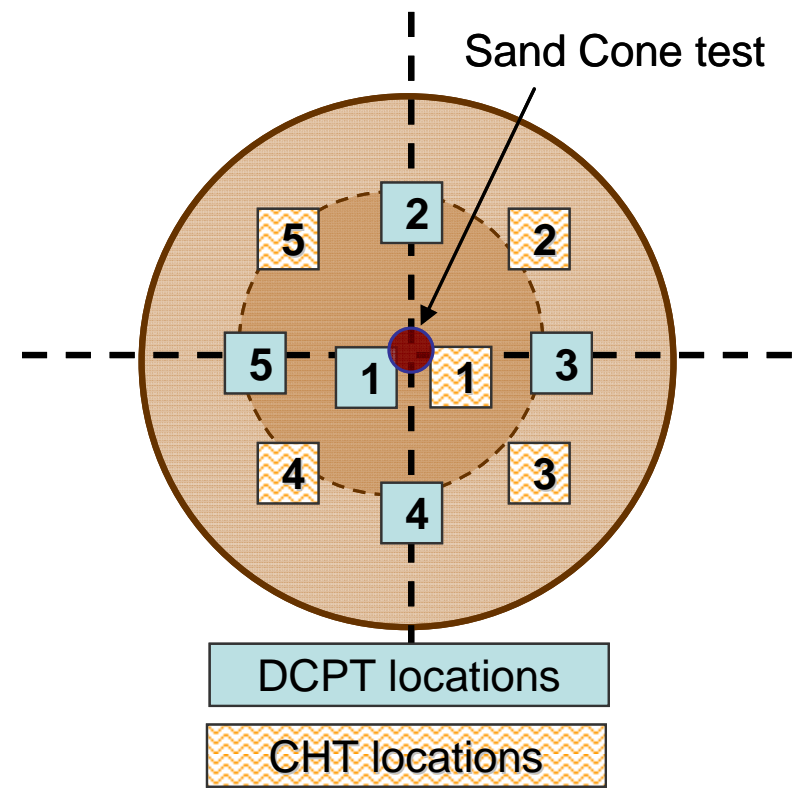

(a)

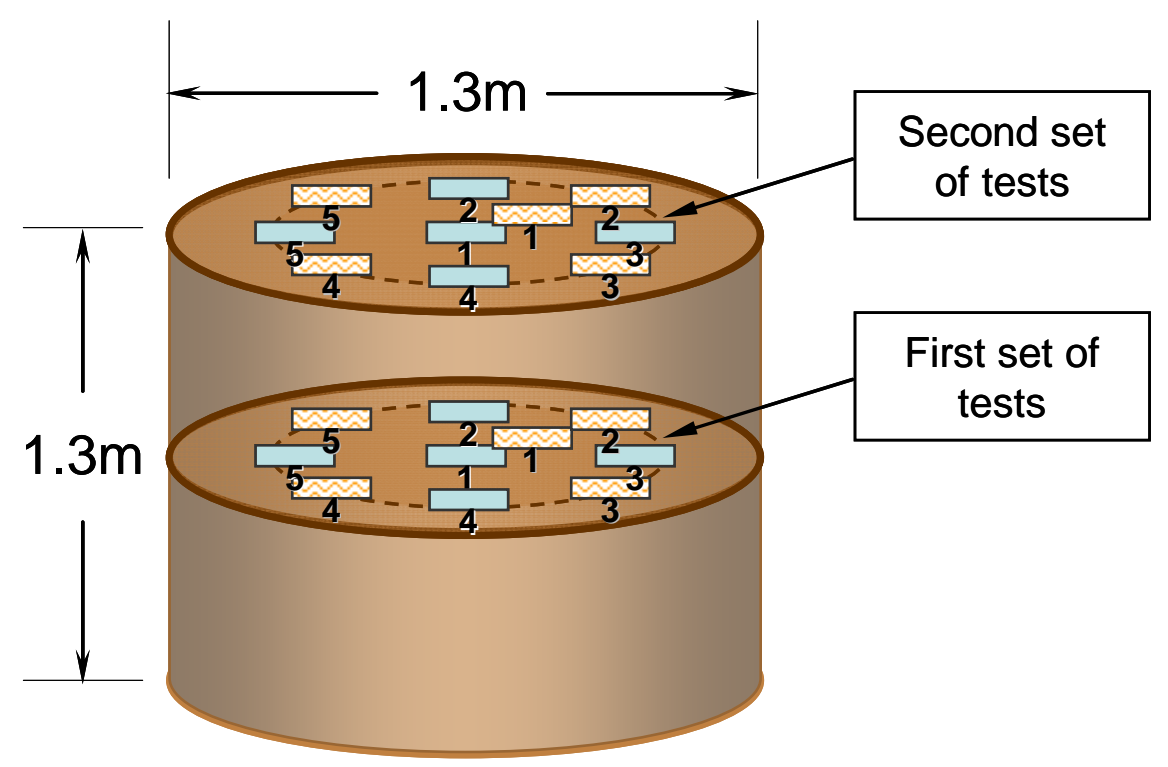

(b)

Figure 6.2 Test pit: (a) Cross-sectional view of DCPT and CHT test locations, and (b) schematic view of the test pit with the test locations 


\subsubsection{Soil Properties}

The soil used for the tests was from a West Lafayette, Indiana location. The gradation of the soil was determined by sieve and hydrometer analysis in accordance with ASTM D422-63. Figure 6.3 shows the particle-size distribution of the soil.

The soil consisted mainly of silt-clay particles with a small percentage of sand. The soil was classified as A-4 soil according to the American Association of State Highway and Transportation Officials (AASHTO) classification system and CL (Sandy lean clay) according to Unified Soil Classification System (USCS) following AASHTO M145-91 and ASTM D2487-06, respectively. Table 6.2 summarizes the grain-size distribution and classification of the soil used in the tests.

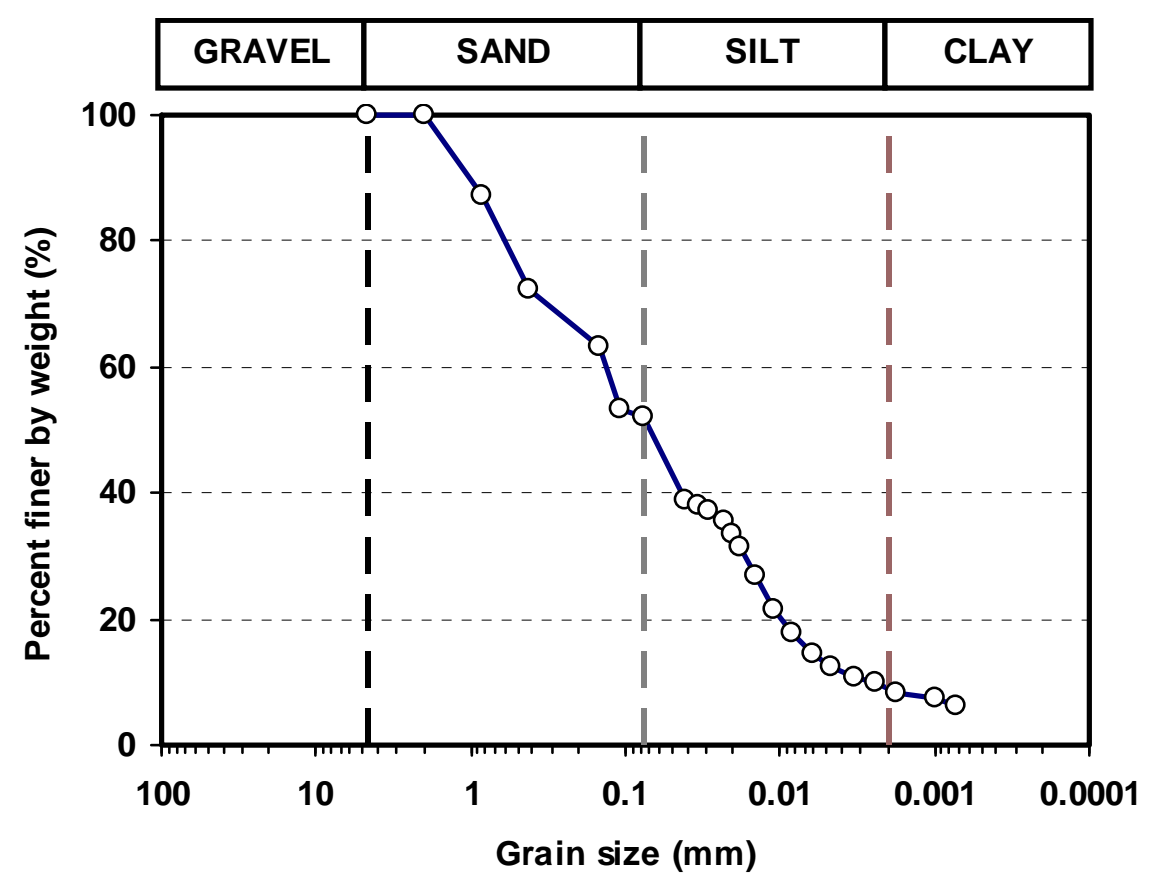

Figure 6.3 Particle-size distributions of the soil tested. 
Table 6.2 The particle-size distribution analysis and classification of the soil sample

\begin{tabular}{|c|c|c|c|c|c|c|c|}
\hline \multirow{2}{*}{ Soil } & \multirow{2}{*}{$\begin{array}{c}\% \\
\text { passing } \\
\text { No. } 10\end{array}$} & \multirow{2}{*}{$\begin{array}{c}\% \\
\text { passing } \\
\text { No. } 40\end{array}$} & \multirow{2}{*}{$\begin{array}{c}\% \\
\text { passing } \\
\text { No. } 200\end{array}$} & \multirow{2}{*}{$C_{u}$} & \multirow{2}{*}{$C_{C}$} & \multicolumn{2}{|c|}{ Classification system } \\
\hline & & & & & & AASHTO & USCS \\
\hline $\begin{array}{c}\text { Purdue } \\
\text { Clay }\end{array}$ & 0 & 72.3 & 52.1 & 54 & 0.86 & A-4 & CL \\
\hline
\end{tabular}

The compaction test was performed in accordance with ASTM D698-00, Standard Test Methods for Laboratory Compaction Characteristics of Soils Using Standard Effort. Figure 6.4 shows the moisture-density relationship of the Purdue soil sample. The Zero-Air-Void Curve (ZAVC) that indicates the maximum possible dry unit weight is also shown in Figure 6.4.

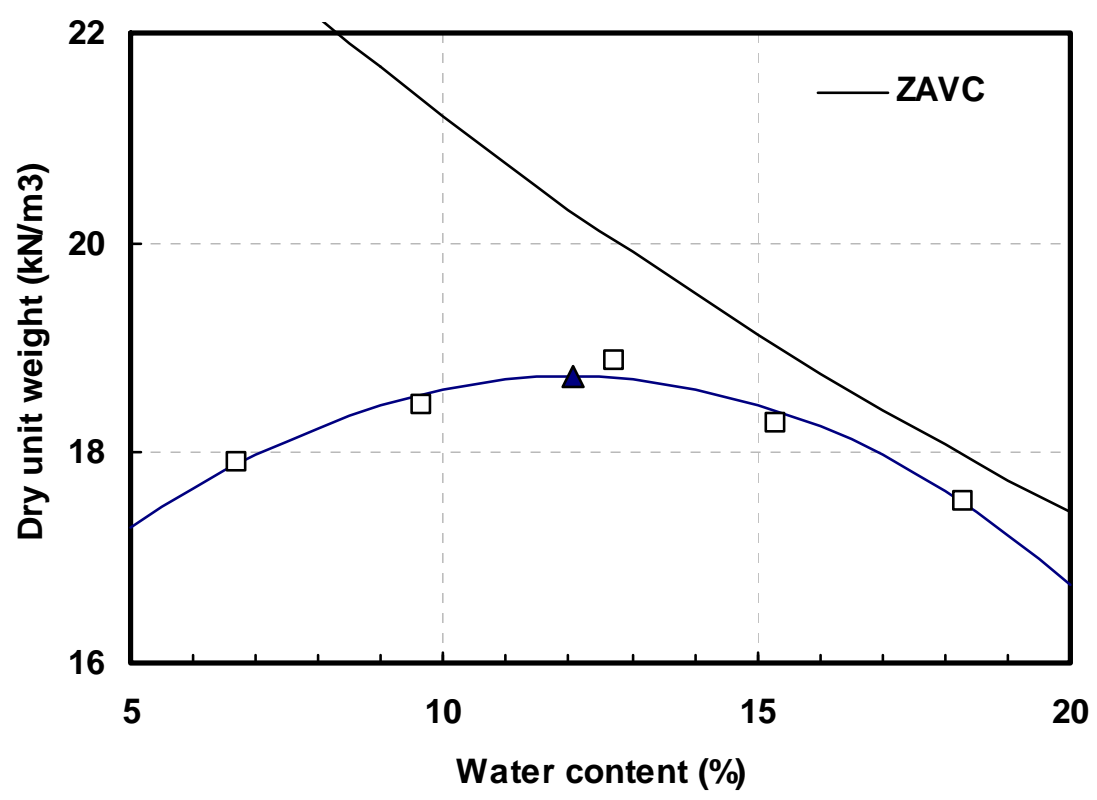

Figure 6.4 Compaction curve for the soil 
The soil that passed through the No. $40(0.425 \mathrm{~mm})$ sieve was tested for Atterberg limits, in accordance with ASTM D4318-05. Table 6.3 summarizes the results of the compaction test and the Atterberg limits test.

Table 6.3 Summary of compaction test and Atterberg limit tests

\begin{tabular}{|c|c|c|c|c|c|c|}
\hline \multirow{2}{*}{ Soil } & \multicolumn{2}{|c|}{$\gamma_{d \max }$} & \multirow{2}{*}{$w C_{o p t}(\%)$} & \multirow{2}{*}{$P L(\%)$} & \multirow{2}{*}{$L L(\%)$} & \multirow{2}{*}{$P I(\%)$} \\
\hline & $\left(\mathrm{kN} / \mathrm{m}^{3}\right)$ & (pcf) & & & & \\
\hline $\begin{array}{c}\text { Purdue } \\
\text { Clay }\end{array}$ & 18.7 & 119.2 & 12.1 & 12.6 & 22.3 & 9.7 \\
\hline
\end{tabular}

In order to estimate the shear strength, a few unconfined compression tests were performed on the soil sample in accordance with ASTM D2166-06. The test specimens were compacted in three equal layers in Harvard Miniature Compaction Apparatus, which consists of a mold $3.3 \mathrm{~cm}$ (1.4 in.) in diameter and $7.2 \mathrm{~cm}(2.8$ in.) in height. For the purpose of varying the relative compaction of the test specimens, they were compacted at three different compaction energy levels by changing the number of blows of the spring hammer, 10, 20, and 30 blows per layer. Figure 6.5 shows the axial strain vs. axial stress curves obtained from the unconfined compression tests performed on the soil sample at different relative compactions. The UC strength increased as the relative compaction increased. 


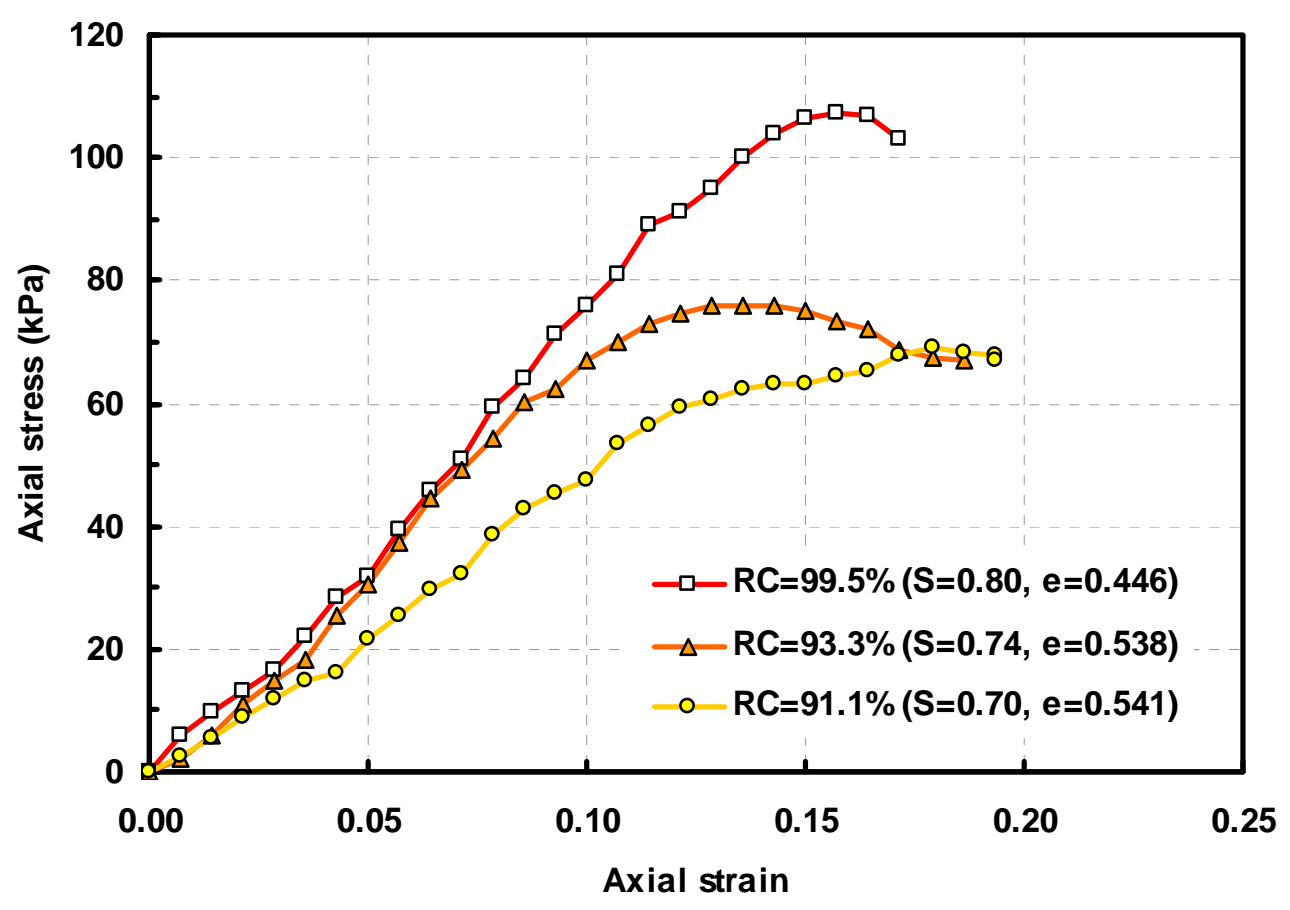

Figure 6.5 Unconfined compression test results on the soil for different relative compaction

\subsubsection{Test Results}

Table 6.4 provides the dry unit weight and the water content at five different relative compaction levels along with the DCPT and CHT results. As shown in Table 6.4, different relative compaction values could be achieved by varying the compaction effort. 
Table 6.4 Summary of the sand cone, DCPT, and CHT results

\begin{tabular}{|c|c|c|c|c|c|c|}
\hline & Test & Case 1 & Case 2 & Case 3 & Case 4 & Case 5 \\
\hline Relati & $\begin{array}{l}\text { e Compaction } \\
\text { (RC) }\end{array}$ & $81.6 \%$ & $86.5 \%$ & $89.6 \%$ & $91.3 \%$ & $95.0 \%$ \\
\hline & $\left(\mathrm{kN} / \mathrm{m}^{3}\right)$ & 15.3 & 16.2 & 16.8 & 17.1 & 17.8 \\
\hline$\gamma^{\prime a}$ & (pcf) & 97.4 & 103.1 & 106.9 & 108.8 & 113.2 \\
\hline & $w c(\%)$ & 13.3 & 13.7 & 12.4 & 13.8 & 11.5 \\
\hline CIV & Avg., $98 \mathrm{~m} / \mathrm{s}^{2}$ ) & 4.6 & 7.8 & 9.5 & 9.8 & 10.6 \\
\hline $\mathrm{N}_{\mathrm{DCP}}$ & $\begin{array}{c}\text { Penetrating } \\
0 \text {-to-6 inches }\end{array}$ & 1.3 & 3.0 & 6.4 & 6.9 & 7.7 \\
\hline (Avg.) & $\begin{array}{l}\text { Penetrating } \\
\text { 6-to-12 inches }\end{array}$ & 1.7 & 3.7 & 6.8 & 9.6 & 9.1 \\
\hline
\end{tabular}

Table 6.4 also summarizes the DCPT and CHT results for the tests performed in a pit. Both the DCPT and the CHT results, on average, indicate trends of increasing $\mathrm{N}_{\mathrm{DCP}}$ and CIV with increasing relative compaction.

Figure 6.6 provides the distributions of all DCPT results conducted in the test pit for 0-to-6 inch $\left(\mathrm{N}_{\mathrm{DCP} \mid 0 \sim 6^{\prime}}\right)$ and 6-to-12 inch $\left(\mathrm{N}_{\left.\mathrm{DCP} \mid 6 \sim 12^{\prime \prime}\right)}\right)$ penetration. The test results

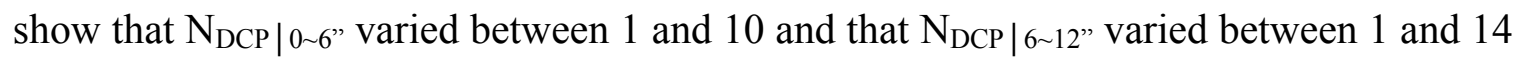
depending on the relative compaction. A significant increase in $\mathrm{N}_{\mathrm{DCP}}$ occurs $\mathrm{RC}>90 \%$, which implies that the soil strength and bearing capacity drastically improve a RC increases beyond $90 \%$. Greater variability was observed for $\mathrm{N}_{\mathrm{DCP} \mid 6 \sim 12 \%}$. 


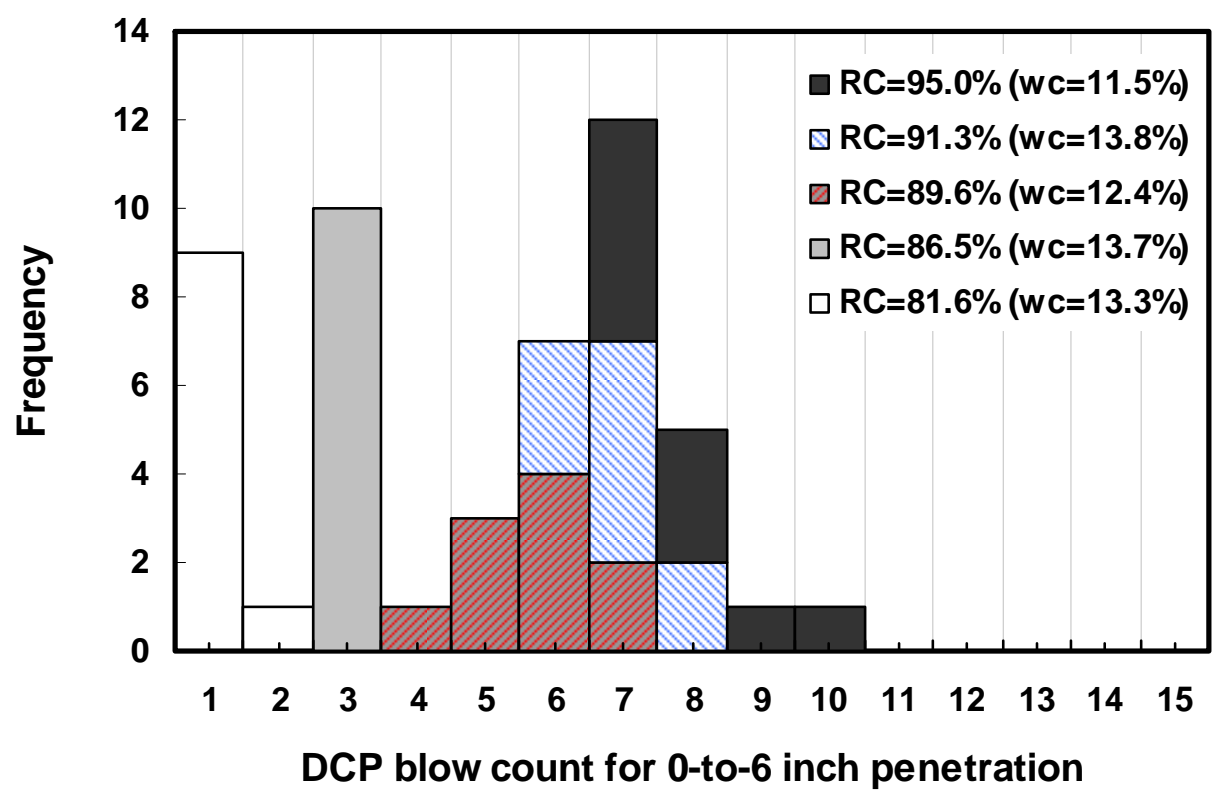

(a)

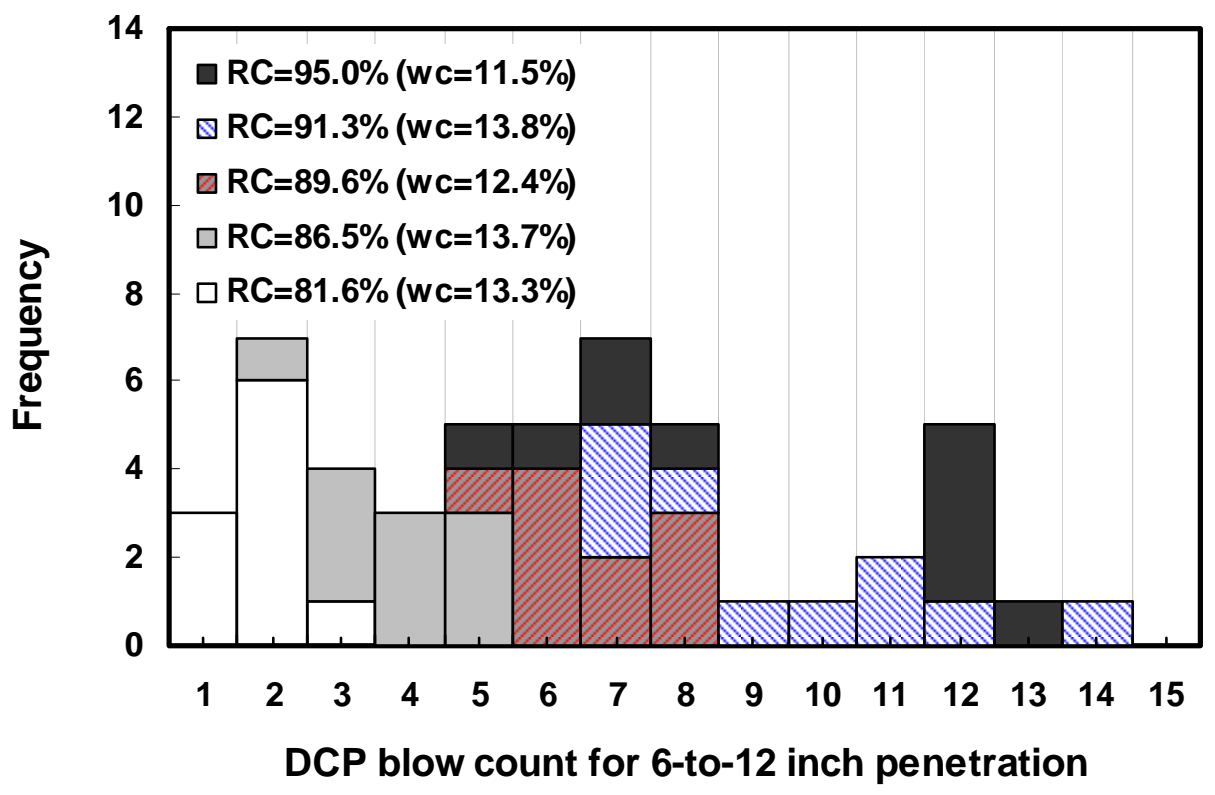

(b)

Figure 6.6 Histograms of DCPT pit results: (a) 0-to-6 inch penetration and (b) 6-to-12 inch penetration. 
The approach presented in section 4.4 for development of compaction quality control criteria is used here in connection with the pit test results. The minimum required blow count is associated with $80 \%$ exceedance for the data shown in Figure 6.7. In other words, the approach assures that the minimum required blow count includes at least $80 \%$ of the occurrences in the histogram of the test results associated with $95 \% \mathrm{RC}$.

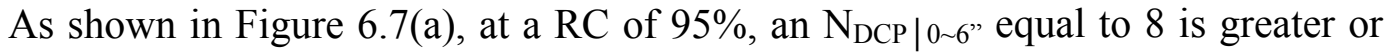
equal to $80 \%$ of the test results. Similarly, the minimum required blow count that is greater or equal to $80 \%$ of the test results for a RC $95 \%$ is 12 [see Figure $6.7(b)$ ].

The proposed minimum required blow count is then checked for the data corresponding to all values of RC, as shown in Figure 6.8. Figure 6.8(a) shows that all other test results are less than the selected value for 0-to- 6 inch penetration. Figure 6.8(b) shows that all the test results except one are below the selected value for 6-to-12 inch penetration. 


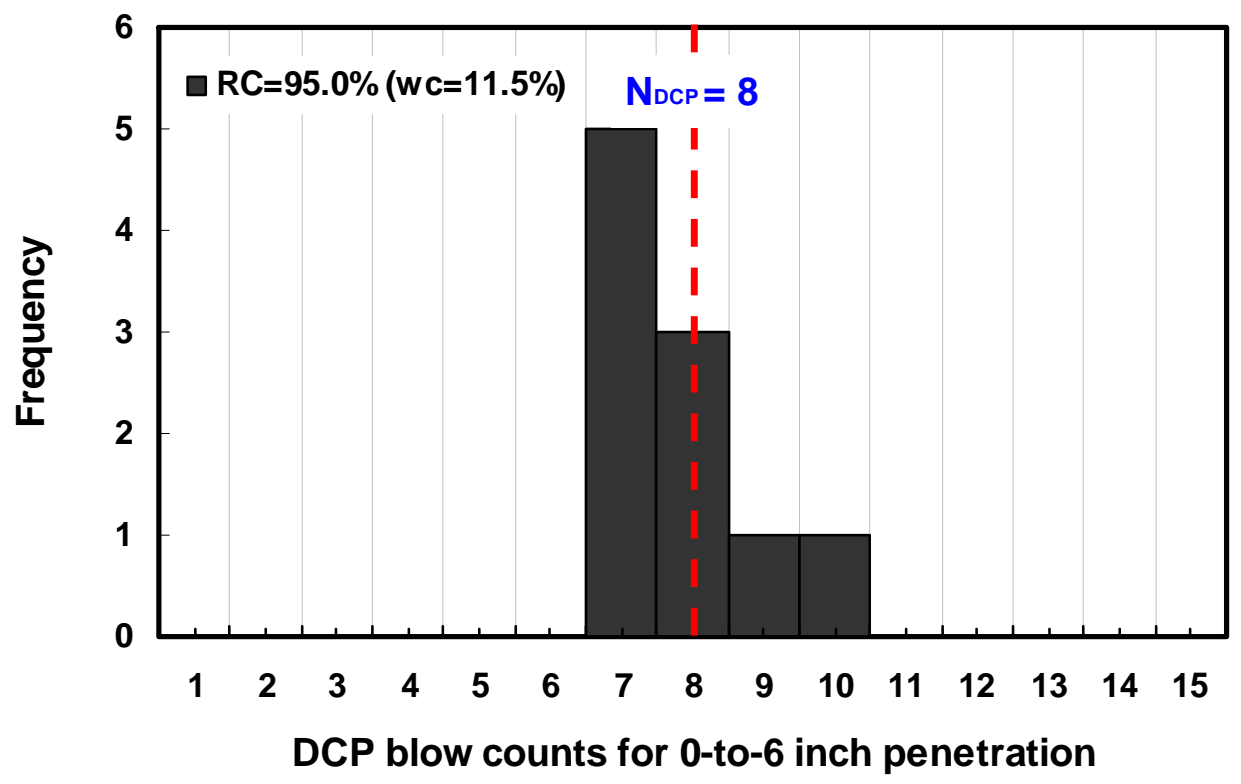

(a)

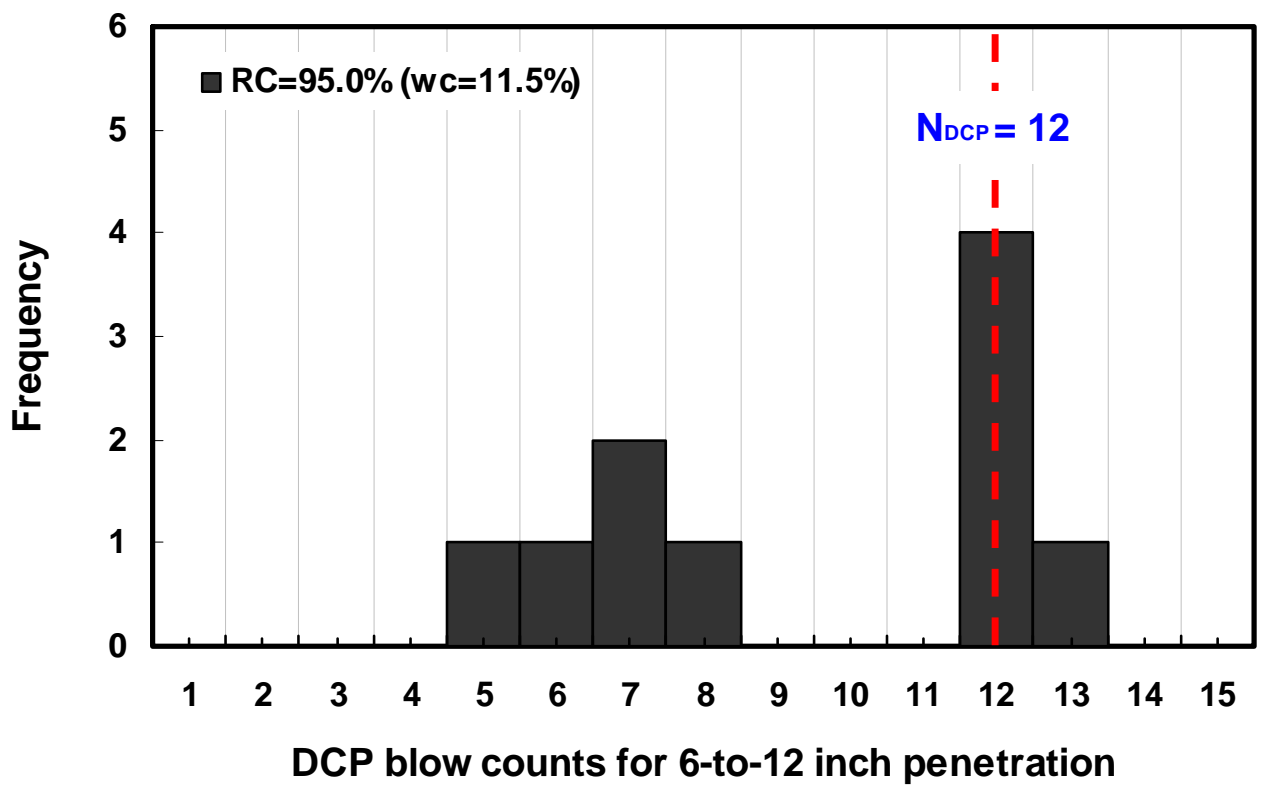

(b)

Figure 6.7 Histograms of DCPT pit results at $95 \%$ RC plotted together with the minimum required blow count: (a) 0-to-6 inch penetration and (b) 6-to-12 inch penetration. 


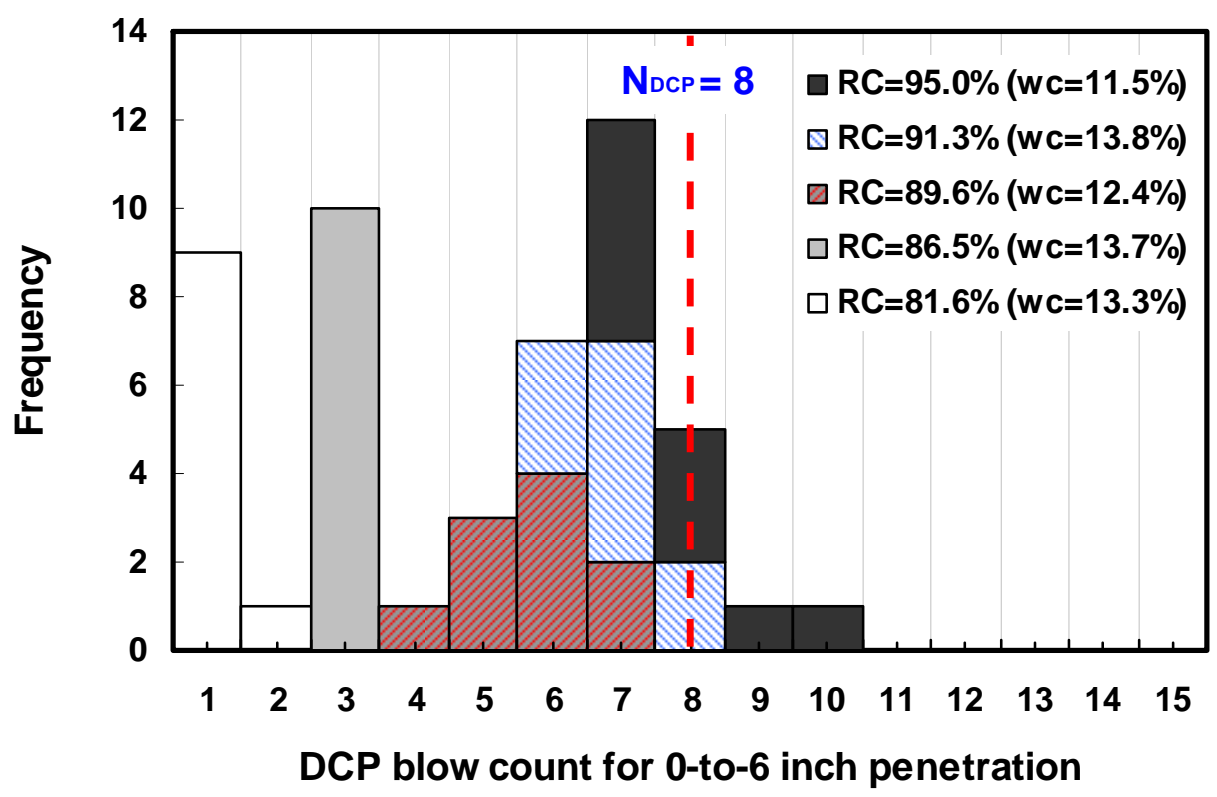

(a)

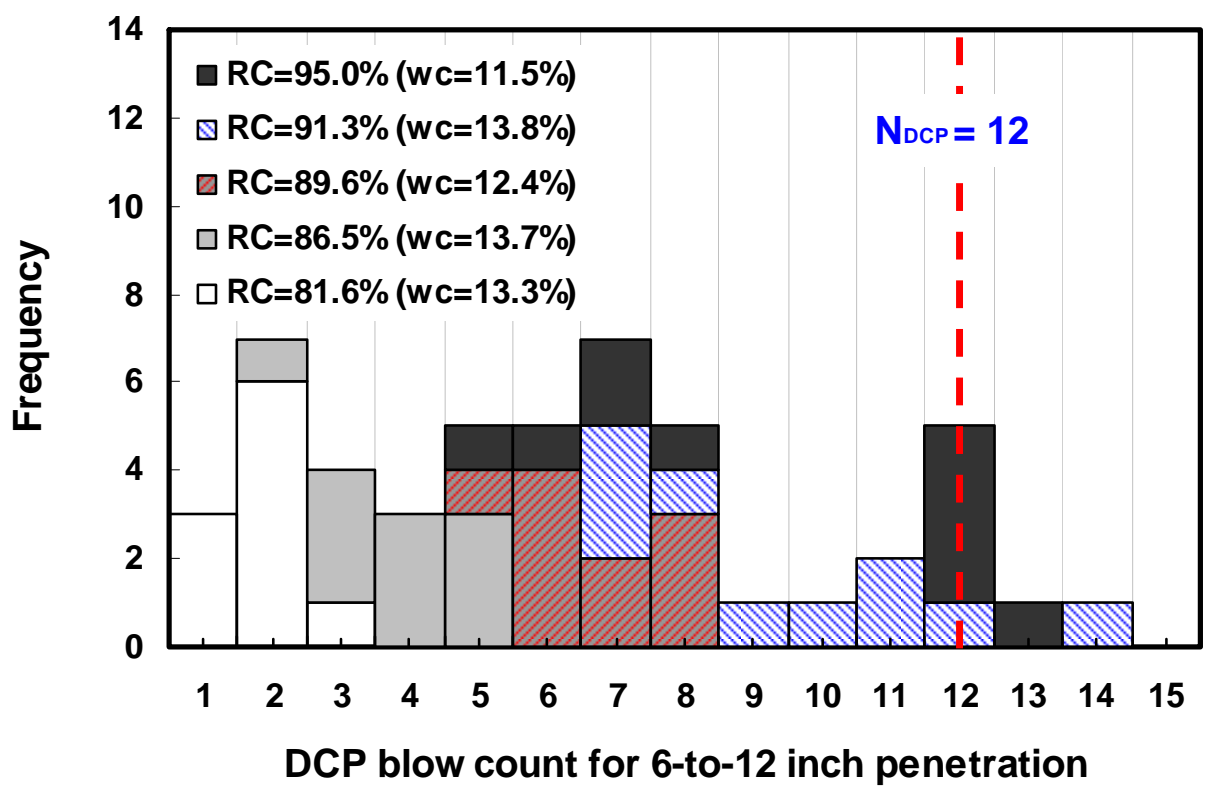

(b)

Figure 6.8 Histograms of DCPT pit results plotted together with the minimum required blow count: (a) 0-to-6 inch penetration and (b) 6-to-12 inch penetration. 
Figure 6.9 shows a plot of relative compaction versus the Clegg Impact Value (CIV). Even though the test results, on average, indicate that the CIV increases with increasing relative compaction, the CIV exhibits high variability at each relative compaction value. The CHT results show that the CIV is, on average, 10.6 for an average $\mathrm{RC}$ of $95 \%$, but the range $(9.0 \sim 13.3)$ was wide.

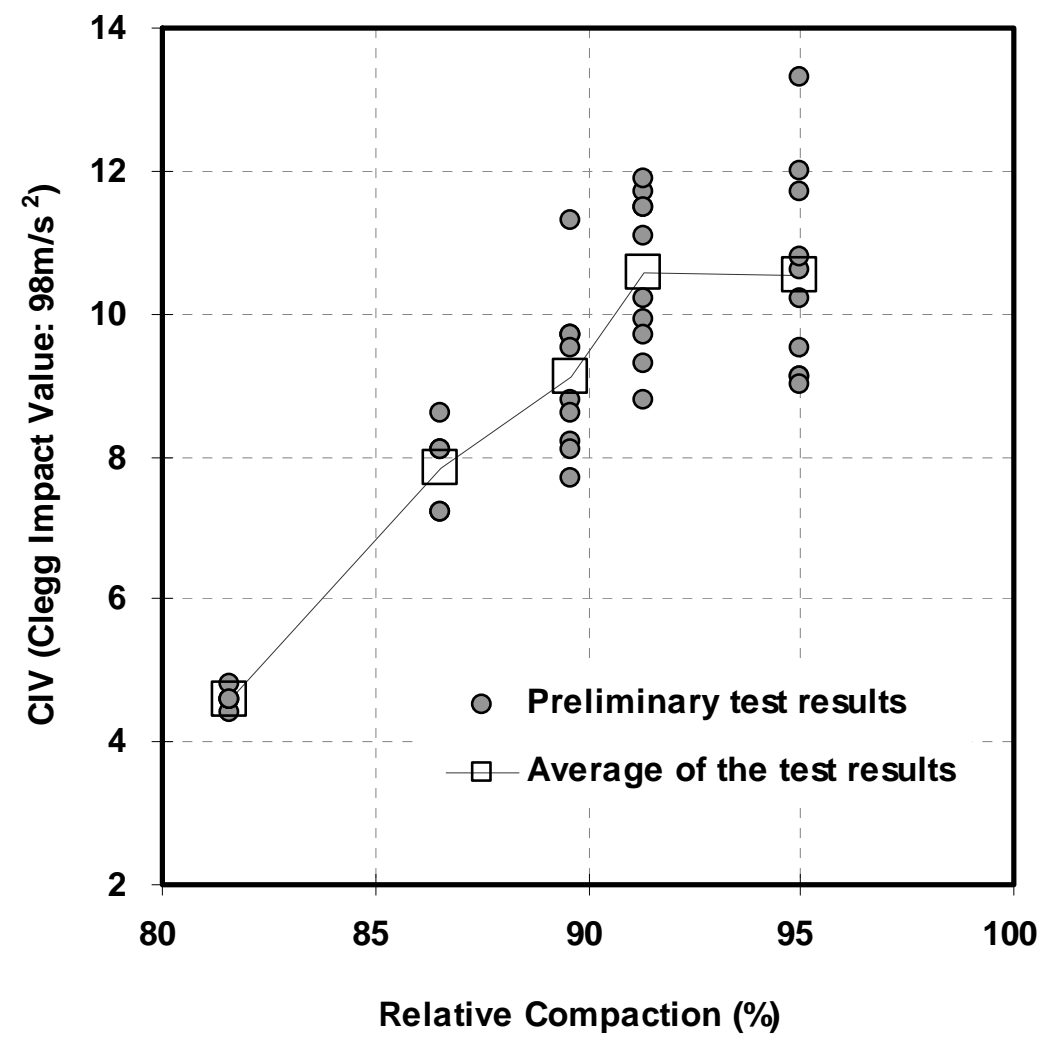

Figure 6.9 The Clegg Hammer Test results in the test pit at five different relative compactions 


\subsection{Field Tests on A-3 Soils}

Three sites were selected for performing the tests on A-3 soil. All of the soils at the sites were cohesionless and contained less than 10 percent passing the \#200 sieve. A-3 soils consist of clean, poorly graded sand. In addition to the density and confinement, the engineering behavior of A-3 soil is mainly influenced by the relative proportions of the different particle sizes present and the shapes of the soil particles.

Figure 6.10 shows the particle-size distribution of the soils tested. The soils mainly consisted of sand particles with minimal percentages of fines and gravels. Those soils are all non-plastic and classified as A-3 soils per the AASHTO classification system and SP (Poorly graded sand) per USCS following AASHTO M145-91 and ASTM D2487-06, respectively. The compaction tests were performed in accordance with ASTM D698-00, Standard Test Methods for Laboratory Compaction Characteristics of Soils Using Standard Effort. Figure 6.11 shows the compaction curves of the soils. 


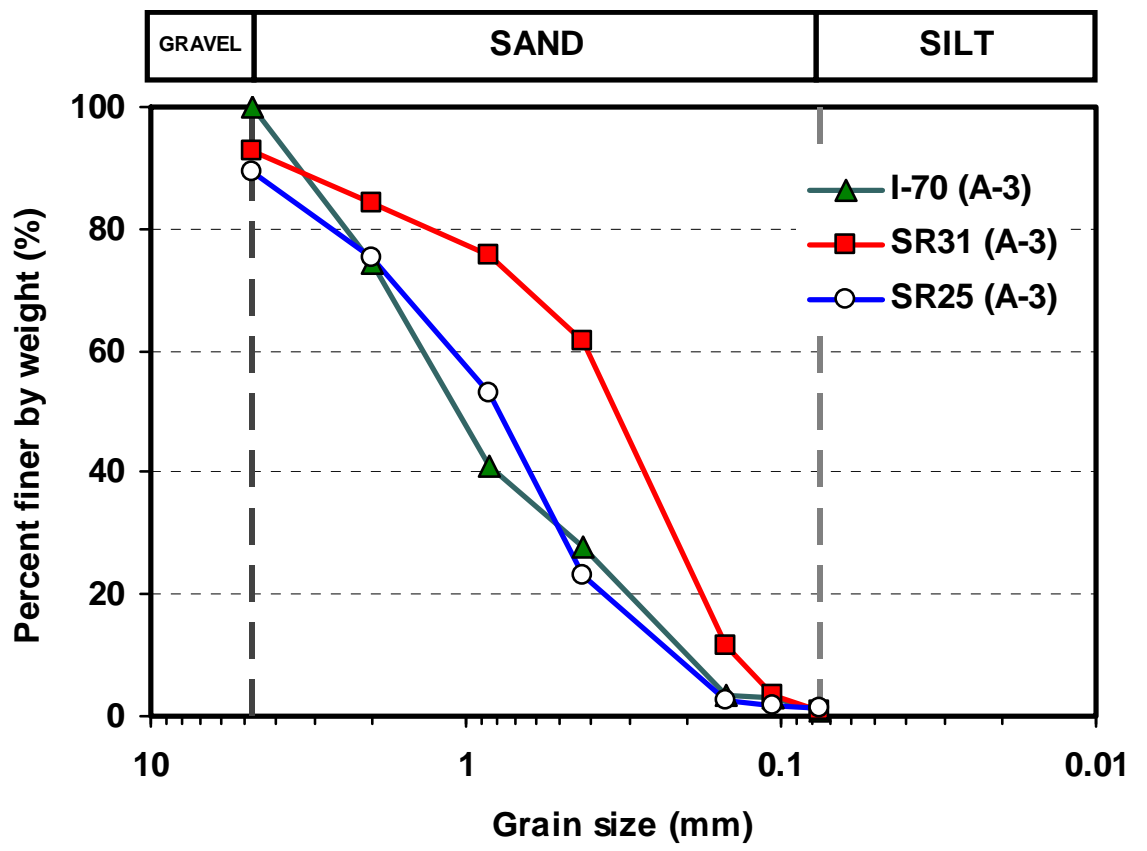

Figure 6.10 Particle-size distributions of A-3 soils.

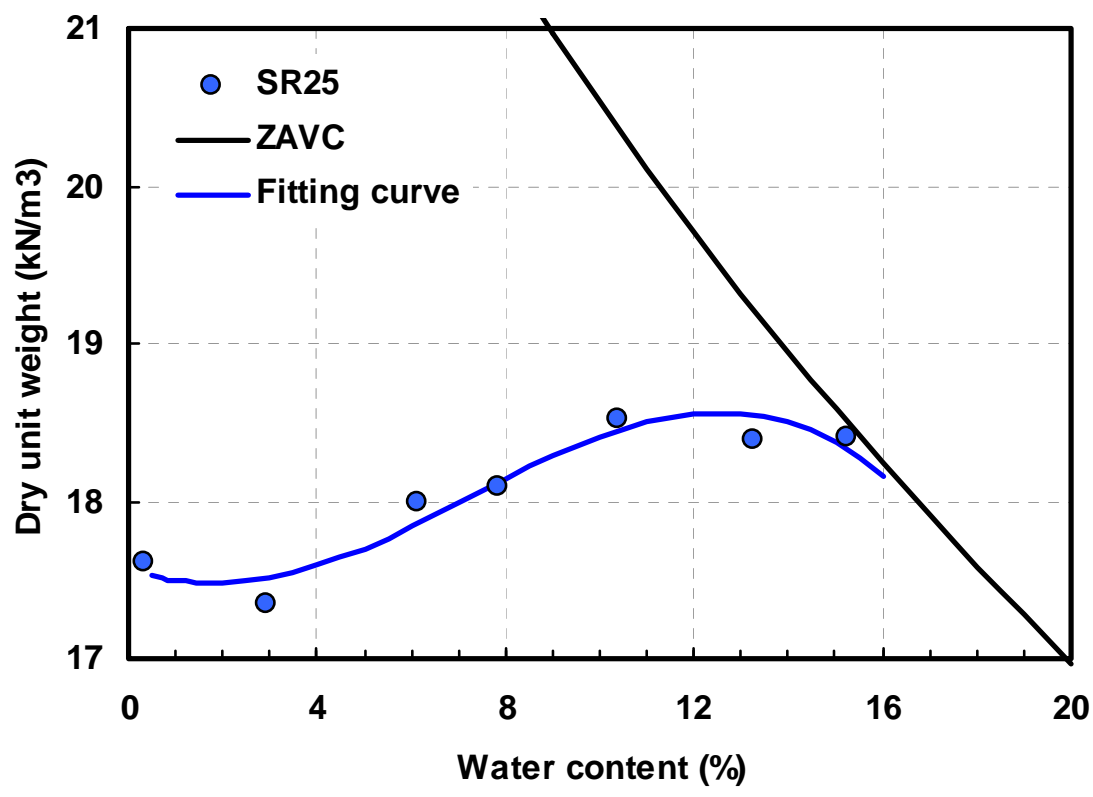

(a)

Figure 6.11 Compaction curves of the soil taken from (a) SR25 site. 


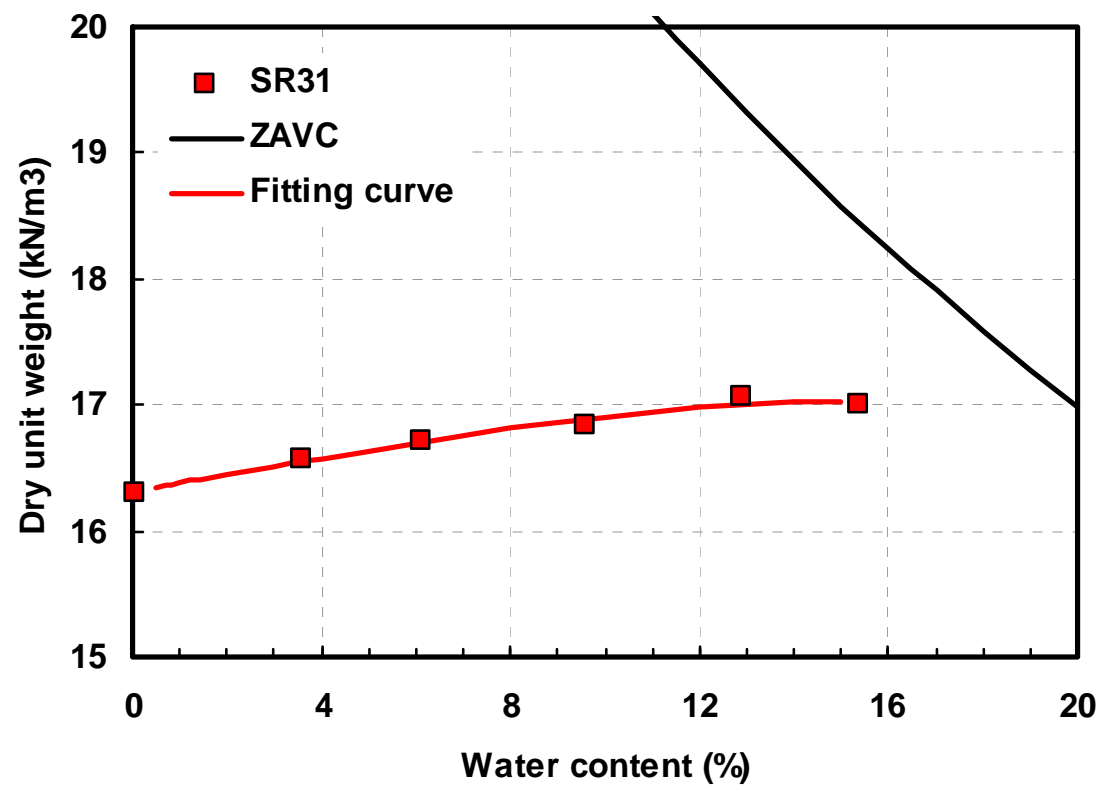

(b)

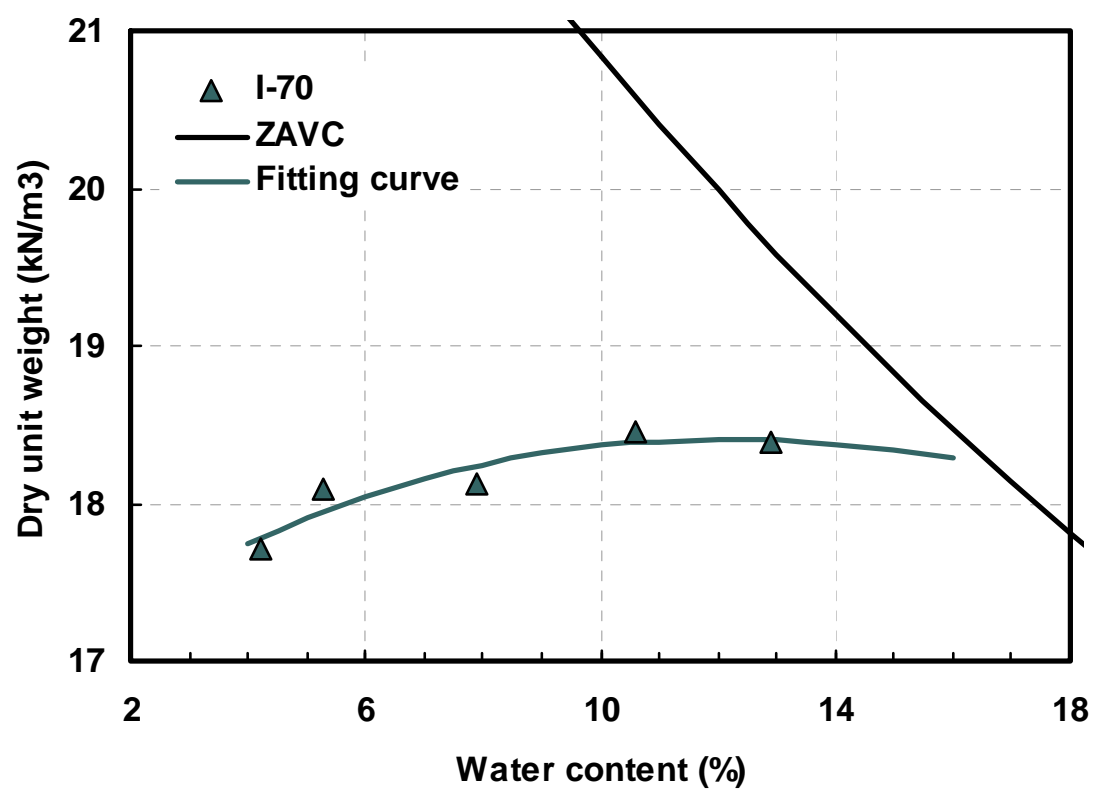

(c)

Figure 6.11 Compaction curves of the soil samples from: (a) SR25 site, (b) SR31 site, and (c) I-70 site (Continued). 
Table 6.5 summarizes the grain-size distributions and classifications of the soil taken from three sites. Each is discussed in detail next.

Table 6.5 Summary of grain-size distribution analyses and compaction tests

\begin{tabular}{|c|c|c|c|c|c|c|c|c|}
\hline Site & $\begin{array}{c}\% \\
\text { passing } \\
\text { No. 10 }\end{array}$ & $\begin{array}{c}\% \\
\text { passing } \\
\text { No. 40 }\end{array}$ & $\begin{array}{c}\% \\
\text { passing } \\
\text { No.200 }\end{array}$ & $C_{u}$ & $C_{c}$ & \multicolumn{2}{|c|}{$\gamma_{d m a x}$} & $\begin{array}{c}w c_{\text {opt }} \\
\text { (\%) }\end{array}$ \\
\hline $\begin{array}{c}\text { SR 25 } \\
\text { at Carroll Co. }\end{array}$ & 75.4 & 23.1 & 1.2 & 5.06 & 1.02 & 18.5 & 117.9 & 12.1 \\
\hline $\begin{array}{c}\text { SR 31 at } \\
\text { Marshall Co. }\end{array}$ & 84.2 & 61.6 & 0.8 & 2.92 & 0.84 & 17.1 & 108.5 & 12.8 \\
\hline $\begin{array}{c}\text { I-70 } \\
\text { at Indianapolis }\end{array}$ & 74.3 & 27.7 & 1.0 & 6.01 & 0.86 & 18.4 & 117.1 & 12.1 \\
\hline
\end{tabular}

\subsubsection{Field Tests on SR25}

An embankment was constructed using A-3 soil as fill material. Field DCP Tests were performed on the embankment at the State Road 25 highway construction site located in Carroll County, Indiana. Figure 6.12 shows the histogram of the DCPT results. The relative compactions in Figure 6.12 were computed using a $\gamma_{\mathrm{dmax}}$ of $18.5 \mathrm{kN} / \mathrm{m}^{3}(117.9$ pcf) taken from the laboratory Standard compaction test. The dry unit weight and the water content were measured using the nuclear gauge tests. In each case, three nuclear gauge tests were performed along with five DCP tests. The relative compaction and the water content results in Figure 6.12 through Figure 6.14 are the average values from three nuclear gauge tests. 
Based on the test results shown in Figures 6.12, the minimum required blow count,

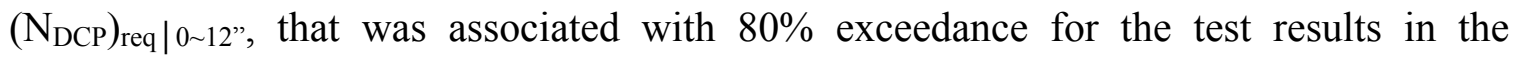
histogram of the test results corresponding to $95.6 \% \mathrm{RC}$ was 8 . However, $\left(\mathrm{N}_{\mathrm{DCP}}\right)_{\text {req }} \mid 0 \sim 12$ " was increased by 9 in order to have two test results associated with less than $95 \% \mathrm{RC}$ equal to the minimum required blow count, as shown in Figure 6.13.

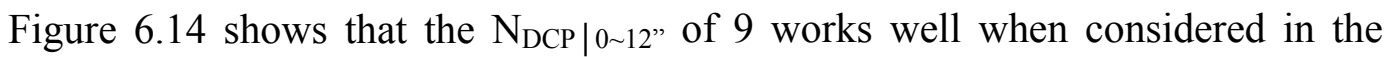
context of all results. The blow counts for $\mathrm{RC}$ of less than $95 \%$ are less than the minimum required blow count except for a case with 93.3\%, where an unusually low water content led to an abnormally high blow count. The test results corresponding to $\mathrm{RC}$ more than 95\% supported this explanation because several DCP test results associated with RC more than $95 \%$ are below the $\left(\mathrm{N}_{\mathrm{DCP}}\right)_{\text {req }} \mid 0 \sim 12$ " of 9, as shown in Figure 6.14.

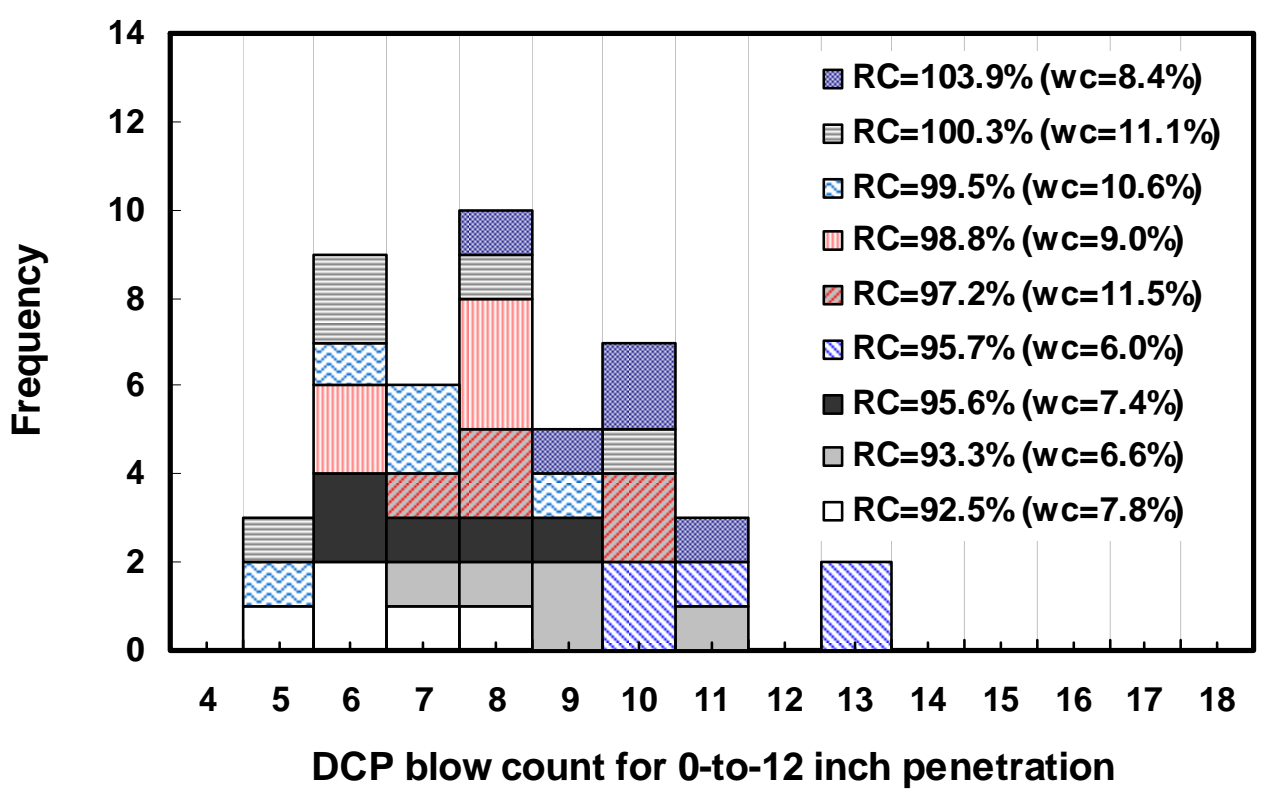

Figure 6.12 Histogram of DCPT results (SR25): 0-to-12 inch penetration. 


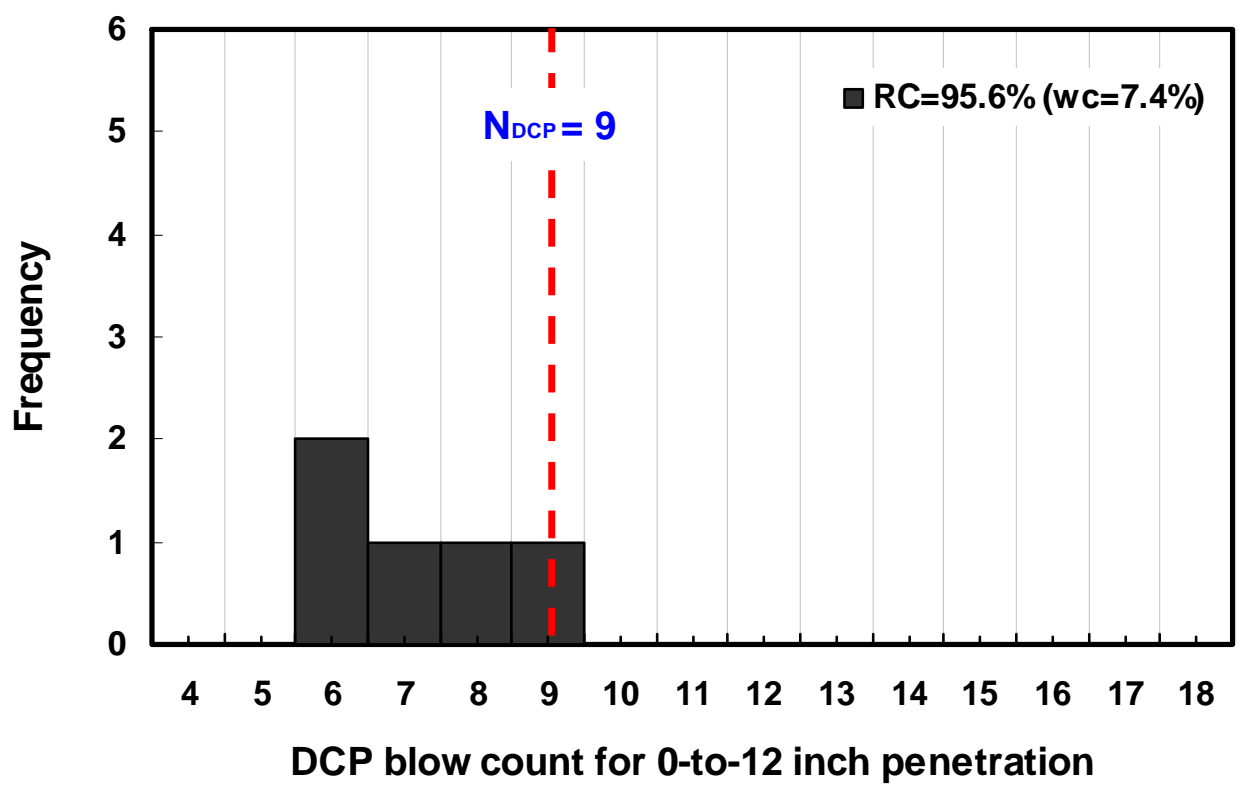

Figure 6.13 Histogram of DCPT results at 95.6\% RC plotted together with the minimum required blow count (SR25): 0-to-12 inch penetration.

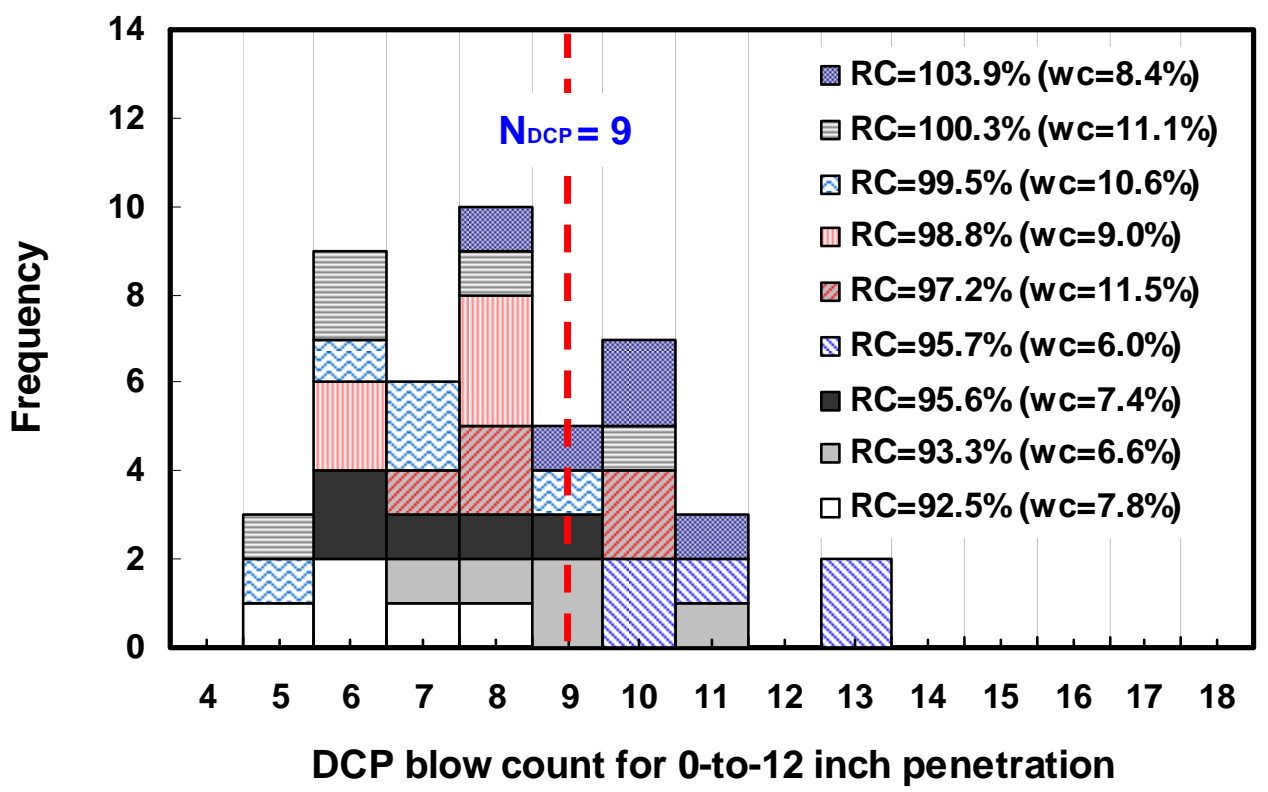

Figure 6.14 Histogram of DCPT results plotted together with the minimum required blow count (SR25): 0-to-12 inch penetration. 


\subsubsection{Field Tests on SR31}

An embankment approaching a bridge was constructed using A-3 soil as a fill material at a highway construction site on State Road 31 in Marshall County, Indiana.

Figure 6.15 shows the histogram of the DCPT blow counts for the site. In the figure, relative compactions were computed using a $\gamma_{\mathrm{dmax}}$ of $17.1 \mathrm{kN} / \mathrm{m}^{3}$ (108.5pcf) obtained from the laboratory Standard compaction test (see Table 6.5). Also, the dry unit weight and the water content were measured using the nuclear gauge test. In each case, three nuclear gauge tests were performed along with five DCP tests. The RC and the water content results in Figures 6.15 through 6.17 represent the arithmetic mean values from three nuclear gauge tests.

Based on the test results shown in Figure 6.16, the minimum required blow count $\left(\mathrm{N}_{\mathrm{DCP}}\right)_{\text {req } \mid 0 \sim 12}$ " was determined. At the site, since DCP test results associated with $95 \%$ RC were not acquired, the DCP test results corresponding to $96.7 \%$ were used to determine the minimum required blow count. Based on the test results shown in Figure 6.16 , the $\left(\mathrm{N}_{\mathrm{DCP}}\right)_{\mathrm{req}} \mid 0 \sim 12$, that is greater or equal to $80 \%$ of the blow counts associated with

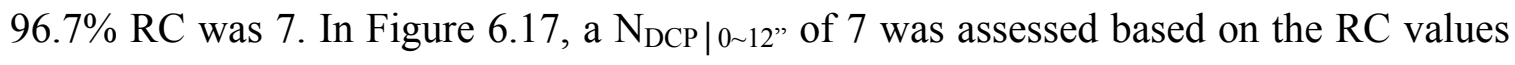
associated with test results exceeding the selected value. 


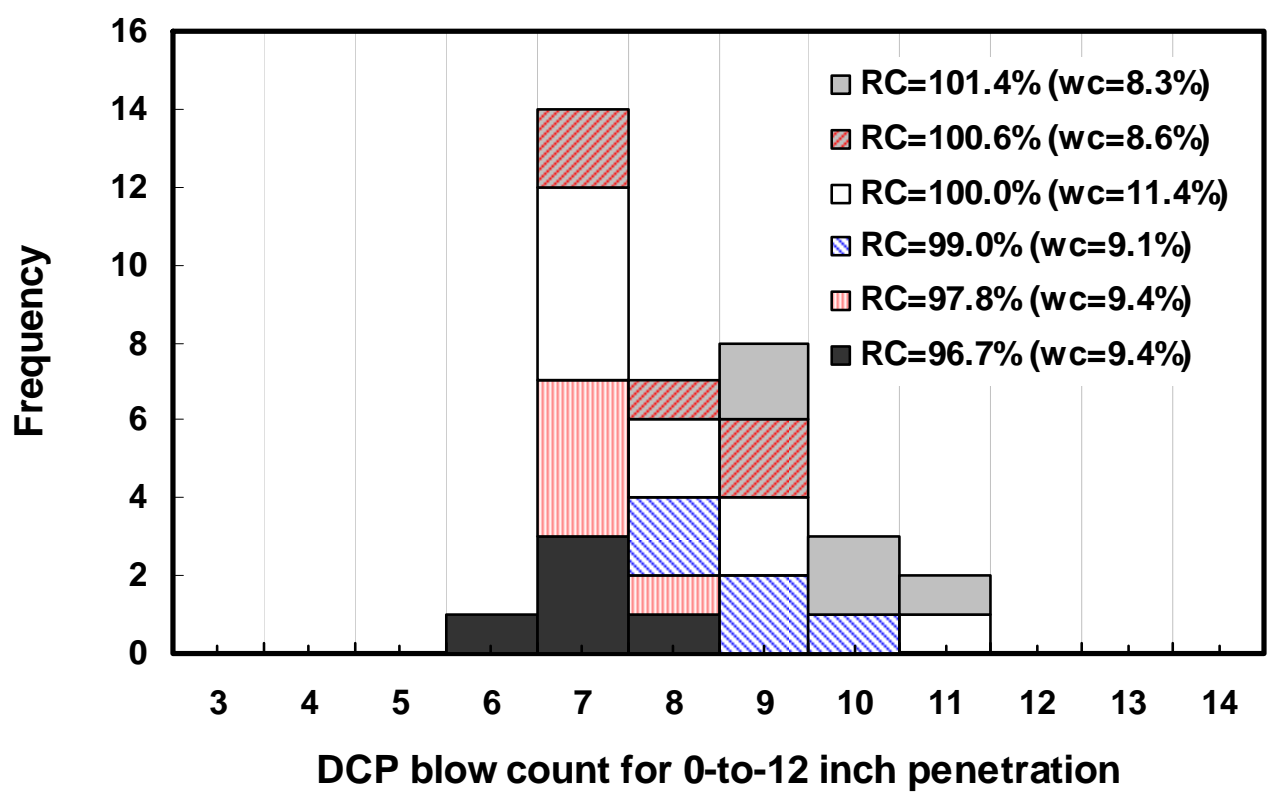

Figure 6.15 Histogram of DCPT results (SR31): 0-to-12 inch penetration.

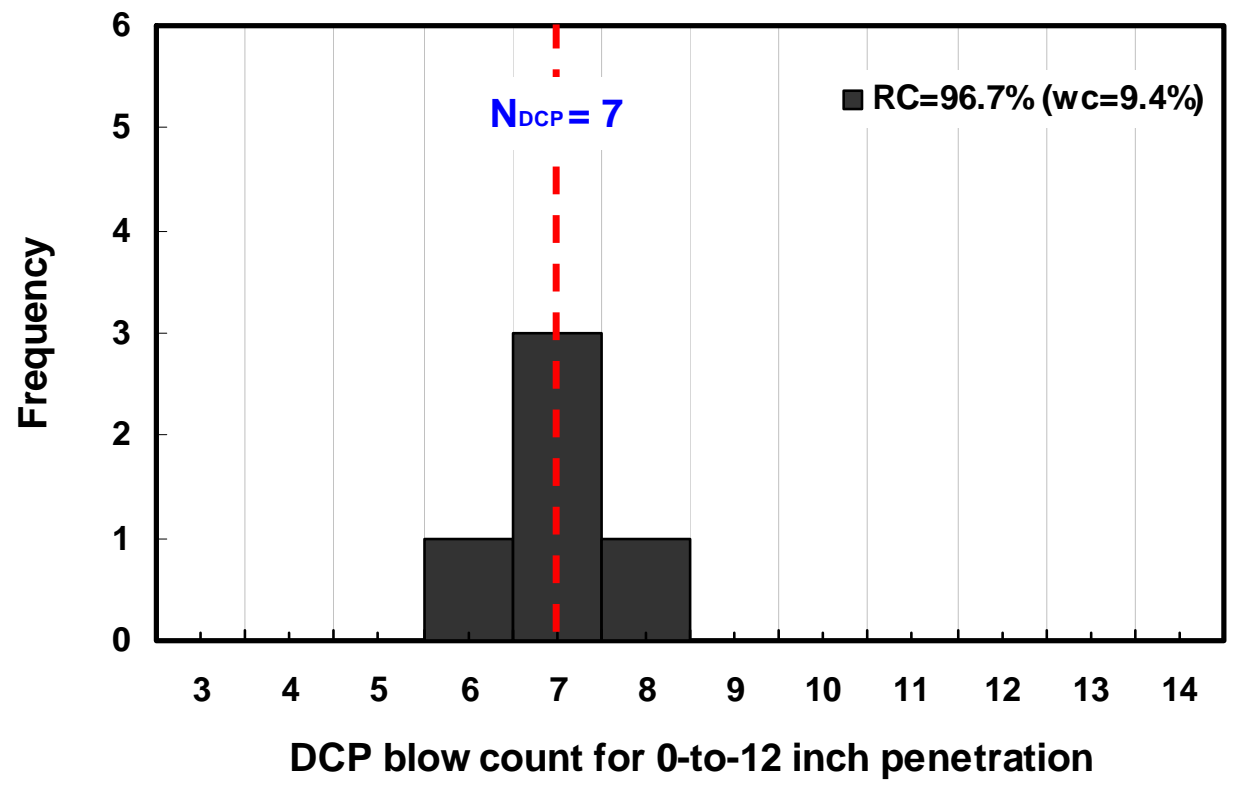

Figure 6.16 Histogram of DCPT results at $96.7 \% \mathrm{RC}$ plotted together with the minimum required blow count (SR31): 0-to-12 inch penetration. 


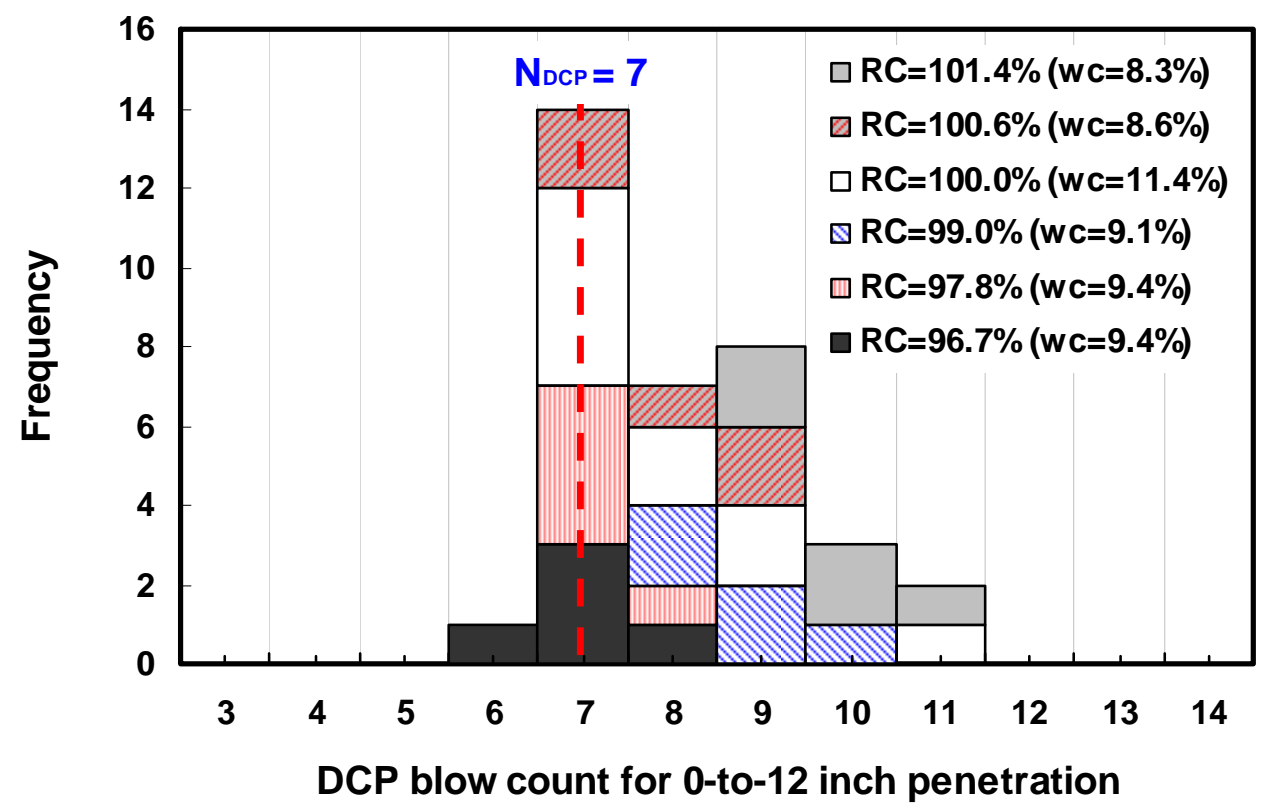

Figure 6.17 Histogram of DCPT results plotted together with the minimum required blow count (SR31): 0-to-12 inch penetration.

\subsubsection{Field Tests on I-70}

An embankment was constructed using A-3 soil as fill material as part of an I-70 extension project in Indianapolis, Indiana, and the DCPTs and CHTs were performed during the construction. For each case of relative compaction, four DCPs and CHTs were conducted along with three nuclear gauge tests.

Figure 6.18 shows the histogram of the DCPT results taken for site. Again, the RC values were computed using a $\gamma_{d \max }$ of $18.6 \mathrm{kN} / \mathrm{m}^{3}(117.1 \mathrm{pcf})$ obtained from the laboratory Standard compaction test (see Table 6.5). Also, the RC and the water content 
values in Figures 6.18 through 6.20 represent the arithmetic mean values from three nuclear gauge tests.

Based on the same approach that we employed for the previous sites, the minimum required blow count that was associated with $80 \%$ exceedance for the test results in the histogram of the test results corresponding to $95.0 \% \mathrm{RC}$ was 8 . However,

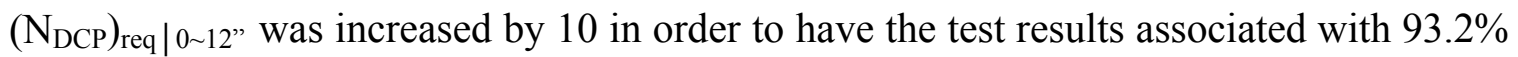
$\mathrm{RC}$ be less or equal to the minimum required blow count, as shown in Figure 6.20. In

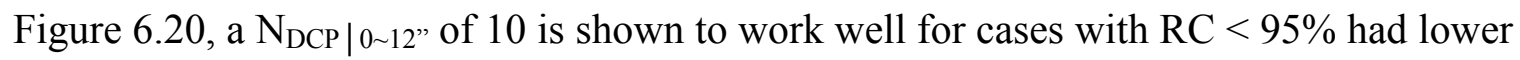
blow counts and cases with $\mathrm{RC}>95 \%$ had higher blow counts.

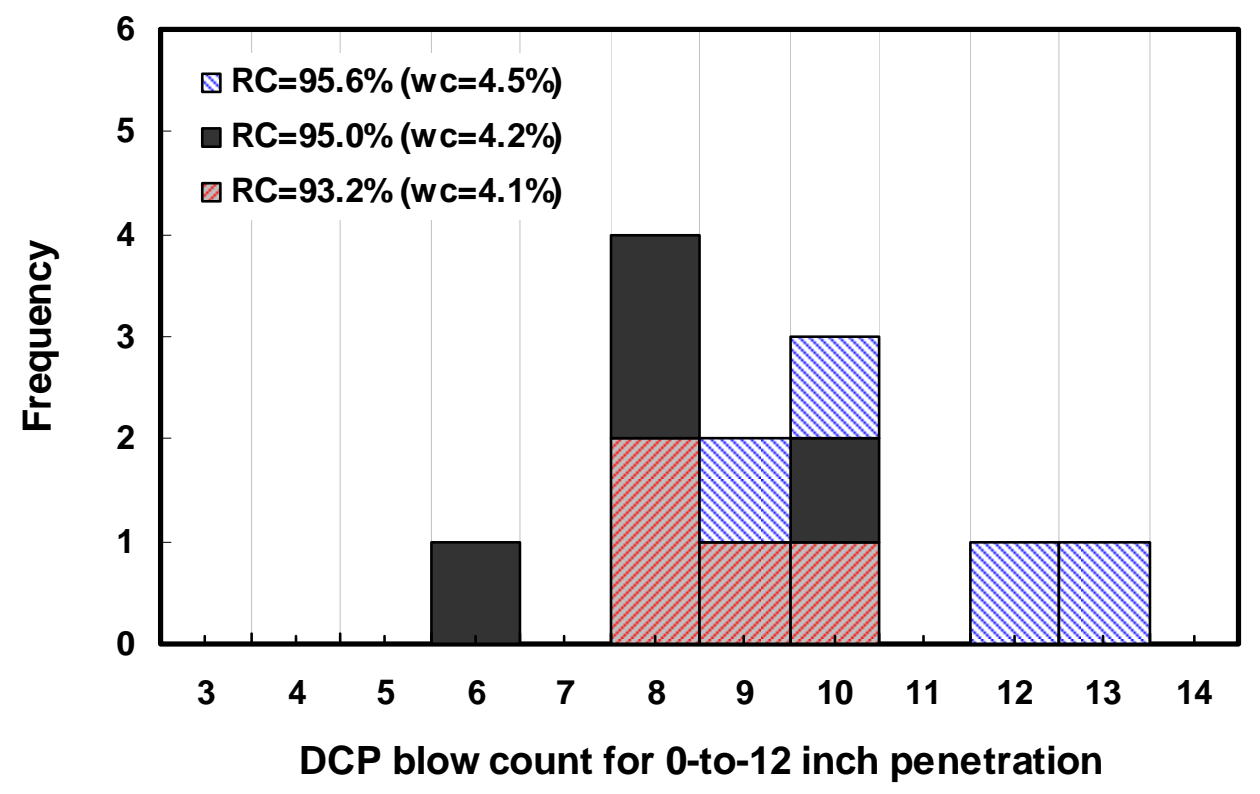

Figure 6.18 Histogram of DCPT results (I-70): 0-to-12 inch penetration. 


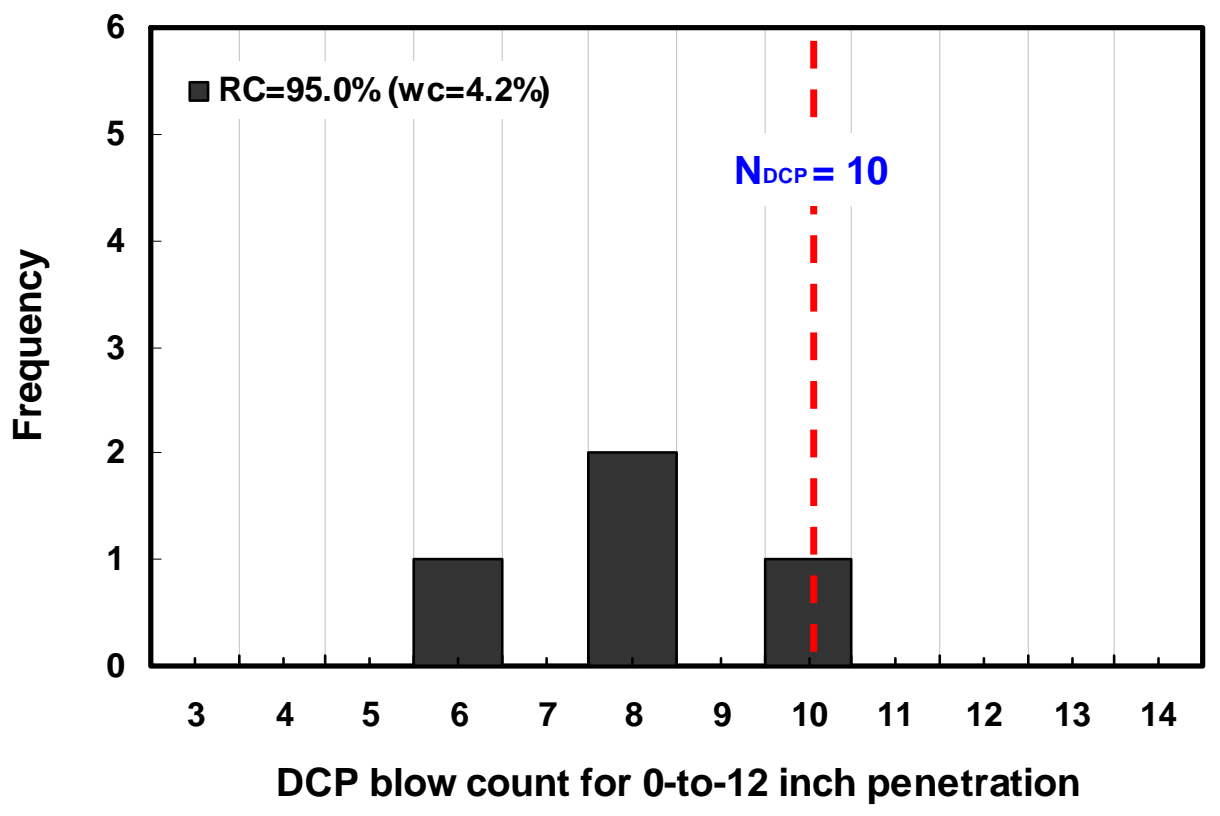

Figure 6.19 Histogram of DCPT results at 95.0\% RC plotted together with the minimum required blow count (I-70): 0 -to-12 inch penetration.

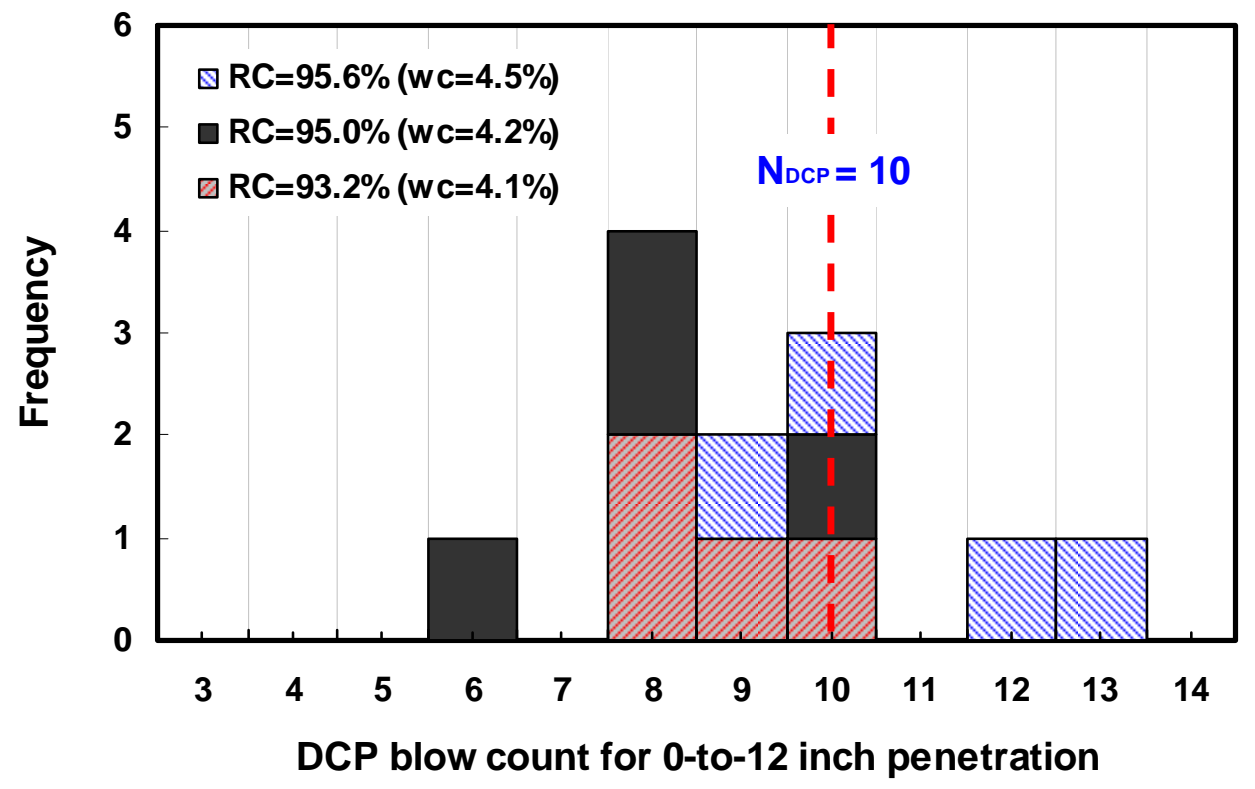

Figure 6.20 Histogram of DCPT results plotted together with the minimum required blow count (I-70): 0-to-12 inch penetration. 
Figure 6.21 shows RC versus CIV for the I-70 site. The CIV vs. RC relationship is highly variable. The CHT results showed that the CIV associated with a RC of 95\% was on an average 5.6, with a 4.8 6.6 range.

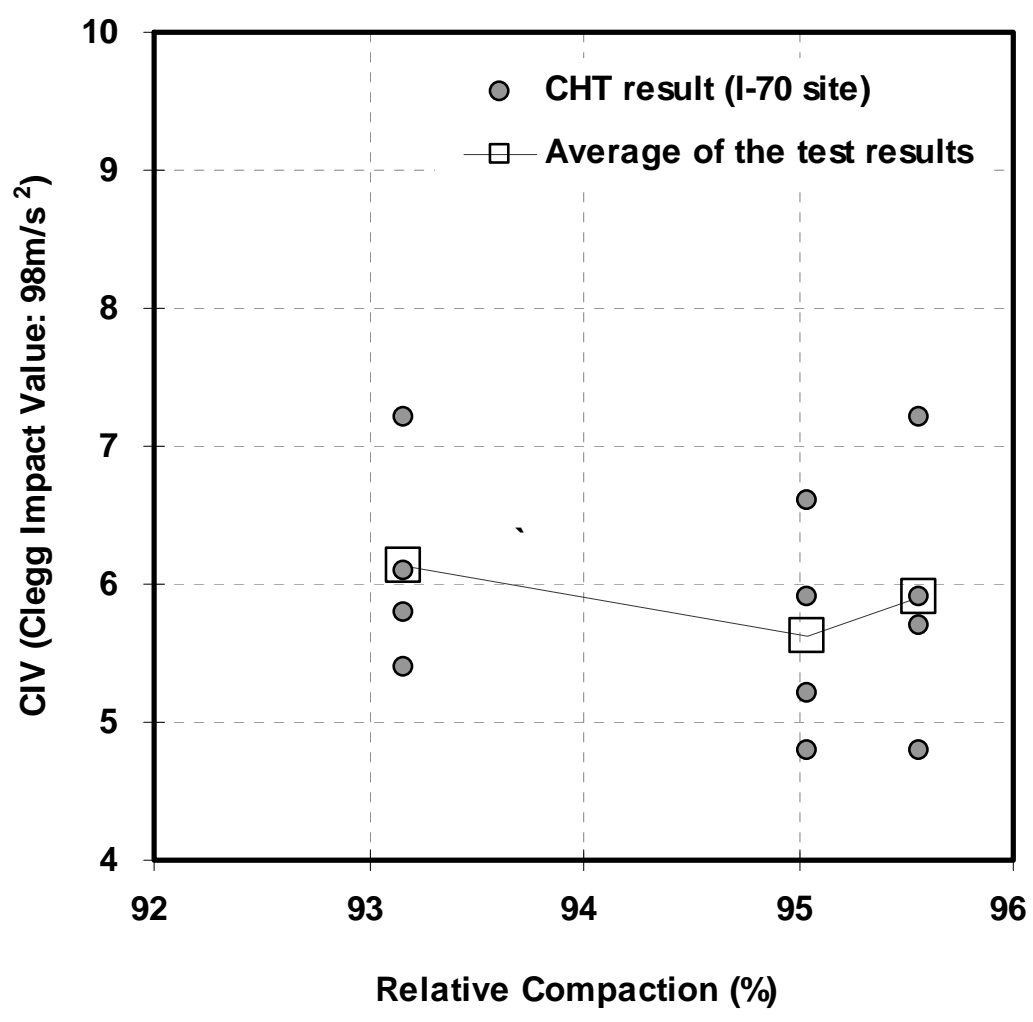

Figure 6.21 CIV versus relative compaction (I-70). 


\subsubsection{Summary of Test Results on A-3 Soils}

Table 6.6 summarizes the DCP test results with the coefficient of uniformity $\left(C_{u}\right)$ and the compaction properties. Table 6.6 also contains the DCP test results performed in the chamber at Purdue University. In the case of A-3 soils, the minimum required blow count, $\left(\mathrm{N}_{\mathrm{DCP}}\right)_{\text {req }}$ 0 12", corresponding to a RC of 95\% varies from 7 to 10 .

Table 6.6 Summary of the DCP results with the coefficient of uniformity $\left(C_{u}\right)$ and compaction properties on A-3 soil

\begin{tabular}{|c|c|c|c|c|c|}
\hline \multicolumn{2}{|c|}{ Test site } & SR25 & SR31 & $\mathrm{I}-70$ & $\begin{array}{c}\text { DCPT in the } \\
\text { Chamber }\end{array}$ \\
\hline \multicolumn{2}{|c|}{ AASHTO classification } & A-3 & A-3 & A-3 & A-3 \\
\hline \multicolumn{2}{|c|}{$\begin{array}{l}\text { Coefficient of } \\
\text { uniformity }\left(C_{u}\right)\end{array}$} & 5.06 & 2.92 & 6.01 & 1.67 \\
\hline \multirow{2}{*}{$\gamma_{d \max }$} & $\left(\mathrm{kN} / \mathrm{m}^{3}\right)$ & 18.5 & 17.1 & 18.4 & $17.7^{\dagger}$ \\
\hline & (pcf) & 117.9 & 108.5 & 117.1 & $112.3^{\dagger}$ \\
\hline \multicolumn{2}{|c|}{$w C_{o p t}(\%)$} & 12.1 & 12.8 & 12.1 & - \\
\hline \multicolumn{2}{|c|}{$\left(\mathrm{N}_{\mathrm{DCP}}\right)_{\mathrm{req}} \mid 0 \sim 12 ”$} & 9 & 7 & 10 & $4 *$ \\
\hline
\end{tabular}

$\dagger$ Maximum dry unit weight were obtained using a vibratory table (ASTM D4253-00)

* The minimum required blow counts are taken from the test results associated with a $\mathrm{RC}$ of $98.1 \%$

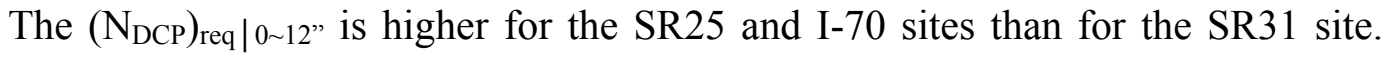
Two factors can explain this outcome. First, the Coefficient of uniformities $\left(C_{u}\right)$ of the soils at the SR25 and I-70 sites were both higher than that of the soil at the SR31 site (see Table 6.6). So a higher $C_{u}$ results in a higher minimum required blow count within a small range. Second, the soils at the SR25 and I-70 sites involved higher percentages 
retained on the \#10 sieve $(2 \mathrm{~mm})$ than the SR31 site. This higher percentage of large size particles may increase or sometimes distort the DCP test results. Note that, if the soil contains a significant amount of gravel-size particles (more than $2 \mathrm{~mm}$ in equivalent grain size per the AASHTO classification), the DCPT should be avoided as a tool for soil compaction quality control.

In summary, we propose the $\left(\mathrm{N}_{\mathrm{DCP}}\right)_{\mathrm{req}} \mid 0 \sim 12$ " for A-3 soils that is a function of the coefficient of uniformity as shown in Figure 6.22. The same figure shows the values proposed by White et al. (1999). Based on numerous DCP tests on A-3 soil, White et al. (1999) proposed that the DCP index would have to be less than or equal to $35 \mathrm{~mm} / \mathrm{blow}$, which is equivalent to $\mathrm{N}_{\mathrm{DCP} \mid 0 \sim 12 "} \geq 8$.7. This blow count was deemed required to achieve $D_{R} \geq 80 \%$ in $90 \%$ of the tests (Larsen et al. 2007). According to Lee and Singh (1971), a $D_{R}$ of $80 \%$ is associated with a $R C$ of $96 \%$, while a $R C$ of $95 \%$ corresponds to a $D_{R}$ of 75\%. However, White et al. (1999) did not account for the difference in DCP test results based on changes in the coefficient of uniformity. 


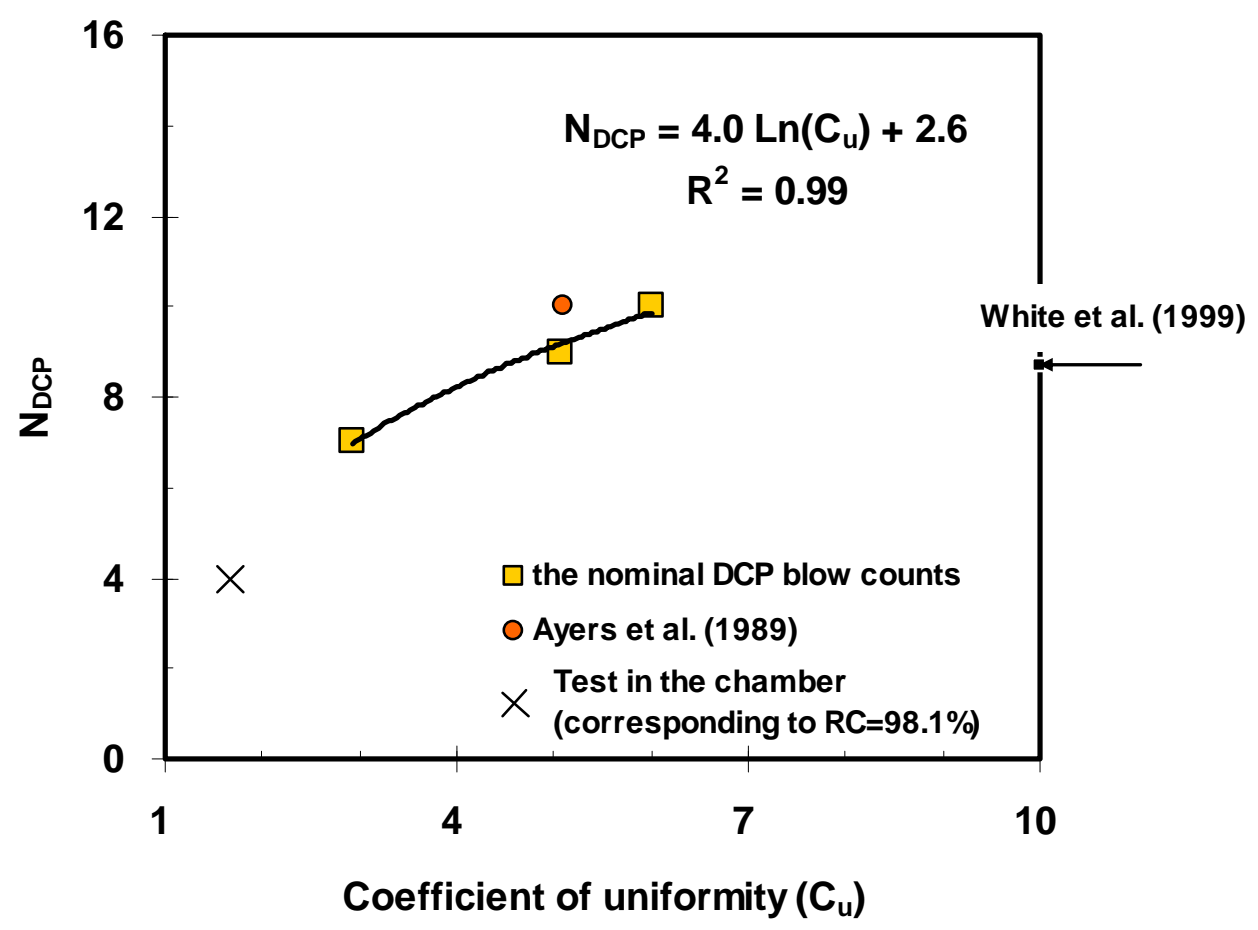

Figure 6.22 The coefficient of uniformity versus the $\left(\mathrm{N}_{\mathrm{DCP}}\right)_{\text {req }} \mid 0 \sim 12$ " for $\mathrm{A}-3$ soils.

With respect to the CHT results, the CIV versus RC relationship was found to be highly variable. The CHT results showed that the CIV associated with a RC of $95 \%$ was, on average, 5.6 with a $4.8 \sim 6.6$ range at the I-70 site. 


\subsection{Field Tests on A-1 and A-2 Soils}

Five different soils at three construction sites were selected for field testing on "granular" soils. The majority of the soils presented in this section are A-2 soils, which consist of "granular" soils with small percentages of fine particles, less than $35 \%$ passing the \# 200 sieve per the AASHTO classification.

Figure 6.23 shows the particle-size distribution of the soils. The soils shown in the figure are classified as either A-1 or A-2 soil as per the AASHTO classification. Figure 6.24 provides the compaction curves of five soil samples taken from the sites.

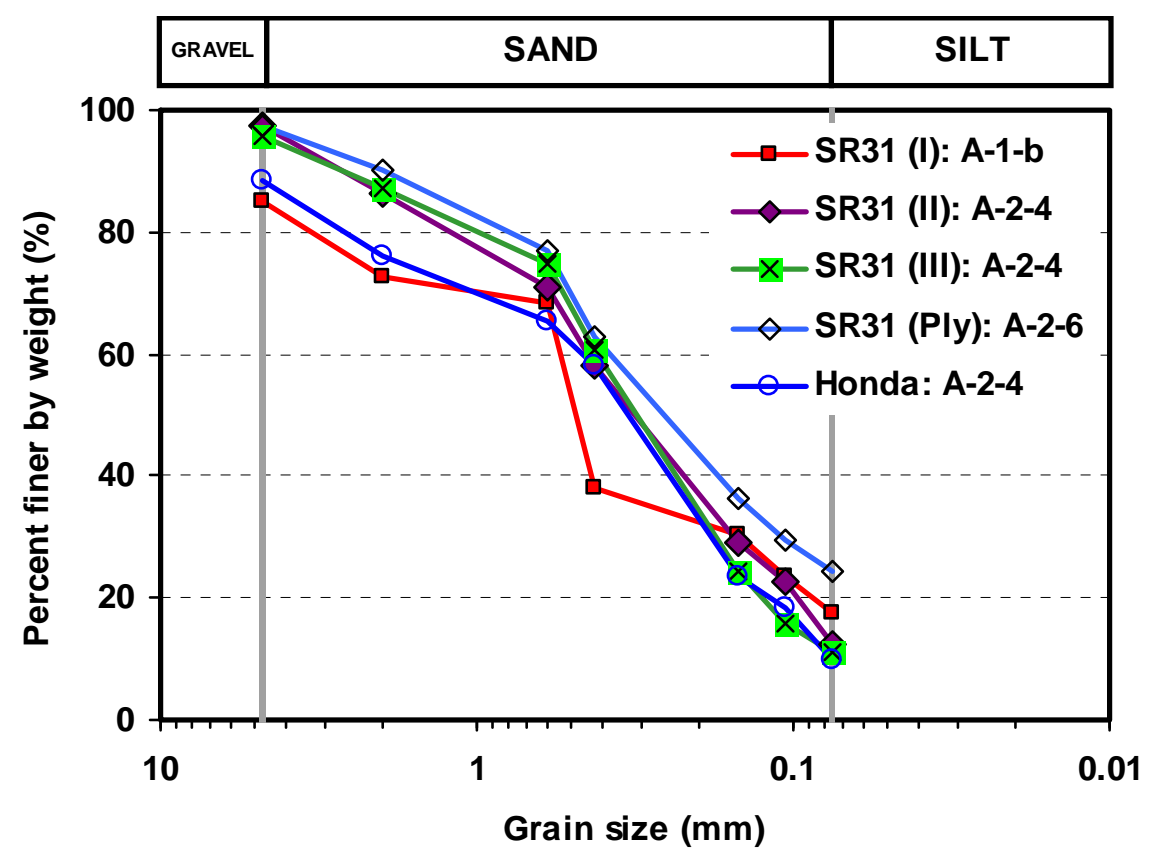

Figure 6.23 Particle-size distributions of "granular" soils. 


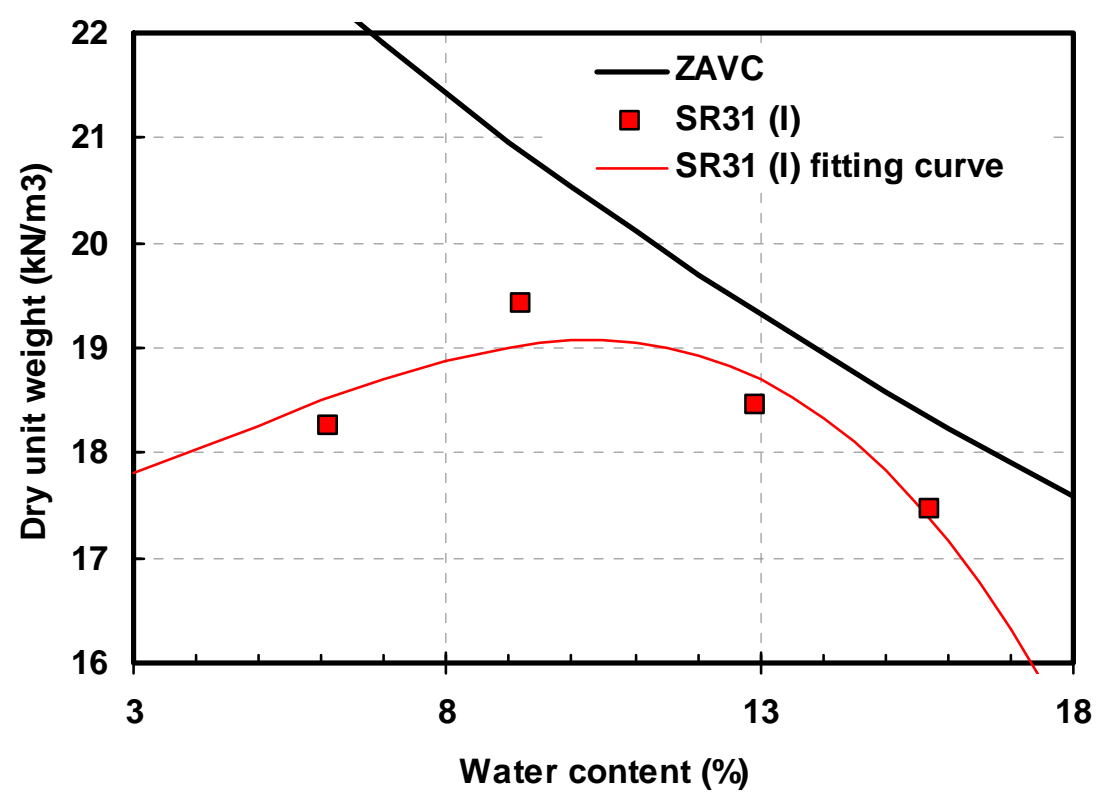

(a)

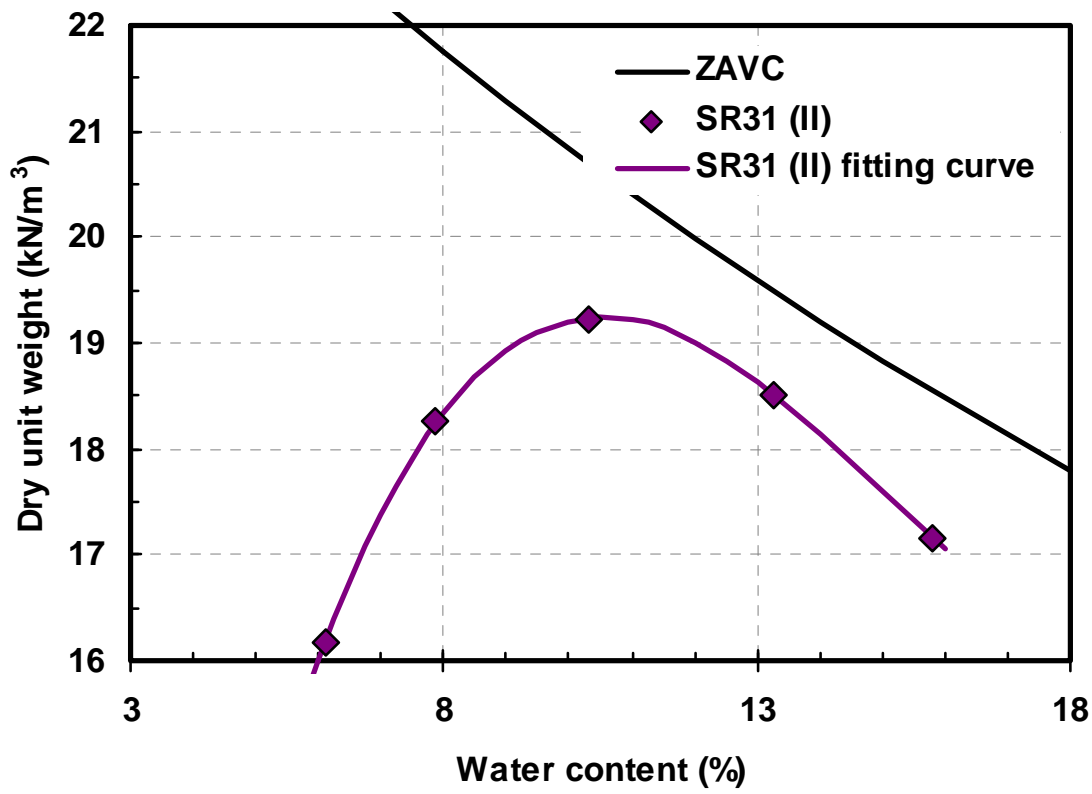

(b)

Figure 6.24 Compaction curves for the soil samples from: (a) SR31 (I) and (b) SR31 (II). 


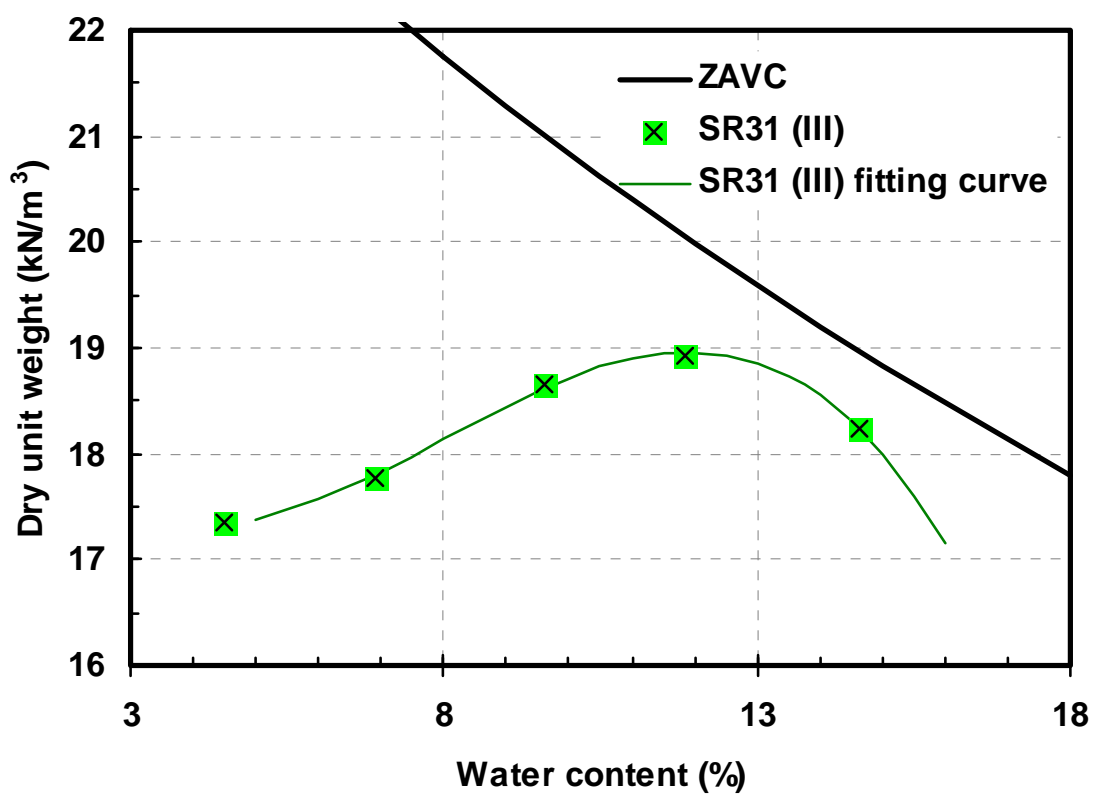

(c)

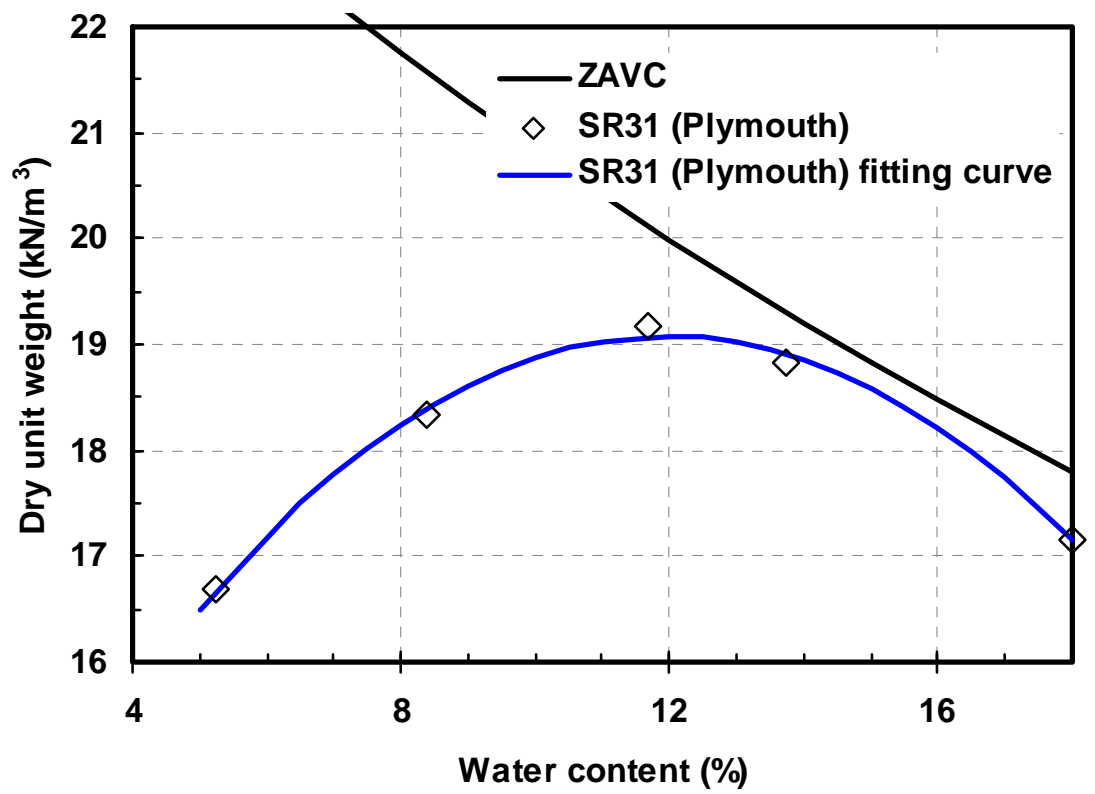

(d)

Figure 6.24 Compaction curves for the soil samples from: (c) SR31 (III) and (d) SR31 (Plymouth) (Continued). 


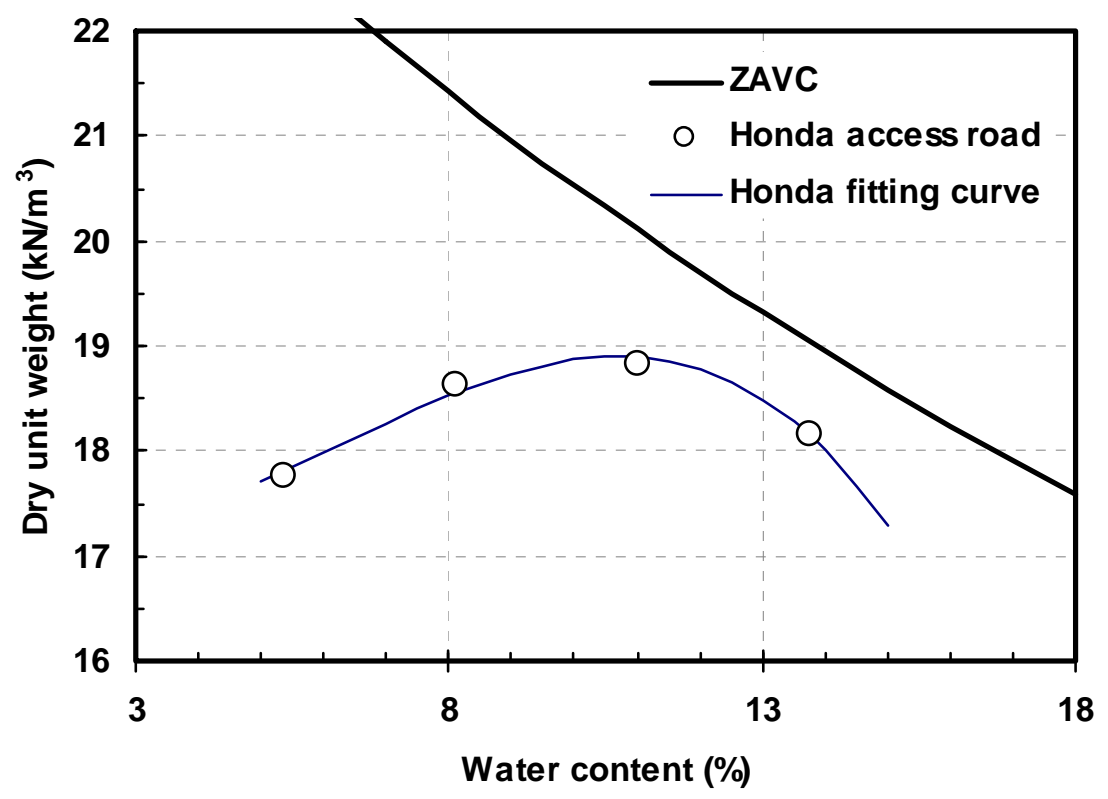

(e)

Figure 6.24 Compaction curves for the soil samples from: (a) SR31 (I) and (b) SR31 (II) (c) SR31 (III) and (d) SR31 (Plymouth) (e) Honda access road site (Continued). 
Table 6.7 summarizes the compaction and the Atterberg limit test results with AASHTO classification of the soils tested in this section.

Table 6.7 Summary of grain-size distribution analyses and compaction tests

\begin{tabular}{|c|c|c|c|c|c|c|c|}
\hline \multirow{2}{*}{ Site } & \multicolumn{3}{|c|}{ Plasticity } & \multicolumn{2}{|c|}{$\gamma_{\text {dmax }}$} & \multirow{2}{*}{$\begin{array}{c}w C_{\text {opt }} \\
(\%)\end{array}$} & $\begin{array}{c}\text { AASHTO } \\
\text { classification }\end{array}$ \\
\cline { 2 - 7 } & $P L$ & $L L$ & $P I$ & $\left(\mathrm{kN} / \mathrm{m}^{3}\right)$ & $(\mathrm{pcf})$ & 10.2 & A-1-b \\
\hline $\begin{array}{c}\text { SR31 (I) at } \\
\text { Marshall Co. }\end{array}$ & 15.0 & 17.1 & 2.1 & 19.1 & 121.3 & 10.2 & A-2-4 \\
\hline $\begin{array}{c}\text { SR31 (II) at } \\
\text { Marshall Co. }\end{array}$ & 13.4 & 21.7 & 8.3 & 19.2 & 122.4 & 10.5 & A-2-4 \\
\hline $\begin{array}{c}\text { SR31 (III) at } \\
\text { Marshall Co. }\end{array}$ & 15.5 & 17.1 & 1.6 & 19.0 & 120.6 & 12.0 & A-2-6 \\
\hline $\begin{array}{c}\text { SR31 at } \\
\text { Plymouth }\end{array}$ & 18.3 & 29.1 & 10.8 & 19.1 & 121.3 & 11.9 & A-2-4 \\
\hline $\begin{array}{c}\text { Access road to } \\
\text { Honda plant }\end{array}$ & 16.4 & 21.2 & 4.8 & 18.9 & 120.2 & 10.7 & \\
\hline
\end{tabular}

\subsubsection{Field Tests on SR31 (I)}

An embankment was constructed using A-1-b soil as fill material. The site is a part of the extension project of State Road 31 in Marshall County, Indiana.

Figure 6.25 shows the histogram of the DCPT blow counts for the site. In the figure, the RC was computed using a $\gamma_{d \max }$ of $19.1 \mathrm{kN} / \mathrm{m}^{3}(121.3 \mathrm{pcf})$ obtained from the laboratory Standard compaction test (see Table 6.7). Also, the dry unit weight and the water content were measured using the nuclear gauge test. In each case, three nuclear gauge tests were performed along with five DCP tests. The RC and the water content 
values in Figures 6.25 through 6.27 represent the arithmetic mean values from three nuclear gauge tests.

The same approach that we employed earlier was adopted in order to develop the criteria for compaction quality control for the soil. Based on the test results shown in Figure 6.26 , the minimum required blow count that was associated with $80 \%$ exceedance for the test results in the histogram of the test results corresponding to $95.1 \% \mathrm{RC}$ was 18 . In Figure 6.27, a $\mathrm{N}_{\mathrm{DCP} \mid 0 \sim 12,}$ of 18 is greater than all the DCP test results associated with a $\mathrm{RC}$ of less than $95 \%$ and even some test results corresponding to a RC of more than $95 \%$.

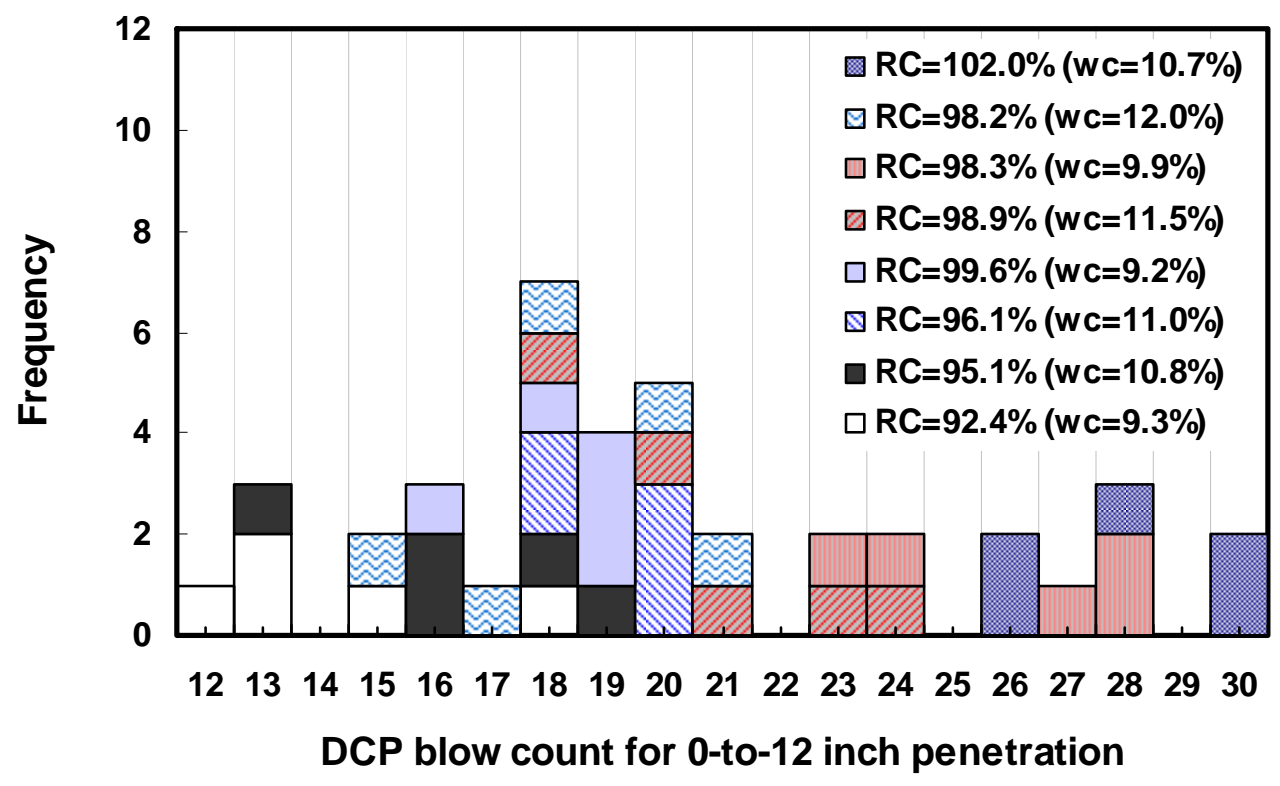

Figure 6.25 Histogram of DCPT results [SR31 (I)]: 0-to-12 inch penetration. 


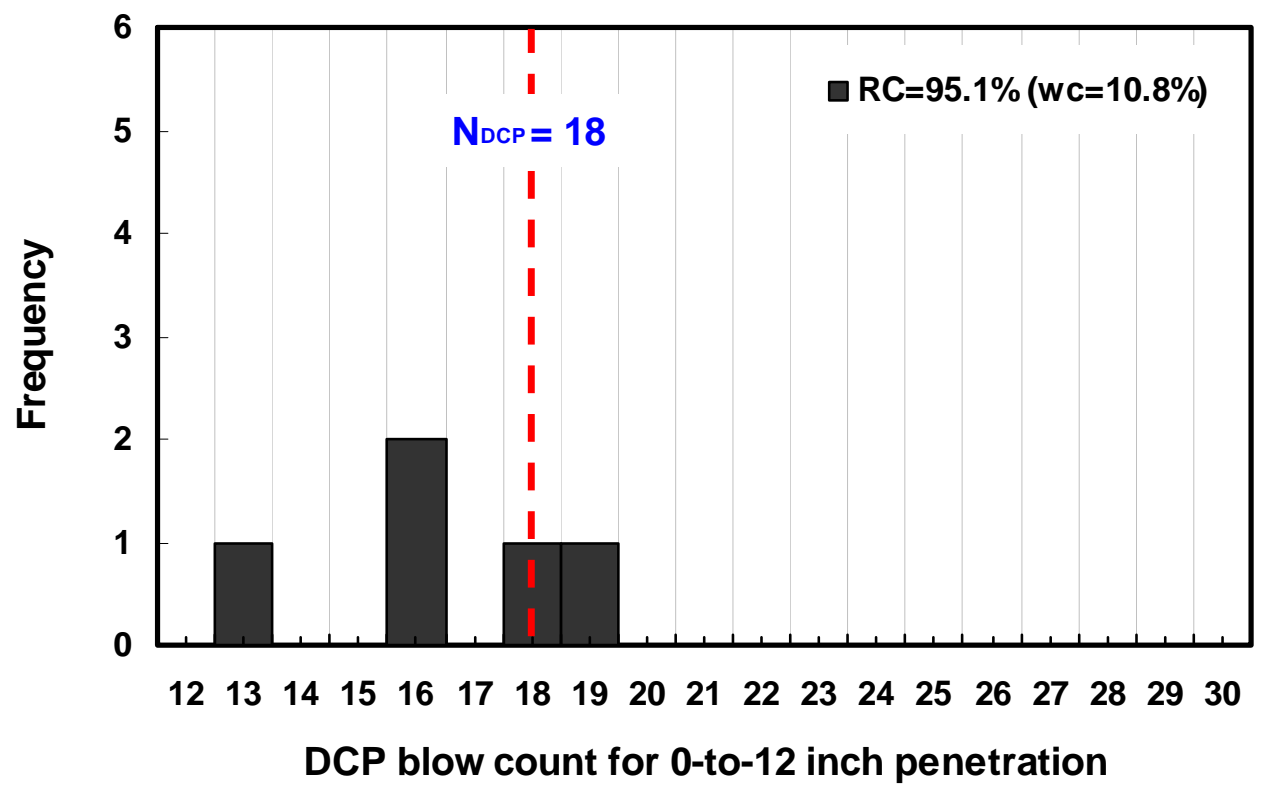

Figure 6.26 Histogram of DCPT results at 95.1\% RC plotted together with the minimum required blow count [SR31 (I)]: 0-to-12 inch penetration.

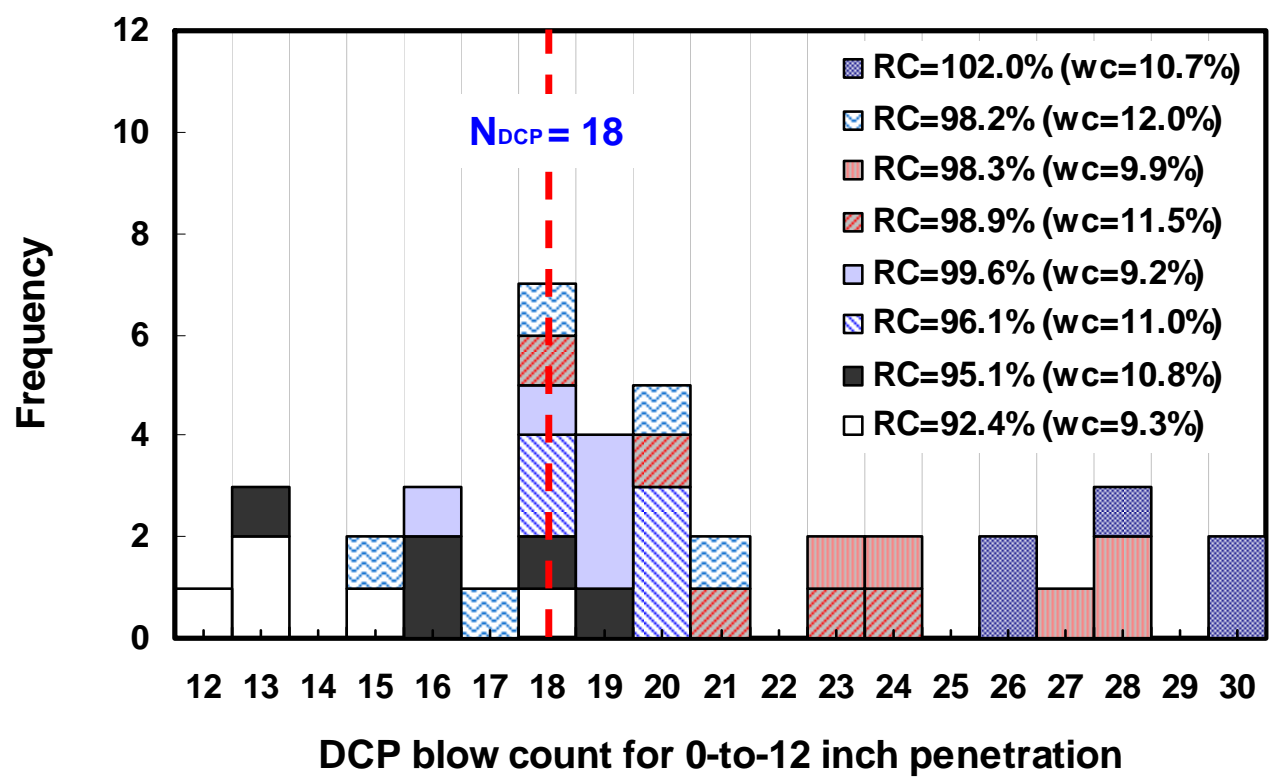

Figure 6.27 Histogram of DCPT results plotted together with the minimum required blow count [SR31 (I)]: 0-to-12 inch penetration. 


\subsubsection{Field Tests on SR31 (II)}

This site is at the same location described in the previous section. However, the soil on which the tests were performed was slightly different from those we collected from SR31 (I). This section summarizes the test results for this soil, which is an A-2-4 soil as per the AASHTO classification.

Figure 6.28 shows the histogram of the DCPT blow counts for the site. In the figure, the RC was computed using a $\gamma_{\text {dmax }}$ of $19.2 \mathrm{kN} / \mathrm{m}^{3}(122.4 \mathrm{pcf})$ obtained from the laboratory Standard compaction test (see Table 6.7). The dry unit weight and the water content were measured using the nuclear gauge test. In each case, three nuclear gauge tests were performed in combination with five DCP tests. The RC and the water content values in Figures 6.28 through 6.30 represent the arithmetic mean values from three nuclear gauge tests.

Based on the test results shown in Figure 6.28, the minimum required blow count that was associated with $80 \%$ exceedance for the test results in the histogram of the test results corresponding to $94.7 \% \mathrm{RC}$ was 15 (see Figure 6.29).

Figure 6.29 shows that the $\left(\mathrm{N}_{\mathrm{DCP}}\right)_{\text {req } \mid 0 \sim 12}$, of 15 is greater or equal to $80 \%$ of the test results associated with a $94.7 \% \mathrm{RC}$. The $\left(\mathrm{N}_{\mathrm{DCP}}\right)_{\text {req } \mid 0 \sim 12 \%}$ of 15 is also greater or equal to $80 \%$ of test results associated with a $96.3 \% \mathrm{RC}$, as shown in Figure 6.30 . We also observe that the minimum required blow count exceeds a majority of the DCP test results regardless of the RC. This may be due to the fact that the soil associated with $94.7 \%$ and $96.3 \% \mathrm{RC}$ values was compacted more to the dry of the optimum moisture content than the test results corresponding to the other $\mathrm{RC}$ values. 


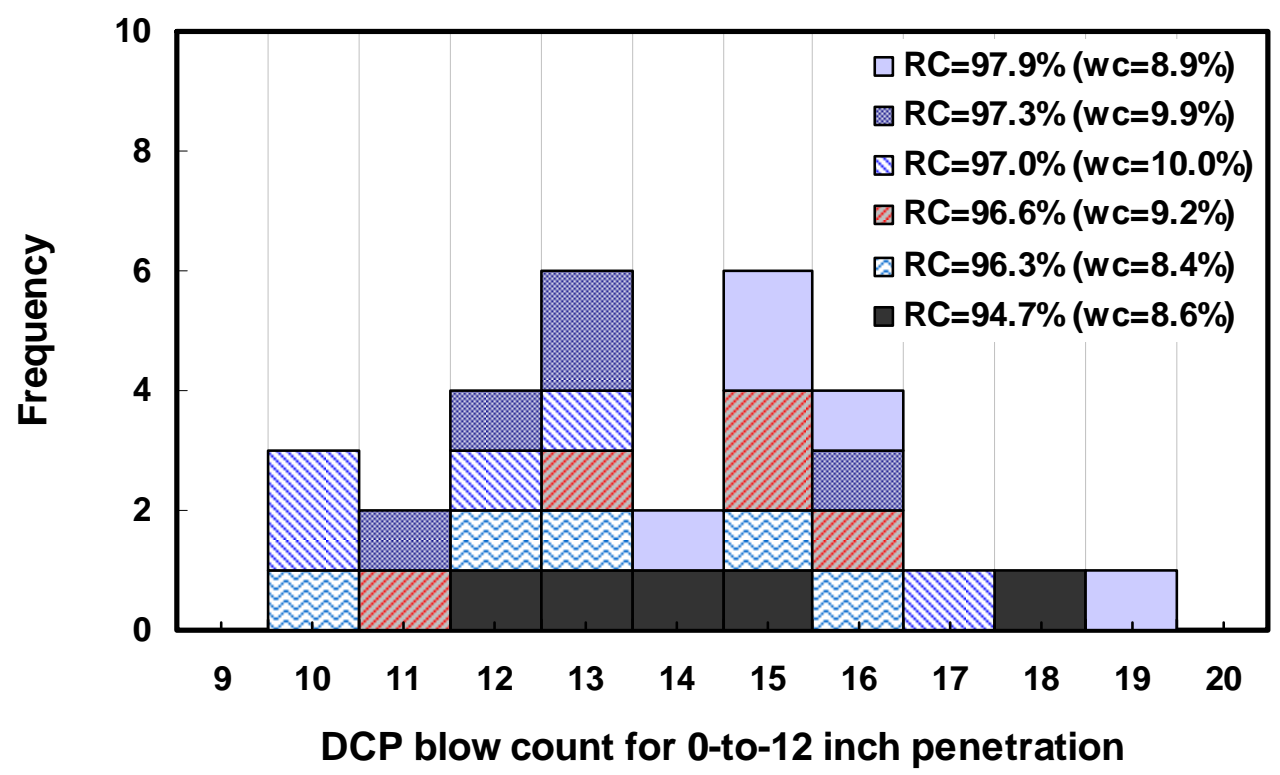

Figure 6.28 Histogram of DCPT results [SR31 (II)]: 0-to-12 inch penetration.

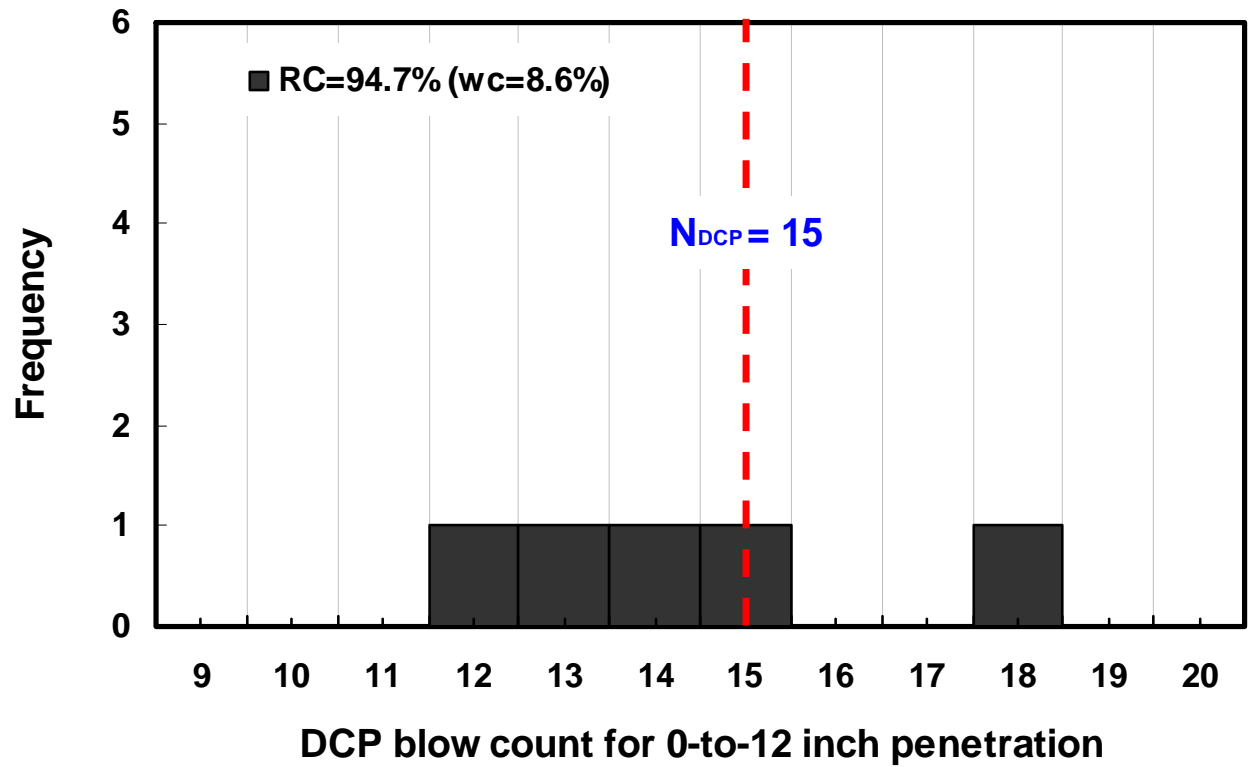

Figure 6.29 Histogram of DCPT results at $94.7 \% \mathrm{RC}$ plotted together with the minimum required blow count [SR31 (II)]: 0-to-12 inch penetration. 


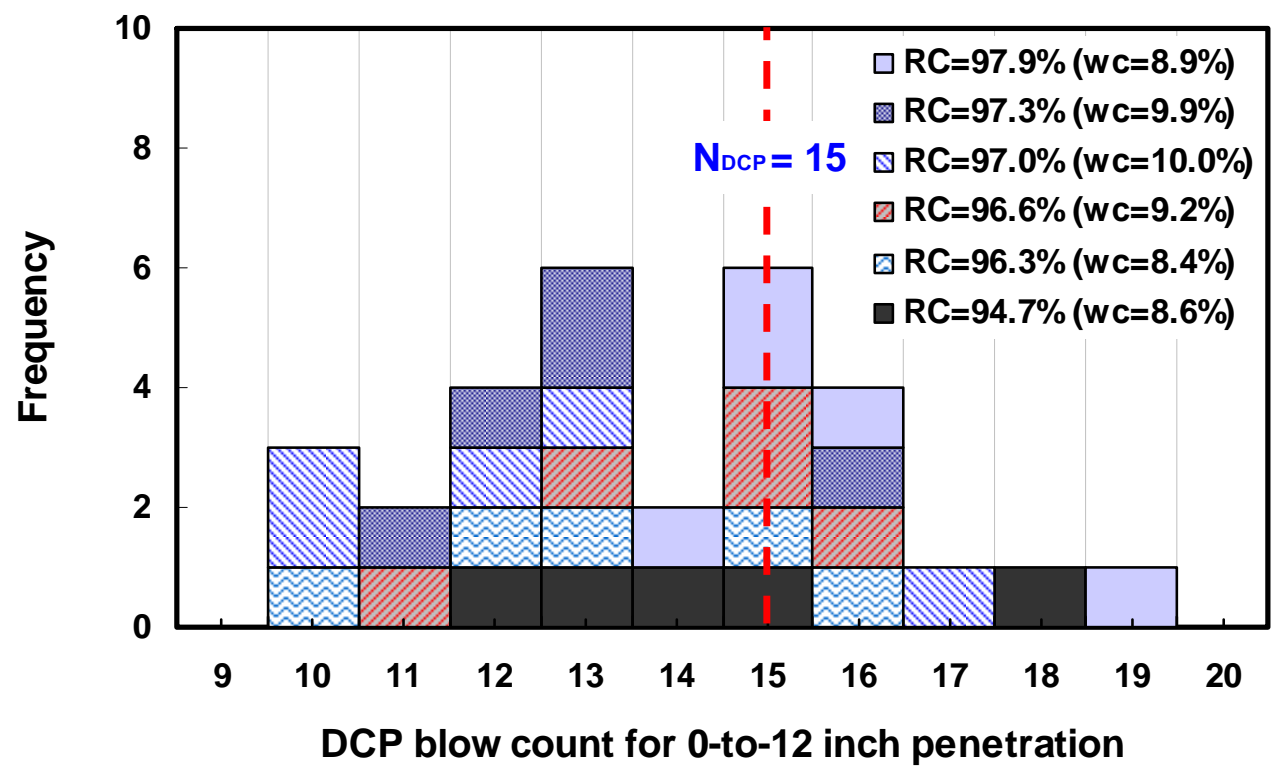

Figure 6.30 Histogram of DCPT results plotted together with the minimum required blow count [SR31 (II)]: 0-to-12 inch penetration.

\subsubsection{Field Tests on SR31 (III)}

This site is at the same location as the two previous sections. The soil is classified as A-24 according to AASHTO.

Figure 6.31 shows the histogram of the DCPT blow counts for the site. In the figure, relative compactions were computed using a $\gamma_{d \max }$ of $19.0 \mathrm{kN} / \mathrm{m}^{3}$ (120.6pcf) obtained from the laboratory Standard compaction test (see Table 6.7). The dry unit weight and the water content were measured using the nuclear gauge tests. In each case, three nuclear gauge tests were performed along with five DCP tests. The RC and water 
content values in Figures 6.31 through 6.33 represent the arithmetic mean values from three nuclear gauge tests.

Based on the test results shown in Figure 6.32, the minimum required blow count that was associated with at least $80 \%$ exceedance for the test results in the histogram of the test results corresponding to $94.8 \% \mathrm{RC}$ was 14 . Note that in order to determine the minimum required blow count for this site, test results corresponding to $94.8 \% \mathrm{RC}$ tested at $w c=8.2 \%$ were used because other test results associated with $94.8 \% \mathrm{RC}$ tested at $w c=6.6 \%$ were too dry considering the optimum moisture content of this soil, $12.0 \%$. The DCP blow count increases as the water content decreases due to the effect of a decreasing degree of saturation and increased suction. The DCP blow counts tested at $97.5 \%$ RC showed the effect of water content because the test results corresponding to $97.5 \% \mathrm{RC}$ are lower than all test results corresponding to $94.8 \% \mathrm{RC}$ tested at $w c=6.6 \%$ and some test results corresponding to $94.0 \% \mathrm{RC}$ tested at $w c=6.3 \%$. 


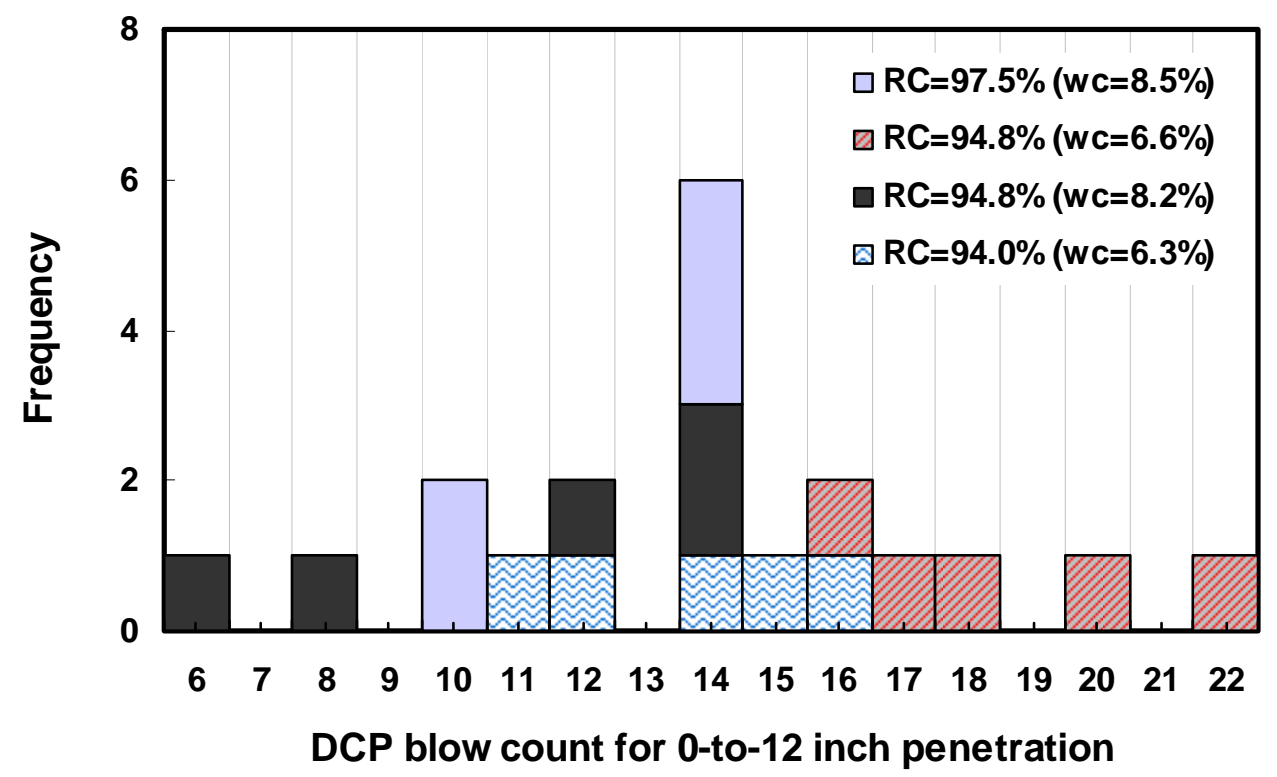

Figure 6.31 Histogram of DCPT results [SR 31 (III)]: 0-to-12 inch penetration.

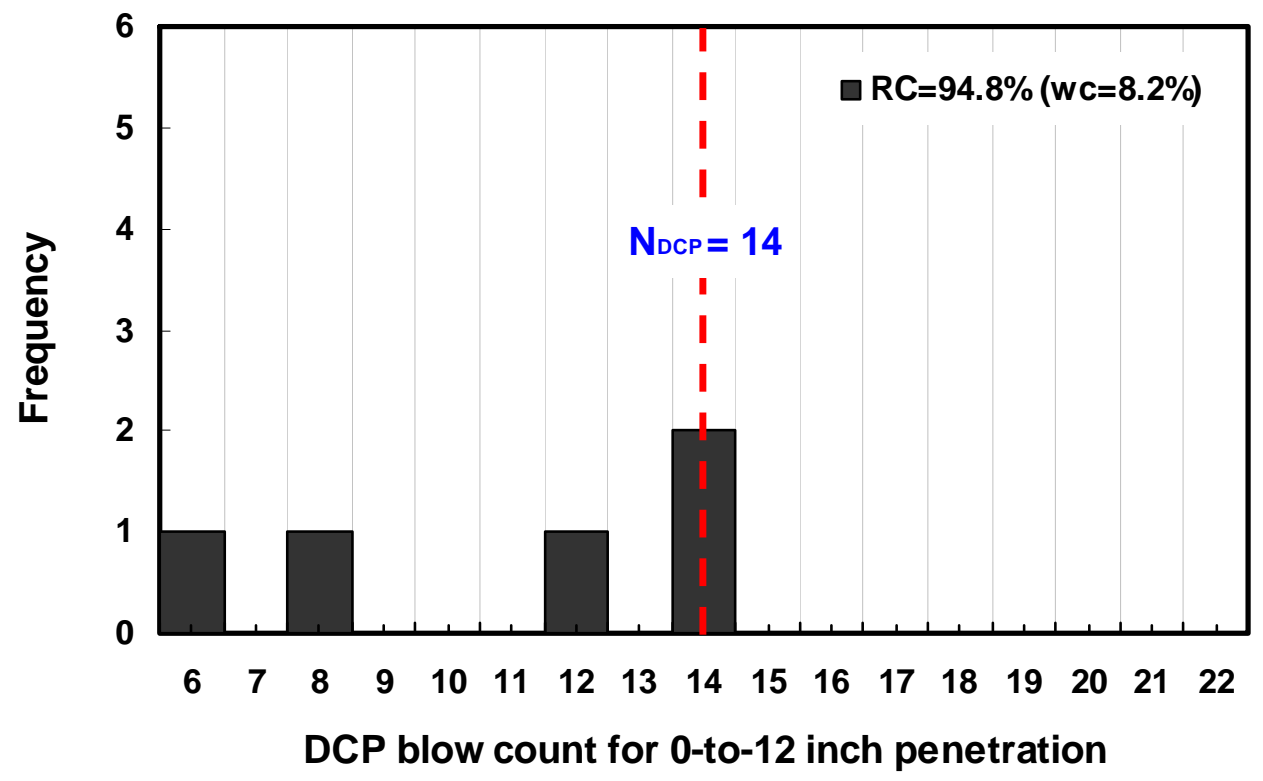

Figure 6.32 Histogram of DCPT results at $94.8 \% \mathrm{RC}$ plotted together with the minimum required blow count [SR31 (III)]: 0-to-12 inch penetration. 


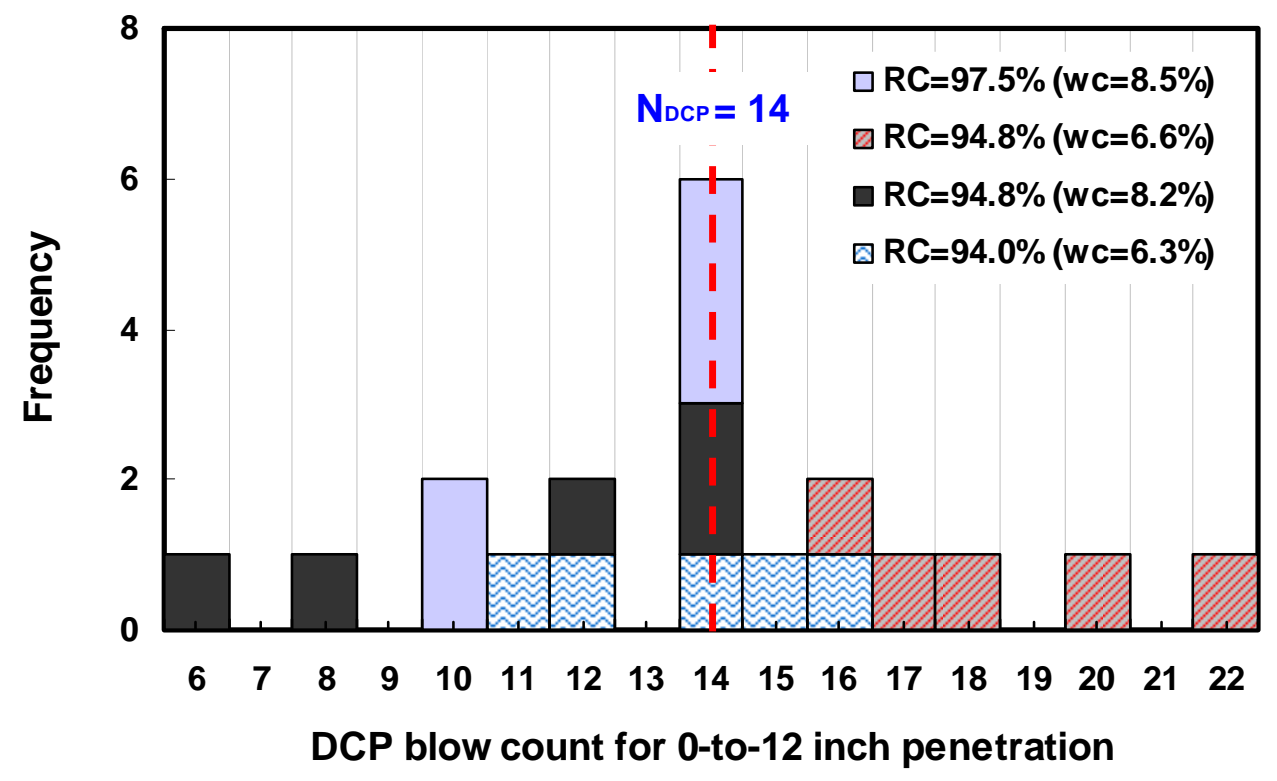

Figure 6.33 Histogram of DCPT results plotted together with the minimum required blow count [SR31 (III)]: 0-to-12 inch penetration

\subsubsection{Field Tests on SR31 (Plymouth)}

A subgrade embankment was constructed using A-2-6 soil as fill material as part of the extension project of State Road 31 in Plymouth, Indiana.

Figure 6.34 shows the histogram of the DCPT blow counts for the site. In the figure, RC was computed using a $\gamma_{d \max }$ of $19.1 \mathrm{kN} / \mathrm{m}^{3}(121.3 \mathrm{pcf})$ obtained from the laboratory Standard compaction test (see Table 6.7). Also, the dry unit weight and the water content were measured using nuclear gauge tests. In each case, three nuclear gauge tests were performed along with ten DCP tests. The RC and the water content in Figures 6.34 through 6.36 represent the arithmetic mean values from three nuclear gauge tests. 
Based on the test results, the minimum required blow count that was associated with $80 \%$ exceedance for the test results in the histogram of the test results corresponding to $95.0 \%$ RC was 13 (see Figure 6.35). In Figure 6.36, a minimum required blow count of 13 exceeds the blow counts of all DCP tests associated with RC less than $95 \%$, except one case, and even some test results corresponding to RC greater than $95 \%$.

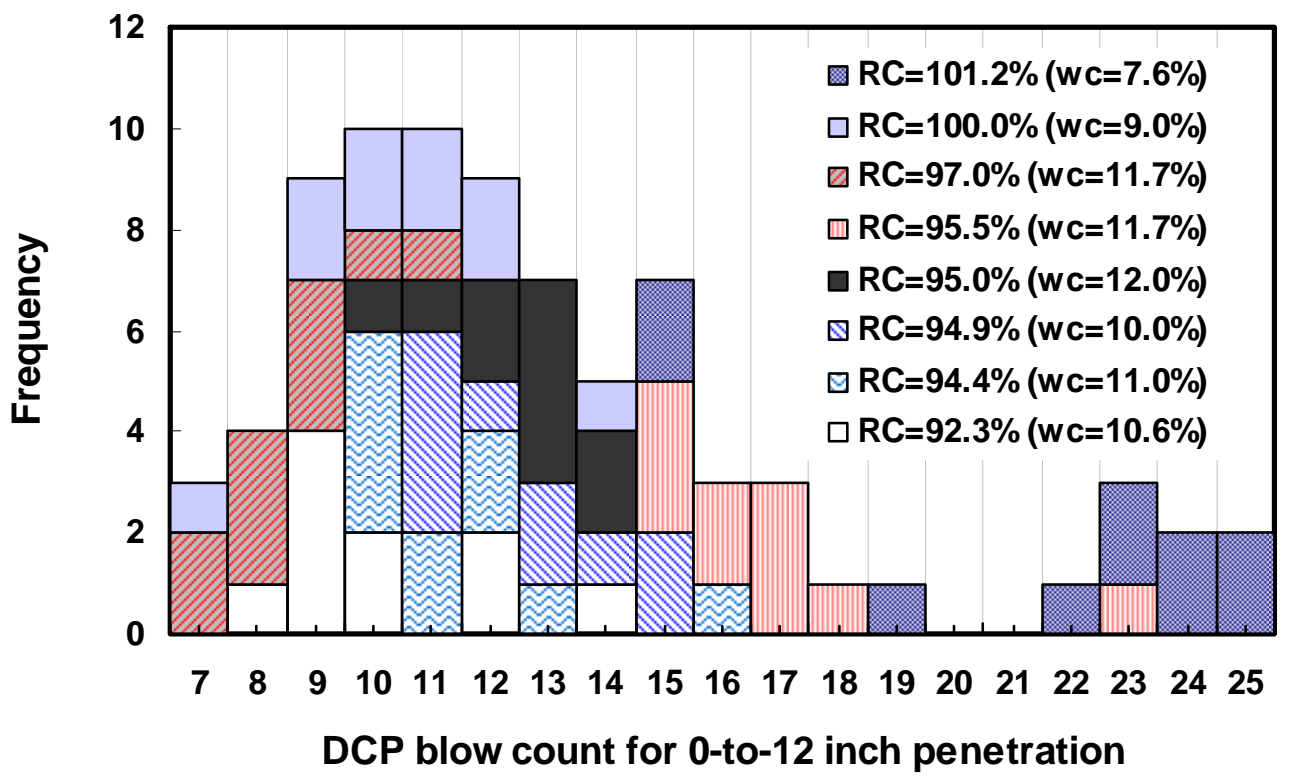

Figure 6.34 Histogram of DCPT results [SR 31 (Plymouth)]: 0-to-12 inch penetration. 


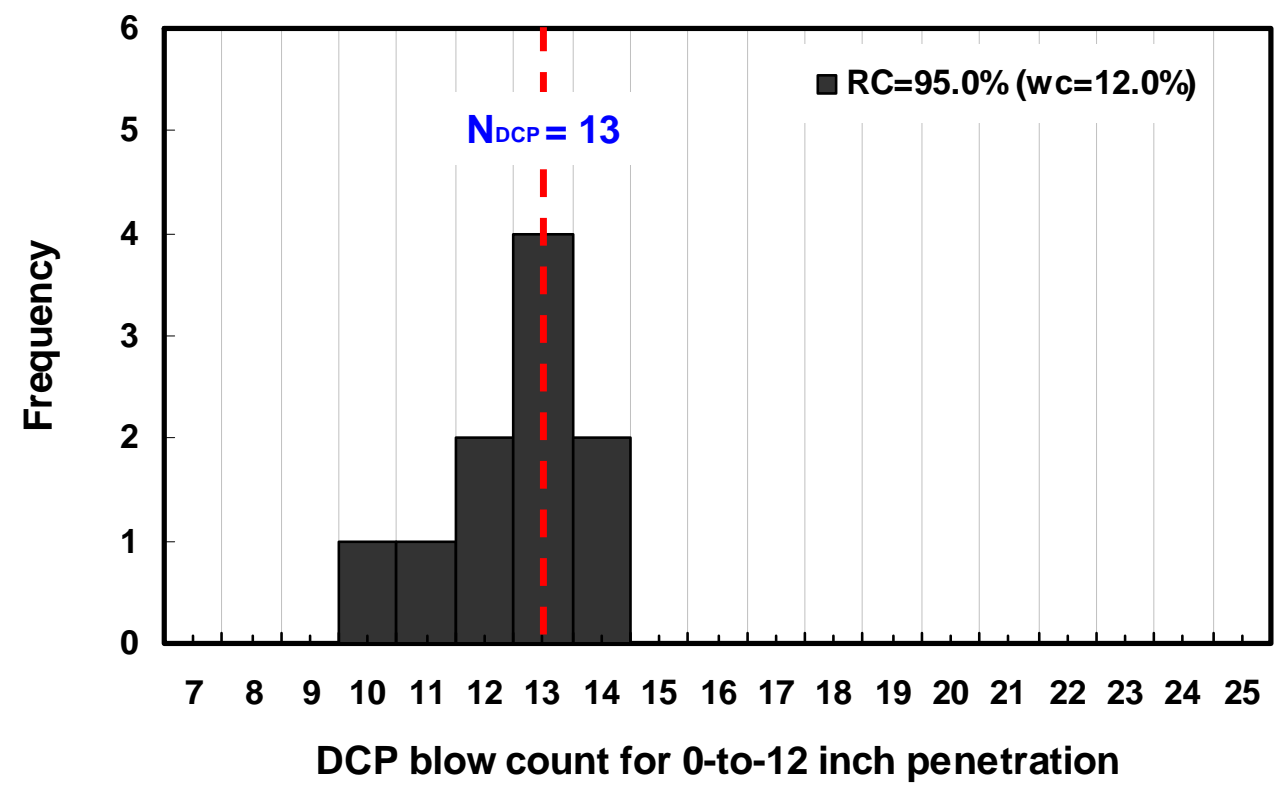

Figure 6.35 Histogram of DCPT results at 95.0\% RC plotted together with the minimum required blow count [SR 31 (Plymouth)]: 0-to-12 inch penetration.

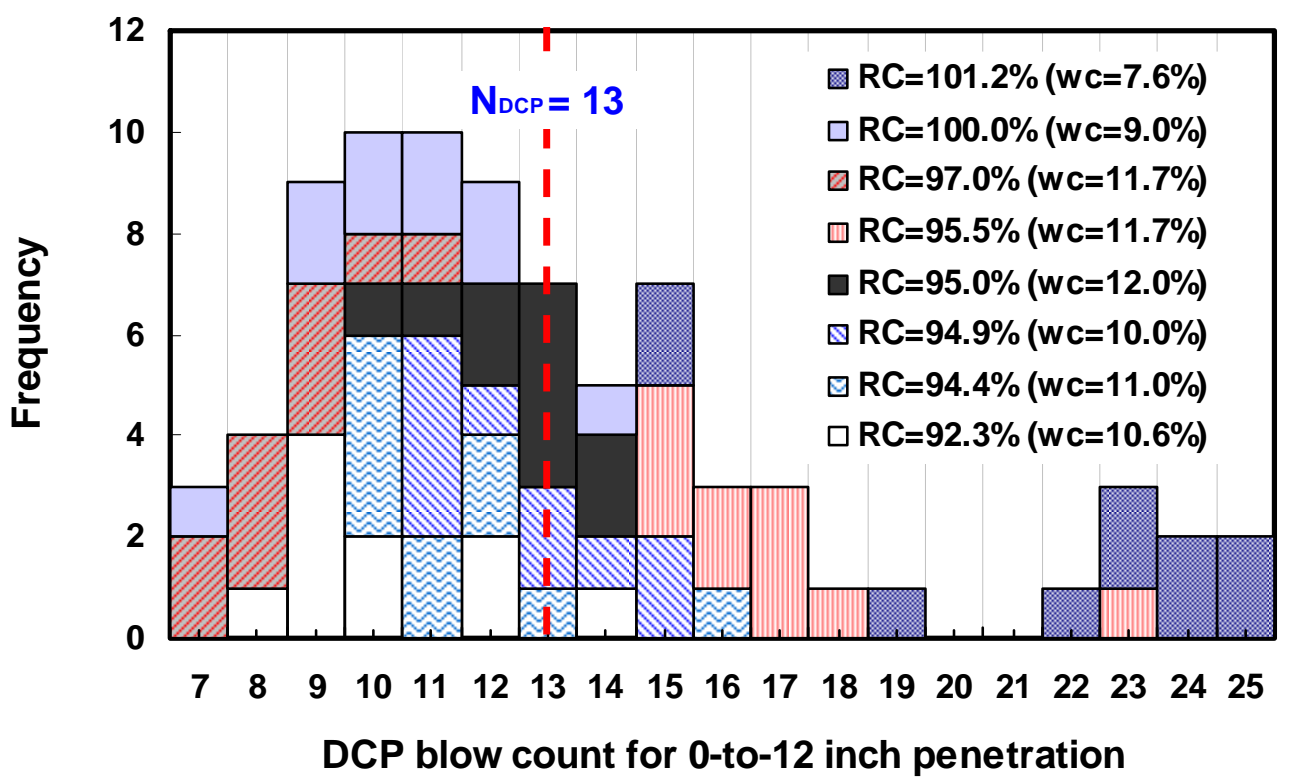

Figure 6.36 Histogram of DCPT results plotted together with the minimum required blow count [SR 31 (Plymouth)]: 0-to-12 inch penetration. 


\subsubsection{Field Tests on Access Road to Honda Plant}

A subgrade embankment was constructed using A-2-6 soil as fill material. The site was a road extension project for access to the Honda Plant located in Greensburg, Indiana.

DCPT, CHT, and nuclear gauge tests were conducted after every two roller pass at this site. Thus, several different RC values, from a very low RC up to more than $100 \%$ $\mathrm{RC}$, were attained throughout the testing on the site. Figure 6.37 shows histogram of DCPT results taken from the site. The $\left(\mathrm{N}_{\mathrm{DCP}}\right)_{\mathrm{req}} \mid 0 \sim 12$, that was associated with at least $80 \%$ exceedance for the test results in the histogram of the test results corresponding to 95.6\% RC was 15 (see Figure 6.38). In the same way, a ( $\left.\mathrm{N}_{\mathrm{DCP}}\right)_{\text {req }} \mid 0 \sim 12$ " of 15 was assessed with the entire test results (see Figure 6.39).

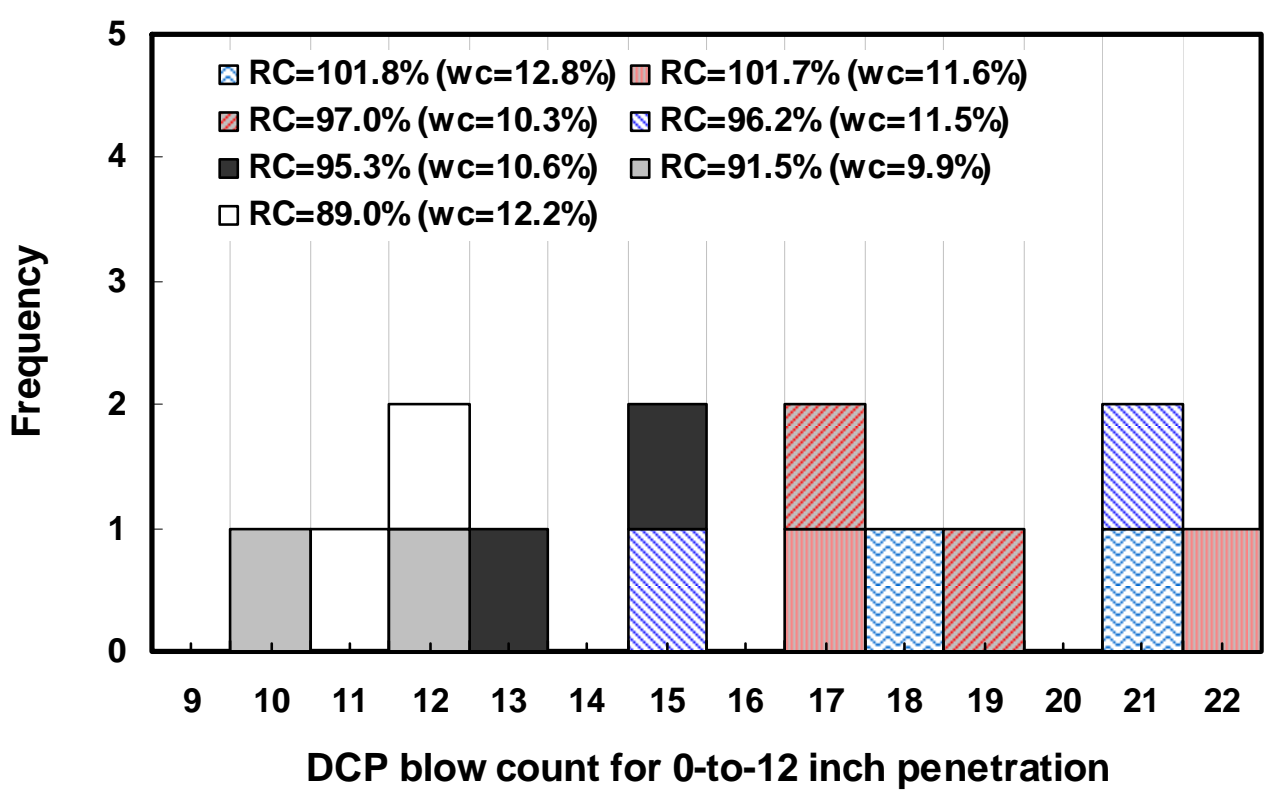

Figure 6.37 Histogram of DCPT results (access road to Honda plant): 0-to-12 inch penetration. 


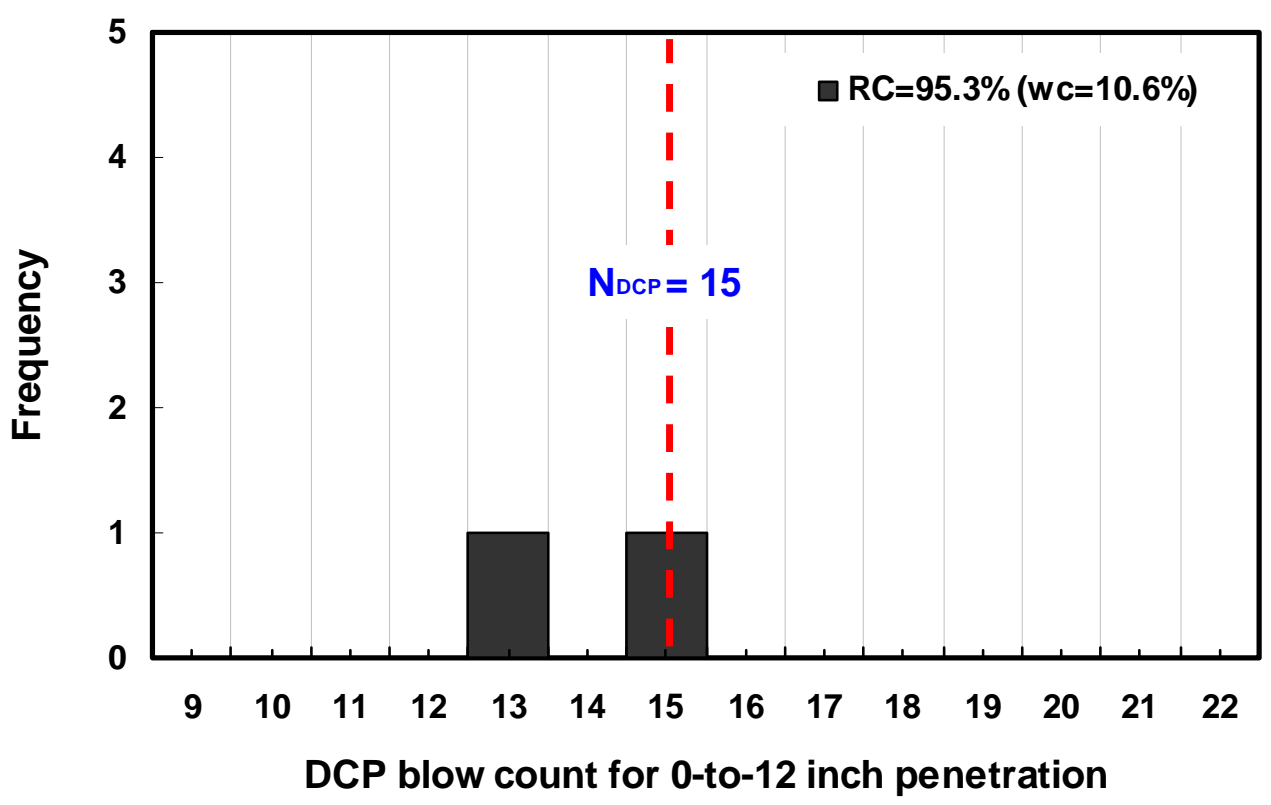

Figure 6.38 Histogram of DCPT results at 95.3\% RC plotted together with the minimum required blow count (access road to Honda plant): 0 -to-12 inch penetration

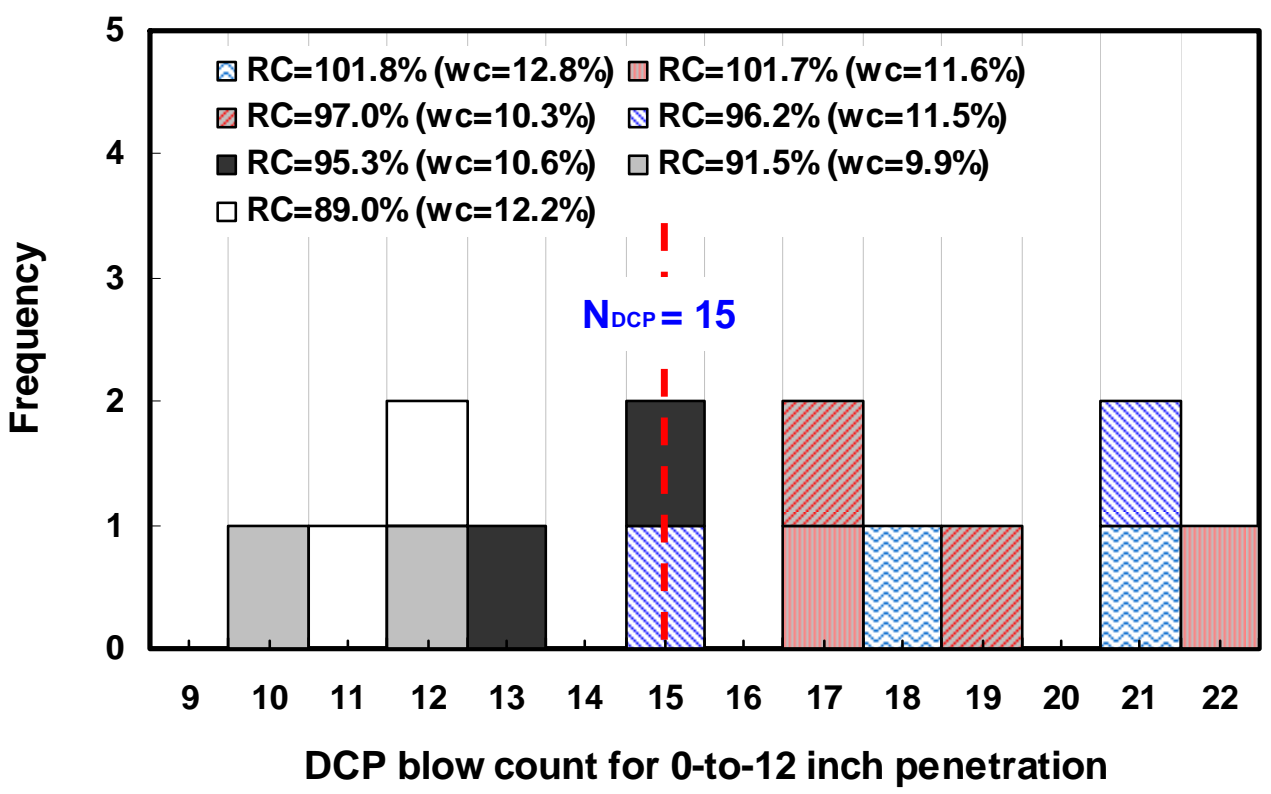

Figure 6.39 Histogram of DCPT results plotted together with the minimum required blow count (access road to Honda plant): 0-to-12 inch penetration. 
Figure 6.40 shows the CIV versus RC for the access road to Honda site. The trend observed for the CHT results in the test pit (i.e., the higher the $\mathrm{RC}$, the greater the CIV) was not observed. The average of the test results also decreased as the RC increased. The test results shown in Figure 6.40 can be explained by the water content of the soil tested at each relative compaction. Figure 6.41 illustrates the water content versus the CHT test results.

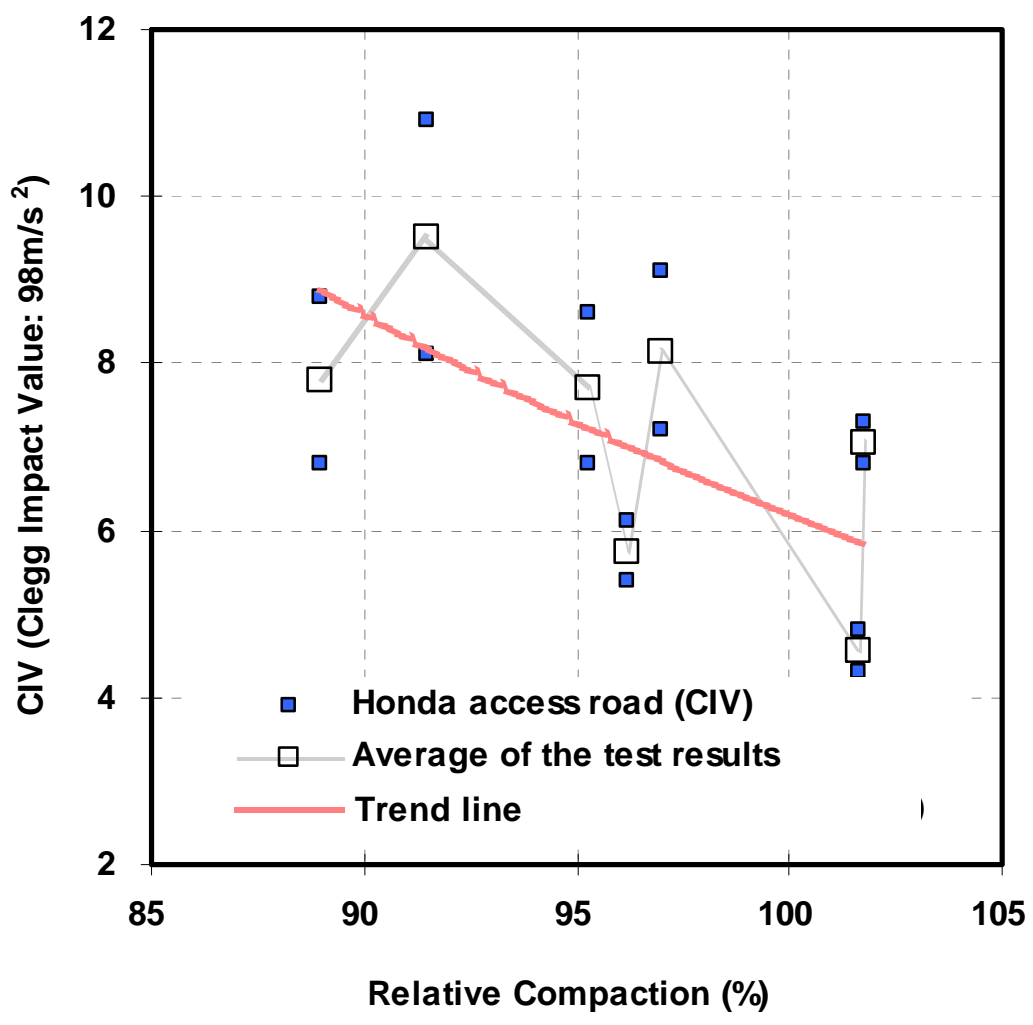

Figure 6.40 CIV versus relative compaction (access road to Honda plant). 


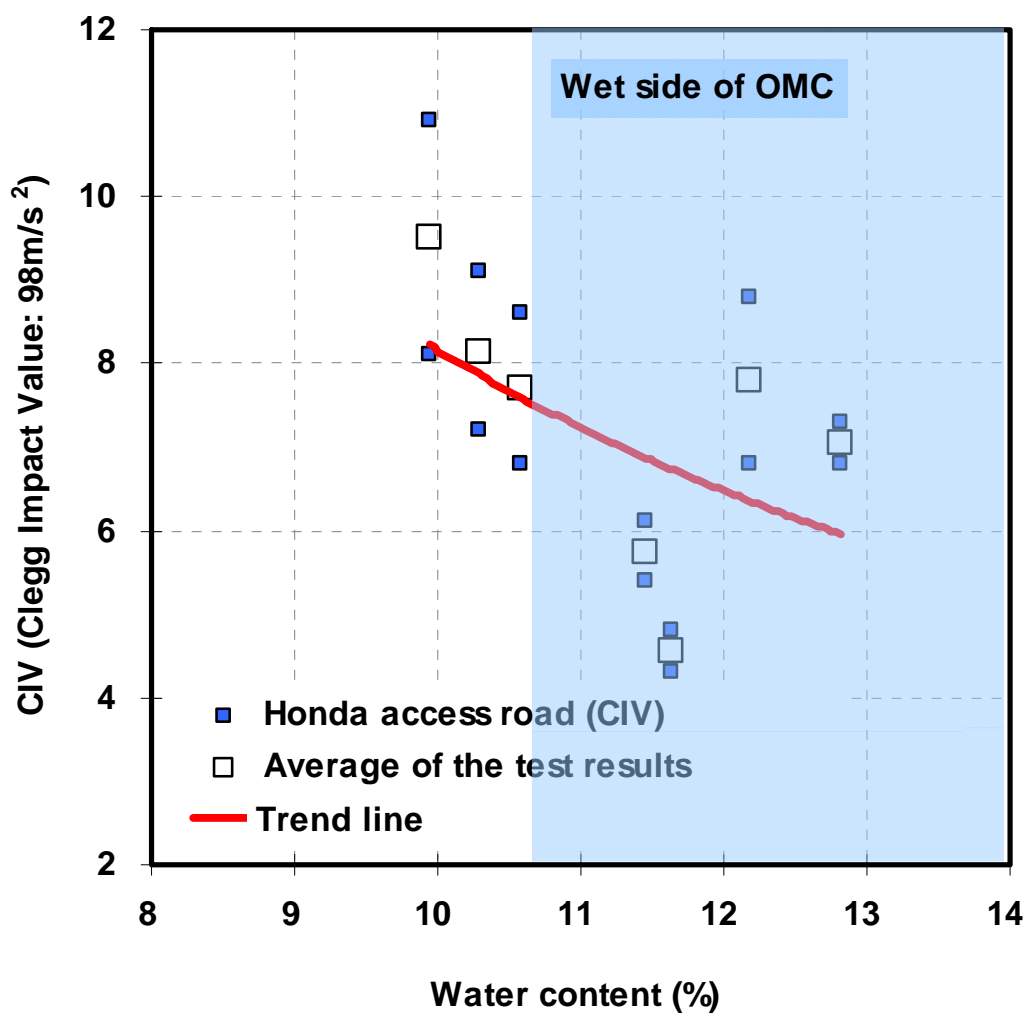

Figure 6.41 The CHT results vs. water contents (access road to Honda plant).

The dynamic resistance of soil increases as the water content decreases due to the effect of a decreasing degree of saturation and increased suction. Regardless of the effect of water content on, more precisely, degree of saturation, the CIV versus relative compaction was again highly variable. 


\subsubsection{Summary of Test Results on A-1 and A-2 Soils}

In the case of "granular" soils (A-1 and A-2 soils except containing the gravels), the minimum required blow count for 0 -to-12 inch penetration, $\left(\mathrm{N}_{\mathrm{DCP}}\right)_{\text {req }} \mid 0 \sim 12 "$, is summarized in Table 6.8 together with the compaction properties.

Table 6.8 Summary of the DCP results together with compaction properties of "granular" soils

\begin{tabular}{|c|c|c|c|c|c|c|}
\hline \multicolumn{2}{|c|}{ Test site } & SR31 (I) & SR31 (II) & SR31 (III) & $\begin{array}{c}\text { SR31 } \\
\text { (Plymouth) }\end{array}$ & Honda \\
\hline \multicolumn{2}{|c|}{$\begin{array}{l}\text { AASHTO } \\
\text { classification }\end{array}$} & $A-1-b$ & A-2-4 & $A-2-4$ & $A-2-6$ & A-2-4 \\
\hline \multirow{2}{*}{$\gamma_{d \max }$} & $\left(\mathrm{kN} / \mathrm{m}^{3}\right)$ & 19.1 & 19.2 & 19.0 & 19.1 & 18.9 \\
\hline & (pcf) & 121.3 & 122.4 & 120.6 & 121.3 & 120.2 \\
\hline & ${ }_{t}(\%)$ & 10.2 & 10.5 & 12.0 & 11.9 & 10.7 \\
\hline \multicolumn{2}{|c|}{$\left(\mathrm{N}_{\mathrm{DCP}}\right)_{\mathrm{req}} \mid 0 \sim 12 "$} & 18 & 15 & 14 & 13 & 15 \\
\hline
\end{tabular}

The composition of the "granular" soils in Table 6.8 consists of an A-3 soil with a small percentage of fine particles (10 to 35 percent passing the \#200 sieve). The

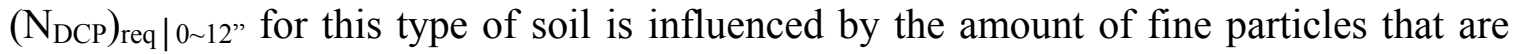
present in the soil. Also, the plasticity index of fine particles contained in the soil is also one of the factors to control DCP blow counts. It is interesting to note that, as indicated in 
Section 2.4.4, the optimum moisture content correlates both with the amount of fine particles and with the plasticity index of soil. Based on this concept, we propose the

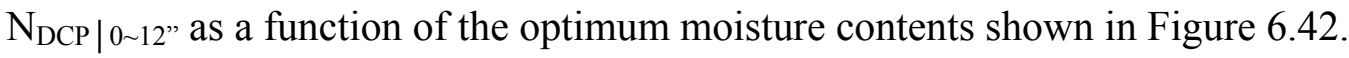

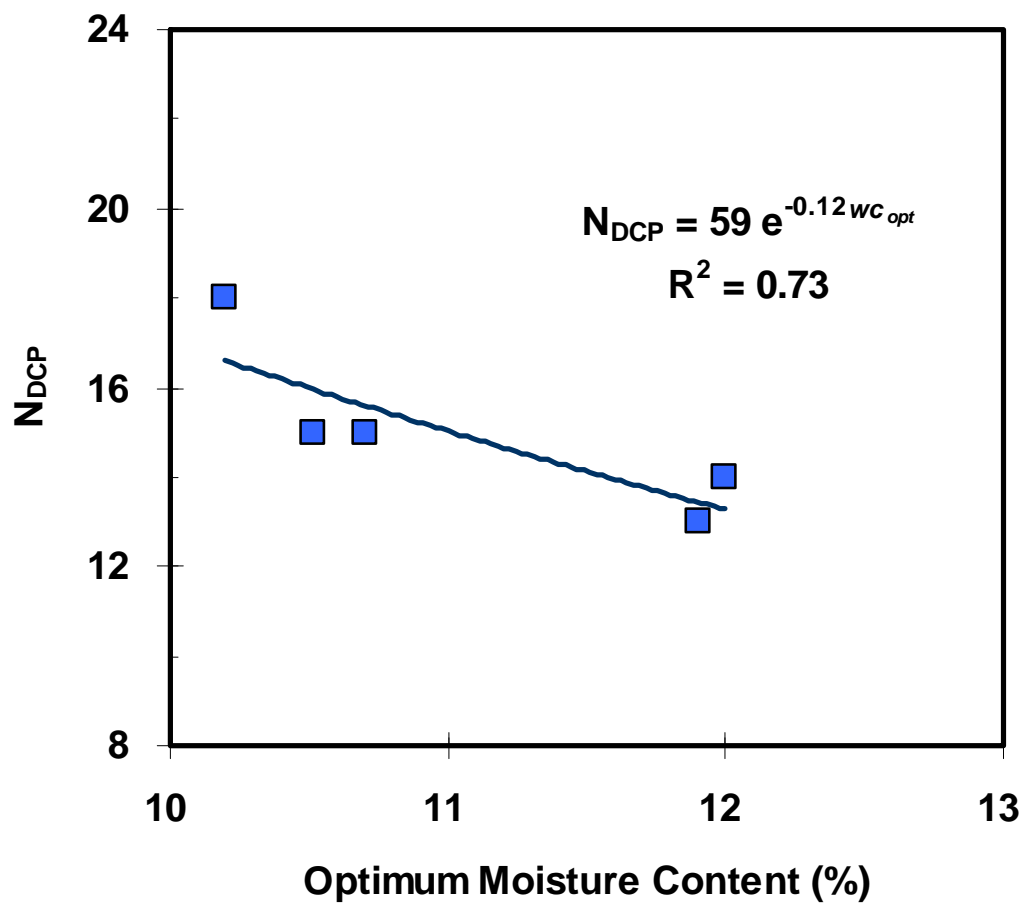

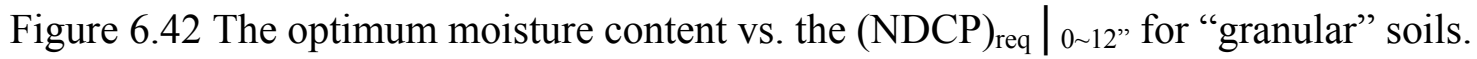




\subsection{Field Tests on Silty Clay (A-4 to A-7 soil)}

Three sites were selected to perform the tests on silty clay. This type of soil contains a high percentage of soil by weight more than 35\% passing the \#200 sieve.

Figure 6.43 shows the particle-size distribution of the soils tested for this study. Two soil samples taken from SR64 and SR66 sites are classified as A-4 soil and one soil sample taken from SR24 site is classified as A-7-6 as per AASHTO. Figure 6.44 provides the compaction curves of three soil samples taken from the sites.

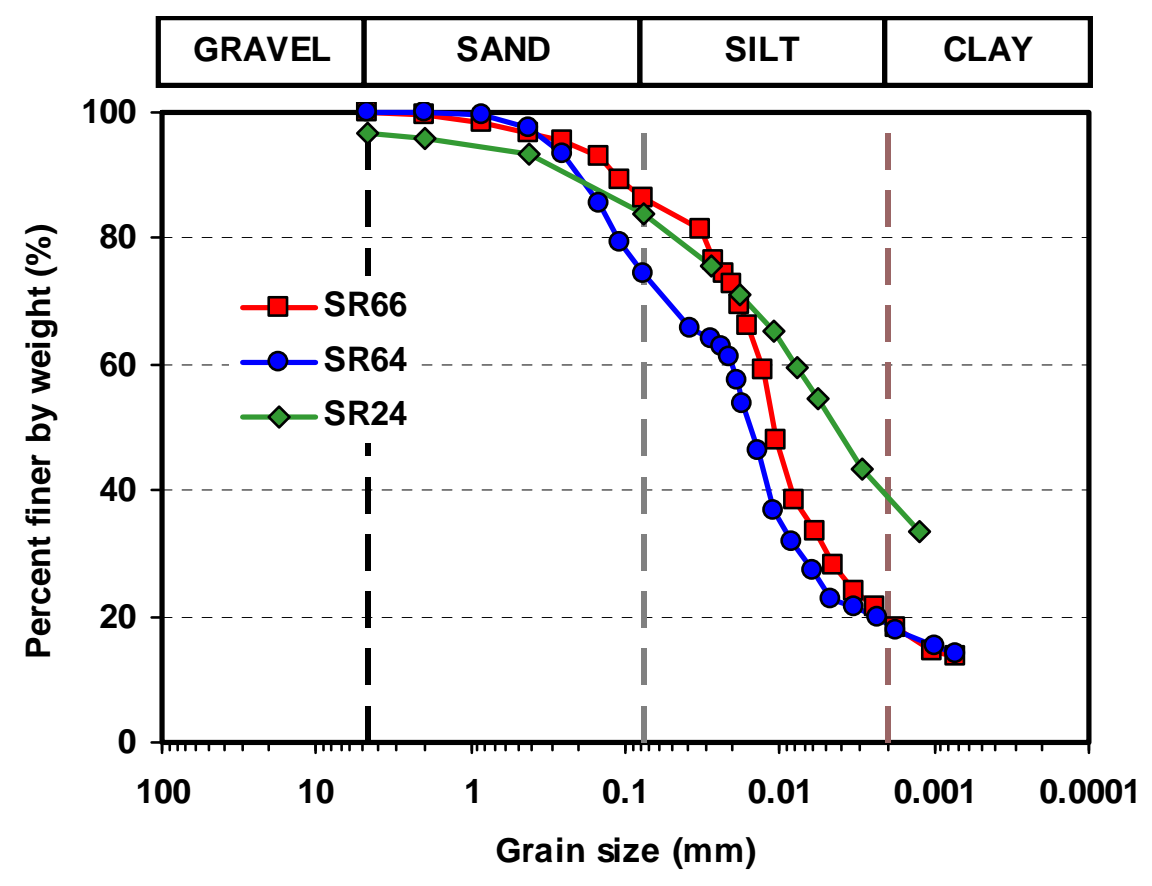

Figure 6.43 Particle size distributions of silty clay soils. 


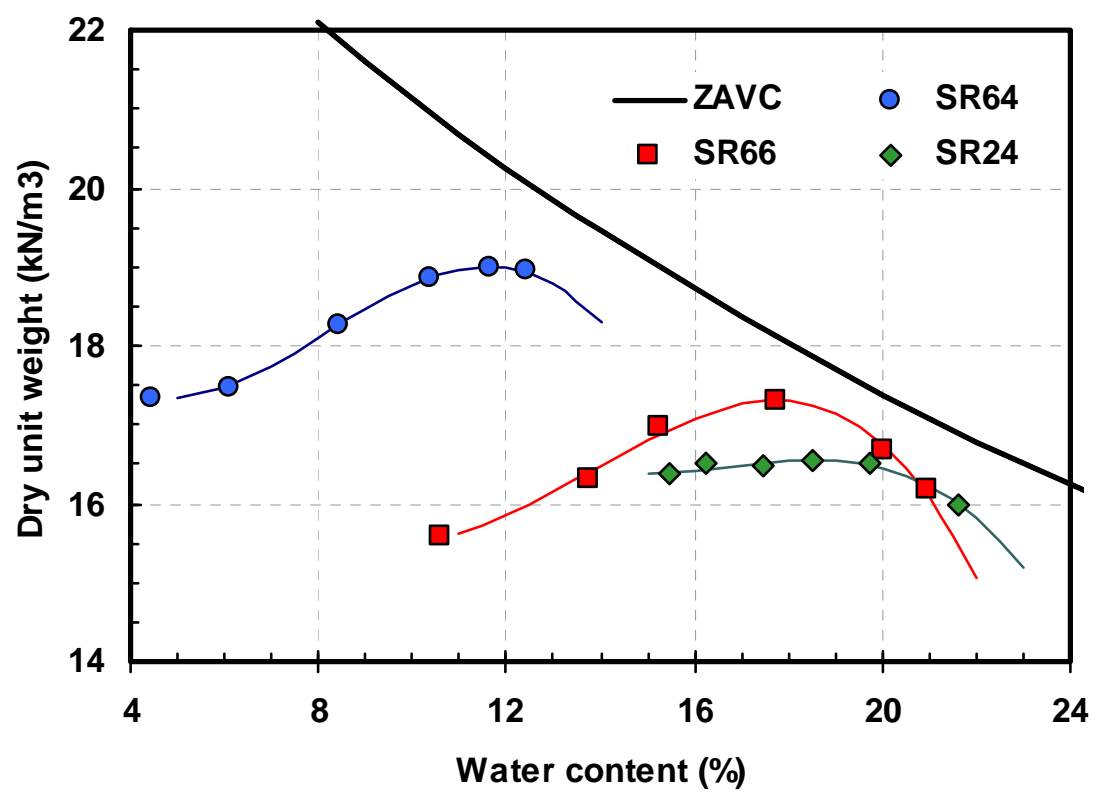

Figure 6.44 Compaction curves of the soil samples from SR66, SR64, and SR24 sites.

Table 6.9 summarizes the grain-size distributions and classifications of the soil taken from these sites.

Table 6.9 Summary of the plasticity and compaction properties of the soil samples

\begin{tabular}{|c|c|c|c|c|c|c|c|c|}
\hline \multirow{2}{*}{ Site } & \multirow{2}{*}{$\begin{array}{c}\% \\
\text { passing } \\
\text { No.200 } \\
\text { sieve }\end{array}$} & \multicolumn{3}{|c|}{ Plasticity } & \multicolumn{2}{|c|}{$\gamma_{d \max }$} & \multirow{2}{*}{$\begin{array}{c}w C_{o p t} \\
(\%)\end{array}$} & \multirow{2}{*}{$\begin{array}{l}\text { AASHTO } \\
\text { classification }\end{array}$} \\
\hline & & $P L$ & $L L$ & $P I$ & $\left(\mathrm{kN} / \mathrm{m}^{3}\right)$ & (pcf) & & \\
\hline SR64 & 72.0 & 18.1 & 20.4 & 2.3 & 19.0 & 120.9 & 11.7 & A-4 \\
\hline SR66 & 86.2 & 22.6 & 26.1 & 3.5 & 17.3 & 110.1 & 17.7 & A-4 \\
\hline SR24 & 83.8 & 21.2 & 43.5 & 22.3 & 16.6 & 105.3 & 18.4 & A-7-6 \\
\hline
\end{tabular}




\subsubsection{Field Tests on SR64}

A subgrade embankment was constructed using A-4 soil as fill material. The site is located at a construction site on State Road 64 in Gibson County, Indiana.

Figure 6.45 shows the histogram of DCPT blow counts for the site. The RC was computed using a $\gamma_{d \max }$ of $19.0 \mathrm{kN} / \mathrm{m}^{3}$ (120.9 pcf) obtained from the laboratory Standard compaction test (see Table 6.9). Also, the dry unit weight and the water content were measured using the sand cone tests. In each case, one sand cone test was performed along with four DCP tests. In addition, the test results obtained from a test pad built by INDOT $(\mathrm{RC}=92.2 \%)$ are also plotted in the figure. 


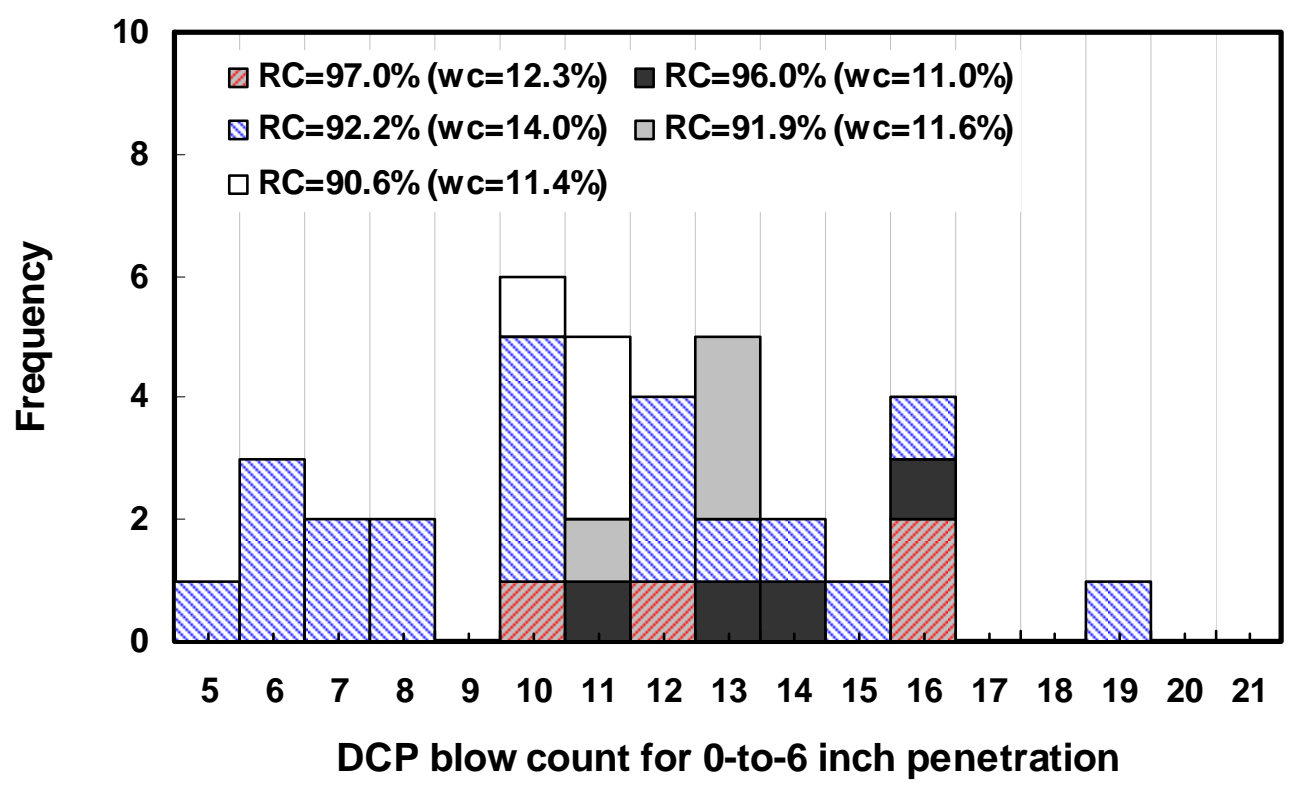

(a)

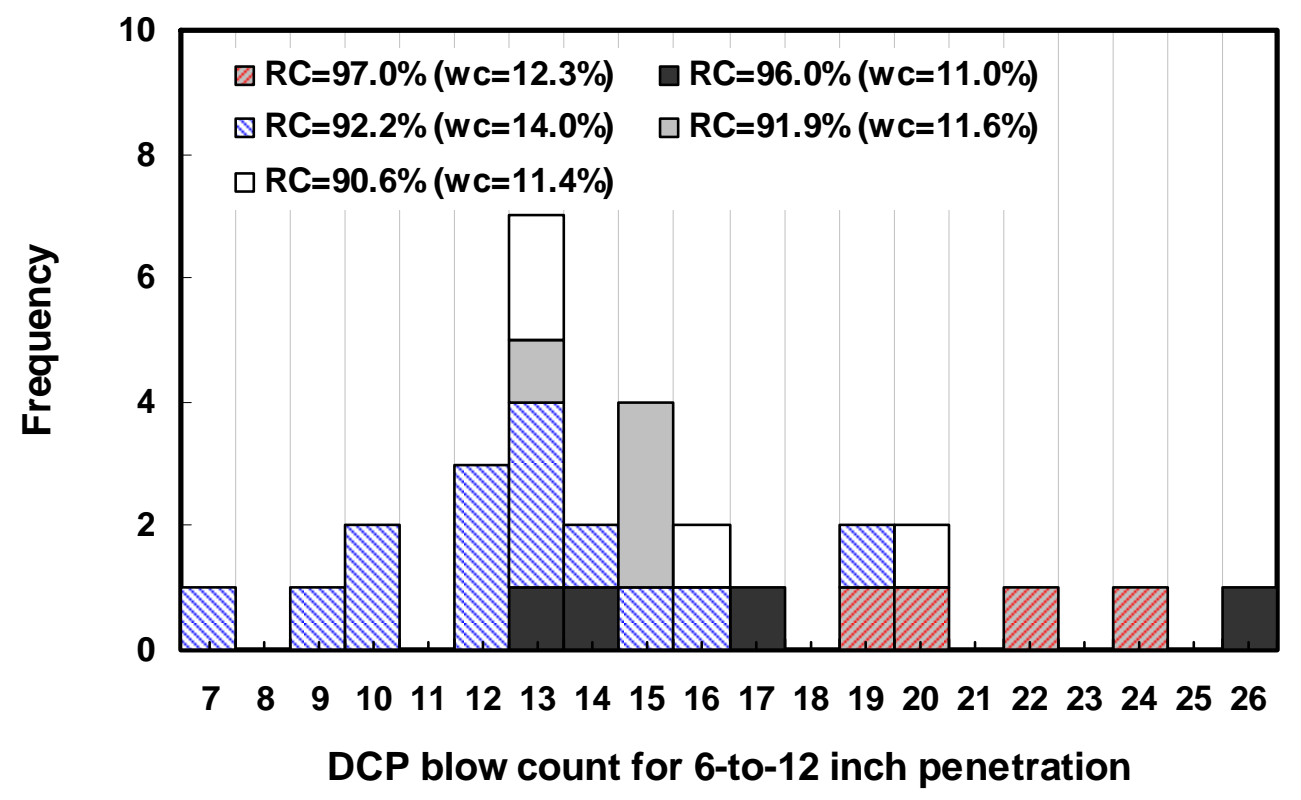

(b)

Figure 6.45 Histograms of DCPT results (SR64): (a) 0-to-6 inch penetration and (b) 6-to12 inch penetration. 
Based on the same approach we adopted for other types of soil, we take the minimum required blow count, $\left(\mathrm{N}_{\mathrm{DCP}}\right)_{\text {req }} \mid 0 \sim 6$, being greater than at least $80 \%$ of the occurrences in the histograms of blow counts associated with $96.0 \% \mathrm{RC}$ was 16 [see Figure 6.46 (a)]. Similarly, the minimum required blow count, $\left(\mathrm{N}_{\mathrm{DCP}}\right)_{\text {req }} \mid 6 \sim 12$ " is equal to 26 [see Figure $6.46(\mathrm{~b})$ ]. Comparison of the $\left(\mathrm{N}_{\mathrm{DCP}}\right)_{\text {req } \mid 0 \sim 6 \text { " }}$ and $\left(\mathrm{N}_{\mathrm{DCP}}\right)_{\text {req }} \mid 6 \sim 12$ "', with all test results is as shown in Figure 6.47. On this site, one out of 20 DCP test results associated with $92.2 \%$ RC exceeded the $\left(\mathrm{N}_{\mathrm{DCP}}\right)_{\text {req }}$ 0 6\%. For 6-to-12 inch penetration, all DCP test results associated with less than $95 \% \mathrm{RC}$ were included by $.\left(\mathrm{N}_{\mathrm{DCP}}\right)_{\text {req }} \mid 6 \sim 12 \%$. 


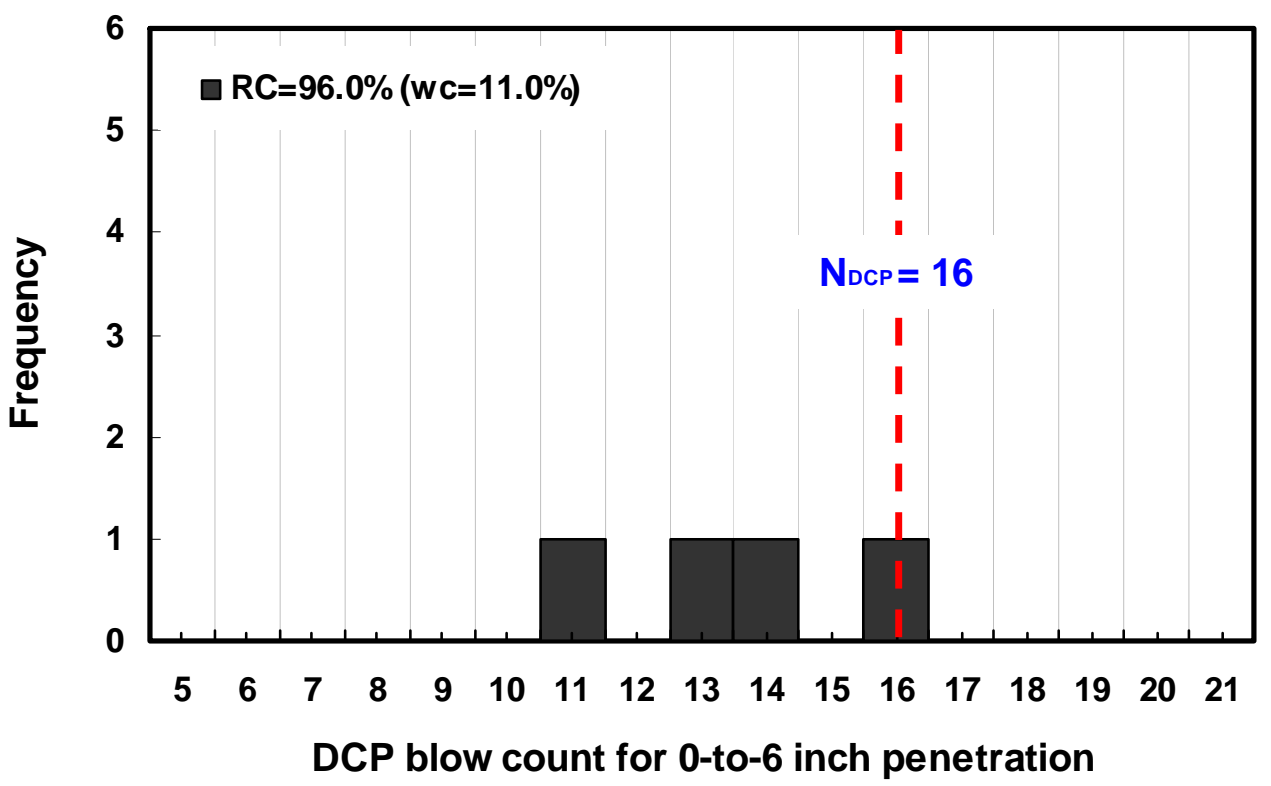

(a)

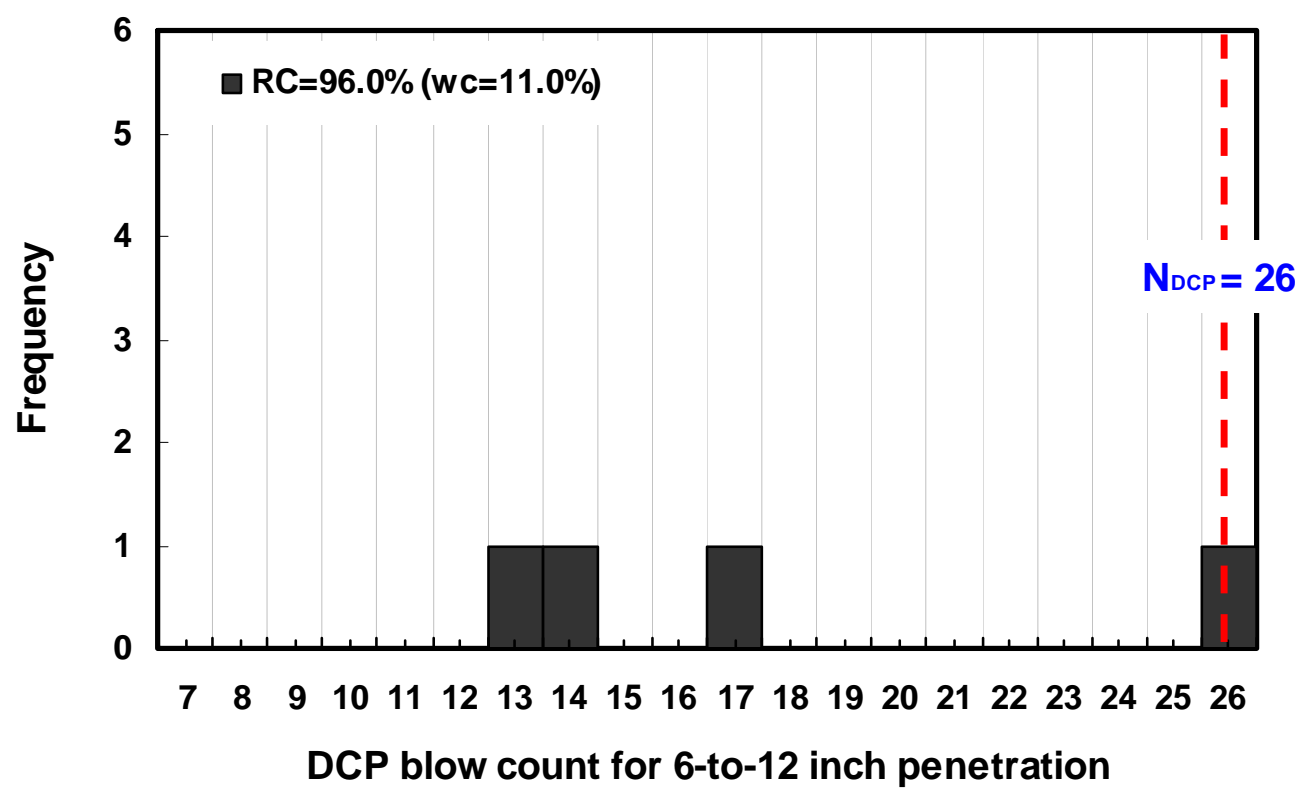

(b)

Figure 6.46 Histograms of DCPT results at $96.0 \% \mathrm{RC}$ plotted together with the minimum required blow count (SR64): (a) 0-to-6 inch penetration and (b) 6-to-12 inch penetration. 


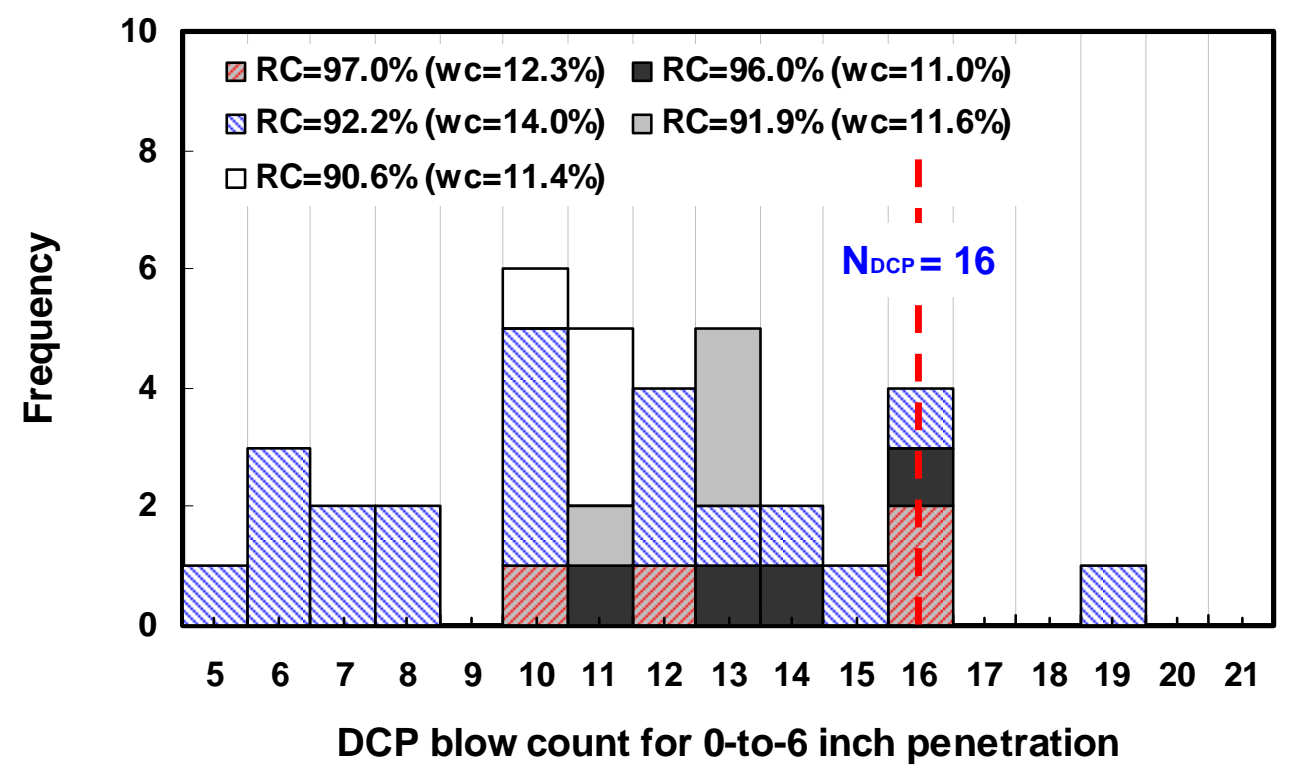

(a)

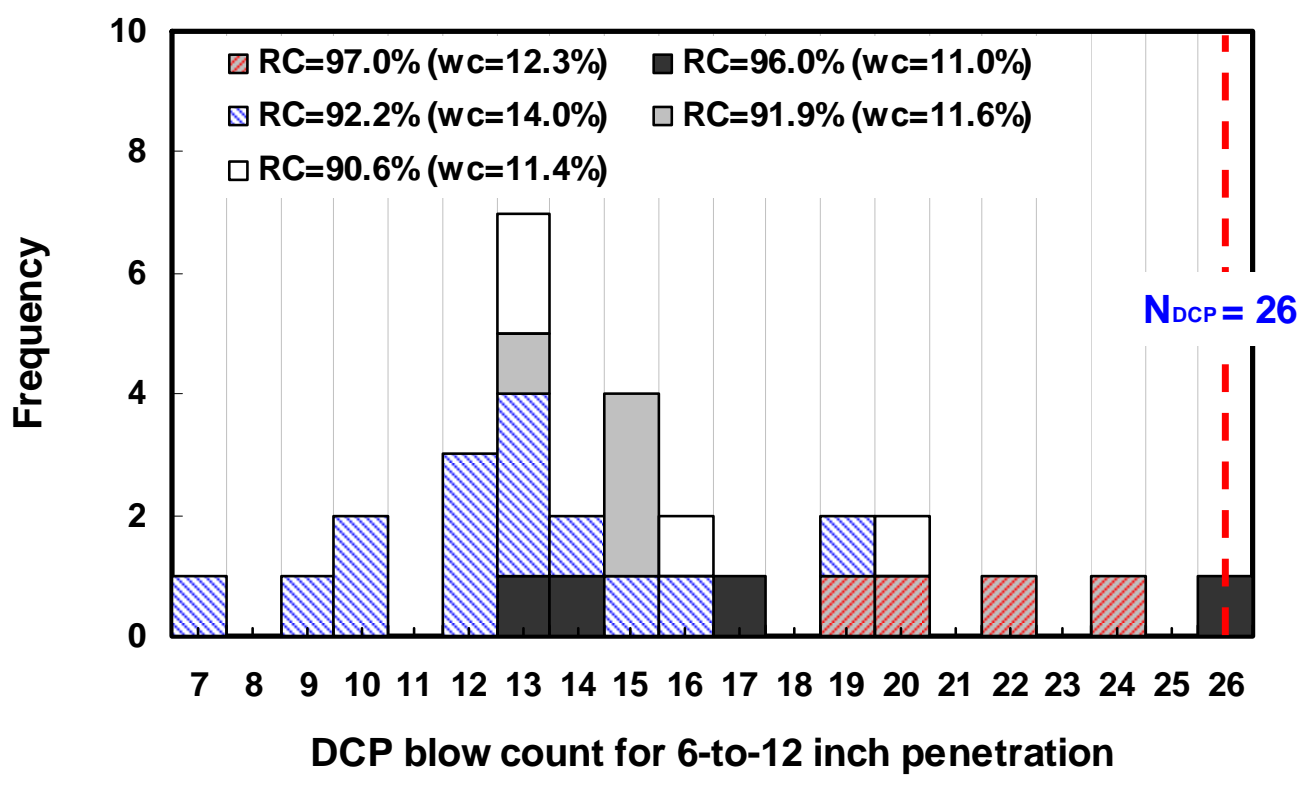

(b)

Figure 6.47 Histograms of the DCPT results plotted together with the minimum required blow count (SR64): (a) 0-to-6 inch penetration and (b) 6-to-12 inch penetration. 


\subsubsection{Field Tests on SR66}

A subgrade embankment was constructed using A-4 soil as fill material. The site is at the construction of State Road 66 located in Warrick County, Indiana.

Figure 6.48 shows the histogram of the DCPT blow counts for the site. In the figure, the RC was computed using a $\gamma_{d \max }$ of $17.3 \mathrm{kN} / \mathrm{m}^{3}(110.1 \mathrm{pcf})$ obtained from the laboratory Standard compaction test (see Table 6.9). The dry unit weight and the water content were measured using the sand cone tests. In each case, one sand cone test was performed along with four DCP tests. In addition, the test results obtained from the test pad by INDOT $(\mathrm{RC}=92.0 \%)$ are also plotted in the figure. 


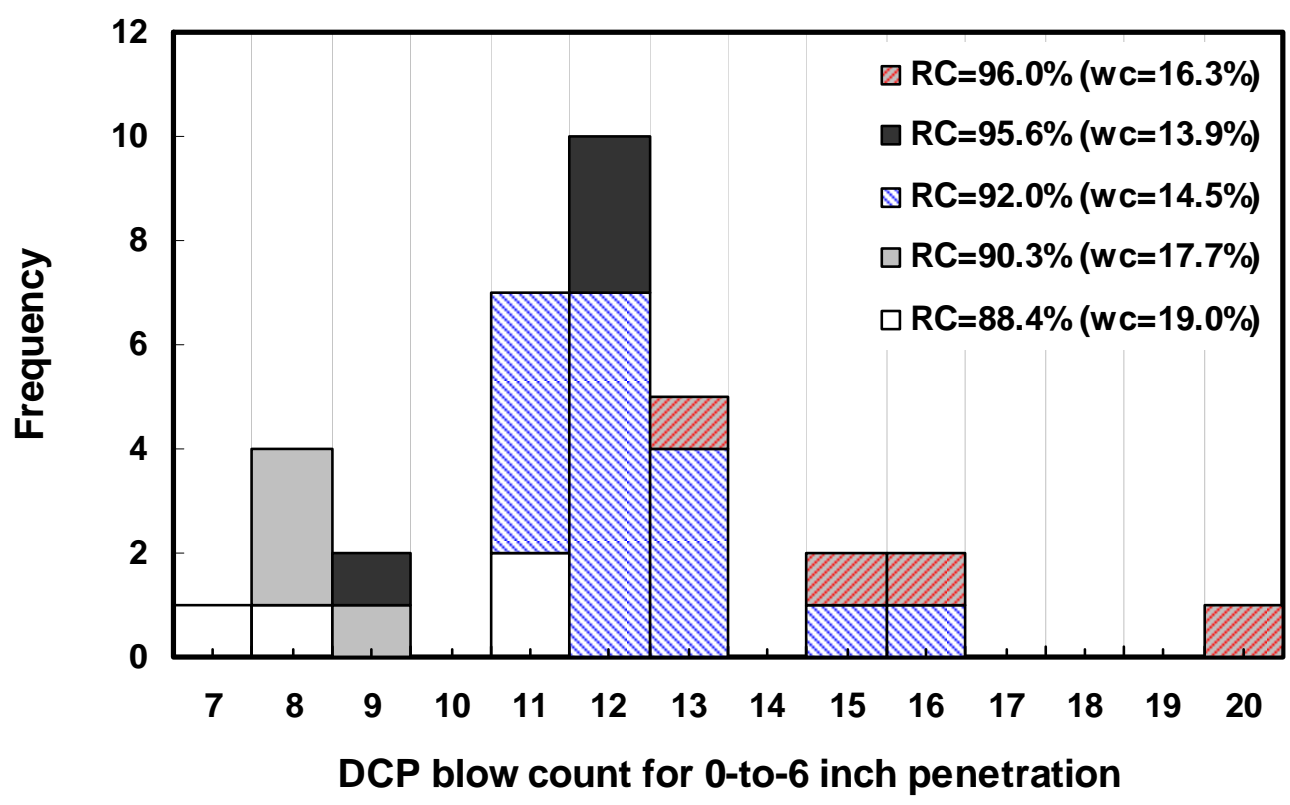

(a)

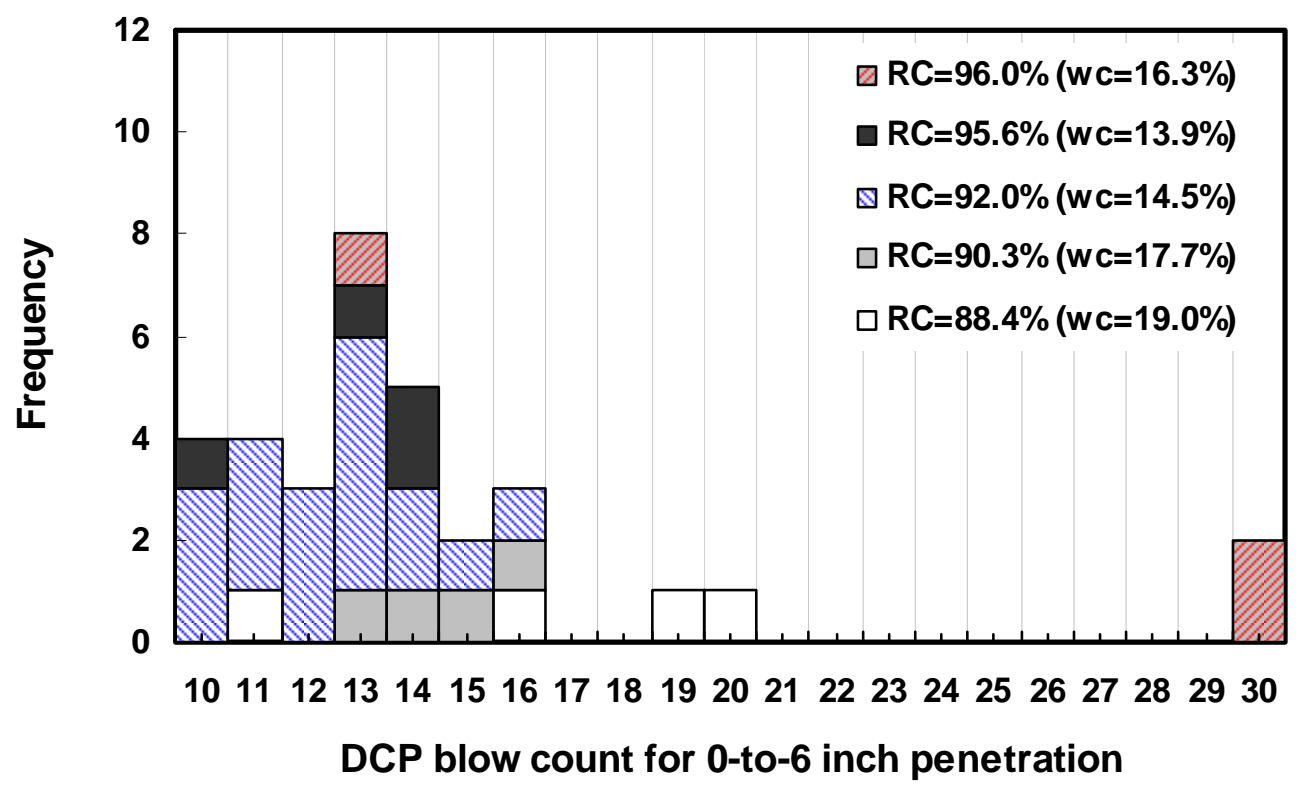

(b)

Figure 6.48 Histograms of DCPT results (SR66): (a) 0-to-6 inch penetration and (b) 6-to12 inch penetration. 
Based on the same approach we adopted to develop the DCP subgrade assessment

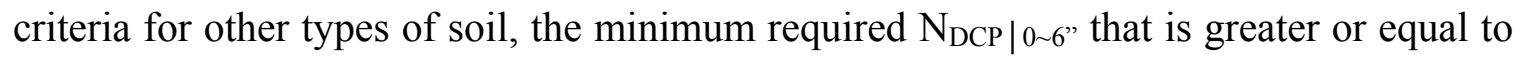
at least $80 \%$ of occurrences in the histogram of test results associated with a $95.6 \% \mathrm{RC}$ was 12. Similarly, the minimum required $\mathrm{N}_{\mathrm{DCP} \mid 6 \sim 12}$ " was equal to 14 . However, those blow counts do not exceed $90 \%$ of test measurements corresponding to less than the

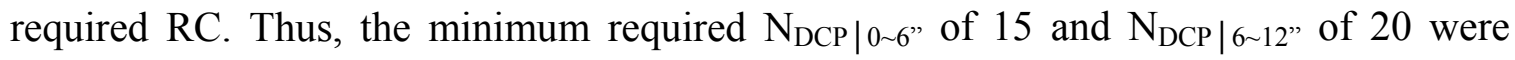
reselected to satisfy the requirement (see Figure 6.49). Figure 6.50 shows the minimum required blow counts for 0 -to-6 inch penetration, $\left(\mathrm{N}_{\mathrm{DCP}}\right)_{\text {req }} \mid 0 \sim 6$ ", and for 6-to-12 inch penetration, $\left(\mathrm{N}_{\mathrm{DCP}}\right)_{\text {req }}$ 6 12", plotted with all the test results. As shown in the Figure 6.50(a), one out of 20 DCP test results associated with $92.0 \%$ RC exceeded the

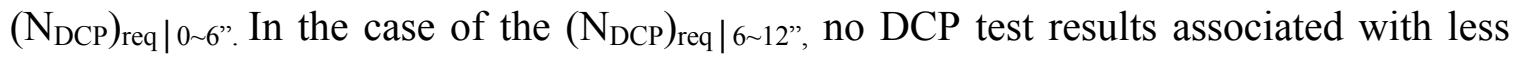
than required $\mathrm{RC}$ exceeded the minimum required blow count. 


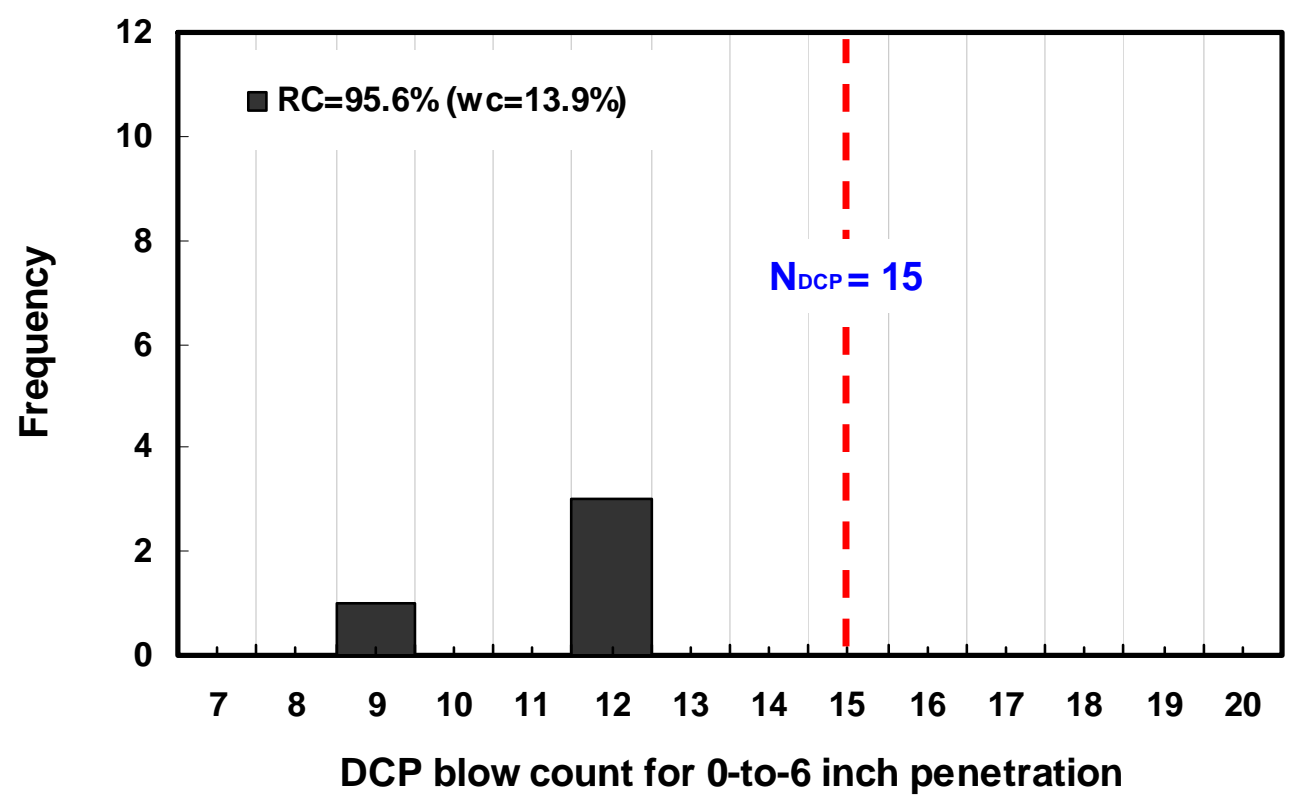

(a)

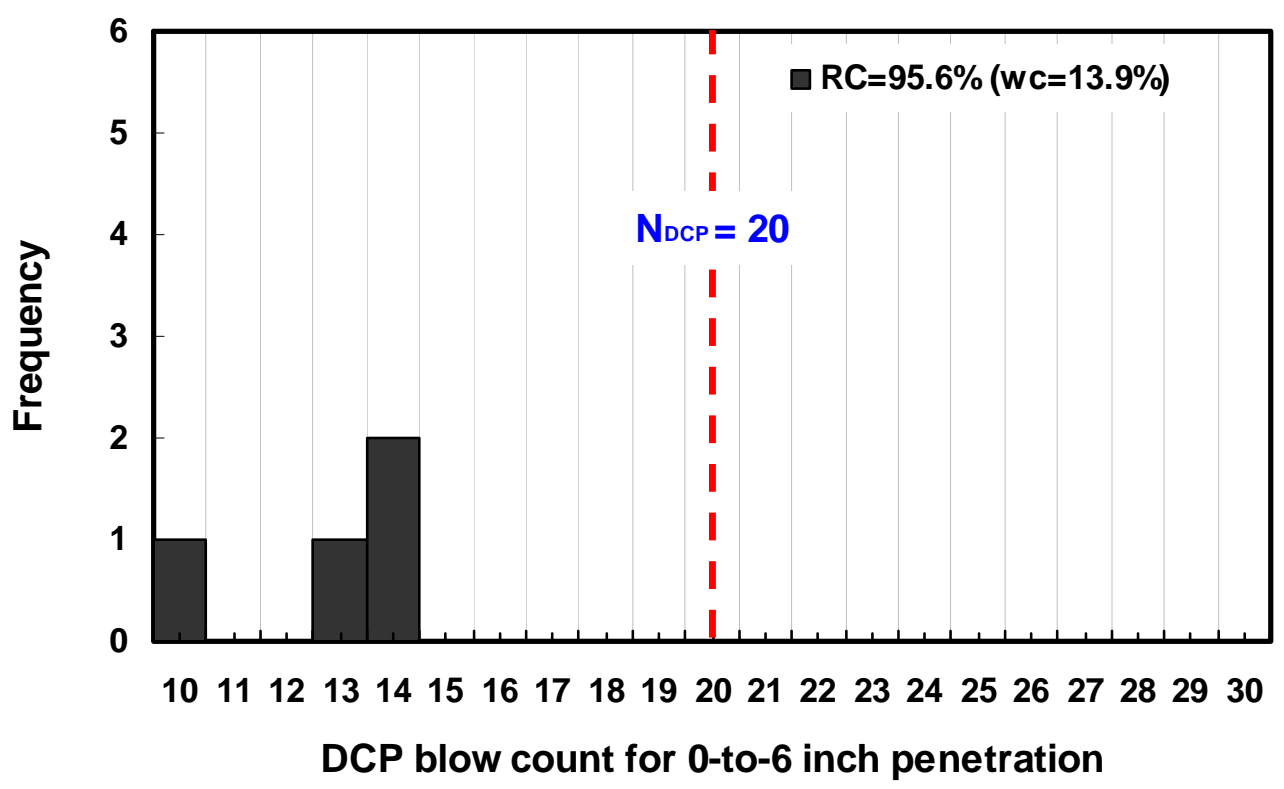

(b)

Figure 6.49 Histograms of DCPT results at $95.6 \%$ RC plotted together with the minimum required blow count (SR66): (a) 0-to-6 inch penetration, and (b) 6-to-12 inch penetration. 


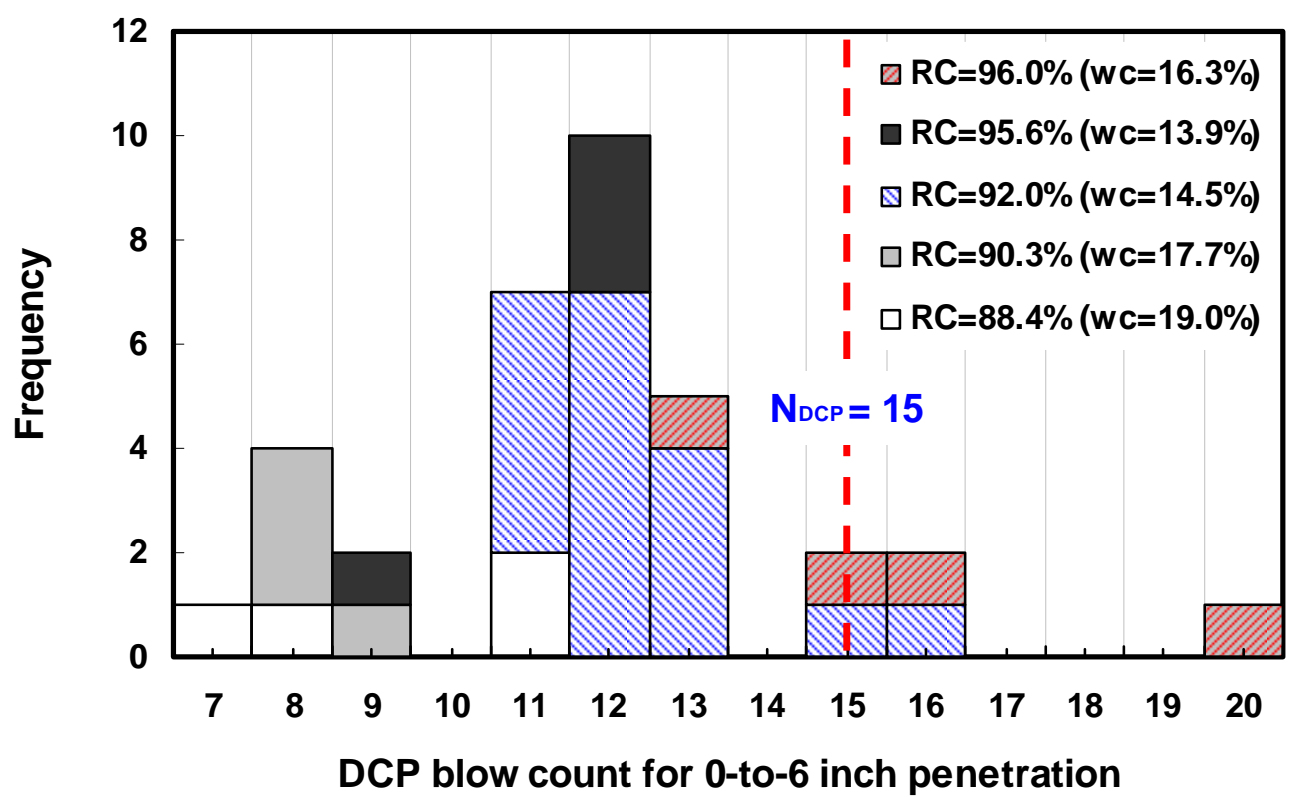

(a)

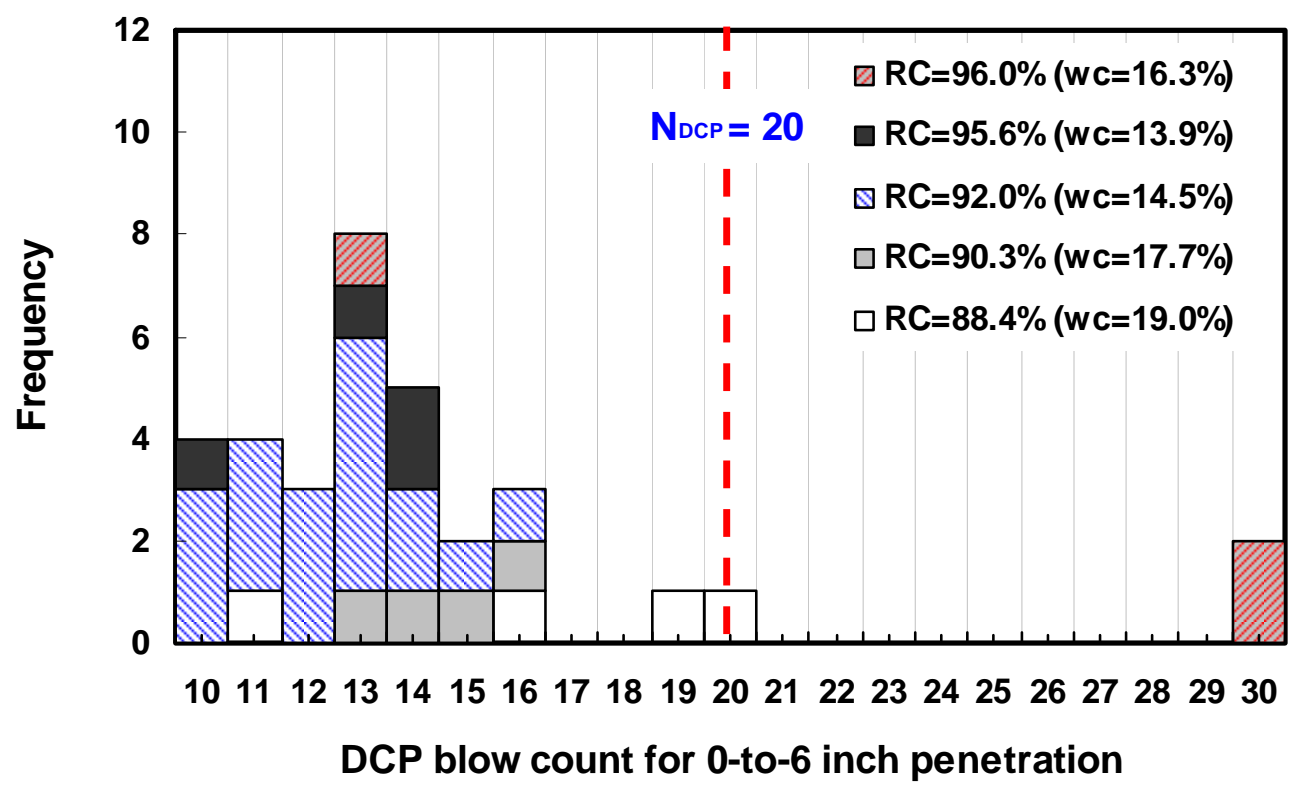

(b)

Figure 6.50 Histograms of DCPT results plotted together with the minimum required blow count (SR66): (a) 0-to-6 inch penetration and (b) 6-to-12 inch penetration. 


\subsubsection{Field Tests on SR24}

A subgrade embankment was constructed using A-7-6 soil as fill material. The site is at the construction of State Road 24 located in Fort Wayne, Indiana.

Figure 6.51 shows the histogram of the DCPT blow counts for the site. In the figure, the $\mathrm{RC}$ was computed using a $\gamma_{d \max }$ of $16.6 \mathrm{kN} / \mathrm{m}^{3}$ (105.3 pcf) obtained from the laboratory Standard compaction test (see Table 6.9). The laboratory Standard compaction test and the sieve analysis results were provided by INDOT. The dry unit weight and the water content were measured using a nuclear gauge test. In each case, one nuclear gauge test was performed along with seven DCP tests. 


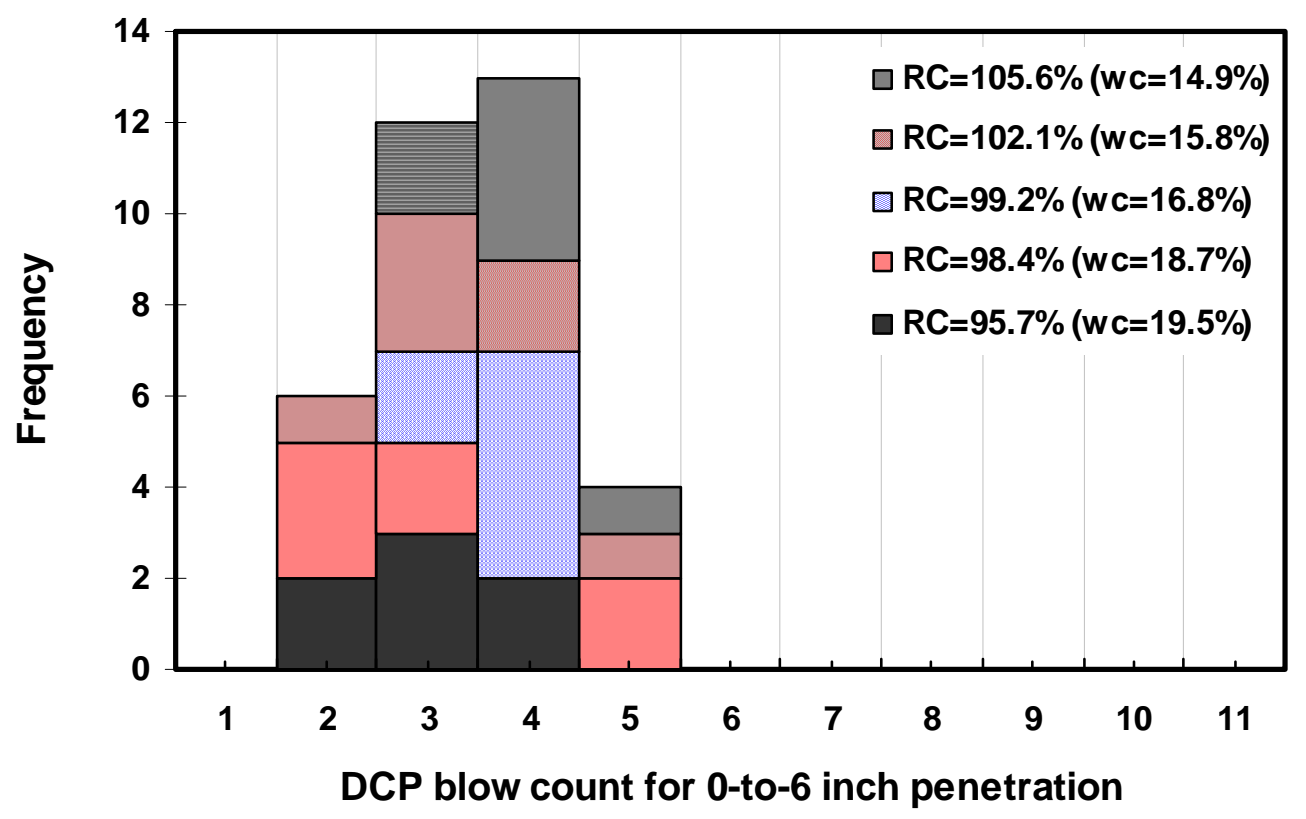

(a)

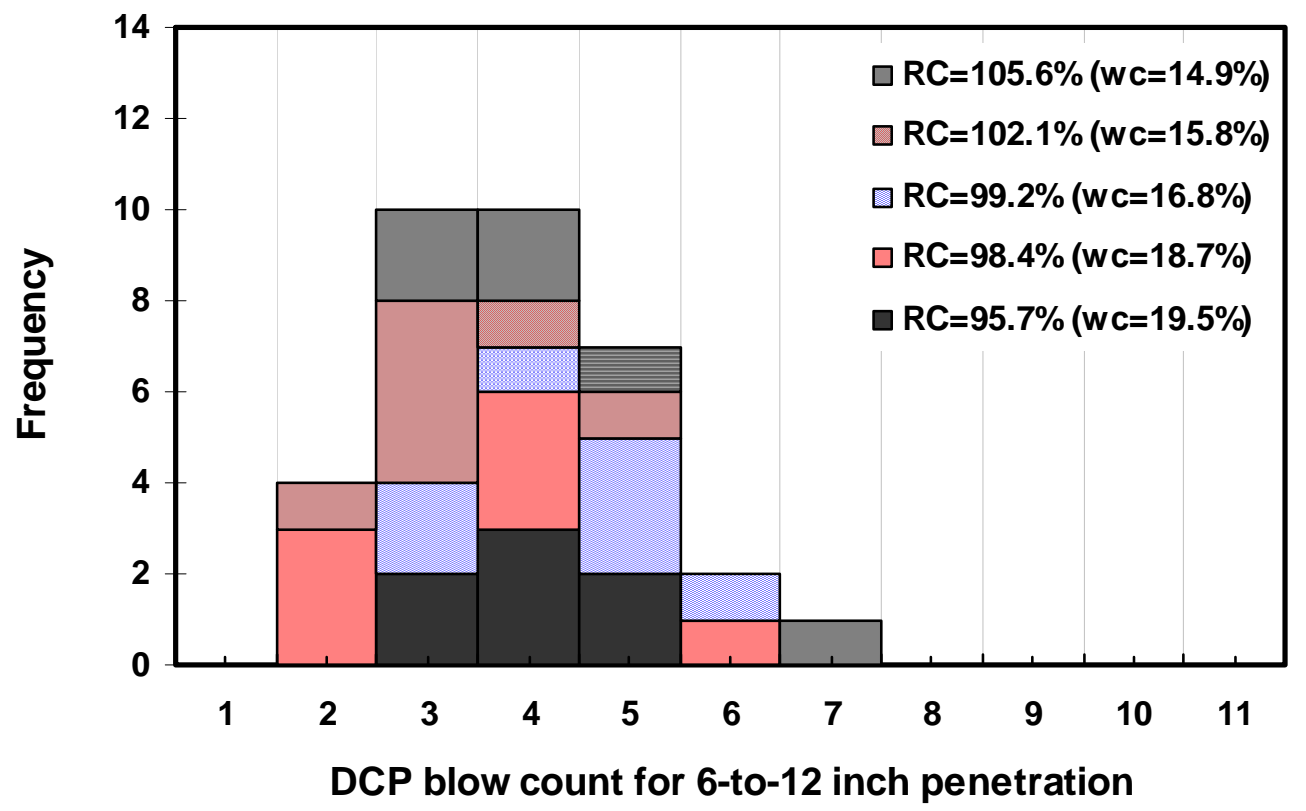

(b)

Figure 6.51 Histograms of DCPT results (SR24): (a) 0-to-6 inch penetration and (b) 6-to12 inch penetration. 
Based on the same approach we adopted to develop the DCP subgrade assessment

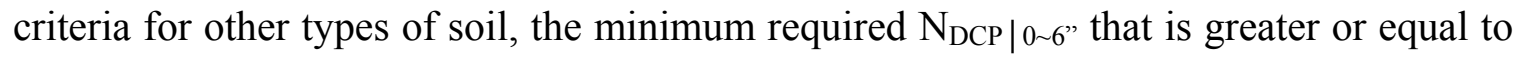
at least $80 \%$ of occurrences in the histogram of test results associated with a $95.7 \%$ RC

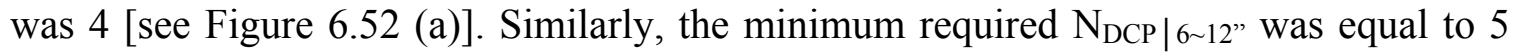
[see Figure 6.52 (b)]. Figure 6.53 shows the minimum required blow counts for 0-to-6 inch penetration, $\left(\mathrm{N}_{\mathrm{DCP}}\right)_{\text {req }} \mid 0 \sim 6$ ", and for 6-to-12 inch penetration, $\left(\mathrm{N}_{\mathrm{DCP}}\right)_{\mathrm{req}} \mid 6 \sim 12^{\prime \prime}$, plotted with all the test results. 


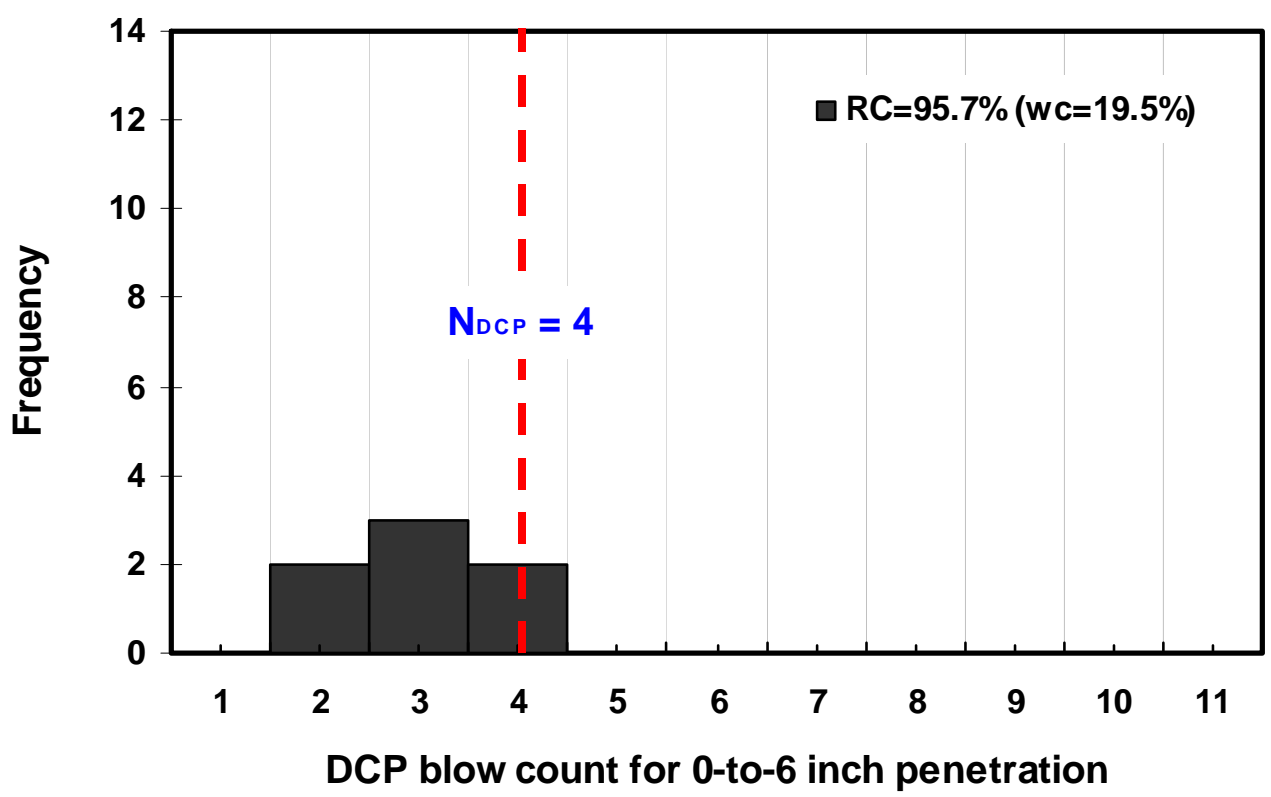

(a)

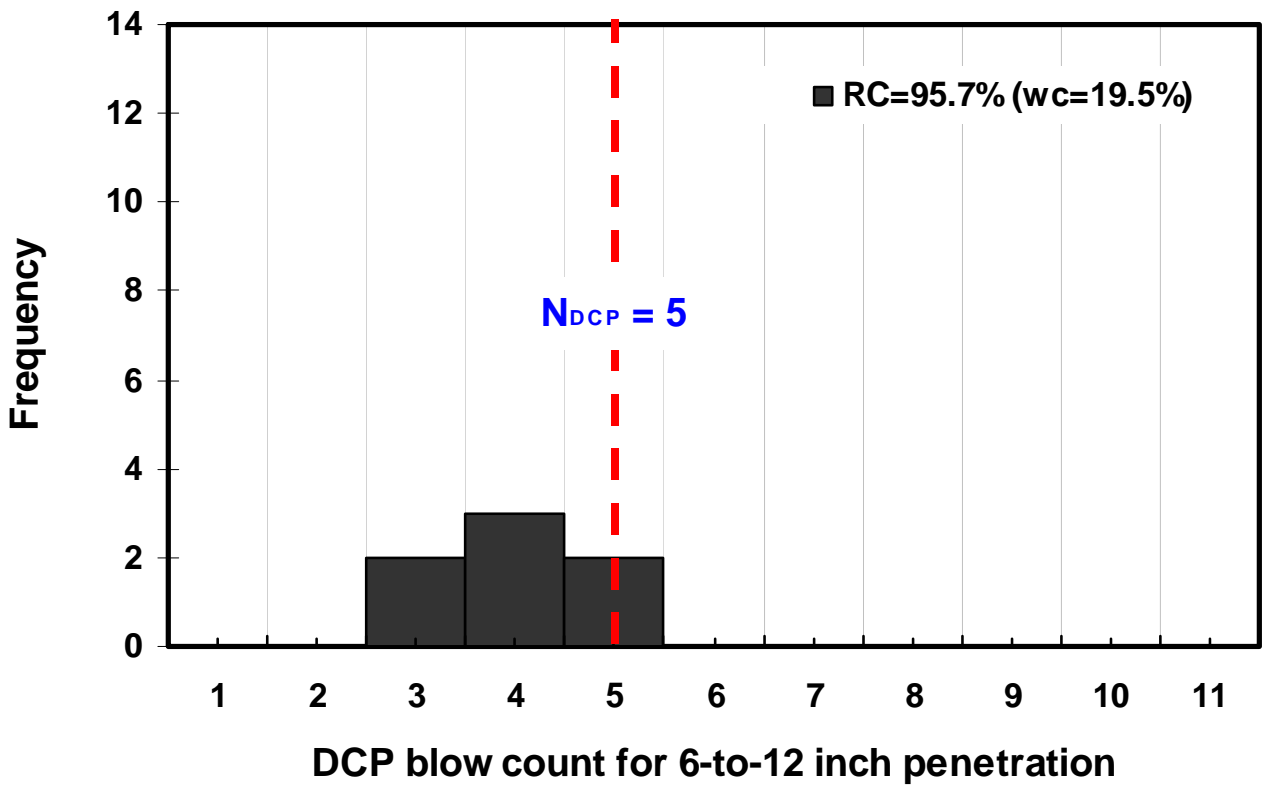

(b)

Figure 6.52 Histograms of DCPT results at $95.6 \% \mathrm{RC}$ plotted together with the minimum required blow count (SR24): (a) 0-to-6 inch penetration, and (b) 6-to-12 inch penetration. 


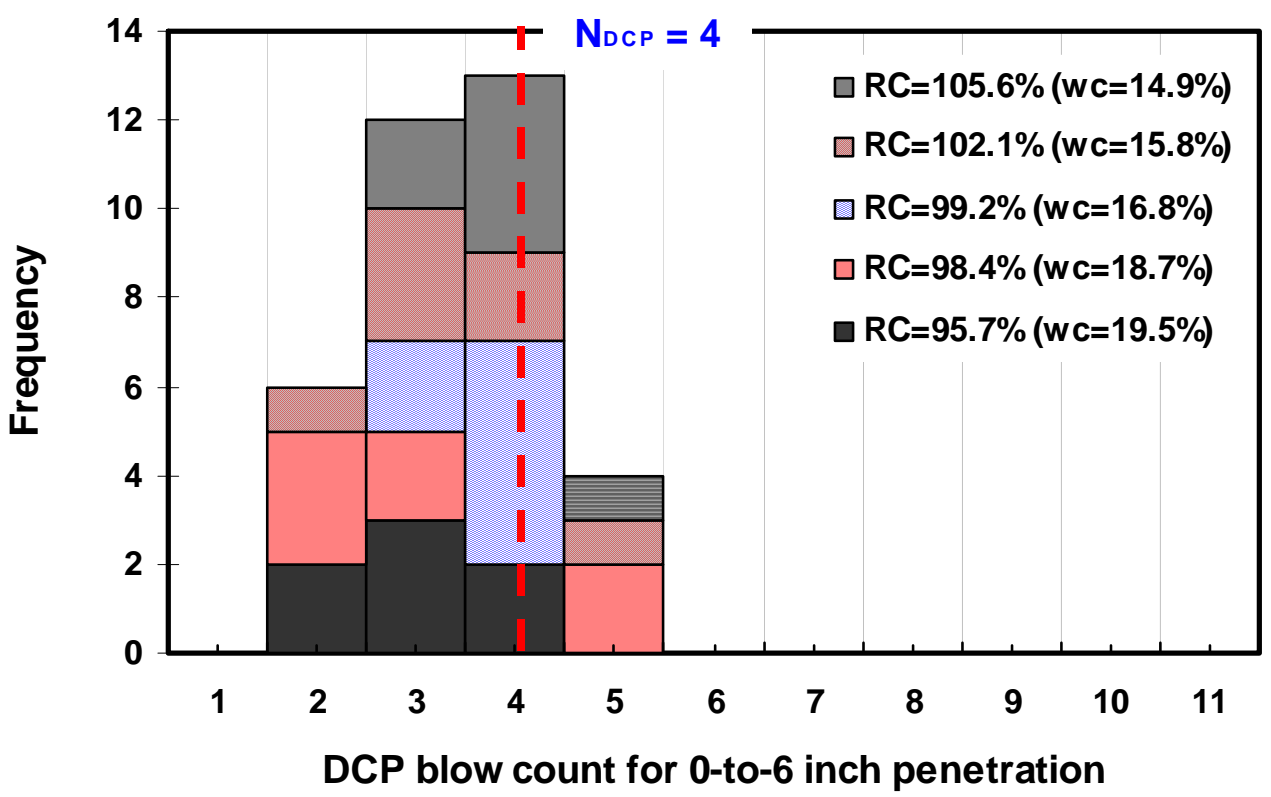

(a)

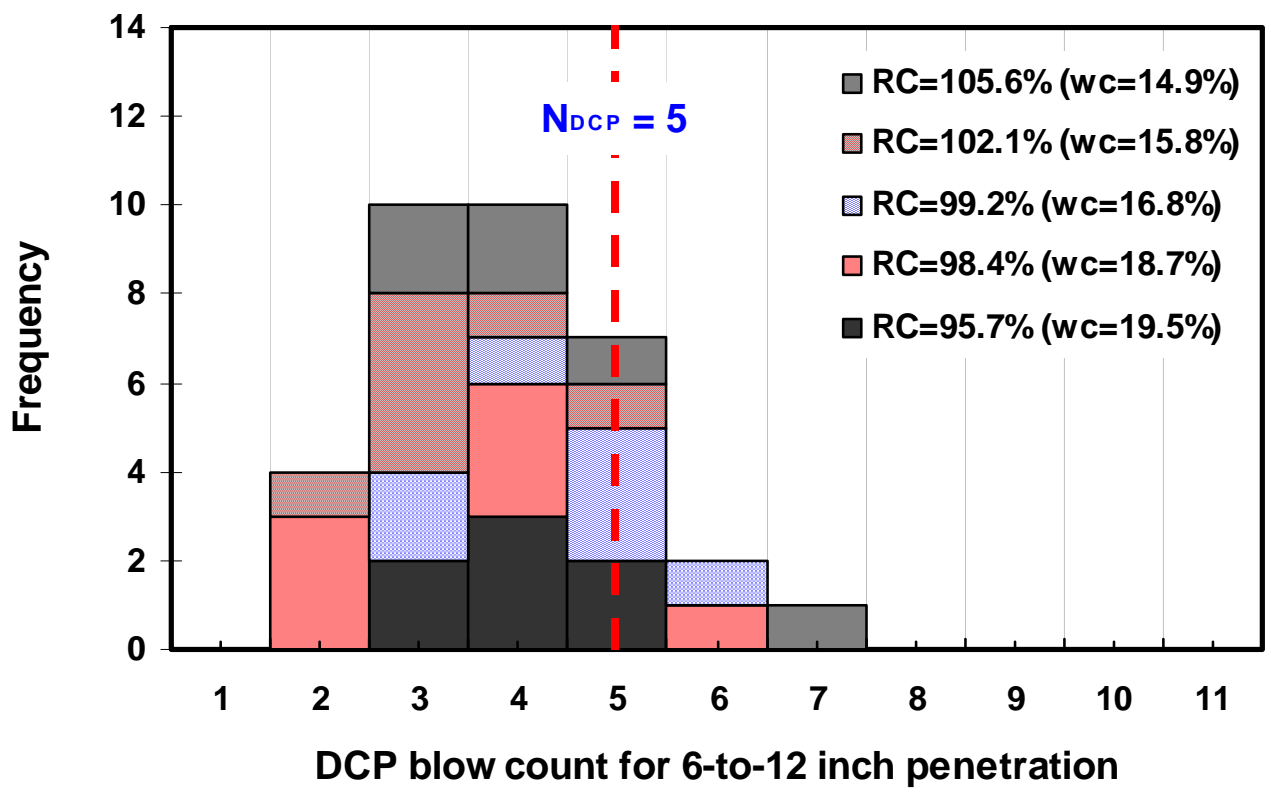

(b)

Figure 6.53 Histograms of DCPT results plotted together with the minimum required blow count (SR24): (a) 0-to-6 inch penetration and (b) 6-to-12 inch penetration. 


\subsubsection{Summary of Test Results on Silty Clay}

In order to develop for compaction quality control criteria DCPT-based for silty clayey soil, the test results in the test pit are combined with the test results for the SR64, SR66 and SR24 sites. In the case of silty clayey soils, the minimum required blow counts for 0to-6 inch penetration, $\left(\mathrm{N}_{\mathrm{DCP}}\right)_{\mathrm{req}} \mid 0 \sim 6$ ", and for 6-to-12 inch penetration, $\left(\mathrm{N}_{\mathrm{DCP}}\right)_{\text {req }} \mid 6 \sim 12$ ", are given in Table 6.10 along with the Atterberg limits and percent passing the $\# 40$ and the \#200 sieve.

Table 6.10 Summary of the DCP results with the plasticity and percent passing the \#200 sieve on silty clay soils

\begin{tabular}{|c|c|c|c|c|}
\hline Test site & SR64 & SR66 & SR24 & $\begin{array}{c}\text { Purdue test } \\
\text { pit }\end{array}$ \\
\hline $\begin{array}{c}\text { AASHTO } \\
\text { classification }\end{array}$ & A-4 & A-4 & A-7-6 & A-4 \\
\hline $\begin{array}{c}\text { Percent passing the } \\
\text { \#40ve }\end{array}$ & 97.4 & 96.8 & 93.4 & 72.3 \\
\hline $\begin{array}{c}\text { Percent passing the } \\
\# 200 \text { sieve }\end{array}$ & 72.0 & 86.2 & 83.8 & 52.1 \\
\hline$P L(\%)$ & 18.1 & 22.6 & 21.2 & 12.6 \\
\hline$L L(\%)$ & 20.4 & 26.1 & 43.5 & 22.3 \\
\hline$P I(\%)$ & 2.3 & 3.5 & 22.3 & 9.7 \\
\hline$\left.\left(\mathrm{N}_{\mathrm{DCP}}\right)_{\text {req }}\right|_{0 \sim 6 \%}$ & 16 & 15 & 4 & 8 \\
\hline$\left(\mathrm{N}_{\mathrm{DCP}}\right)_{\text {req }}$ (6 12\% & 26 & 20 & 5 & 12 \\
\hline
\end{tabular}

According to the AASHTO classification, a silty clayey soil contains a significant amount of fine particles (from $35 \%$ to $100 \%$ ). The dynamic resistance is influenced by 
the amount of fine particles in addition to the plasticity index which is an indicator of the characteristics of the fine particles. Thus, the minimum required blow count correlates with the plasticity index and the amount of fine particles. Since the Atterberg limit tests are performed using the soil passing the \#40 sieve, according to ASTM D4318-05, we propose the minimum required blow count for silty clayey soils as a function of the plastic index (PI) and percent passing the \#40 sieve. The relationship appears in Figure 6.51 .

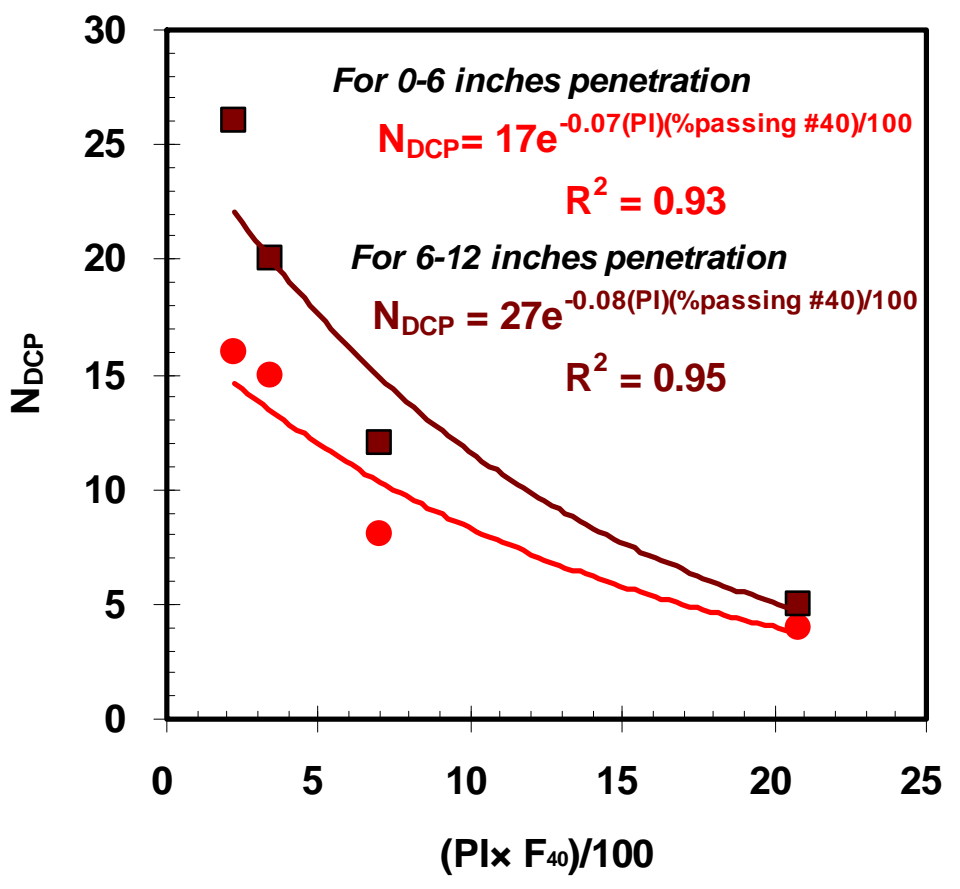

Figure 6.54 The $(\mathrm{PI})(\%$ passing the $\# 40$ sieve $)$ versus the $\left(\mathrm{N}_{\mathrm{DCP}}\right)_{\text {req }} \mid 0 \sim 6$ " and $\left(\mathrm{N}_{\mathrm{DCP}}\right)_{\text {req }} \mid 6 \sim 12$ " for silty clayey soil. 


\subsection{Summary}

A comprehensive experimental program was undertaken to assess the DCPT and the $\mathrm{CHT}$ as tools for soil compaction quality control. The main objective of the experimental program was to investigate the DCPT and CHT test results for various soil types on road sites and also in a test pit at Purdue University. The DCP test results are summarized in Table 6.11. Note that the minimum required blow counts should be rounded up to the nearest integer.

Table 6.11 Relationship between $\mathrm{N}_{\mathrm{DCP}}, C_{u}, w c_{\text {opt }}, P I$, and percent the $\# 40$ passing sieve

\begin{tabular}{|c|c|c|c|}
\hline \multicolumn{2}{|c|}{ Type of soil } & $\begin{array}{l}\text { Parameters } \\
\text { in }\end{array}$ & Relationship \\
\hline A-3 soils & $\mathrm{N}_{\mathrm{DCP} \mid 0 \sim 12 "}$ & $C_{u}$ & $\begin{array}{c}\mathrm{N}_{\mathrm{DCP} \mid 0 \sim 12 "}=4.0 \ln \left(C_{u}\right)+2.6 \\
\left(\text { see Figure } 6.22, \mathrm{R}^{2}=0.99\right)\end{array}$ \\
\hline $\begin{array}{l}\text { "Granular" } \\
\text { soils }\end{array}$ & $\mathrm{N}_{\mathrm{DCP} \mid 0 \sim 12 "}$ & $w C_{o p t}$ & $\begin{array}{c}\mathrm{N}_{\mathrm{DCP} \mid 0 \sim 12 "}=59 \exp \left(-0.12 w c_{o p t}\right) \\
\quad\left(\text { see Figure } 6.42, \mathrm{R}^{2}=0.73\right)\end{array}$ \\
\hline \multirow{2}{*}{$\begin{array}{l}\text { Silty, } \\
\text { clayey soils }\end{array}$} & $\mathrm{N}_{\mathrm{DCP} \mid 0 \sim 6 "}$ & $\begin{array}{l}P I, \% \\
\text { passing the } \\
\# 40 \text { sieve }\end{array}$ & $\begin{array}{c}\mathrm{N}_{\mathrm{DCP} \mid 0 \sim 6}=17 \exp [-0.07(\mathrm{PI})(\% \text { passing } \\
\# 40) / 100] \\
\left(\text { see Figure } 6.51, \mathrm{R}^{2}=0.93\right)\end{array}$ \\
\hline & $\mathrm{N}_{\mathrm{DCP} \mid 6 \sim 12 "}$ & $\begin{array}{c}P I, \% \\
\text { passing the } \\
\# 40 \text { sieve }\end{array}$ & $\begin{array}{c}\mathrm{N}_{\mathrm{DCP} \mid 6 \sim 12 \%}=27 \exp [-0.08(\mathrm{PI})(\% \text { passing } \\
\# 40) / 100] \\
\left(\text { see Figure } 6.51, \mathrm{R}^{2}=0.95\right)\end{array}$ \\
\hline
\end{tabular}

In order to facilitate the use of DCP criteria as a quality tool in INDOT sites, we also introduce the tables based on the relationships that were presented in Table 6.11.

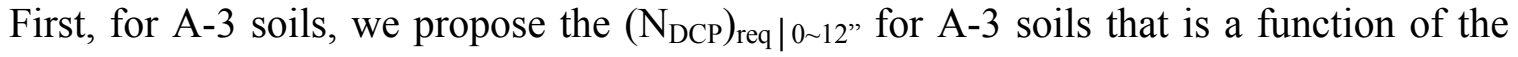




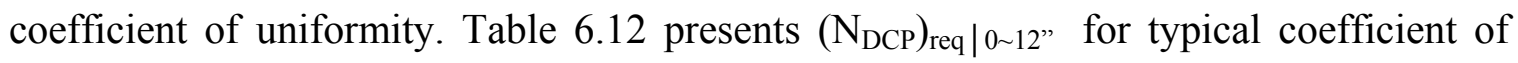
uniformity values.

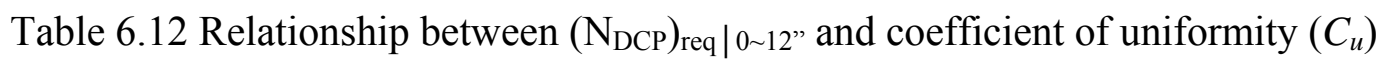

\begin{tabular}{|c|c|}
\hline Coefficient of uniformity $\left(C_{u}\right)$ & $\mathrm{N}_{\mathrm{DCP} \mid 0 \sim 12 \%}$ \\
\hline 2 & 6 \\
\hline 3 & 7 \\
\hline 4 & 9 \\
\hline 5 & 10 \\
\hline 6 & 10 \\
\hline 7 & 11 \\
\hline 8 & 11 \\
\hline
\end{tabular}

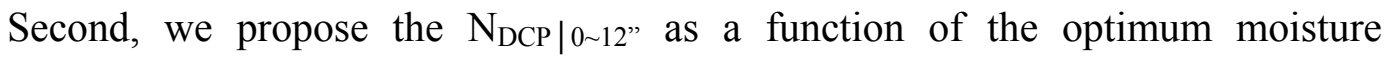
contents. Table 6.13 presents $\left(\mathrm{N}_{\mathrm{DCP}}\right)_{\text {req }} \mid 0 \sim 12$ " for typical optimum moisture content values.

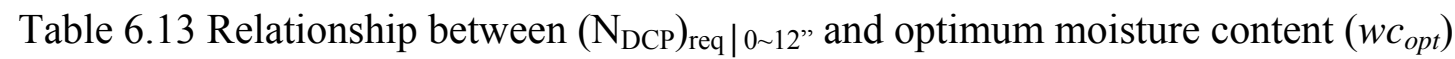

\begin{tabular}{|c|c|}
\hline optimum moisture content $\left(w C_{\text {opt }}\right)$ & $\mathrm{N}_{\text {DCP } \mid \text { O 12” }}$ \\
\hline 10 & 18 \\
\hline 11 & 16 \\
\hline 12 & 14 \\
\hline 13 & 13 \\
\hline 14 & 11 \\
\hline
\end{tabular}

Lastly, we propose the minimum required blow count for silty clayey soils as a function of the plastic index (PI) and percent passing the \#40 sieve. Table 6.14 presents

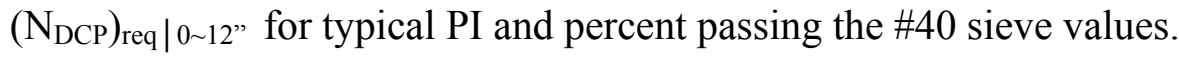


Table 6.14 Relationship between $\mathrm{N}_{\mathrm{DCP}}, C_{u}, w C_{o p t}, P I$, and percent the $\# 40$ passing sieve

\begin{tabular}{|c|c|c|c|}
\hline PI (\%) & \#40 passing sieve $(\%)$ & $\mathrm{N}_{\mathrm{DCP} \mid 0 \sim 6 "}$ & $\mathrm{~N}_{\mathrm{DCP} \mid 6 \sim 12 "}$ \\
\hline \multirow{4}{*}{3} & 70 & 15 & 23 \\
\hline & 80 & 15 & 23 \\
\hline & 90 & 15 & 22 \\
\hline & 100 & 14 & 22 \\
\hline \multirow{4}{*}{6} & 70 & 13 & 20 \\
\hline & 80 & 13 & 19 \\
\hline & 90 & 12 & 18 \\
\hline & 100 & 12 & 17 \\
\hline \multirow{4}{*}{9} & 70 & 11 & 17 \\
\hline & 80 & 11 & 16 \\
\hline & 90 & 10 & 15 \\
\hline & 100 & 10 & 14 \\
\hline \multirow{4}{*}{12} & 70 & 10 & 14 \\
\hline & 80 & 9 & 13 \\
\hline & 90 & 8 & 12 \\
\hline & 100 & 8 & 11 \\
\hline \multirow{4}{*}{15} & 70 & 9 & 12 \\
\hline & 80 & 8 & 11 \\
\hline & 90 & 7 & 10 \\
\hline & 100 & 6 & 9 \\
\hline \multirow{4}{*}{18} & 70 & 8 & 10 \\
\hline & 80 & 7 & 9 \\
\hline & 90 & 6 & 8 \\
\hline & 100 & 5 & 7 \\
\hline \multirow{4}{*}{21} & 70 & 7 & 9 \\
\hline & 80 & 6 & 8 \\
\hline & 90 & 5 & 6 \\
\hline & 100 & 4 & 6 \\
\hline \multirow{4}{*}{24} & 70 & 6 & 8 \\
\hline & 80 & 5 & 6 \\
\hline & 90 & 4 & 5 \\
\hline & 100 & 4 & 4 \\
\hline
\end{tabular}


The DCPT appears to hold some promise as an economical tool for soil compaction quality control. Minimum required blow counts for $\mathrm{RC} \geq 95 \%$ with high probability were determined, but these results are preliminary and further research is advised. With respect to the CHT, considerable variability was observed. The research team and the study advisory committee decided to not explore the CHT further at this time. 


\section{CHAPTER 7. DYNAMIC CONE PENETRATION TESTS AND CLEGG HAMMER TESTS PERFORMED IN A TEST CHAMBER}

\subsection{Introduction}

This chapter describes dynamic cone penetration tests, Clegg hammer tests, and static load tests performed in a large-scale chamber. The chamber is located in the Bowen Laboratory for Large-Scale Civil Engineering Research at Purdue University. The details of the test chamber and pluviation procedure were presented by Lee (2008). The purpose of the tests was to obtain dynamic test results as well as static test results under fully controlled conditions in a large-scale test chamber, in order to avoid the uncertainties that are inevitable in the field. 


\subsection{Test Equipment}

\subsubsection{Test Chamber and Pluviation Procedure}

The soil chamber used in this study is a cylindrical steel tank that was designed and manufactured at Purdue University. The details of the test chamber and pluviation procedure were presented by Lee (2008). The chamber was has an internal diameter of $200 \mathrm{~cm}$ and a height of $160 \mathrm{~cm}$ (see Figure 7.1). The chamber has two supports for setting up a reaction $\mathrm{H}$-beam (width $=17 \mathrm{~cm}$, height $=21 \mathrm{~cm}$, flange thickness $=11.8 \mathrm{~cm}$, and web thickness $=6.4 \mathrm{~cm}$ ). The H-beam is attached to the supports using nuts and bolts after installing either the DCP bar or the set of plates for the static load tests. 


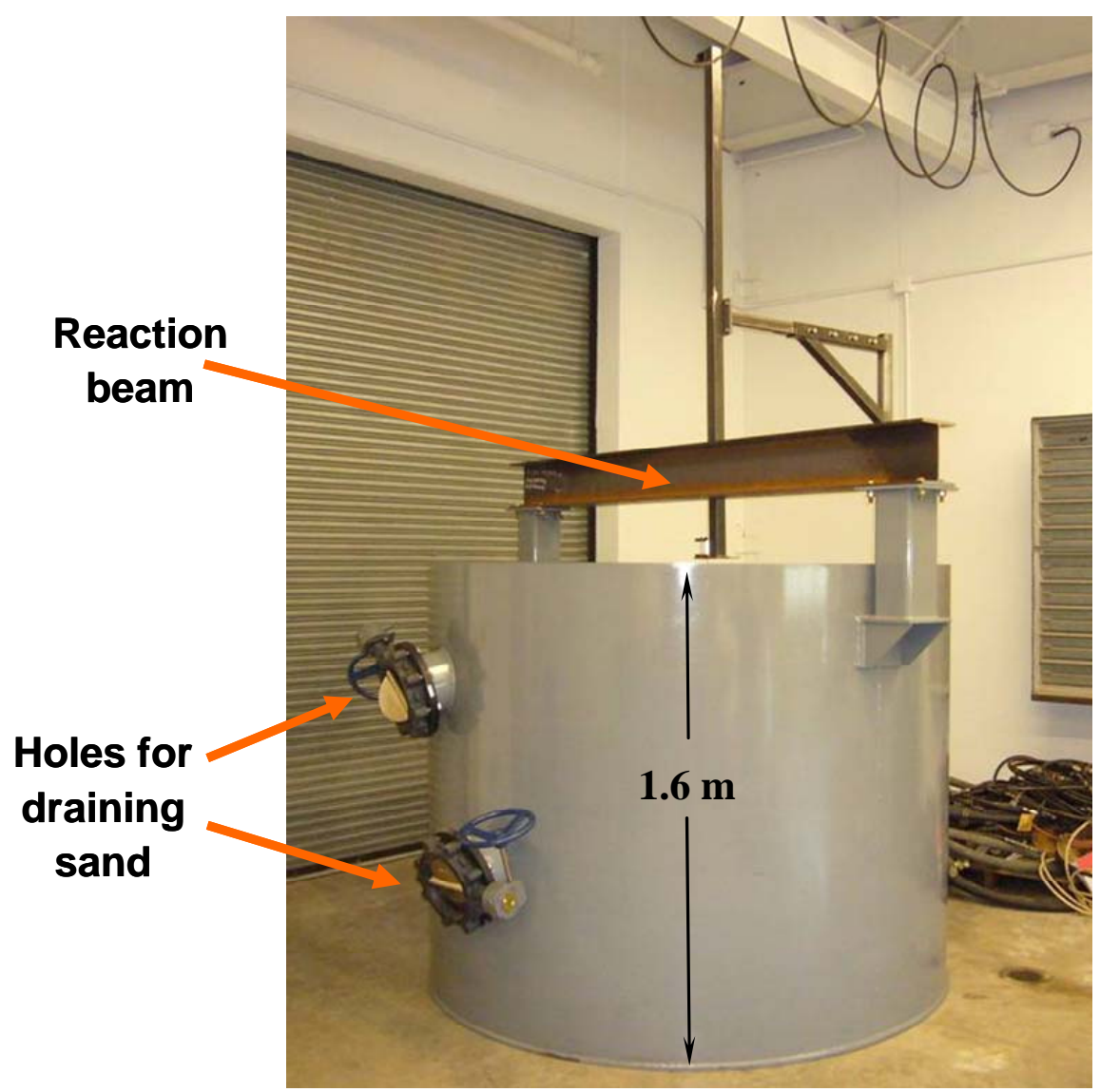

Figure 7.1 Photograph of the soil chamber (modified after Lee 2008).

A sand pluviator was used to prepare sand samples in the chamber with the desired density. The sand pluviator enabled control of the relative density of the sand deposited in the chamber. The pluviator also facilitated the pouring of sand into the chamber. In order to facilitate the removal of the sand pluviated in the chamber after the tests, the chamber contains two drain holes on the side (see Figure 7.1).

Figure 7.2 shows a schematic view of the sand pluviator used in this research. The diameter of the sand pluviator is $190.5 \mathrm{~cm}$. The pluviator consists of a shallow steel cylinder of height $15.2 \mathrm{~cm}$. The bottom of the cylinder has two layers: one layer is a perforated circular steel plate and the other layer is a perforated acrylic plate of the same 
size as the steel plate. When the holes of the plates are not aligned, then they work as a shutter plate. These plates are positioned to produce an identical hole pattern for pluviation to begin.

The relative density of the sand deposited in the chamber using the sand pluviator is controlled by the dropping velocity of the sand particles. The relative density of the sand deposited in the chamber is controlled by two factors: (1) the opening size of the sieves at the bottom of the pluviator (see Figure 7.2), and (2) the sand drop height. The two sieves located below the shutter plate have different opening sizes [No. $6(3.35 \mathrm{~mm})$ and No. $16(1.18 \mathrm{~mm})]$. 


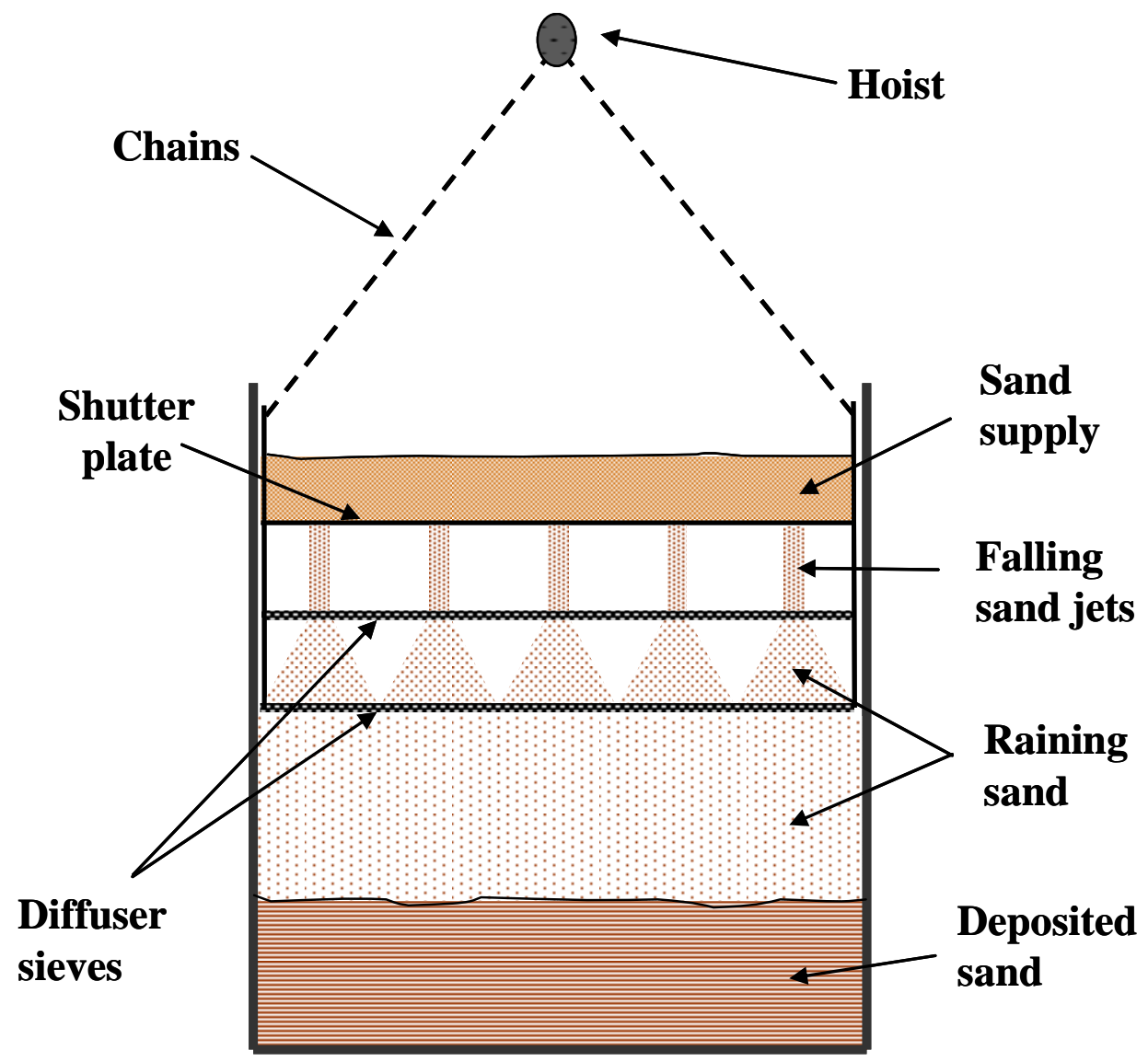

Figure 7.2 Schematic view of the sand pluviator (modified after Lee 2008).

The pluviator falling height was controlled by a gantry crane of a 1,000 kg capacity. The gantry crane moved the pluviator freely so that it could be located above the chamber during sand deposition and away from it during testing.

\subsubsection{Engineering Properties of Test Sand}

According to the Unified Soil Classification System (USCS), the test sand was classified as poorly graded sand. The test sand, referred to as F-55 sand, was obtained from the U.S. Silica company in large quantities with consistent properties. It has engineering 
properties similar to those of ASTM standard Ottawa sand (designated as ASTM C77806). Table 7.1 summarizes the engineering properties of F-55 sand.

Table 7.1 Engineering properties of F-55 sand (data from Lee 2008)

\begin{tabular}{|c|c|}
\hline Engineering property & Value \\
\hline Specific Gravity $\left(\mathrm{G}_{\mathrm{s}}\right)$ & 2.65 \\
\hline Effective particle size $\left(\mathrm{D}_{10}\right)$ & $0.15 \mathrm{~mm}$ \\
\hline Mean particle size $\left(\mathrm{D}_{50}\right)$ & $0.23 \mathrm{~mm}$ \\
\hline Coefficient of Uniformity $(\mathrm{Cu})$ & 1.67 \\
\hline Coefficient of Curvature $(\mathrm{Cc})$ & 1.07 \\
\hline Percentage passing No.200 sieve $(\%)$ & 0 \\
\hline Max. dry unit weight $\left(\gamma_{\mathrm{dmax}}\right)$ & $17.66 \mathrm{kN} / \mathrm{m}^{3}$ \\
\hline Min. dry unit weight $\left(\gamma_{\mathrm{dmin}}\right)$ & $14.62 \mathrm{kN} / \mathrm{m}^{3}$ \\
\hline Min. void ratio $\left(\mathrm{e}_{\min }\right)$ & 0.78 \\
\hline Max. void ratio $\left(\mathrm{e}_{\max }\right)$ & 0.47 \\
\hline Critical-state friction angle $\left(\phi_{\mathrm{c}}\right)$ & $32.8^{\circ}$ \\
\hline Grain shape description & Rounded to subrounded \\
\hline
\end{tabular}




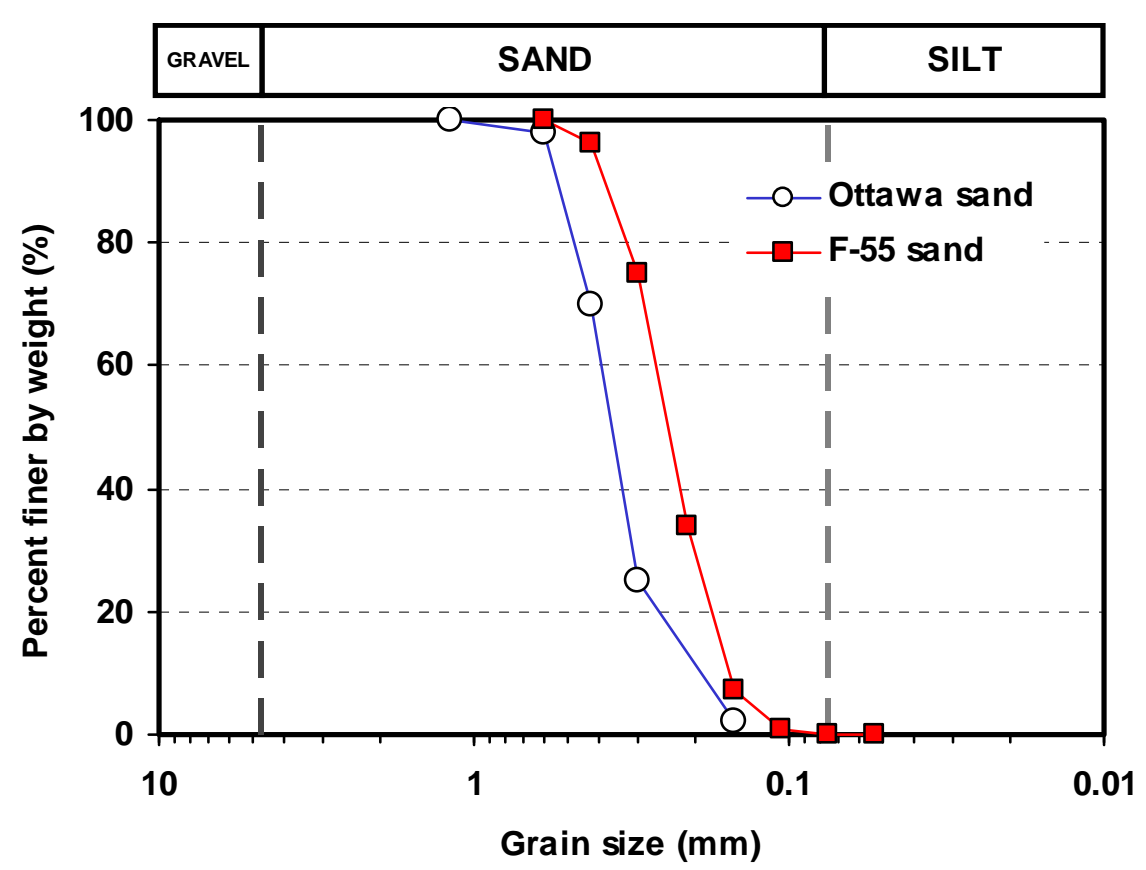

Figure 7.3 Grain size distribution of F-55 sand and Ottawa sand (modified after Lee 2008).

Figure 7.4 shows a micrograph of the F-55 sand grains obtained using the Scanning Electron Microscope (SEM). The micrograph shows that the shape of the sand particles are rounded to subrounded. The dominant mineral of the sand is silica $\left(\mathrm{SiO}_{2}\right)$, which is the main mineral of quartz.

According to Lee (2008), the critical-state friction angle of F-55 sand was obtained from the results of triaxial tests performed under confining pressures ranging from $50 \mathrm{kPa}$ to $200 \mathrm{kPa}$. Since axial strains greater than $26 \%$ were not reached in these tests due to the limitations of the test apparatus, the extrapolation technique suggested by Murthy et al. (2007) was used for determining the critical-state friction angle. The critical-state friction angle was determined to be $32.8^{\circ}$. 


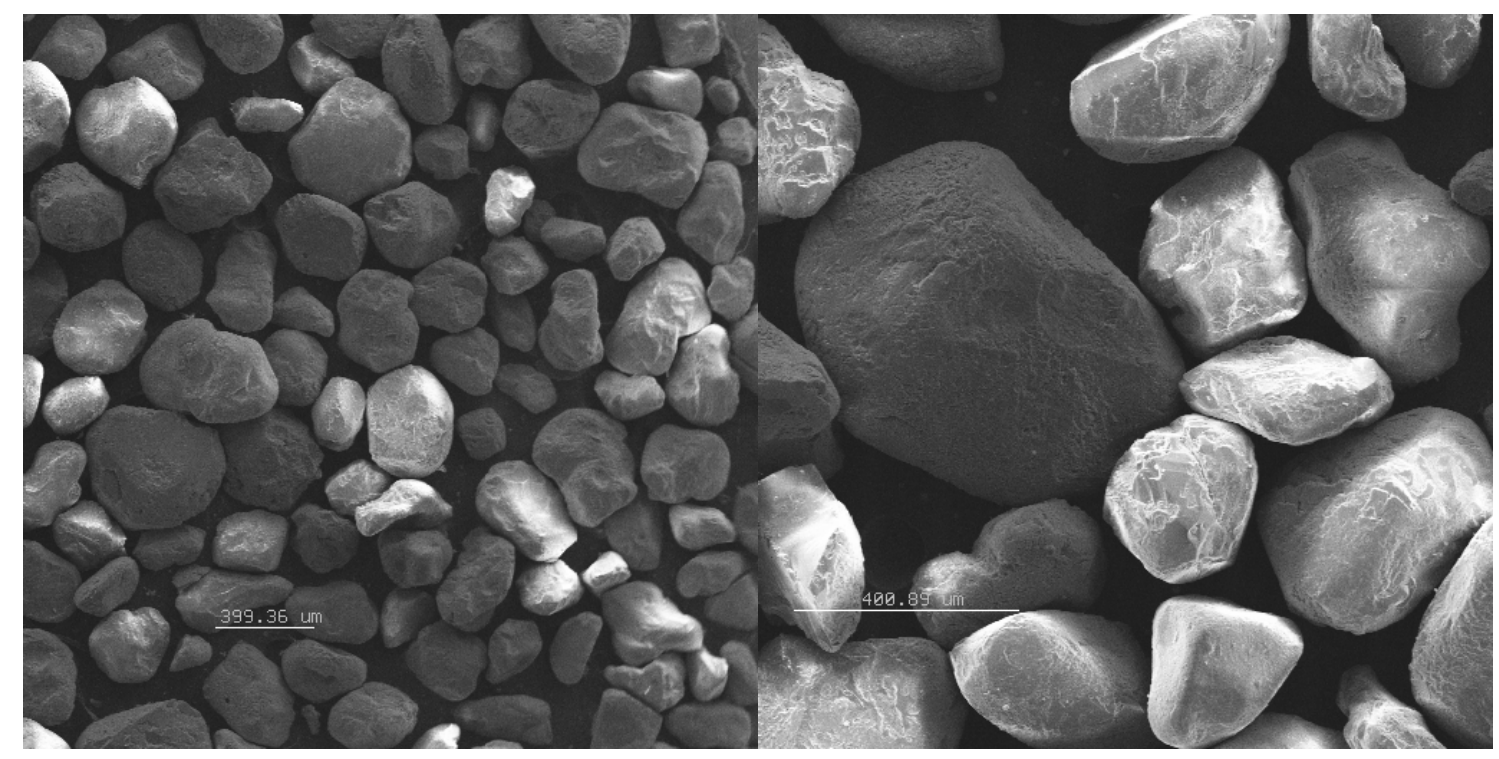

Figure 7.4 A SEM micrograph of F-55 sand grains.

With respect to the scale effects in the chamber, two factors were considered. First, the ratio of the diameter of the DCP to that of the sand particles sizes. If the size of the soil particles becomes too large compared with the DCP diameter, the particulate nature of soil (i.e., the geometry of the particles and their arrangement) will have too great an influence on the test results. Related to this factor, Ovesen (1975) demonstrated that, in centrifuge testing, the particle size effects become significant for pile circumference to mean particle size $\left(\mathrm{D}_{50}\right)$ ratios less than 40 for foundations on quartz sand. Bolton et al. (1999) indicated that the soil particle size does affect cone penetrometer measurements for the ratios of the width (B) of the cone to $\mathrm{D}_{50}$ below about 20. In this research, $\mathrm{B} / \mathrm{D}_{50}$ was approximately 87 (tip) and 70 (bar), which were greater than the suggested values in the literature. Certainly, the CHT satisfies this requirement because the diameter of the Clegg Hammer is larger than that of the DCP. 
Second, the ratio $D_{L}$ of chamber diameter to the diameter of the Clegg Hammer and the DCP is another important factor. The tests on soil chambers cannot perfectly simulate full-scale field tests due to the boundary effects of the chamber. Salgado et al. (1998) indicated that initial values of relative density and stress state mainly control the ratio $D_{L}$ at which the size effect is no longer important. In the case of cone, as in the case of the DCP, Parkin et al. (1980) suggested that a chamber-to-penetrometer diameter ratio of at least 50 is desirable for dense sand and 20 for loose sand. Been et al. (1986) proposed that the ratio must be greater than 50 for dense sand to minimize the effect of the chamber size on the test results. Similarly, Schnaid and Houlsby (1991) suggested, based on numerical and experimental studies, that the chamber-to-probe diameter ratio should be at least 50 in dense sand to eliminate chamber size effects. However, based on the penetration-resistance analysis, Salgado et al. (1998) showed that, in order to minimize chamber size effects on cone resistance, the ratio $D_{L}$ should be larger than 150 . In this study, the chamber-to-DCP diameter ratio was about 50.

For the plate load test, the chamber-to-plate diameter ratio is another factor that needs to be addressed. According to Salgado and Lee (1999), the size effects in calibration chambers are more pronounced in dense sands than in loose sands. Recently, based on finite element analysis, Loukidis and Salgado (2009) showed that the slip surfaces below a circular footing extended up to about eight times the circular footing diameter to the sides in the dense sand with $\phi=40^{\circ}$. In this study, the ratio of the diameter of the chamber to the diameter of the CHT was 14.5 with $\phi_{c}=32.8^{\circ}$. 


\subsubsection{Details of Instrumentation}

(1) Static load tests

The DCP used for the static load tests is identical to the one described in section 3.3.6 and ASTM D6951-03. The plate load tests were performed with a steel plate $13.75 \mathrm{~cm}$ in diameter, which is very close to the diameter of the Clegg Hammer $(13.0 \mathrm{~cm}$ in diameter). A set of circular steel bearing plates were arranged in pyramidal fashion to ensure rigidity, as per ASTM D 1196-03. Figure 7.5 shows (a) the DCP bar and (b) the set of plates installed for the static load test. 


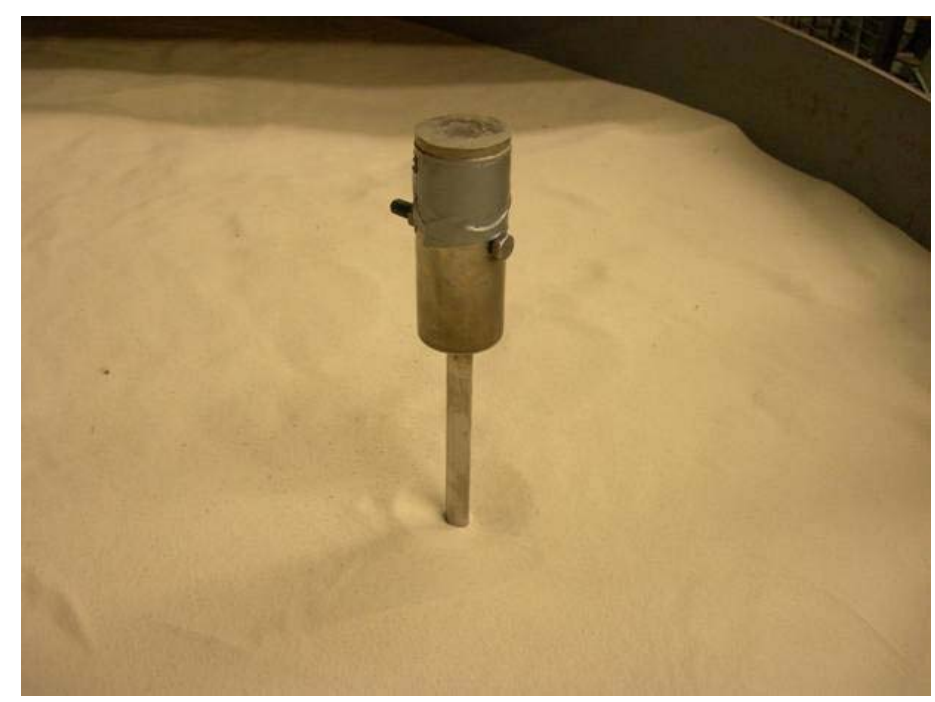

(a)

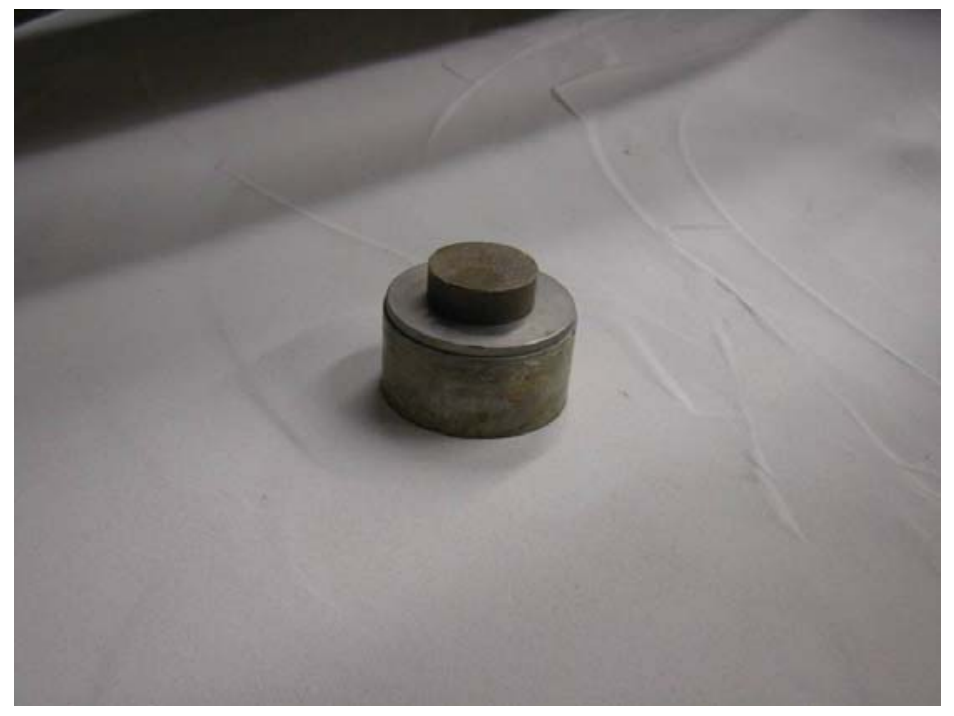

(b)

Figure 7.5 Photographs of (a) DCP bar, and (b) set of plates used in the tests. 
The instrumentation used for both static loads tests (with the DCP or the plates) was identical. In order to apply the load on the DCP or the plates, a hydraulic jacking pump was used. The reaction to the applied load was provided by the H-beam connected to the soil chamber. A load cell installed on the hydraulic jack was used for measuring the load applied on the DCP or the plates. The maximum capacity of the load cell is 20 $\mathrm{kN}$, with a resolution of $0.01 \mathrm{~N}$. Also, the maximum displacement of the Linearly Variable Differential Transducers (LVDT) is $50 \mathrm{~mm}$, with a resolution of $0.0001 \mathrm{~mm}$. In order to record the load cell and the LVDT data, a data acquisition system, the CR5000 manufactured by Campbell Scientific, was used.

(2) Dynamic Cone Penetrometer Tests

A Pile Driving Analyzer (PDA) was used to record the values the DCP penetration data. The dynamic measurements were taken with two piezoelectric accelerometers attached in pairs on both sides of the DCP head (see Figure 7.6). Figure 7.6 shows the equipment used in the dynamic load tests. 


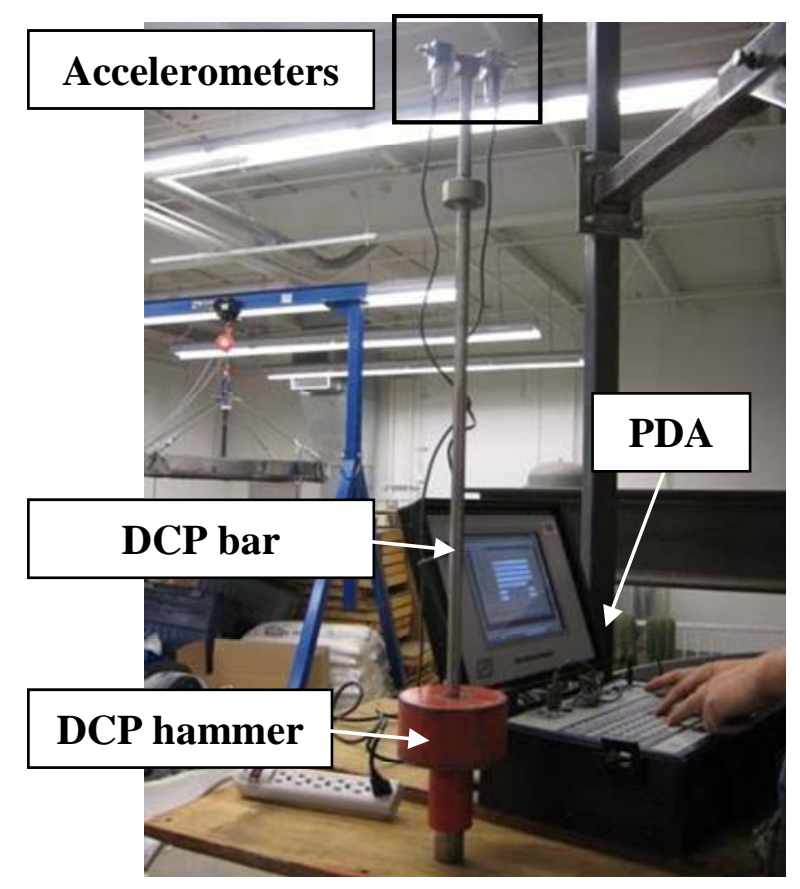

(a)

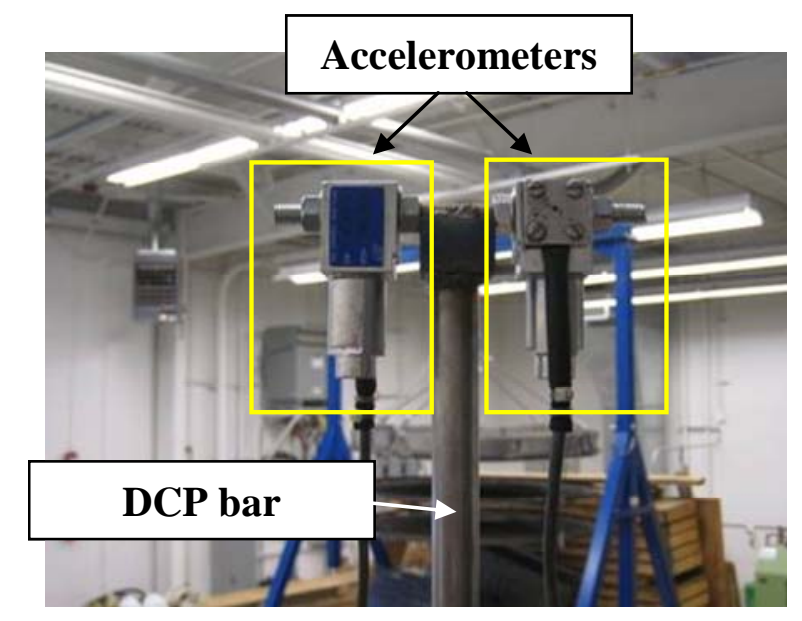

(b)

Figure 7.6 Photographs of (a) the Pile Driving Analyzer, and (b) the accelerometers attached on the DCP bar. 


\section{(3) Clegg Hammer Tests}

The CHT apparatus (Model 95055A) used for the tests was manufactured by the Lafayette Instrument Co., Lafayette, IN. As indicated in CHAPTER 3, this model includes the hammer, which is $10 \mathrm{~kg}$ weight, $0.3 \mathrm{~m}$ diameter, and $0.13 \mathrm{~m}$ drop height. An accelerometer was attached on the hammer by the manufacturer. Tektronix Model No. TDS 3014B Oscilloscope by Tektronix Co. was used to record the acceleration of the hammer. Figure 7.7 shows the equipment used in the dynamic load tests. 


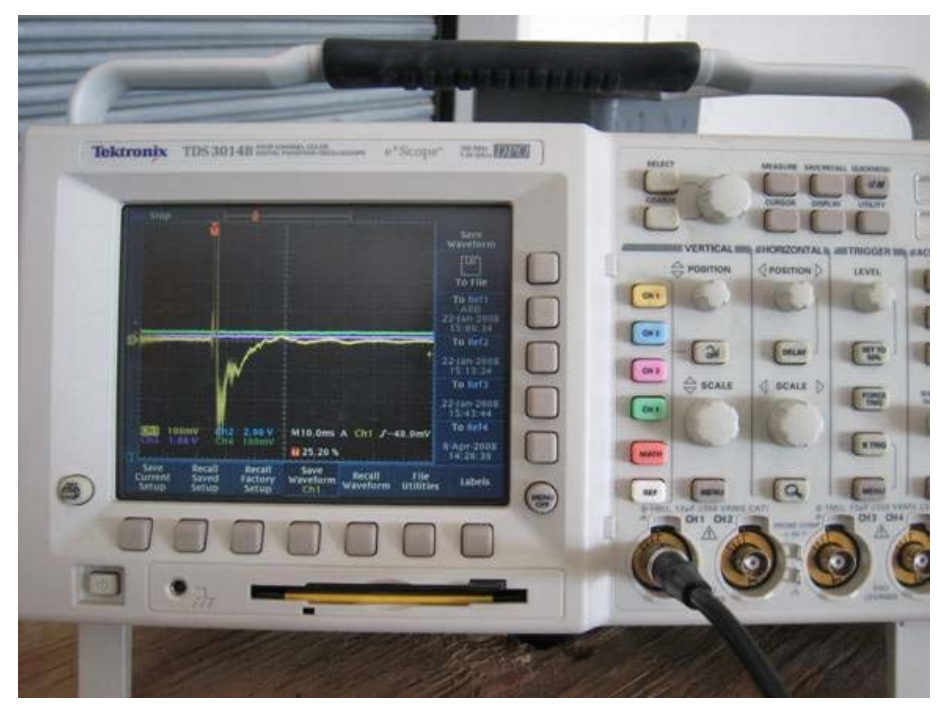

(a)

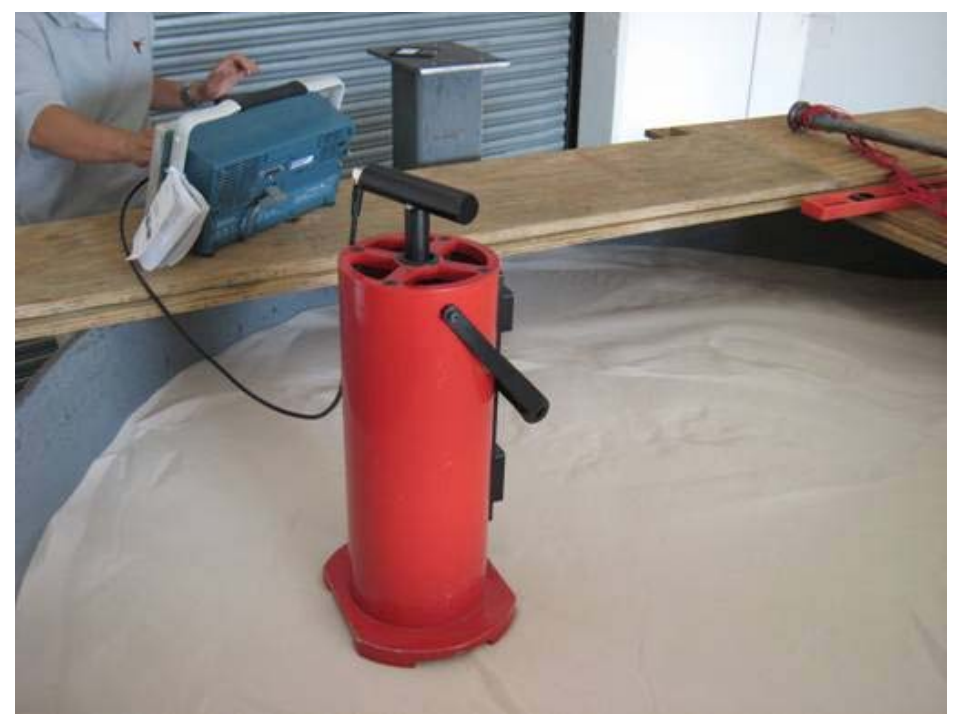

(b)

Figure 7.7 Photographs of (a) the oscilloscope and (b) the CHT. 


\subsubsection{Test Procedure}

(1) Preparation of the sand samples in the chamber

Prior to performing the DCPT or CHT, the test sand was pluviated into the soil chamber. The final height of the sand samples prepared in the chamber was about $140 \mathrm{~cm}$. The target relative density values for dense and medium dense sand samples were about $91 \%$ and $58 \%$, respectively, which correspond to relative compaction values of $98.1 \%$ and $91.8 \%$. Based on the preliminary tests, dense sand samples were prepared with a drop height of $60 \mathrm{~cm}$ using both sieves No. 6 and No.16, while medium dense sand samples were prepared with a drop height of $40 \mathrm{~cm}$ using only sieve No.6. The variability in the relative density values was about $\pm 2.1 \%$ for dense sand samples and $\pm 2.3 \%$ for medium dense sand samples (Lee 2008).

(2) Test procedure for the static load tests

The DCP load tests were performed in accordance with ASTM D 1143. After depositing the sand in the chamber, the DCP was inserted up to about $90 \mathrm{cmin}$ the sand sample. The H-beam was then positioned and attached to the two supports on both sides of the soil chamber. Four sets of nuts and bolts were used to firmly attach the H-beam to each of the supports. The hydraulic jacking pump, the calibrated load cell, and the LVDTs were placed in between the head of the DCP bar and the H-beam [see Figure 7.8 (a)]. The LVDTs were installed at equal distances from the center of the DCP. Magnetic holders were used to attach the LVDTs to the reference beam. During the static load tests, the load applied to the head of the DCP was measured by the load cell, while the displacement of the DCP bar was measured by the two LVDTs. The load was applied in 
increments of $0.1 \mathrm{kN}$. At each step, the load was maintained until the displacement measurement was stabilized.

The plate load tests were performed in accordance with ASTM D 1196-93. After placing the set of plates on the surface of the sand sample, the load cell and the LVDTs were positioned in the same manner as in the DCP tests [see Figure $7.8(\mathrm{~b})$ ]. 


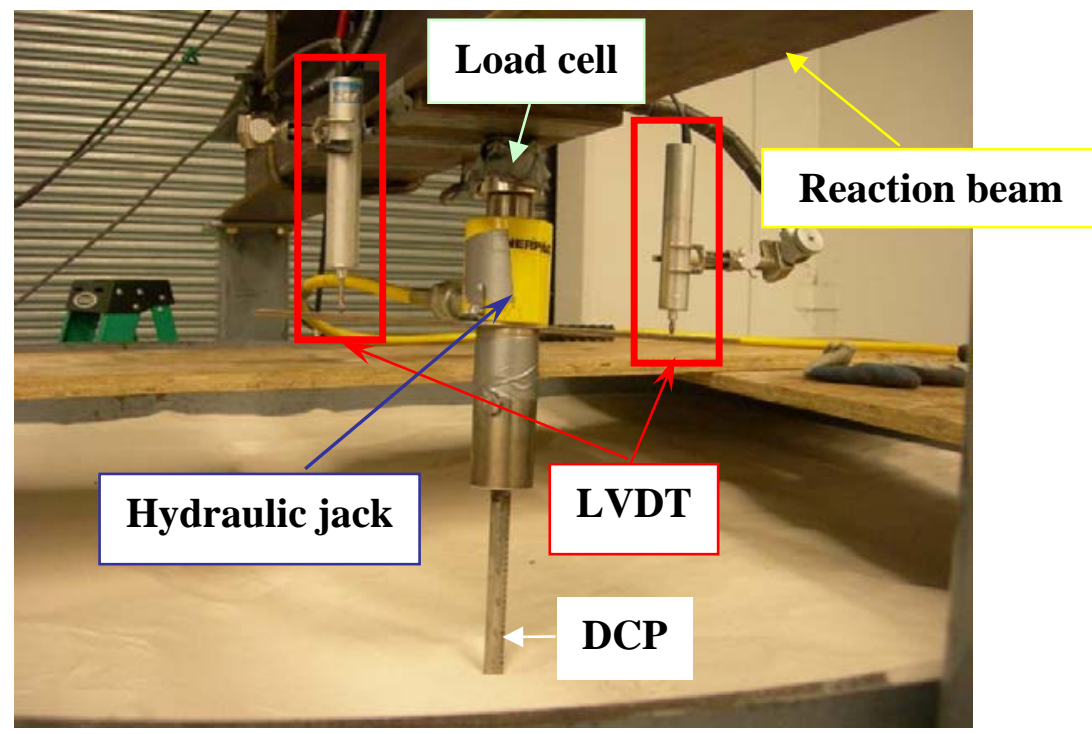

(a)

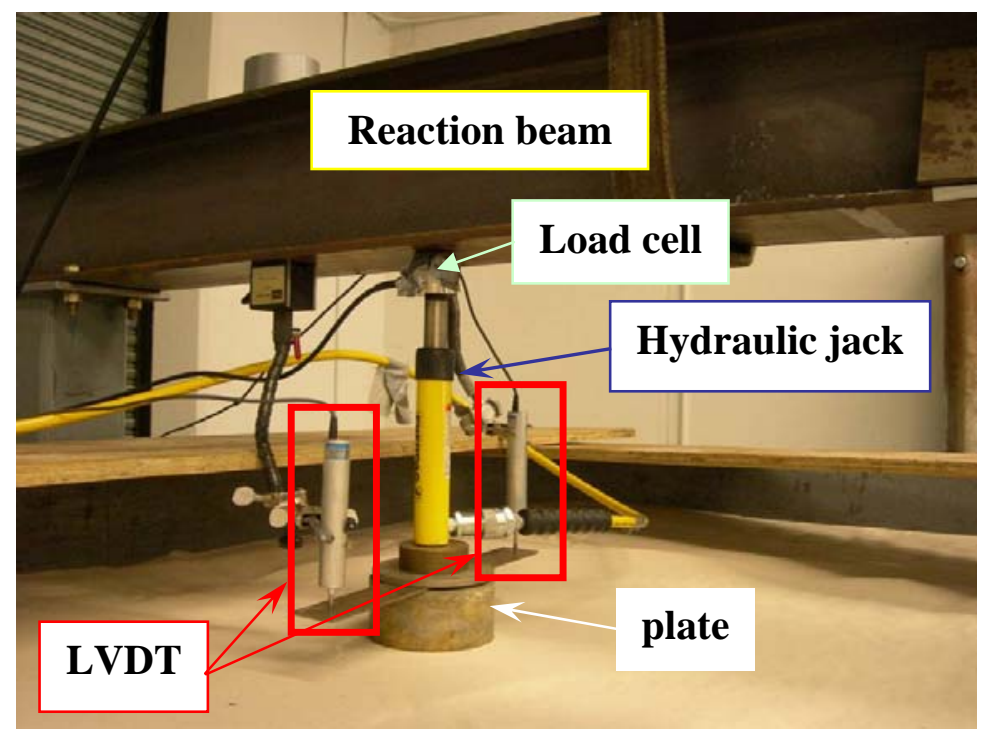

(b)

Figure 7.8 Static load test set-up for (a) the DCP tests, and (b) the plate load tests. 
(3) Test procedure for the dynamic tests

The DCP used for this research has the same geometry presented in Section 3.3.6, also specified in ASTM D6951-03. The DCP has an 8kg drop hammer, and the drop height is $57.5 \mathrm{~cm}$. The DCP penetration per hammer blow was recorded during the test.

The CHT used for the research is Model No. 95055A manufactured by Lafayette Co. The CHT has $10 \mathrm{~kg}$ drop hammer, and the drop height is $30.0 \mathrm{~cm}$. When a CHT was performed, the Clegg hammer was lifted and dropped from a fixed height that was determined by the size of the cylinder surrounding the Clegg Hammer. For each hammer blow, the acceleration was recorded using the oscilloscope.

\subsection{Chamber Test Results}

\subsubsection{Static Test Results}

\section{(1) DCP load test results}

Figure 7.9 presents the limit load versus settlement curves for the DCP load tests performed in dense and medium dense sand samples. The ultimate load $\mathrm{Q}_{\mathrm{b}, 10 \% \text { associated }}$ with the load based on a settlement equal to $10 \%$ of the DCP diameter for dense sand was 2.7 times larger than that of medium dense sand. 


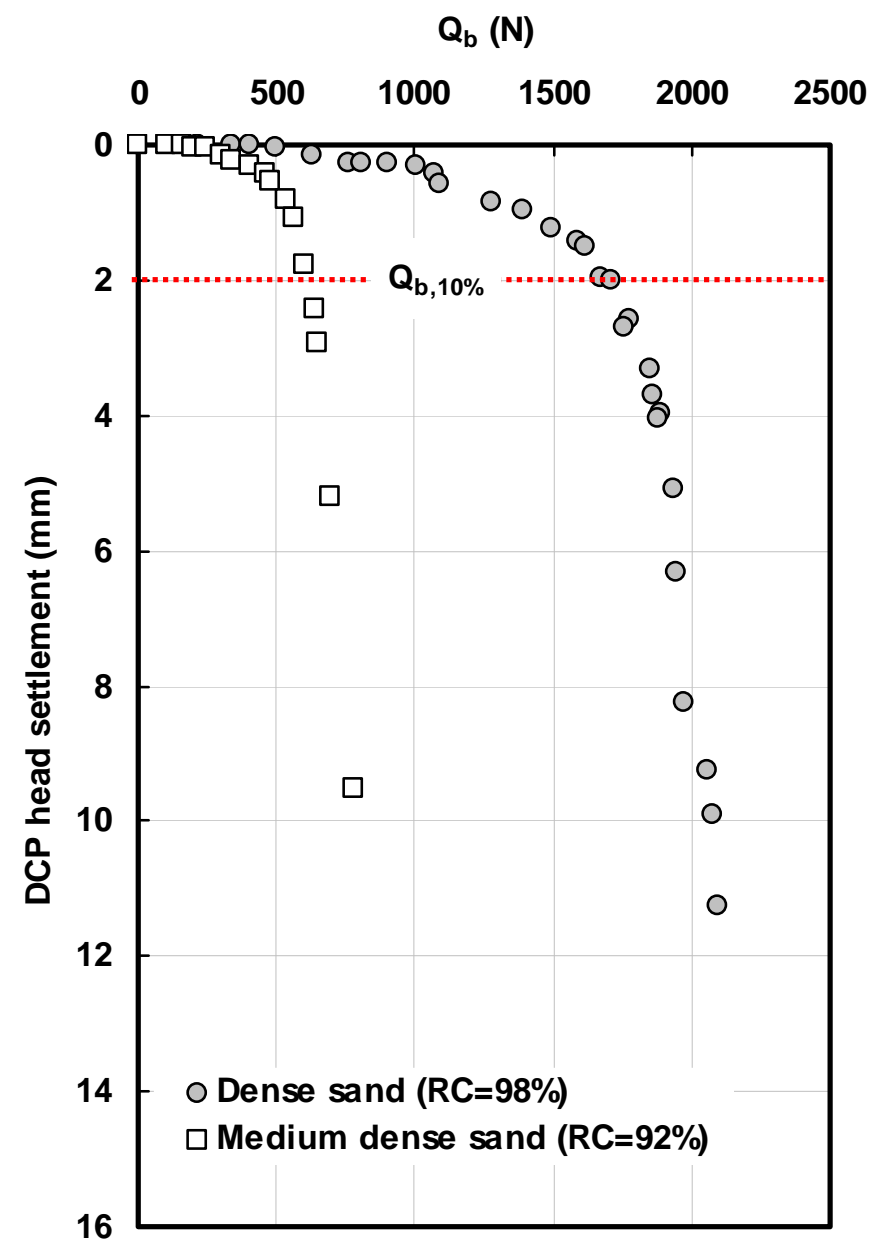

Figure 7.9 Static load-settlement curves obtained for dense and medium dense sand using dynamic cone penetrometer. 
(2) Plate load test results

Figure 7.10 shows the load versus settlement curves obtained for the set of plates tested on dense and medium dense sand samples. The limit load $\left(\mathrm{Q}_{\mathrm{bL}}\right)$ for dense sand was 2.6 times larger than that of medium dense sand. Also, the load-settlement curve for dense sand showed a peak value, while the curve for medium dense sand did not show any peak. Different bearing capacity failure modes were observed on the sand surface for these tests. In the case of the dense sand sample, the slip surfaces extended all the way to the soil surface [see Figure 7.11 (a)], whereas no slip surfaces were observed on the surface of the medium dense sand sample [Figure 7.11 (b)].

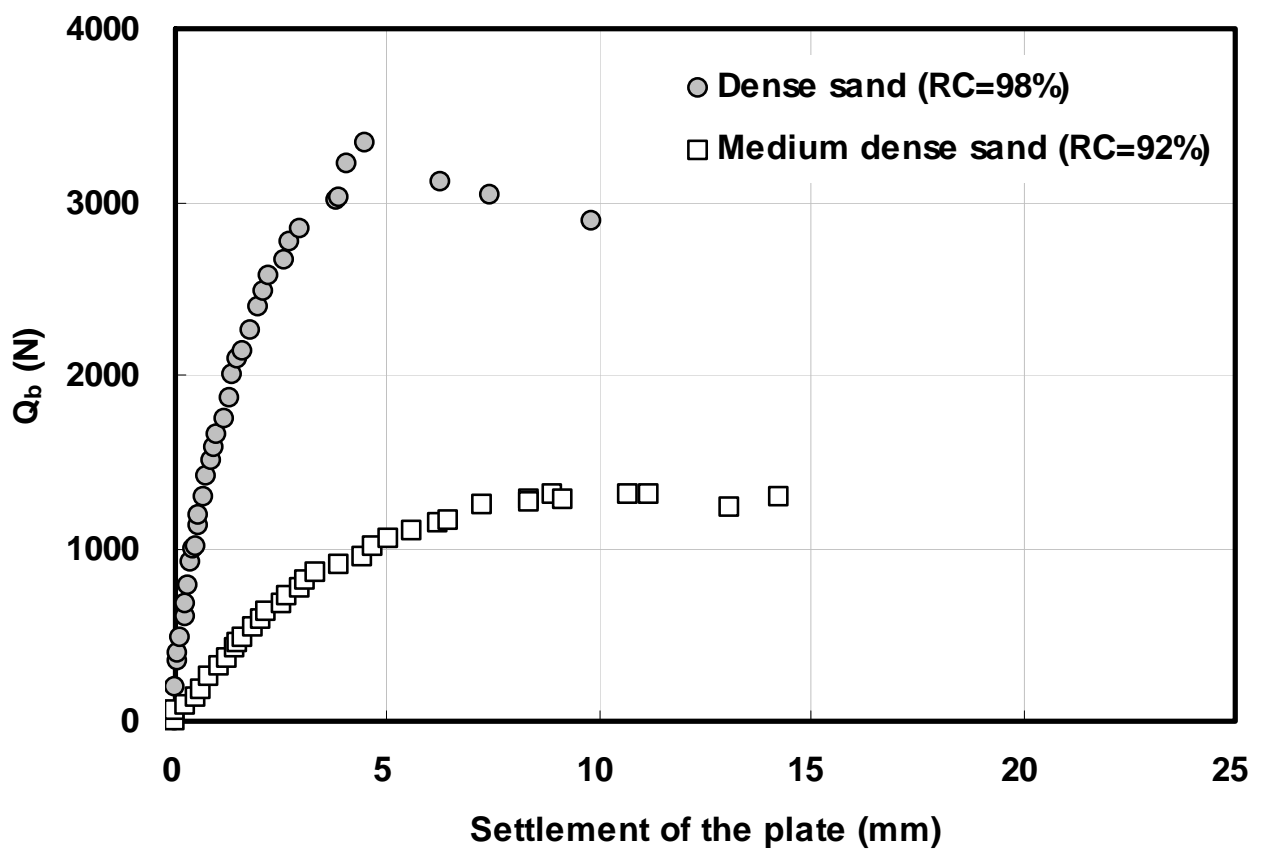

Figure 7.10 Load-settlement curves for the plates bearing on sand. 


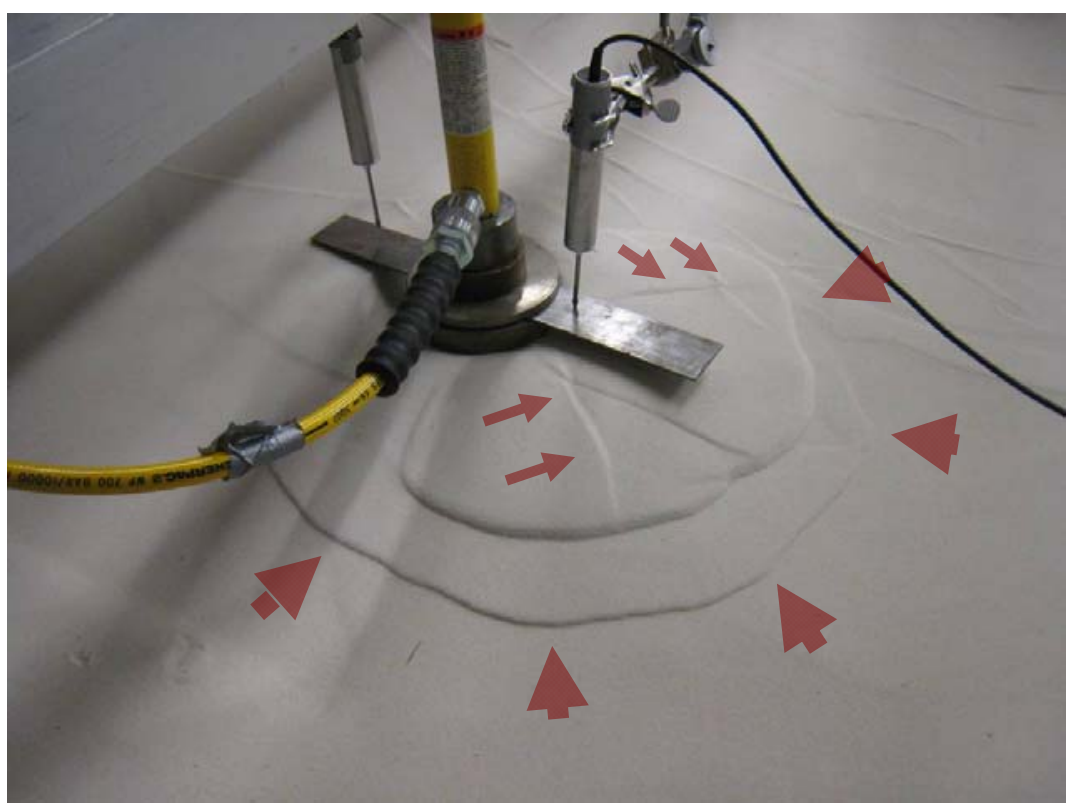

(a)

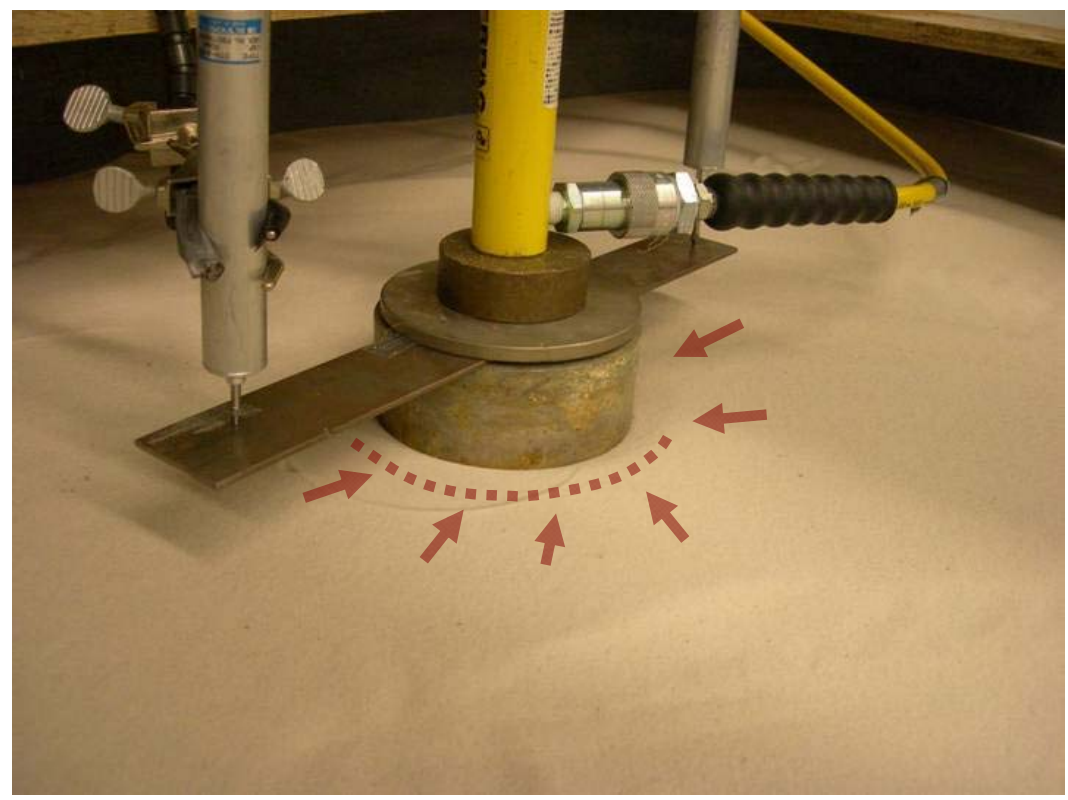

(b)

Figure 7.11 Photographs of the surface of the samples after testing on (a) dense sand and (b) medium dense sand. 


\subsubsection{Dynamic Test Results}

\section{(1) DCP test results}

Dynamic tests were performed for dense $(\mathrm{RC}=98.1 \%)$ sand samples only. Figures 7.12(a) and (b) show the penetration and velocity time history curves at the head of the DCP for several depths. The figure shows that the penetration values decreased as the depth of penetration increased. 


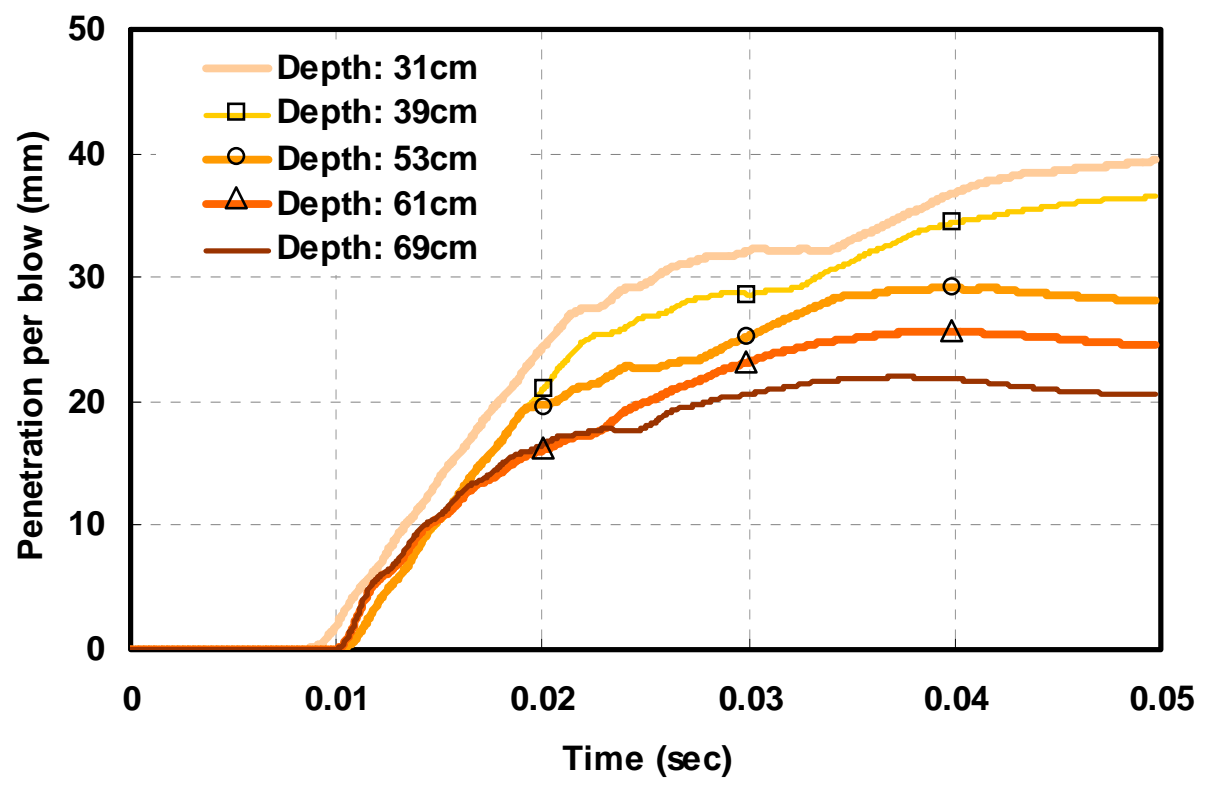

(a)

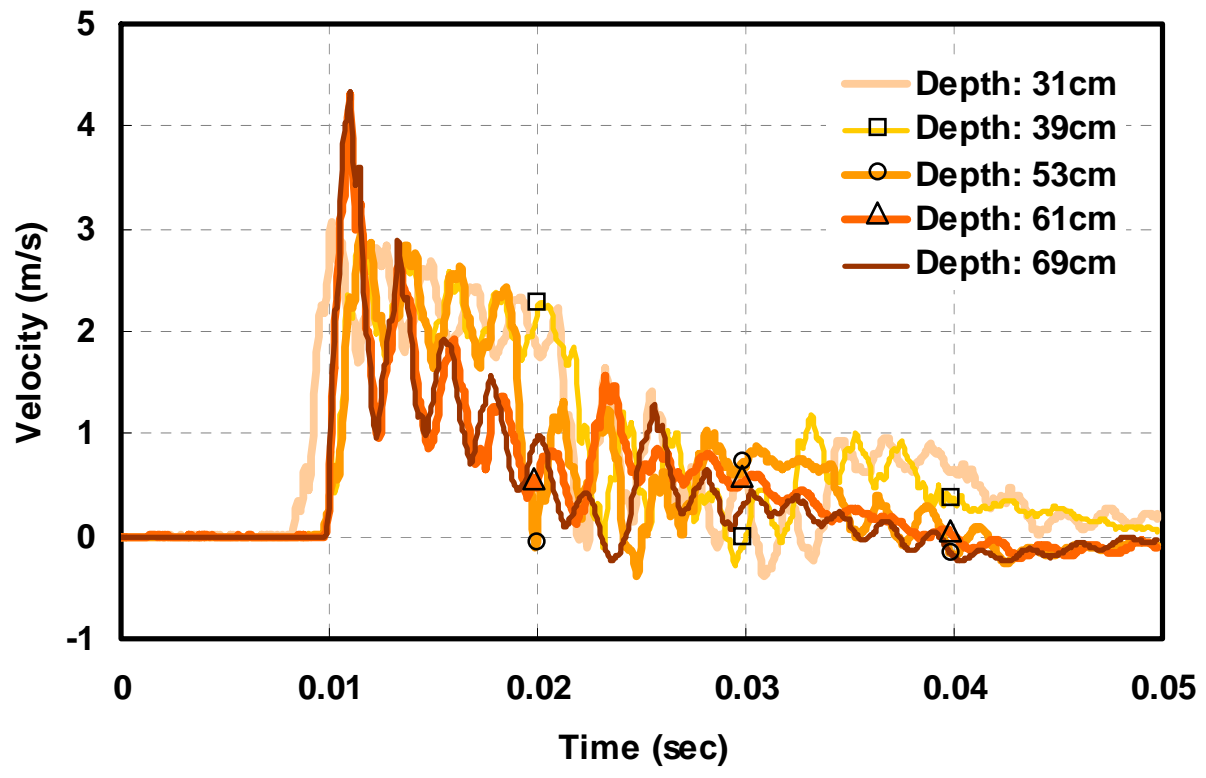

(b)

Figure 7.12 Time history curves at several depths of (a) penetration, and (b) velocity. 
Figure 7.13 compares the measured displacement at the DCP head vs. the calculated displacement from the PDA. The displacements at the DCP head were directly measured using a ruler after each blow, while the calculated displacements were found using the acceleration rates recorded by the PDA. The figure shows that the measured and computed penetration values are in reasonable agreement.

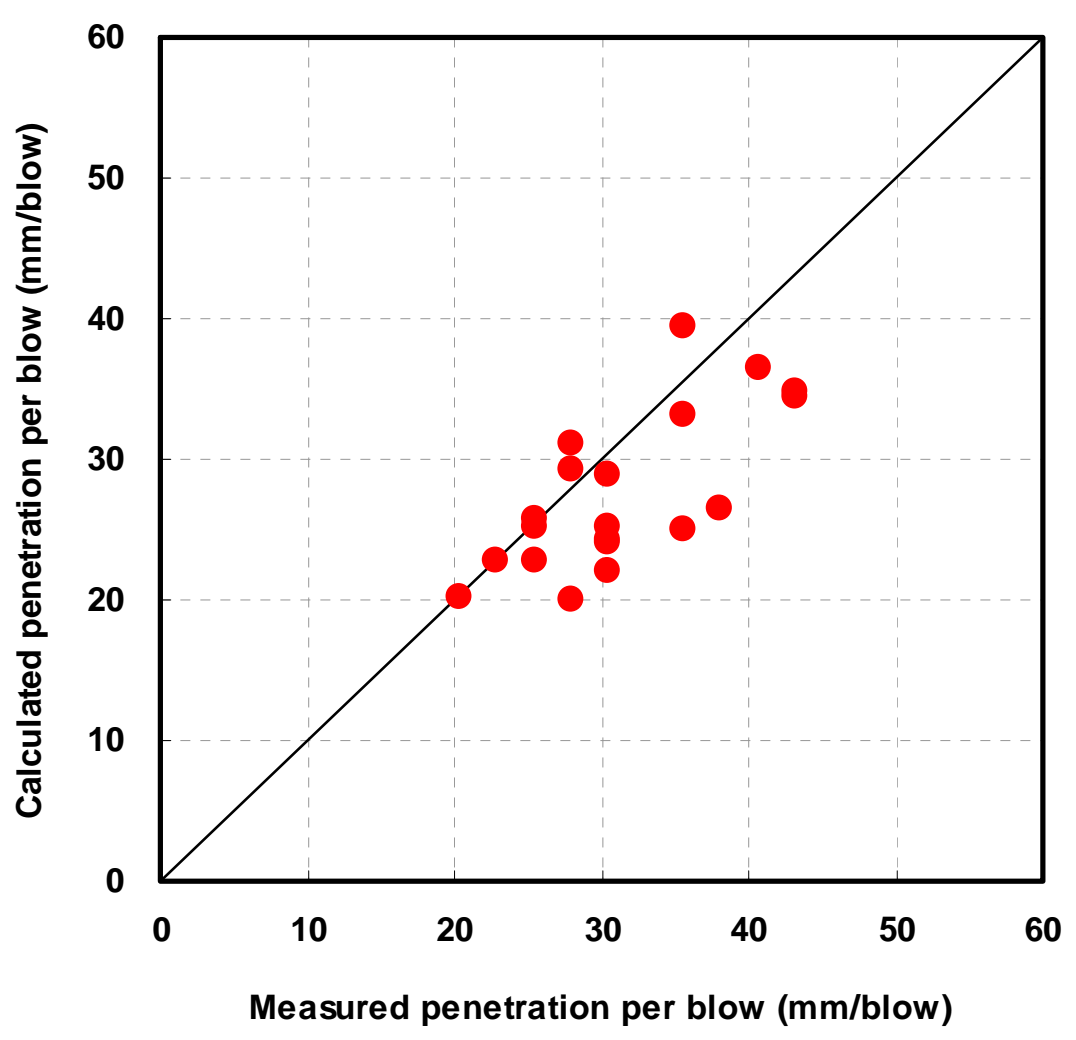

Figure 7.13 Measured vs. calculated penetration per blow ( $\mathrm{mm} / \mathrm{blow})$ at the DCP head. 


\section{(2) $\mathrm{CH}$ test results}

Figure 7.14 shows the acceleration vs. time curves for each blow. As the measured acceleration with time history shows, initially acceleration values peaked quickly and then decreased to almost zero within five milliseconds. The curves also show that this trend was very similar regardless of the number of blows, but the maximum acceleration decreased as the number of blows increased.

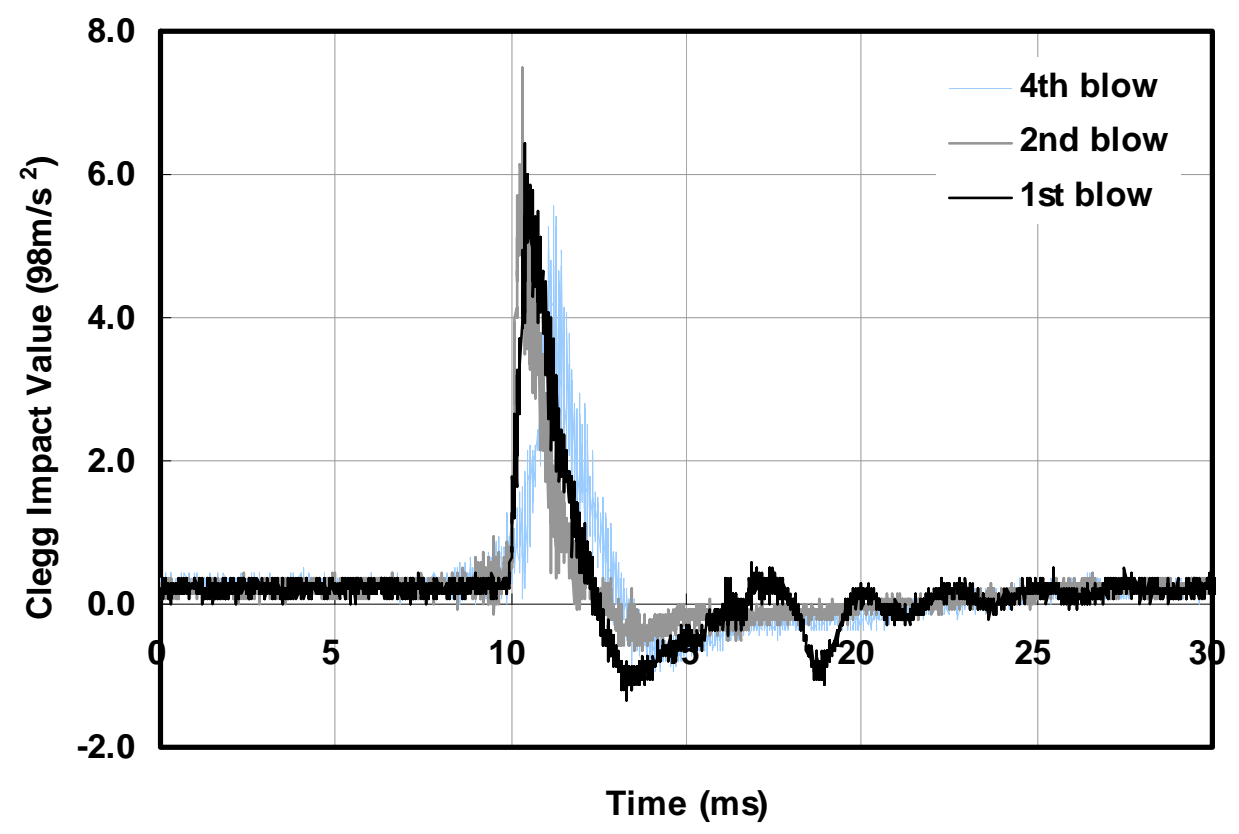

Figure 7.14 Acceleration versus time history for Clegg Hammer Tests on dense sand.

Figure 7.15 shows the CIV (Clegg Impact Value) vs. the relative compaction of the sand samples tested. In the case of a RC of $98.1 \%$, CIV varied mostly between 5.0 and 9.2, but was mostly below 7.7. In the case of a $\mathrm{RC}$ of $91.8 \%$, the CIV was not recorded with many cases because of the lower limit of the data acquisition. However, 
some CIV values were recorded and varied between 5.0 and 6.8. According to Lafayette Co., the CIV can be recorded if the value exceeds 3.0 (Lafayette Co. 2008, personal communication). To summarize, the CIV varied significantly even for the same relative compaction.

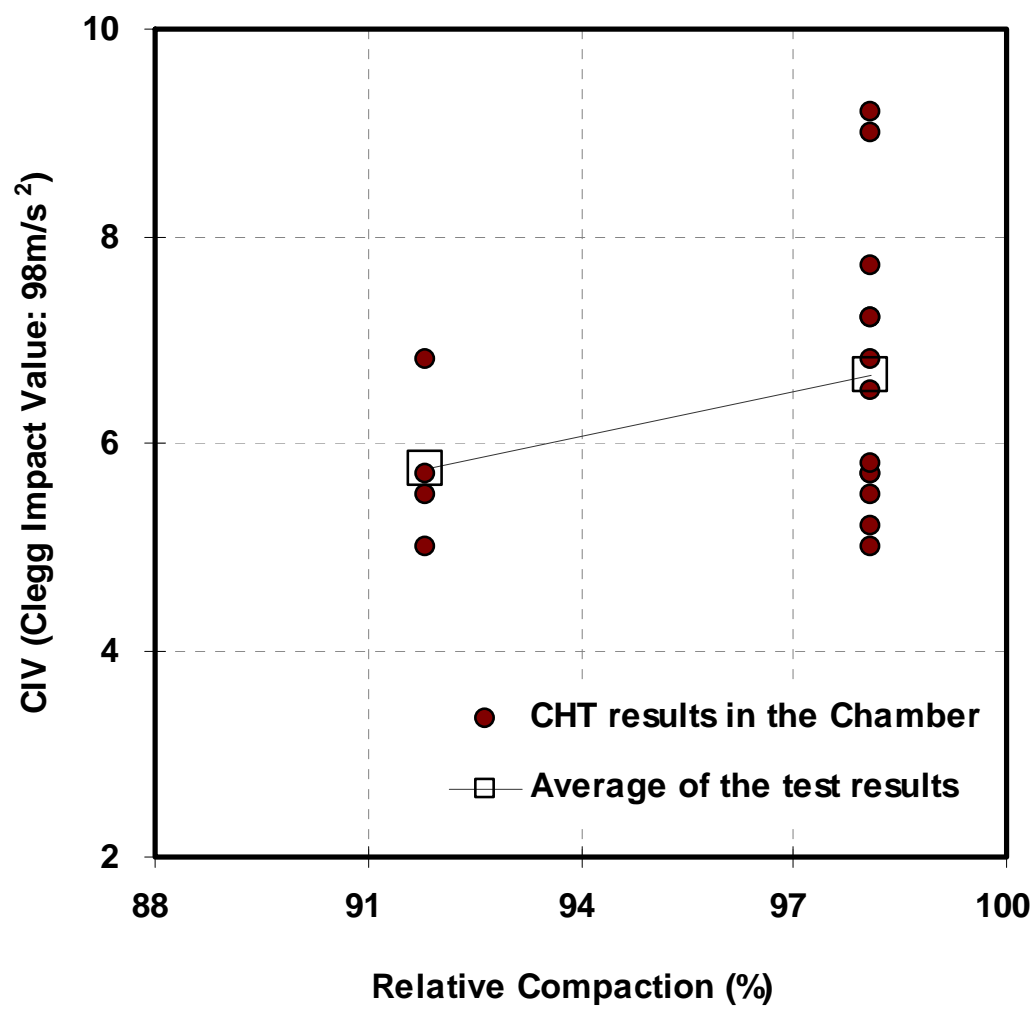

Figure 7.15 CIV versus relative compaction for the sand sample. 


\subsection{Summary}

The chapter discussed presented the Dynamic Cone Penetration Test (DCPT) and the Clegg Hammer Test (CHT) performed in a test chamber. The test conditions and the test program were explained. The test procedure for both the static tests and the dynamic tests were discussed in detail. The dimensions of the test chamber were large enough and of the silica sand particles small enough to minimize scale effects.

Static load tests were performed on the DCP rod and cone and on a plate with the same size as the Clegg Hammer. In the case of the DCP, the ultimate load $\mathrm{Q}_{\mathrm{b}, 10 \%}$ associated with a settlement equal to $10 \%$ of the DCP diameter for dense sand was 2.7 times larger than that of medium dense sand. In the case of the plate with the same size as the Clegg hammer, the limit load for dense sand was 2.6 times larger than that for medium dense sand.

It was shown that integration of measured accelerations leads to reasonable estimates of the penetration of the DCP into the soil. For CHT, the acceleration of the Clegg hammer was recorded on the soil in a test chamber. The acceleration values peaked quickly and then decreased to almost zero within five milliseconds. In the case of $98.1 \%$ RC, the CIV varied between 5.0 and 9.2, but was mostly below 7.7. . 


\section{CHAPTER 8. INTERPRETATION OF THE RESULTS USING DYNAMIC ANALYSIS}

\subsection{Introduction}

This chapter discusses the DCPT and CHT results by comparing them with the predictions done using the analyses using the selected models presented in CHAPTER 5 and proposes a framework for the interpretation of the results of these tests for soils. The predicted test results were compared with the results of preliminary tests performed in a test pit outside the Bowen laboratory, presented in section 6.2, and with results of tests performed in the soil chamber, presented in section 7.3. The measured DCP blow counts $\left(\mathrm{N}_{\mathrm{DCP}}\right)$ were compared with the predicted values. The measured Clegg Impact Values (CIV), which are the peak decelerations of the hammer upon impact with the soil, were compared with the predicted maximum deceleration values. 


\subsection{Input Parameters for the Dynamic Analyses}

The input parameters for the dynamic analyses are summarized in Table 8.1. Each is discussed in detail next.

Table 8.1 Input parameters for the dynamic analyses

\begin{tabular}{|c|c|c|}
\hline Input parameters & $\begin{array}{c}\text { Clegg Hammer Test } \\
\text { (CHT) }\end{array}$ & $\begin{array}{c}\text { Dynamic Cone } \\
\text { Penetration Test } \\
\text { (DCPT) }\end{array}$ \\
\hline In-place dry unit weight $\left(\gamma_{d}\right)$ & V & V \\
\hline Specific gravity $\left(G_{s}\right)$ & V & V \\
\hline Max. shear modulus $\left(G_{\max }\right)$ & V & V \\
\hline Poisson's ratio of the soil $(v)$ & V & V \\
\hline $\begin{array}{l}\text { Critical-state friction angle of the } \\
\text { soil }\left(\phi_{c}\right) \text { for sand }\end{array}$ & V & V \\
\hline $\begin{array}{l}\text { Undrained shear strength }\left(s_{u}\right) \text { of } \\
\text { clay }\end{array}$ & V & V \\
\hline $\begin{array}{l}\text { Constants for viscous damping ( } m \\
\text { and } n \text { ) }\end{array}$ & V & V \\
\hline $\begin{array}{l}\text { Geometry of DCP bar and the tip } \\
\text { (diameter of bar and tip and length) }\end{array}$ & & V \\
\hline $\begin{array}{c}\text { Geometry of Clegg Hammer } \\
\text { (Radius, weight, and drop height) }\end{array}$ & V & \\
\hline Impact velocity & V & \\
\hline
\end{tabular}


(1) Maximum dry unit weights and specific gravities

The maximum dry unit weight values were obtained from the results of the laboratory compaction tests. The specific gravities were also measured after taking the samples from the field as presented in the previous chapters. Table 8.2 summarizes the test results, which were also given in earlier chapters.

Table 8.2 Maximum dry unit weight and specific gravity used for the dynamic analysis

\begin{tabular}{|c|c|c|}
\hline Input parameters & $\begin{array}{c}\text { Sand sample used in } \\
\text { the chamber }\end{array}$ & $\begin{array}{c}\text { Clay sample used in the } \\
\text { pit }\end{array}$ \\
\hline In-place dry unit weight $\left(\gamma_{d}, \mathrm{kN} / \mathrm{m}^{3}\right)$ & $15.3 \sim 17.8^{\dagger}$ & $16.2 \sim 17.3^{\dagger}$ \\
\hline Specific gravity $\left(G_{s}\right)$ & 2.65 & 2.74 \\
\hline
\end{tabular}

${ }^{\dagger}$ the dry unit weights were varied depending on the relative compaction values.

(2) Maximum shear modulus and Poisson's ratio

The small-strain shear modulus is the shear modulus corresponding to the linear elastic portion of the soil deformation curve. This linear elastic soil behavior takes place only at very small deformation levels associated with shear strains typically less than $10^{-5}$ (Salgado 2008). The maximum shear modulus can be expressed as (Hardin and Black 1968):

$$
\left(\frac{\mathrm{G}_{0}}{\mathrm{p}_{\mathrm{A}}}\right)=\mathrm{C}_{\mathrm{g}} \frac{\left(\mathrm{e}_{\mathrm{g}}-\mathrm{e}\right)^{2}}{1+\mathrm{e}}\left(\frac{\sigma_{\mathrm{m}}^{\prime}}{\mathrm{p}_{\mathrm{A}}}\right)^{\mathrm{n}_{\mathrm{g}}}
$$


where $\mathrm{p}_{\mathrm{A}}$ is a reference stress $(=100 \mathrm{kPa}=0.1 \mathrm{MPa} \approx 1 \mathrm{tsf}), \sigma_{\mathrm{m}}^{\prime}=\left(\sigma_{\mathrm{v}}^{\prime}+2 \sigma_{\mathrm{h}}^{\prime}\right) / 3$ is the mean effective stress after consolidation but before any shearing has taken place; $C_{g}, e_{g}, n_{g}$ are constants for a given soil. Thus, $\mathrm{G}_{0}$ varies depending on the in-place unit weight and depth of soil. Figure 8.1 shows the distribution of computed $\mathrm{G}_{0}$ in a chamber.

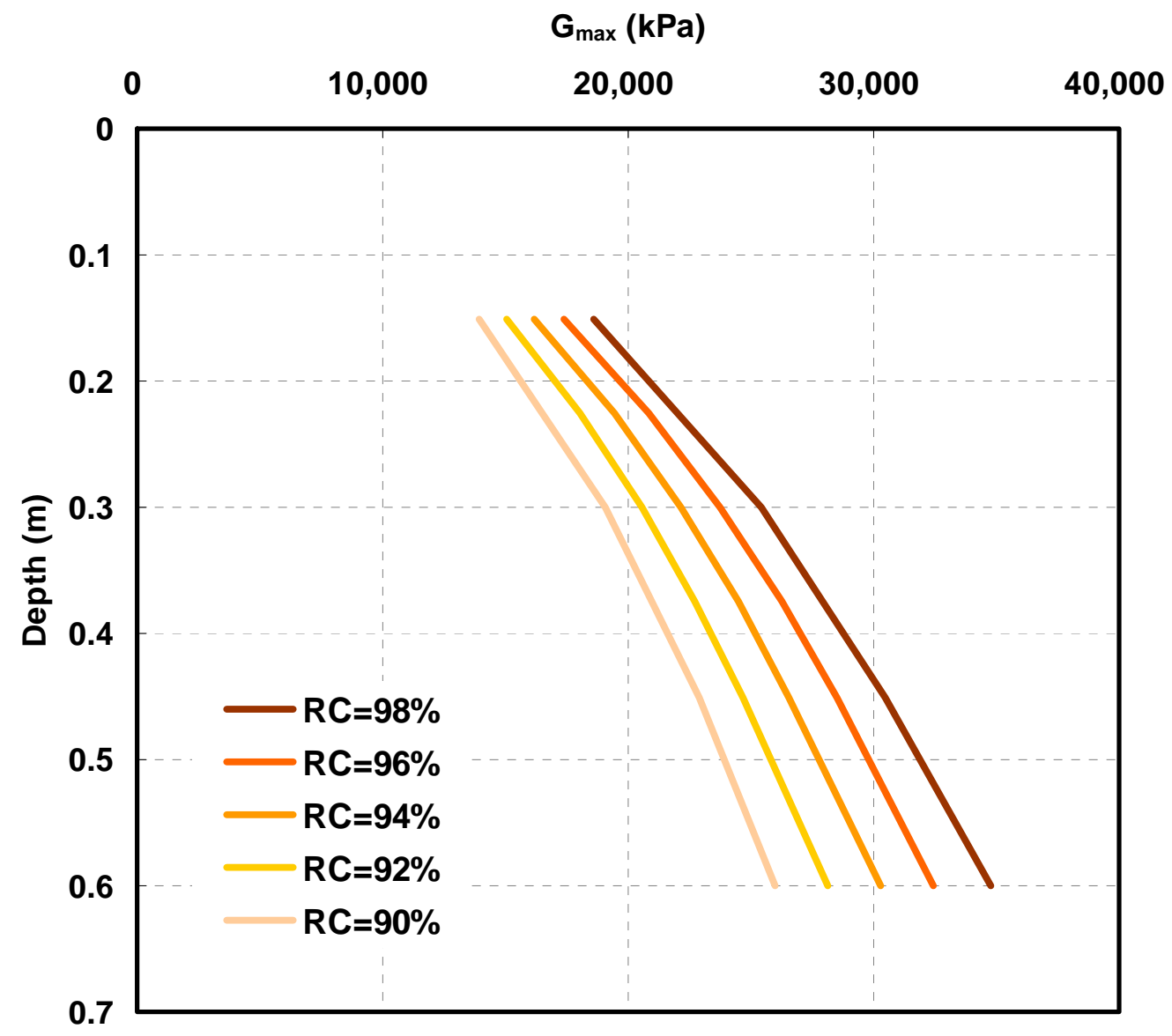

Figure $8.1 \mathrm{G}_{0}$ values for the test sand

The Poisson's ratio of soil at very low strain ranges between 0.1 and 0.2 for sand and is a little higher for clay. The value of Poisson's ratio of saturated clay reaches 0.5 
under undrained conditions. For the dynamic analysis, the Poisson's ratio of 0.15 was used for the sand, 0.3 for the clay.

\section{(3) Shear strength of soil}

The shear strength of sand is determined by the mobilized friction angle. The critical-state friction angle values range from $28^{\circ}$ to $36^{\circ}$ for most clean silica sands (Salgado 2008). In the dynamic analysis, the critical-state friction angle of $32.8^{\circ}$ was used, which was obtained from the triaxial compression tests, presented in CHAPTER 7.

The undrained shear strength of clay can be measured by performing Cone Penetration Tests (CPT) in the field or by performing unconfined compression tests in the laboratory. In the dynamic analysis, we used the undrained shear strength obtained from the unconfined compression tests presented in CHAPTER 6.

(4) The geometry of in situ dynamic tests

The geometry of the DCP is specified in ASTM D 6951-03, which is used for the dynamic analysis. The geometry of the CHT depends on the apparatus used. Since we used Model 95055A in testing, the weight of the Clegg hammer of the model is $10 \mathrm{~kg}$ with a drop height of $0.3 \mathrm{~m}$.

(5) Impact velocity of Clegg hammer

With respect to the impact velocity of the Clegg hammer, the coefficient of restitution is assumed to be 0 (perfectly plastic impact). The ratio of the rebound velocity and the impact velocity is normally referred to as the coefficient of restitution. According 
to Roesset et al. (1994), this coefficient is not very sensitive to the impact velocity. If the principle of conservation of energy is applied, the following equations can be set:

$$
T=\frac{1}{2} m_{c}\left(u_{c}\right)^{2}
$$

where $T$ is energy at the time of impact $(=29.42 \mathrm{~J}$ from the geometry of Clegg hammer), $\mathrm{m}_{\mathrm{c}}$ is the mass of Clegg hammer, and $\mathrm{u}_{\mathrm{c}}$ is the approach velocity of Clegg hammer right before the impact. Hence, the Clegg hammer and underlying soil move together right after the impact. Since this mass of the soil is very small, it is negligible. As a result, based on Eq. 8.2., the impact velocity of the Clegg hammer is $2.40 \mathrm{~m} / \mathrm{s}$. 


\subsection{Validation of the Results of the Tests Performed in the Purdue Test Chamber}

\subsubsection{Prediction of Static Test Results in Sand}

There are numerous methods available for estimating the static bearing capacity of a circular footing (or of a circular plate, as is the case here for the Clegg Hammer Test). In this research, as discussed in CHAPTER 5, the representative mean effective stress suggested by Loukidis and Salgado (2006) was employed for the analysis.

Figure 8.2 compares computed bearing capacities with capacities obtained from plate load tests performed on the sand in the chamber. For the comparison, the computed bearing capacities using the representative mean effective stress suggested by Perkins and Madson (2000) were also plotted on Figure 8.2. At two different relative compaction values, the plate load test results validated the effectiveness of the representative mean effective stress suggested by Loukidis and Salgado (2006). 


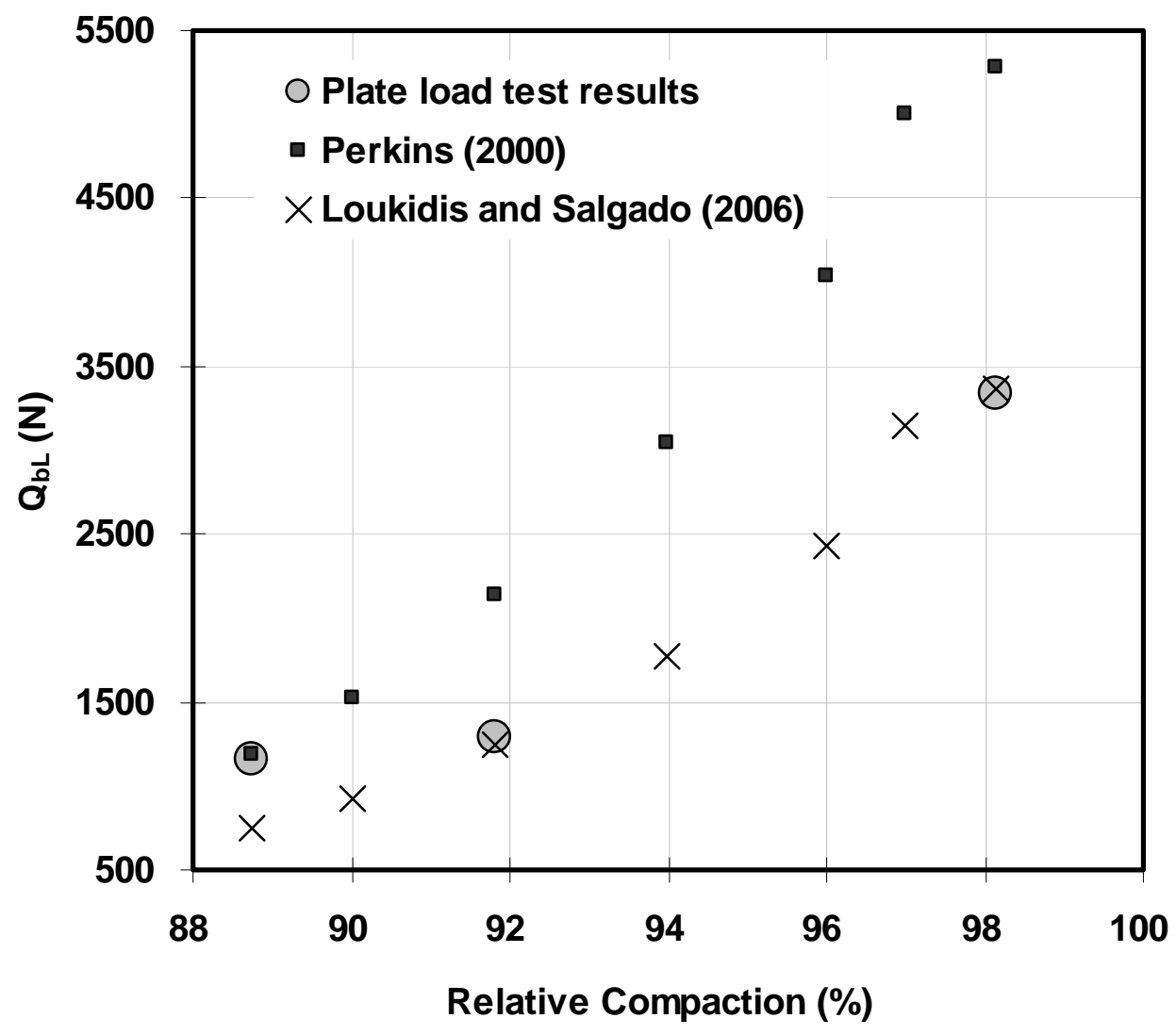

Figure 8.2 Comparison of predicted and measured capacities for plate load tests performed on dense and medium dense sand samples.

With respect to the static bearing capacity of the DCP, the equation by Salgado and Prezzi (2007) was adopted for the analysis. Again, the static load tests were performed as discussed in section 7.3.1 and test results were compared with the solutions based on the equation by Salgado and Prezzi (2007). Table 8.3 summarizes the measured and predicted limit capacities. 
Table 8.3 Summary of measured and predicted static penetration resistance of the DCP

\begin{tabular}{|c|c|c|c|c|}
\hline \multirow{2}{*}{$\begin{array}{c}\text { Unit weight } \\
\text { of sand } \\
\left(\mathrm{KN} / \mathrm{m}^{3}\right)\end{array}$} & $\mathrm{D}_{\mathrm{R}}$ & $\mathrm{G}_{0}(\mathrm{MPa})$ & \multicolumn{2}{|c|}{$\mathrm{Q}_{\mathrm{bL}}(\mathrm{N})$} \\
\cline { 4 - 5 } & & & Predicted & Measured \\
\hline 16.25 & 58 & 34.8 & 1104 & 667 \\
\hline 17.37 & 91 & 41.7 & 3098 & 1893 \\
\hline
\end{tabular}

Based on the comparison, the equation overestimates the limit bearing capacity. This is because the static load tests were conducted under low confining pressure condition, hence $\mathrm{Q}=10$ and $\mathrm{R}=1$ cannot be adopted, which were used for the development of the equation by Salgado and Prezzi (2007). Based on the comparison between test results and the solution of the equation, static resistances by Salgado and Prezzi (2007) were about 1.6 times larger than the measured static resistance as shown in Table 8.3. Thus, the equation by Salgado and Prezzi (2007) could be rewritten as:

$$
\frac{\mathrm{q}_{\mathrm{bL}}}{\mathrm{p}_{\mathrm{A}}}=\exp \left[0.1041 \phi_{\mathrm{c}}+\left(0.0264-0.0002 \phi_{\mathrm{c}}\right) \mathrm{D}_{\mathrm{R}}\right]\left(\frac{\sigma_{\mathrm{h}}^{\prime}}{\mathrm{p}_{\mathrm{A}}}\right)^{0.841-0.0047 \mathrm{D}_{\mathrm{R}}} \text { Eq. } 8.3
$$

\subsubsection{Prediction of Dynamic Test Results in Sand}

The equation of motion presented in section 5.4.1 was used for the dynamic analysis. Based on the equation along with numerical scheme, the acceleration can be obtained. Since the CHT is a Single Degree Of Freedom (SDOF) problem, spreadsheet can be used 
to conduct the dynamic analysis. Based on the selected dynamic model, the acceleration was calculated and compared with the dynamic measurements made in the chamber. Figure 8.3 shows the comparison between measured and predicted accelerations for the Clegg hammer test.

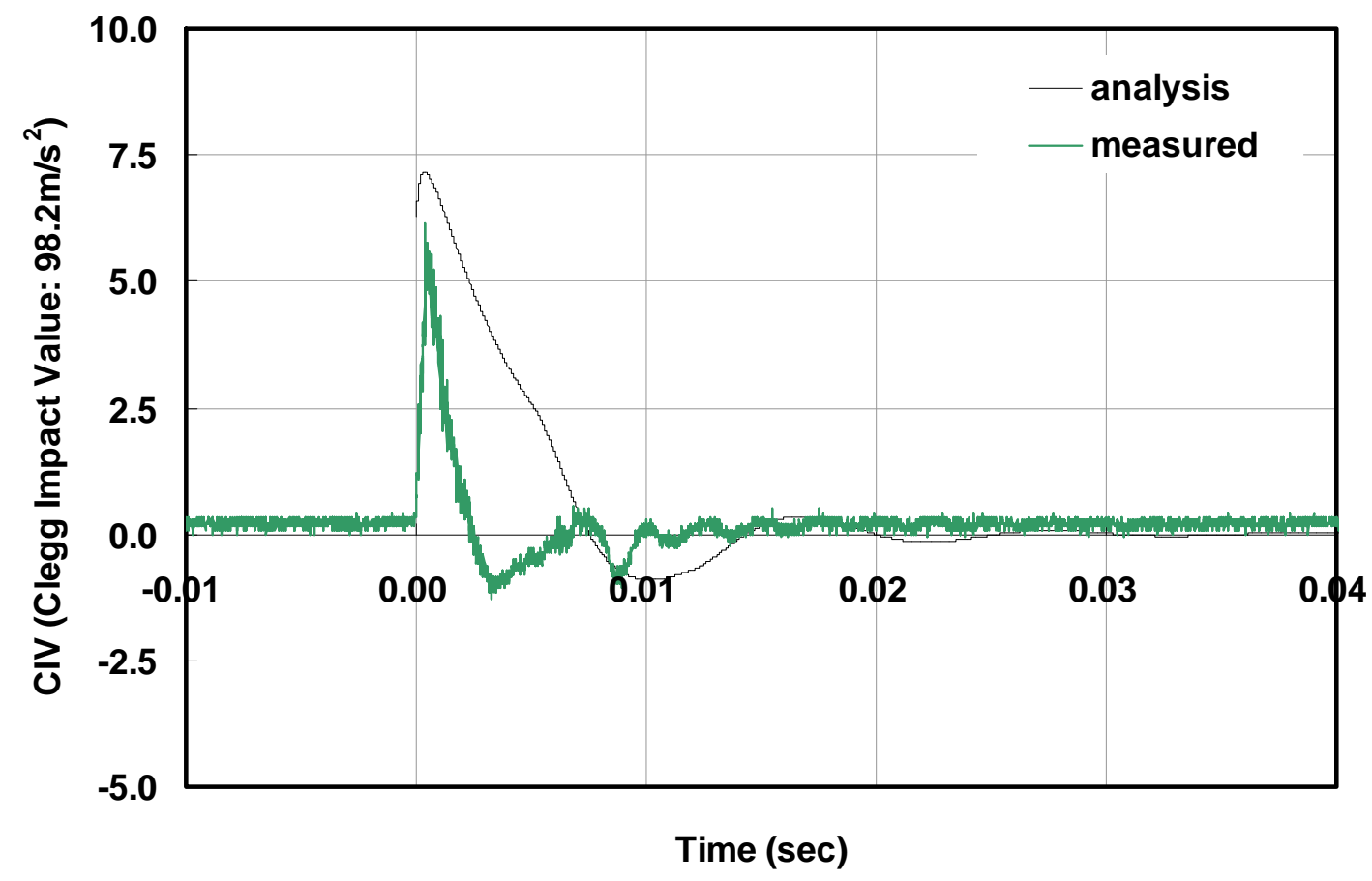

Figure 8.3 Comparison of predicted and measured acceleration in the chamber.

Figure 8.3 shows that the selected dynamic model has a good agreement with the acceleration of the Clegg Hammer during the impact. The analytical results of CIV depend of the impact velocity. Figure 8.3 compares the measured and predicted peak acceleration values with all CIV values tested in the Purdue test chamber. 


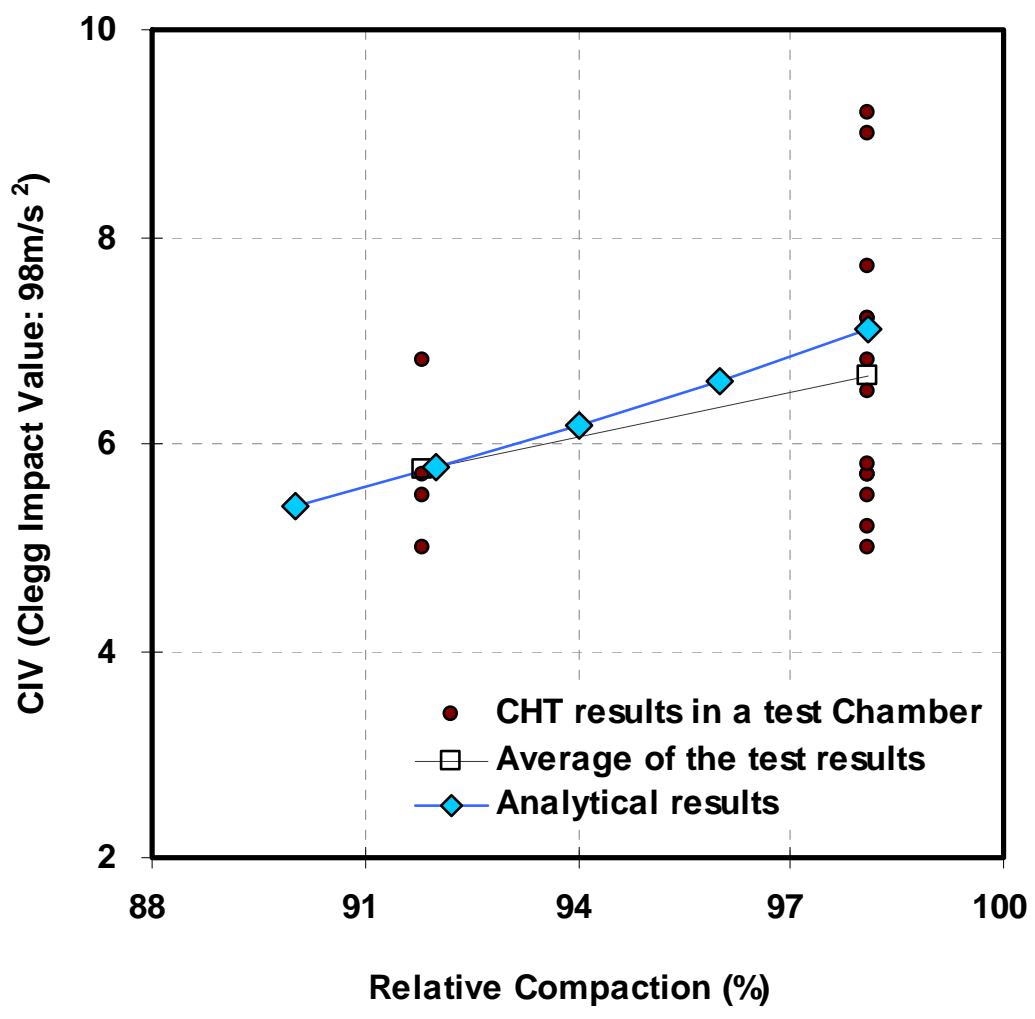

Figure 8.4 Predicted and measured CIV versus relative compaction.

Figure 8.4 compares the predicted and measured penetration values for the dynamic cone penetrometer at different depths. As shown in the figure, the dynamic analysis shows good agreement with the penetration per blow gotten from the integration of the acceleration values recorded in the test chamber. Figure 8.4 shows that the dynamic model overestimates the penetration values by seven millimeters. 


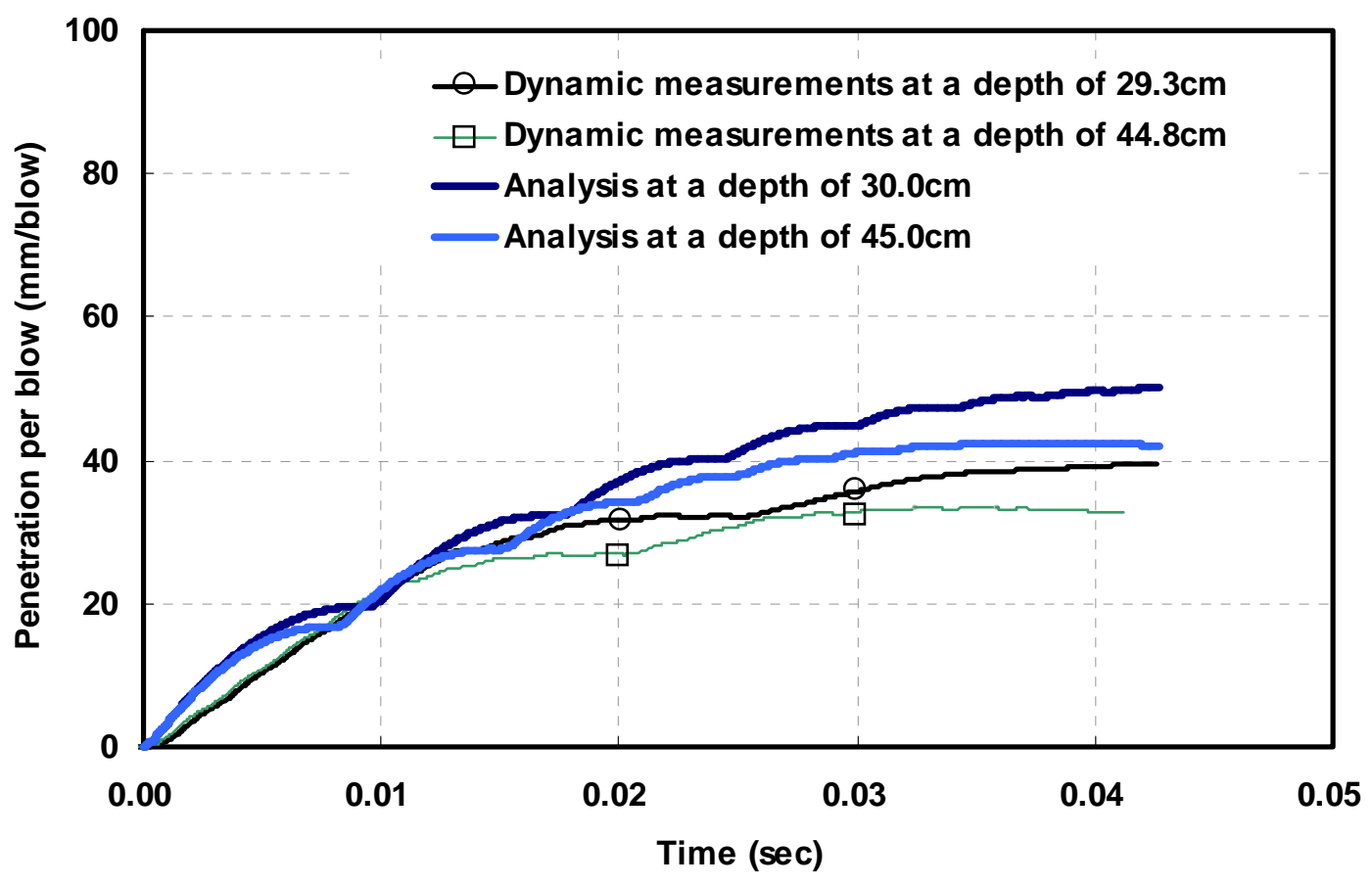

Figure 8.5 Comparison of predicted and measured penetration per blow ( $\mathrm{mm} / \mathrm{blow})$ at different depths in the test chamber.

\subsection{Validation of the Preliminary Test Results in Clay}

The dynamic models presented in CHAPTER 5 were also used to predict the penetration of the DCP and the Clegg Impact Value (CIV). Unconfined compression tests were performed on clay samples extracted from the test pit to obtain its undrained shear strength, as discussed in section 6.2. 
Figure 8.5 compares predicted and measured CIV for different relative compaction values. The dynamic model shows good agreement with the average values of the tests results performed in the test pit.

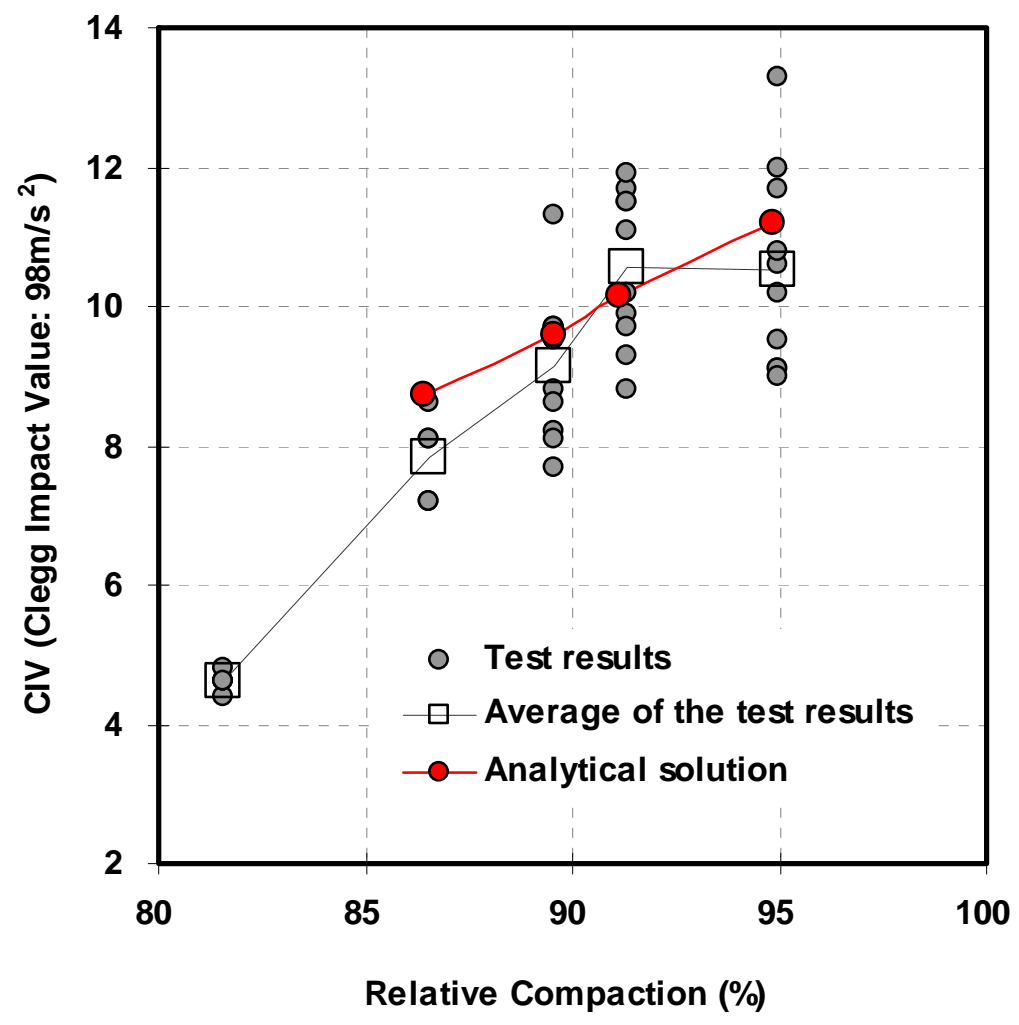

Figure 8.6 Predicted and measured CIV versus relative compaction for the pit tests.

Dynamic analysis of dynamic penetration was conducted using the input parameters that were given in section 8.2 . Table 8.3 shows the summary of measured and predicted $\mathrm{N}_{\mathrm{DCP}}$ of clay in the test pit. 
Table 8.4 Summary of measured and predicted $\mathrm{N}_{\mathrm{DCP}}$ of clay in the test pit

\begin{tabular}{|c|c|c|c|c|c|}
\hline \multicolumn{2}{|c|}{$\mathrm{N}_{\mathrm{DCP}} \mathrm{RC}$ of the clay } & $86.4 \%$ & $89.6 \%$ & $91.3 \%$ & $95.0 \%$ \\
\hline \multirow{2}{*}{$\begin{array}{l}\text { Test } \\
\text { results }\end{array}$} & $\begin{array}{l}0 \text {-to-6 inch } \\
\text { penetration }\end{array}$ & 3.0 & 6.4 & 6.9 & 7.7 \\
\hline & $\begin{array}{l}\text { 6-to-12 inch } \\
\text { penetration }\end{array}$ & 3.7 & 6.8 & 9.6 & 9.1 \\
\hline \multirow{2}{*}{$\begin{array}{l}\text { Analytical } \\
\text { results }\end{array}$} & $\begin{array}{l}0 \text {-to-6 inch } \\
\text { penetration }\end{array}$ & 3.1 & 4.0 & 4.5 & 5.6 \\
\hline & $\begin{array}{l}\text { 6-to-12 inch } \\
\text { penetration }\end{array}$ & 3.4 & 4.6 & 5.3 & 6.5 \\
\hline
\end{tabular}




\subsection{Summary}

In this chapter, the dynamic response of the DCPT and CHT were predicted using the dynamic model presented in CHAPTER 5. The test results were then compared with the analytical results both in case of sand and clay. In order to predict the dynamic response of the DCPT and CHT, the static bearing capacity should be accurately calculated.

For the CHT, the peak acceleration values were captured in the analysis and showed good agreement with test results, though the test results were highly variable. DCPT the penetration per blow was also predicted well by the selected dynamic model. 


\section{CHAPTER 9. SUMMARY AND CONCLUSIONS}

\subsection{Summary}

The most common soil compaction quality control method involves the use of the nuclear gauge to determine the in-place dry unit weight. However, the nuclear gauge is inherently hazardous and costly because of strict safety-related requirements. Thus, several alternative tests, such as the Dynamic Cone Penetration Test (DCPT) and the Clegg Hammer Test (CHT), have been developed as alternatives. In spite of significant research performed to interpret the results of DCPTs and CHTs, no reliable correlation is available in the literature to employ these tests for soil compaction quality control.

The main goal of this study was to propose and evaluate possible interpretation methods for the DCPT and the CHT. A number of DCPTs and CHTs were performed on road sites in Indiana, in a test pit, and in a test chamber at Purdue University. The soils tested were characterized through a series of laboratory tests (grain-size analysis, the laboratory compaction test, and the Atterberg limits tests). Results were targeted statistically to consider compaction variability to develop compaction criteria based on the DCPT. Analytical solutions of the DCPT and the CHT were also explored in this study for creating a basis to interpret test results. 


\subsection{Conclusions}

Based on the findings of the present study, the following conclusions are drawn:

1. Correlations exist between compaction properties $\left(\gamma_{\text {dmax }}\right.$ and $\left.w c_{o p t}\right)$ and the plasticity index (Basheer 2001; Gurtug and Sridrahan 2003; Omar et. al. 2003; Sridharan and Nagaraj 2004; Sivrikaya 2007; Sivrikaya et al. 2008). Based on the test results provided by INDOT, we also found a correlation between $\gamma_{d m a x}$, Optimum Moisture Content $\left(\mathrm{OMC}, w c_{o p t}\right)$, plastic limit $(P L)$, and liquid limit $(L L)$ for Indiana soils.

2. The specification of many agencies in the U.S. for density control (e.g., 95\% relative compaction) has effectively worked for more than 30 years and therefore can be used as a basis for control of compaction.

3. The data available in the literature indicated that the actual mean value of relative compaction achieved on the sites were roughly two to three percent greater than the specification requirements and that about $20 \%$ of the test results did not meet the specification requirement ( $90 \%$ or $95 \%$ relative compaction).

4. Based on the experimental program undertaken to assess the Dynamic Cone penetration Test (DCPT) and the Clegg Hammer Test (CHT), DCP minimum required blow count criteria were suggested by grouping the soil into three categories related to 
AASHTO soil classification. In addition, statistical variability of the test results was considered. As a result, the equations discussed next are proposed in this report.

(a) A-3 soil: the minimum required blow count $\left.\left(\mathrm{N}_{\mathrm{DCP}}\right)_{\text {req }}\right|_{0 \sim 12}$, for $0-12$ " penetration corresponding to an $\mathrm{RC}$ of $95 \%$ varies from 7 to 10 ; it is a function of coefficient of uniformity. The following equation was proposed for A-3 soils:

$$
\left.\left(\mathrm{N}_{\mathrm{DCP}}\right)_{\mathrm{req}}\right|_{0 \sim 12}=4.0 \ln \left(C_{u}\right)+2.6
$$

where $C_{u}=$ the coefficient of uniformity. The $\left.\left(\mathrm{N}_{\mathrm{DCP}}\right)_{\text {req }}\right|_{0 \sim 12}$, is the minimum required blow count for 0 -to- 12 inch penetration that implies an $\mathrm{RC}$ of $95 \%$ with high probability. The minimum required blow count should be rounded up to the nearest integer. Table 9.1 presents $\left(\mathrm{N}_{\mathrm{DCP}}\right)_{\text {req }}$ 0 12" for typical coefficient of uniformity values.

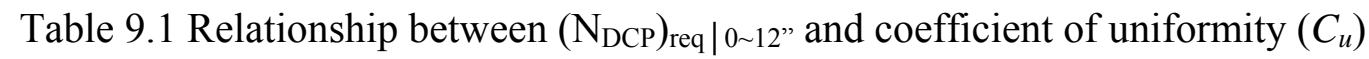

\begin{tabular}{|c|c|}
\hline Coefficient of uniformity $\left(C_{u}\right)$ & $\mathrm{N}_{\text {DCP } \mid 0 \sim 12 \%}$ \\
\hline 2 & 6 \\
\hline 3 & 7 \\
\hline 4 & 9 \\
\hline 5 & 10 \\
\hline 6 & 10 \\
\hline 7 & 11 \\
\hline 8 & 11 \\
\hline
\end{tabular}


(b) "Granular" soil (A-1 and A-2 soils except soils containing gravel): the minimum required blow count $\left.\left(\mathrm{N}_{\mathrm{DCP}}\right)_{\text {req }}\right|_{0 \sim 12}$, for this type of soil is influenced by the fine particles that are present in the soil. Since the plasticity index and the amount of fine particles contained in the "granular" soil correlate with the $\mathrm{OMC}$, the minimum required blow count for "granular" soils was proposed as a function of the OMC as follows:

$$
\left.\left(\mathrm{N}_{\mathrm{DCP}}\right)_{\text {req }}\right|_{0 \sim 12^{\prime}}=59 \exp \left(-0.12 w c_{\text {opt }}\right)
$$

where $w c_{\text {opt }}=$ the optimum moisture content. The $\left.\left(\mathrm{N}_{\mathrm{DCP}}\right)_{\text {req }}\right|_{0 \sim 12}$, is the minimum required blow count for 0 -to- 12 inch penetration that implies an RC of $95 \%$ with high probability. The minimum required blow count should be rounded up to the nearest integer. Table 9.2

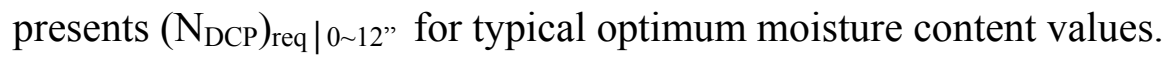

Table 9.2 Relationship between $\left(\mathrm{N}_{\mathrm{DCP}}\right)_{\text {req }} \mid 0 \sim 12$ ", and optimum moisture content $\left(w c_{\text {opt }}\right)$

\begin{tabular}{|c|c|}
\hline optimum moisture content $\left(w C_{\text {opt }}\right)$ & $\mathrm{N}_{\text {DCP } \mid \text { O 12” }}$ \\
\hline 10 & 18 \\
\hline 11 & 16 \\
\hline 12 & 14 \\
\hline 13 & 13 \\
\hline 14 & 11 \\
\hline
\end{tabular}


(c) Silty, clayey soil: test results showed that the minimum required $\mathrm{N}_{\mathrm{DCP}}$ for this soil correlates with the plasticity index and the percentage of soil by weight passing the \#40 sieve. Thus, we propose that the minimum required $\mathrm{N}_{\mathrm{DCP}}$ for silty clayey soils be estimated as a function of the plasticity index and the percentage of soil by weight passing the \#40 sieve according to:

$$
\left.\left(\mathrm{N}_{\mathrm{DCP}}\right)_{\text {req }}\right|_{0 \sim 6}=17 \exp [-0.07(\mathrm{PI})(\% \text { passing \#40)/100] }
$$

where $\left.\left(\mathrm{N}_{\mathrm{DCP}}\right)_{\text {req }}\right|_{0 \sim 6}$ " = minimum required blow count for 0 -to-6 inch penetration that implies an RC of $95 \%$ with high probability, $P I=$ plasticity index; and

$$
\left.\mathrm{N}_{\mathrm{DCP}}\right|_{6 \sim 12}=27 \exp [-0.08(\mathrm{PI})(\% \text { passing \#40)/100] }
$$

where $\left.\left(\mathrm{N}_{\mathrm{DCP}}\right)_{\text {req }}\right|_{6 \sim 12 "}=$ minimum required blow count for 6 -to-12 inch penetration that implies an RC of $95 \%$ with high probability. The minimum required blow counts should

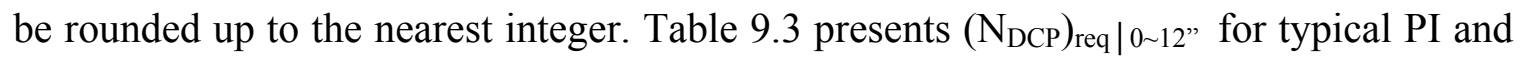
percent passing the \#40 sieve values. 
Table 9.3 Relationship between $\mathrm{N}_{\mathrm{DCP}}, C_{u}, w c_{\text {opt }}, P I$, and percent the $\# 40$ passing sieve

\begin{tabular}{|c|c|c|c|}
\hline PI (\%) & $\# 40$ passing sieve $(\%)$ & $\mathrm{N}_{\mathrm{DCP} \mid 0 \sim 6 "}$ & $\mathrm{~N}_{\mathrm{DCP} \mid 6 \sim 12 "}$ \\
\hline \multirow{4}{*}{3} & 70 & 15 & 23 \\
\hline & 80 & 15 & 23 \\
\hline & 90 & 15 & 22 \\
\hline & 100 & 14 & 22 \\
\hline \multirow{4}{*}{6} & 70 & 13 & 20 \\
\hline & 80 & 13 & 19 \\
\hline & 90 & 12 & 18 \\
\hline & 100 & 12 & 17 \\
\hline \multirow{4}{*}{9} & 70 & 11 & 17 \\
\hline & 80 & 11 & 16 \\
\hline & 90 & 10 & 15 \\
\hline & 100 & 10 & 14 \\
\hline \multirow{4}{*}{12} & 70 & 10 & 14 \\
\hline & 80 & 9 & 13 \\
\hline & 90 & 8 & 12 \\
\hline & 100 & 8 & 11 \\
\hline \multirow{4}{*}{15} & 70 & 9 & 12 \\
\hline & 80 & 8 & 11 \\
\hline & 90 & 7 & 10 \\
\hline & 100 & 6 & 9 \\
\hline \multirow{4}{*}{18} & 70 & 8 & 10 \\
\hline & 80 & 7 & 9 \\
\hline & 90 & 6 & 8 \\
\hline & 100 & 5 & 7 \\
\hline \multirow{4}{*}{21} & 70 & 7 & 9 \\
\hline & 80 & 6 & 8 \\
\hline & 90 & 5 & 6 \\
\hline & 100 & 4 & 6 \\
\hline \multirow{4}{*}{24} & 70 & 6 & 8 \\
\hline & 80 & 5 & 6 \\
\hline & 90 & 4 & 5 \\
\hline & 100 & 4 & 4 \\
\hline
\end{tabular}


5. The Clegg Impact Value (CIV) versus relative compaction exhibited considerable variability.

6. Dynamic analyses hold promise in forming the basis for interpretation of the DCPT and CHT, as prediction of the penetration process (DCPT) and accelerations (CHT) for sand under controlled conditions were very reasonable.

\subsection{Suggestions for Future Research}

Based on the work performed in this study, the following is recommended for future research.

1. Extensive testing could be performed on various types of soil in conjunction with conventional density-control tests such as nuclear gauge tests. This would allow refinement of the relationship between the minimum required DCP blow count $\left(\mathrm{N}_{\mathrm{DCP}}\right)_{\mathrm{req}}$ and other geotechnical properties suggested in this research.

2. Theories should be explored further to develop more rigorous methods of interpretation. 
3. In order to employ the Clegg hammer test as a tool for compaction quality control, refinement of the data acquisition system and change of geometry, weight and size of the Clegg hammer should be considered. 


\section{LIST OF REFERENCES}

American Association of State Highway and Transportation Officials, AASHTO (2003), "Standard Specifications for Transportation Materials and Methods of Sampling and Testing (23rd ed.)." Washington, D.C.

Abou-Jaoude, G. (2006). "Assessment of Static Pile Design Methods and Non-linear Analysis of Pile Driving." Ph.D. dissertation, Dept. of Civil Eng., Purdue Univ., West Lafayette, IN.

Abu-Farsakh, M.Y., Nazzal, M.D., Alshibli, K., and Seyman, E. (2005). “Apploication of Dynamic Cone Penetrometer in Pavement Construction Control." In Transportation Research Record: Journal of the Transportation Research Board, No. 1913, Transportation Research Board of the National Academies, Washington, D.C., pp. 53-61.

Adam, D. (2007). "Roller integrated continuous compaction control (CCC) technical contractual provisions and recommendations. Design and construction of pavements and rail tracks: geotechnical aspects and processed materials (eds A. G. Correia, Y. Momoya and F. Tatsuoka)." pp. 111-138. London: CRC Press.

Alshibli, K, Abu-Farsakh, M, and Seyman, E. (2005). "Laboratory Evaluation of the Geogauge and Light Falling Weight Defletometer as Construction Control Tools." Journal of Materials in Civil Engineering, ASCE, Vol. 17, No. 5, pp. 560-569.

American Association of State Highway and Transportation Officials, AASHTO M145-91, "Standard specification for classification of soils and soil-aggregate mixtures for highway construction purposes." Philadelphia, PA.

Ampadu, S.K. and Arthur, T.D. (2006). "The Dynamic Cone Penetrometer in Compaction Verification on a Model Road Pavement", Geotechnical Testing Journal, Vol.29, No.1, pp.1-10.

Anam, I., and Roesset, J.M. (2004). "Dynamic Stiffness of Surface Foundations: An Explicit Solution." International Journal of Geomechanics, ASCE, Vol. 4 No. 3, pp. 216-223.

Asai, S. (1960). "Measurement of bearing capacity of subgrade by drop impact method." Soils and Foundations, Vol. 1, No. 1, pp. 42-52.

American Society for Testing and Materials, ASTM C778-06, "Standard Specification for Standard Sand." Philadelphia, PA. 
American Society for Testing and Materials, ASTM C127-07, "Standard Test Method for Density, Relative density (Specific gravity), and Absorption of Coarse Aggregate.” Philadelphia, PA.

American Society for Testing and Materials, ASTM D422-63, "Standard Test Method for Particle-Size Analysis of Soils." Philadelphia, PA.

American Society for Testing and Materials, ASTM D698-00, "Standard Test Methods for Laboratory Compaction Characteristics of Soils using Standard Effort $(12,400 \mathrm{ft}-$ $\left.\mathrm{lb} / \mathrm{ft}^{3}(600 \mathrm{kN}-\mathrm{m} / \mathrm{m} 3)\right)$." Philadelphia, PA.

American Society for Testing and Materials, ASTM D1196-93, "Standard Test Methods for Nonrepetitive Static Plate Load Tests of Soils and Flexible Pavement Components, for Use in Evaluation and Design of Airport and Highway Pavements" Philadelphia, PA.

American Society for Testing and Materials, ASTM D1556-07, "Standard Test Method for Density and Unit Weight of Soil in place by Sand-Cone Method." Philadelphia, PA.

American Society for Testing and Materials, ASTM D1557-09, "Standard Test Methods for Laboratory Compaction Characteristics of Soils using Modified Effort $\left(56,000 \mathrm{ft}-\mathrm{lb} / \mathrm{ft}^{3}(2,700 \mathrm{kN}-\mathrm{m} / \mathrm{m} 3)\right)$." Philadelphia, PA.

American Society for Testing and Materials, ASTM D2166-06, "Standard Test Methods for Unconfined Compressive Strength of Cohesive Soil." Philadelphia, PA.

American Society for Testing and Materials, ASTM D2487-06, "Standard practice for classification of soils for engineering purposes (Unified Soil Classification System)." Philadelphia, PA.

American Society for Testing and Materials, ASTM D3282-93, "Standard Practice for Classification of Soils and Soil-Aggregate Mixtures for Highway Construction Purposes." Philadelphia, PA.

American Society for Testing and Materials, ASTM D4253-00, "Standard Test Methods for Maximum Index Density and Unit Weight of Soils Using a Vibratory Table." Philadelphia, PA.

American Society for Testing and Materials, ASTM D4318-05, "Standard Test Method for Liquid Limit, Plastic Limit, and Plasticity Index of Soils.” Philadelphia, PA.

American Society for Testing and Materials, ASTM D5874-02, "Standard Test Method for Determination of the Impact Value (IV) of a Soil." Philadelphia, PA.

American Society for Testing and Materials, ASTM D6951-03, "Standard Test Method for Use of the Dynamic Cone Penetrometer in Shallow Pavement Applications." Philadelphia, PA.

Amini, F. (2003). "Potential Applications of the Static and Dynamic Cone Penetrometers in MDOT Pavement Design and Construction." FHWA/MS-DOT-RD03-162, Jackson State University, Jackson, MS. 
American Research Associate, Inc., ARA (2004). "Guide for Mechanistic-Empirical Design of New and Rehabilitated Pavement Structures." Part 2. Design Input, NCHRP, TRB, National Research Council.

Ayers, M. E., Thompson, M. R., Uzarski, D. R. (1989). "Rapid Shear Strength Evaluation of In Situ Granular Materials." In Transportation Research Record: Journal of the Transportation Research Board, No. 1227, Transportation Research Board of the National Academies, Washington, D.C., pp. 134-146.

Balthaus, H.G. and kielbasa, S. (1986). "Numerical Modeling of Pile Driving", Proceedings, Second International Symposium on Numerical Models in Geomechanics, Ghent.

Been, K., Crooks, J.H.A., Becker, D.E., and Jefferies, M.G. (1986). "The Cone Penetration Test in Sands: Part I, State Parameter Interpretation." Géotechnique, Vol. 36, No.2, pp.239-249.

Beyer, M., and Roesler, J. (2009), "Mechanistic-Empirical Design Concepts for Continuously Reinforced Concrete Pavements in Illinois.” ICT-09-040, UILU-ENG2009-2011, Illinois Department of Transportation, Springfield, IL.

Bolton, M.D. (1986). "The strength and Dilatancy of Sands.", Géotechnique, Vol. 36, No.1, pp. 65-78.

Bolton, M.D., Gui, M.W., Garnier, J., Corte, J.F., Bagge, G., Laue, J., and Renzi, R. (1999). "Centrifuge Cone Penetration Tests in Sand." Géotechnique, Vol. 49, No.4, pp. 543-552.

Brown, S. F. (1996). "Soil Mechanics in Pavement Engineering." Géotechnique, Vol. 46, No. 3, 1996, pp. 383-426

Bureau of Materials and Physical Research. (2005). Pavement Technology AdvisoryDynamic Cone Penetrometer. Testing and Data Collection, PTA-T4, Illinois Department of Transportation.

Burnham, T. R. (1997). "Application of the Dynamic Cone Penetrometer to Minnesota Department of Transportation Pavement Assessment Procedures." Report No. MN/RC 97-19, Minnesota Department of Transportation.

Camargo, F., Larsen, B., Chadbourn, B., Roberson, R., and Siekmeier, J. (2006). "Intelligent compaction: a Minnesota case history." Proc., 54th Annual University of Minnesota Geotech.Conf., Minneapolis, CD-ROM.

Canaway, P.M., Bell, M.J., Holmes, G., and Baker, S.W. (1990), "Standards for the Playing Quality of Natural Turf for Association Football.” ASTM STP1073, American Society of Testing Materials, pp 29-47.

Chakraborty, T. \& Salgado, R. (2008). "Dilatancy of Sand at Very Low Confining Stresses." Journal of Geotechnical and Geoenvironmental Engineering, accepted for publication. 
Christian, J.T., Ladd, C.C., and Baecher, G.B. (1994). "Reliability applied to slope stability analysis." Journal of the Geotechnical Engineering Division, ASCE, Vol. 120 No. 12, pp. 2180-2207.

Chopra, A.K., (2007). "Dynamics of Structures-theory and applications to earthquake engineering, $3^{\text {rd }}$ ed." Prentice Hall, New Jersey.

Christopher, B. R., Schwartz, C., and Boudreau, R., (2006). "Geotechnical aspects of pavements.” FHWA, Publication No. FHWA NHI-05-037.

Clegg, B. (1976). "An impact testing device for in situ base course evaluation." Australian Road Res. Bur. Proc. Vol. 8, pp. 1-6.

Clegg, B. (1980). “An Impact Soil Test as Alternative to California Bearing Ratio.” In Proceedings of the 3rd ANZ Geomechanics Conference, Vol. 1, Wellington, New Zealand, pp. 225-230.

Clegg, B. (1983). "Design Compatible Control of Base Course Construction." Australian. Road Research, Vol. 13, pp. 112-122.

Clegg Hammer Modulus (CHM). Clegg Impact Soil Tester Newsletter 14. Dr. Baden Clegg Pty Ltd., Jolimont, Western Australia, August 1999. www.clegg.com.au/information_list3.asp. Accessed October 20, 2009.

Croney, D. (1977). "The design and performance of road pavements." Her Majesty's Stationery Office, London, 673p.

Davies, T.G., and Karim, U.F. (1995). “An elastodynamic interpretation of impact test apparatus for soils”, Géotechnique, Vol. 45, No. 4, pp. 691-700.

Deeks, A.J. and Randolph, M.F. (1995). "A Simple Model for Inelastic Footing Response to Transient Loading." International Journal for Numerical and Analytical Methods in Geomechanics, Vol. 19, No. 5, pp. 307-329.

Devore, J.L. (2004). Probability and Statistics for Engineering and the Science sixth edition, Brooks/Cole-Thomson Learning.

El-Naggar, M. and Novak, M. (1994). "Non-Linear Model for Dynamic Axial Pile Response.” Journal of Geotech. Eng. Div., ASCE, Vol. 120, No. 2, pp. 308-329.

Erchul, R. A. (1999). “Compaction Comparison Testing Using a Modified Impact Soil Tester and Nuclear Density Gauge," STP 1358, Field Instrumentation for Soil and Rock, American Society for Testing and Materials, West Conshohocken, PA.

Essigman, M., Jr. (1976). "An Examination of the Variability Resulting from Soil Compaction", Report, Joint Highway Research Project, Report No. JHRP-76-28, in cooperation with FHWA from the study, "Improving Embankment Design and Performance", West Lafayette, IN.

Federal Highway Administration. (2004). "Performance specifications-Strategic roadmap.” Rep. Prepared for Federal Highway Administration, Report No. FHWAIF-04-023, Washington D.C. 
Fiedler, S., Nelson, C., Berkman, E. F., and DiMillio, A. (1998). "Soil Stiffness Gauge for Soil Compaction Control,” Public Road, FHWA, Vol. 61, No. 5. pp. 5-10.

Fleming, P, Frost, M, and Lambert, J. (2007). "Review of Lightweight Deflectometer for Routine In Situ Assessment of Pavement Material Stiffness," In Transportation Research Record: Journal of the Transportation Research Board, No. 2004, Transportation Research Board of the National Academies, Washington, D.C., pp. 80-87.

Forssblad, L. (1980). "Compaction meter on vibrating rollers for improved compaction control,” Proc., Intl. Conf. on Compaction, Vol. II, Paris, pp. 541-546.

Foster, C.R. (1962). "Field Problems: Compaction," Foundation Engineering, G.A.Leonards (ed.), McGraw-Hill, New York, pp. 1000-1024.

Gabr, M. A., K. Hopkins, J. Coonse, and T. Hearne. (2000). "DCP Criteria for Performance Evaluation of Pavement Layers," Journal of Performance of Constructed Facilities, ASCE, Vol. 14, No. 4, pp. 141-148.

Garrick, N. W., Scholer, C. F. (1985). "Rapid Determination of Base Course Strength Using the Clegg Impact Tester." In Transportation Research Record: Journal of the Transportation Research Board, No. 1022, Transportation Research Board of the National Academies, Washington, D.C., pp. 115-119.

Gas Technology Institute (GTI). (2005). "Evaluation of Soil Compaction Measuring Devices," GRI-04/0067, Gas Technology Institute, Des Plaines, IL.

Gas Technology Institute. (2006). "Modification of Clegg Hammer as an Alternative to Nuclear Density Gauge to Determine Soil Compaction," 4W-1850-NANZ, Gas Technology Institute, Des Plaines, IL.

Gregg, L. E.: Earthwork, in K. B. Woods (eds.). (1960). "Highway Engineering Handbook," sec. 14, McGraw-Hill Book Co., New York.

Guthrie, W. S., and G. B. Reese. (2008). “Assessing Rutting Susceptibility of CementTreated Base Material Under Early Trafficking with Heavy Clegg Impact Soil Tester." In Transportation Research Record: Journal of the Transportation Research Board, No. 2059, Transportation Research Board of the National Academies, Washington, D.C., pp. 72-79.

Hardin, B.O. and Black, W.L. (1968). "Vibration Modulus of Normally Consolidated Clay." Journal of the Soil Mechanics and Foundations Division, ASCE, Vol. 94 No. 2, pp. 353-369.

Hilf, J.W. (1991). "Compacted Fill” In H.-Y. Fang (Ed.), Foundation Engineering Handbook, 2nd Edition, New York: Van Nostrand Reinhold, pp. 249-316.

Hogentogler, C.A., and Terzaghi, C. (1929). "Interrelationship of Load, Road, and Subgrade." Public Roads, Vol. 10, No. 3., pp. 37-64.

Holtz, R.D., and Kovacs, W.D. (1981). An Introduction to Geotechnical Engineering, Prentice-Hall, Englewood Cliffs, New Jersey. 
Holtz et al. (1990), "Guide to earthwork construction, State of the Art Report 8," Transportation Research Board, National Research Council, Washington D.C., 107 p.

Houghton Miffin Company (2001). “American Heritage Dictionary.” Houghton Miffin Company.

Hughes, C. (1996). "Variability in Highway Pavement Construction," Synthesis of Highway Practice 232, Transportation Research Board, National Research Council, Washington D.C., 38 p.

Huang, Y.H. (2004). Pavement Analysis and Design, $2^{\text {nd }}$ edition, Pearson Prentice Hall, New Jersey, $775 \mathrm{p}$.

Illinois Department of Transportation. (2007). Standard Specifications for Road and Bridge Construction, Illinois Department of Transportation.

Indiana Department of Transportation. (2006). Indiana Department of Transportation Standard Specifications, Indiana Department of Transportation.

Indiana Department of Transportation. (2007). Certified Technician Program Training Manual for Construction Earthworks, Indiana Department of Transportation.

International Society for Soil Mechanics and Geotechnical Engineering (ISSMGE). (2005). "Roller-Integrated continuous compaction control (CCC): Technical Contractual Provisions, Recommendations," TC3: Geotechnics for Pavements in Transportation Infrastructure, ISSMGE.

Janoo, V. C., Fricano, A. J., Barna, L. A., and Orchino, S. A. (1999). "Field testing of stabilized soils," Journal of Cold Regions Engineering, ASCE, Vol. 31, No. 1, pp. 37-53.

Jayawickrama, P., Amarasiri, A.L., and P.E. Regino. (2000). "Use of Dynamic Cone Penetrometer to Control Compaction of Granular Fill," In Transportation Research Record: Journal of the Transportation Research Board, No. 1736, Transportation Research Board of the National Academies, Washington, D.C., pp. 71-80.

Jumikis., A. R. (1962), Soil Mechanics, D. Van Nostrand Co., Princeton, New Jersey.

Kausel, E. (1974). "Forced Vibration of Circular Foundations on Layered Media," PhD thesis, Massachusetts Institute of Technology.

Kausel, E. (2010). "Early history of soil-structure interaction." Soil Dynamics and Earthquake Engineering, doi:10.1016/j.soildyn.2009.11.001.

Kim, J., Kang, H., Kim, D., Park, D., and Kim, W. (2007). "Evaluation of In Situ Modulus of Compacted Subgrades Using Portable Falling Weight Defletometer and Plate-Bearing Load Test," Journal of Materials in Civil Engineering, ASCE, Vol. 19, No. 6, pp. 492-499.

Kramer, S.L. (1996). Geotechnical Earthquake Engineering, Prentice Hall, New Jersey, $653 \mathrm{p}$.

Krebs, R. D. and Walker, E. D. (1971), Highway Materials, Mc-Graw-Hill Companies, Inc., New York, 428 p. 
Mathur, T. S., and Coghlans, G. T. (1987). "The use of the Clegg impact tester in managing and designing aggregate-surfaced roads," Transportation Research Board, 4th Int. Conf. on Low-Volume Roads, Washington, D.C., pp. 232-236.

Meyerhof G.G. (1951). "The Ultimate Bearing Capacity of Foundations." Géotechnique, Vol. 2, No.4, pp.301-332.

McConnell, K. G. (1995). Vibration testing, theory and practice, John Wiley \& Sons, Inc, New York, 606 p.

Missouri Highways and Transportation Commission. (1999). Missouri Standard Specification for Highway Construction, Jefferson City, Missouri.

Mississippi Department of Transportation. (2004). Mississippi Standard Specification for Road and Bridge Consturction, Jackson, Mississippi.

Mooney, M. A., Nocks, C. S., Seldon, K. L., Bee, G. T., Senseney. C. T. (2008). "Improving Quality Assurance of MSE wall and Bridge approach Earthwork Compaction," Report, Colorado Dept. of Transportation, Report No. CDOT 2008-11.

Nazzal, M. (2003). Field Evaluation of In-Situ Test Technology for QC/QA during Construction of Pavement Layers and Embankments, MS thesis, Louisiana State University, Louisiana.

Nazzal, M, Abu-Farsakh, M, Alshibli, K and L. Mohammad. (2007). "Deflectometer Device for In Situ Measurement of Elastic Modulus of Pavement Layers" In Transportation Research Record: Journal of the Transportation Research Board, No. 2016, Transportation Research Board of the National Academies, Washington, D.C., pp. 13-22.

Lambe, T.W. (1958a). "The structure of compacted clay," Journal of the Soil Mechanics and Foundations Division, ASCE, Paper 1654, Vol. 84, No. SM 2, pp. 134.

Lambe, T.W. (1958b). "The engineering behavior of compacted clay," Journal of the Soil Mechanics and Foundations Division, ASCE, Paper 1655, Vol. 84, No. SM 2, pp. $1-35$

Lambe, T.W. (1962). “Soil Stabilization”, Foundation Engineering, G.A.Leonards (ed.), McGraw-Hill, New York, pp. 351-437.

Lambe, T.W., and Whitman, R.V. (1969). Soil Mechanics, John Wiley \& Sons, Inc., New York, $553 \mathrm{p}$.

Larsen, B.W., White, D.J., and Jahren, C.T. (2007). "Embankment Construction QC/QA using DCP and Moisture Control: Iowa Case History for Unsuitable Soils." Proceedings of the 2007 Mid-Continent Transportation Research Symposium, Ames, Iowa.

Lavin, P. (2003). Asphalt Pavements: a practical guide to design, production and maintenance for engineers and architects, Taylor \& Francis Group, London. 
Lee, J. (2008). Experimental Investigation of the Load Response of Model Piles in Sand, Ph.D. Dissertation, Dept. of Civil Eng., Purdue Univ., West Lafayette, IN.

Lee, K.L. and Singh, A. (1971). "Relative Density and Relative Compaction," Journal of the Soil Mechanics and Foundations Division, ASCE, Vol. 97, No. 7, pp. 10491052.

Lee, W., Bohra, N., Altschaeffl, A., and White, T. (1993). "Subgrade Resilient Modulus for Pavement Design and Evaluation," Report, Joint Highway Research Project, Report No. FHWA/INDOT/JHRP-92/23.

Lin, D, Liau, C, and J. Lin. (2006). "Factors Affecting Portable Falling Weight Deflectometer Measurements," Journal of Geotechnical Geoenvironmental Engineering, ASCE, Vol. 132, No. 6, pp. 804-808.

Livneh, M., and Goldberg, Y. (2001). "Use of falling-weight deflectometer and light drop-weight for quality assessment during road formation and foundation construction." Transportation Research Board, $80^{\text {th }}$ Annual Meeting, Washington, D.C., Paper No. 01-0106.

Liu, T.K., and Thompson, M.R. (1966). "Variability of Some Selected Laboratory Soil Tests." Proceedings, National Conference on Statistical Quality Control Methodology in Highway and Airfield Construction, pp. 375-395, University of Virginia.

Liu, T.K., and Thornburn, T.H. (1964). "Study of the Reproducibility of Atterberg Limits" Highway Research Record, No. 63, pp.23-40.

Loizos, A, Boukovalas, G and A. Karlaftis. (2003). "Dynamic Stiffness Modulus for Pavement Subgrade Evaluation," Journal of Transportation Engineering, ASCE, Vol. 129, No. 4, pp. 434-443.

Loizos, A., and Boukovalas, G. (2005). "Pavement soil characterization using a dynamic stiffness model." International Journal of Pavement Engineering, Vol. 6 No. 1, pp. 5-15.

Loukidis, D., Salgado, R., and Abou-Jaoude, G., (2008). Assessment of Axially-Loaded Pile Dynamic Design Methods and Review of INDOT Axially-Loaded Pile Design Procedure. FHWA/IN/JTRP-2008/6, Purdue University, West Lafayette, IN.

Loukidis, D., Salgado, R. (2009). "Bearing capacity of strip and circular footings in sand using finite elements." Computers and Geotechnics, Vol. 36, No. 5, pp. 871-879.

Lumb, P. (1974). Application of statistics in soil mechanics, Soil mechanics-New horizons, Butterworth, London.

Lyamin, A., Salgado, R., Sloan, S.W., and Prezzi, M. (2007). "Two-and Three Dimensional Bearing Capacity of Footings in Sand." Géotechnique, Vol.57, No.8, pp. 647-662.

Lysmer, J. (1965). Vertical Motion of Rigid Footings, Ph.D. Dissertation, Dept. of Civil Eng., Univ. of Michigan, Ann Arbor, Mich., 130 p. 
Murthy, T.G., Loukidis, D., Carraro, J., Prezzi, M., and Salgado, R. (2007). "Undrained Monotonic Response of Clean and Silty Sands." Géotechnique, Vol.57, No.3, pp. 273-288.

Noorany, I (1990). "Variability in Compaction Control." Journal of Geotechnical Engineering, ASCE, Vol. 116, No. 7, pp. 1132-1136.

Ogden, B.D. (2007). "Railroad-Highway Grade Crossing Handbook - Revised Second Edition 2007," FHWA-SA-07-010, Washington DC.

Oglesby, C.H. (1975). Highway Engineering Third Edition, John Wiley and Sons, Inc.

Ovesen, N. K. (1975). "Centrigugal testing applied to bearing capacity problems of footings on sand." Géotechnique, Vol. 25, No.2, pp. 394-401.

Parkin, A.K., Holden, J., Aamot, K., Last, N., and Lunne, T. (1980). "Laboratory Investigations of CPT's in Sand." Report 52108-9, Norweigian Geotehncal Institute (NGI), Oslo.

Phoon, K.K. and Kulhawy, F.H. (1996). "On quantifying inherent soil variability" Uncertainty in the geologic environment; from theory to practice; Proceeding of Uncertainty '96, Madison, Wisconsin.

Phoon, K.K. and Kulhawy, F.H. (1999). "Characterization of geotechnical variability," Canadian Geotechnical Journal, Vol. 36, No. 4, pp. 612-624.

Poulos, H., and Davis, E.H. (1974). Elastic solutions for Soil and Rock Mechanics, John Wiley and Sons, Inc.

Price J.T. (1978). "Soil Compaction Specification Procedure for Desired Field Strength Response." Report, Joint Highway Research Project, Report No. JHRP-78-7, in cooperation with FHWA from the study, "Improving Embankment Design and Performance", West Lafayette, IN.

Proctor, R.R. (1933). Fundamental Principles of Soil Compaction, Engineering NewsRecord, Vol. 111, Nos. 9, 10, 12, and 13.

Rad, N.S. and Tumay, M.T. (1987). "Factors Affecting Sand Specimen Preparation by Raining”, Geotechnical Testing Journal, Vol.10, No.1, pp.31-37.

Rahman, F., Hossain, M., Hunt, M. M.., and Romanosch, S.A. (2008). "Soil Stiffness Evaluation for Compaction Control of Cohesionless Embankments." Geotechnical Testing Journal, ASTM, Vol. 31, No.5, pp. 1-10.

Rethati, L., (1988), Probabilistic solutions in geotechnics, Elsevier, Amsterdam, The Netherlands, 451p.

Richart, F. E., Hall, J. R., and R. D. Woods, (1970), Vibrations of soils and foundations, Prentice-Hall, Inc, Englewood Cliffs, New Jersey, 414 p.

Rinehart, R.V. and Mooney, M.A. (2009). "Measurement Depth of Vibratory RollerMeasured Soil Stiffness.” Géotechnique, [doi: 10.1680/geot.8.101] 
Rogers, J. N. III and Waddington, D. V. (1990). "Portable Apparatus for Assessing Impact Characteristics of Athletic Field Surfaces." Natural and Artificial Playing Fields: Characteristics and Safety Features, ASTM STP 1073, American Society for Testing and Materials, Philadelphia, pp. 96-110.

Rollings, M.P., and Rollings, R.S. (1996). Geotechnical Materials in Construction, McGraw-Hill, New York, 525 p.

Roesset, J. M., Kausel, E., Cuellar, V., Monte, J. L., and Valerio, J. (1994). "Impact of Weight Falling onto the Ground." Journal of Geotechnical Engineering, ASCE, Vol. 120 No. 8, pp.1394-1412.

Salgado, R. (2008). The Engineering of Foundations, McGraw-Hill, New York, 882 pp.

Salgado, R., Mitchell, J.K., and Jamiolkowski, M. (1998). "Calibration Chamber Size Effects on Penetration Resistance in Sand", Journal of Geotechnical and Geoenvironmental Engineering, ASCE, Vol.124, No.9, pp.878-888.

Salgado, R., and Lee, J. (1999). Pile Design Based on Cone Penetration Test Results. FHWA/IN/JTRP-99/8, Purdue University, West Lafayette, IN.

Salgado, R., and S. Yoon. (2003). Dynamic Cone Penetration Test (DCPT) for Subgrade Assessment. FHWA/IN/JTRP-2002/30, Purdue University, West Lafayette, IN.

Salgado, R., Lyamin, A., Sloan, S. and Yu, H.S. (2004). "Two- and Three-dimensional Bearing Capacity of Footings in Clay." Géotechnique, Vol. 54, No. 5, pp. 297-306.

Salgado, R. and Prezzi, M. (2007). "Computation of cavity expansion pressure and cone resistance in sand." International Journal of Geomechanics, ASCE, Vol. 7 No. 4, pp. 251-265.

Sandström A.J., and Pettersson, C.B. (2004). "Intelligent systems for QA/QC in soil compaction", Proc., 83rd Annual Transportation Research Board Meeting, Washington, D.C.

Sanglerat, G., (1972), The penetrometer and soil exploration. Interpretation of penetration diagrams-theory and practice, Elsevier Publishing Co., Amsterdam, 464 p.

Scala, A. J. (1956). Simple Methods of Flexible Pavement Design Using Cone Penetrometers. New Zealand Engineering, Vol. 11, No. 2, pp. 34-44.

Schnaid, F. and Houlsby, G.T. (1991). "An Assessment of Chamber Size Effects in the Calibration of in Situ Tests in Sand”, Géotechnique, Vol. 41, No.3, pp.437-445.

Schwartz and Carvalho, (2007), Implementation of the NCHRP 1-37A Design Guide, Volume 2: Evaluation of Mechanistic-Empirical Design Procedure, MDSHA Project No. SP0077B41, The University of Maryland, College Park, Maryland.

Seed, H.B. and Chan, C.K., (1959), Structure and strength characteristics of compacted clays. Journal of the Soil Mechanics and Foundations Division, ASCE, Vol. 85, No. SM 5, pp. 87-128. 
Selig, E. T. (1982). "Compaction Procedures, Specifications, and Control Considerations." Transportation Research Record No. 897, pp. 1-8.

Sherman, G. B., Watkins, R. O., and Prysock, R. H. (1967). A Statistical Analysis of Embankment Compaction. Transportation Research Record No. 177, Washington, D.C., pp. 157-185.

Shook, J.F., and Fang, H. Y. (1961). "A Study of Operator Variability in the Determination of Liquid and Plastic Limits of Soils" Highway Research Record, No. 31, No. 9, pp.26-28.

Siddiki, N. Z., A. Khan, D. Kim, and T. Cole. (2008). "Use of In Situ Tests in Compaction Control of a Bottom Ash Embankment." In Transportation Research Record: Journal of the Transportation Research Board, No. 2045, Transportation Research Board of the National Academies, Washington, D.C., 2008, pp. 10-18.

Smith, E.A.L. (1960). "Pile-Driving Analysis by the Wave Equation." Journal, Soil Mechanics and Foundations Division, ASCE, Vol.86, EM 4, pp. 35-61.

Szendrei, M. E., and C. R. Freeme (1970), Road Responses to Vibration Tests, Journal of the Soil mechanics and foundations division, ASCE, Vol. 96, No. 6, pp. 20992124.

Stanton, T. E., (1928). Highway Fill Studies and Soil Stabilization, California Highways and Public Works, Vol. 16.

Terzaghi. K., (1955), "Evaluation of coefficients of subgrade reaction", Géotechnique, Vol. 5, No. 4, pp. 297-326.

Terzaghi, K., Peck, R., and Mesri, G., (1996), Soil Mechanics in Engineering Practice, $3^{\text {rd }}$ ed., John Wiley \& Sons, Inc., New York, 549 p.

Texas Department of Transportation, 2004, Standard Specifications for Construction and Maintenance of Highways, Streets, and Bridges, Texas Department of Transportation

Thilakasiri, H. S, Gunaratne, M, Mullins, G, Stinnette, P., and Jory B. (1996), "Investigation of Impact Stresses Induced in Laboratory Dynamic Compaction of Soft Soils," International Journal of Numerical and Analytical Methods in Geomechanics, Vol. 20, No. 1, pp. 753-767.

Thurner, H. and Sandström, Å. (1980). "A new device for instant compaction control." Proc., Intl. Conf. on Compaction, Vol. II, 611-614, Paris.

Transportation Research Board (2009), Glossary of Highway Quality Assurance Terms fourth update, Transportation Research Board of the National Academics, Number EC137, Washington D.C., 36 p.

Trifunac, M. D., Hao, T. Y., and M. I. Todorovska, (2001), On Energy Flow in Earthquake Response, Report CE 01-03, Dept. of Civil Engineering, University of Southern California, Los Angeles, California. 
Troxler, W.F., (2000), "Development and Industry Acceptance of Nuclear Gauges", Constructing and Controlling Compaction of Earth Fills, ASTM STP 1384, D.W. Shanklin, K.R. Rademacher, and J.R. Talbot, Eds, American Society for Testing and Materials, West Conshohocken, PA.

Vesic, A. S., (1963), Bearing Capacity of Deep foundations in Sand, National Academy of Sciences, National Research Council, Highway Research Record, Vol. 39, pp. 112153.

Vesic, A. S., (1973), Analysis of Ultimate Loads of Shallow Foundations, Journal of Soil Mechanics and Foundations Division, Vol. 99, No. SM1, pp. 45-73.

Virginia Department of Transportation, (2007), Road and Bridge Specifications, Virginia Department of Transportation.

Vucetic, M., and Dobry, R. (1991). "Effect of soil plasticity on cyclic response." Journal of Geotech. Eng. Div., ASCE, Vol. 117, No. 1, pp. 89-107.

Wahls, H. E., (1967), Current Specifications, Field Practices and Problems in Compaction for Highway Purposes, Proc., 46rd Annual Transportation Research Board Meeting, Washington, D.C., pp. 98-111.

Wermers, L. G., (1963), Evaluation of Abbreviated Methods for Routine Soil Testing, Joint Highway Research Project Report No. 17, Purdue University, West Lafayette, IN.

White, D., K. Bergeson and M. Wermager. (1999), Embankment Quality: Phase II, Department of Civil and Construction Engineering. Iowa DOT Project TR-401, CTRE Project 97-08, Iowa State University, Ames, Iowa.

White, D., K. Bergeson and C. Jahren. (2002). "Embankment Quality: Phase III." Department of Civil and Construction Engineering. Iowa DOT Project TR-401, CTRE Project 97-08, Iowa State University, Ames, Iowa.

White, D.J, Jaselskis, E.J., Schaefer, V.R., Cackler, E.T., Drew, I., and Li, L. (2004). "Field Evaluation of Compaction Monitoring Technology: Phase I." Center for Transportation Research and Education, CTRE project 03-141, Iowa State University, Ames, IA.

White, D.J, Larson, B. W., Jahren, C., and J. Malama (2007). "Embankment Quality Phase IV: Application to Unsuitable Soils" IHRB Report No. TR-492, Center for Transportation Research and Education, CTRE project 03-136, Iowa State University, Ames, IA.

White, D., (2008), Report of the Workshop on Intelligent Compaction for Soils and HMA, the Earthworks Engineering Research Center, ER 08-01, Iowa State University, Ames, Iowa.

White, D., and M. J. Thompson (2008). Relationships between In Situ and RollerIntergrated Compaction Measurements for Granular Soils. Journal of Geotechnical Geoenvironmental Engineering, ASCE, Vol. 134, No. 12, pp. 1763-1770. 
Winter, M. G., and A. R. Selby, (1991), Clegg meter performance assessment with reference to the reinstatement environment, Institution of Highways and Transportation, Vol. 38, No. 6, pp. 17-24.

Winter M.G., and Clarke, B.G., (2002), "Methods for determining representative density-depth profiles using nuclear density gauges", Géotechnique, Vol. 52, No. 7, pp. 519-525.

Wisconsin Department of Transportation. (2009). Standard Specifications for Highway and Structure Constructure, State of Wisconsin.

Woods, K. B., and R. R. Litehiser (1938), Soil Mechanics Applied to Highway Engineering in Ohio, Bulletin 99, Ohio University Experiment Station.

Yoder, E. J., and Witczak, M. W., (1975) Principles of Pavement Design, 2nd ed., John Wiley \& Sons, New York.

Yoder, E. J., Shurig, D. G., and Colucci-Rios, B. (1982). Evaluation of Existing Aggregate Roads to Determine Suitability for Resurfacing, In Transportation Research Record: Journal of the Transportation Research Board, No. 875, Transportation Research Board of the National Academies, Washington, D.C., pp. 17.

Zorn Stendal. (2005). "Light Drop Weight Tester ZFG 2000 Operating manual." Stendal, Germany. 